Universidade de São Paulo-UsP

Escola de Engenharia de SÃo Carlos

Departamento de Engenharia Elétrica e de Computação Programa de Pós-Graduação em Engenharia Elétrica

Tiago Henrique dos Santos

\title{
UMA PROPOSTA DE ESTIMADOR NEURAL DA VELOCIDADE PARA CONTROLE VETORIAL DO MOTOR DE INDUÇÃO
}





\title{
Tiago Henrique dos Santos
}

\section{UMA PROPOSTA DE ESTIMADOR NEURAL DA VELOCIDADE PARA CONTROLE VETORIAL DO MOTOR DE INDUÇÃO}

\author{
Tese de doutorado apresentada ao Pro- \\ grama de Engenharia Elétrica da Escola \\ de Engenharia de São Carlos como parte \\ dos requisitos para a obtenção do título de \\ Doutor em Ciências.
}

Área de concentração: Sistemas Dinâmicos

Orientador: Prof. Dr. Ivan Nunes da Silva Coorientador: Prof. Dr. Alessandro Goedtel

São Carlos 
AUTORIZO A REPRODUÇÃO TOTAL OU PARCIAL DESTE TRABALHO, POR QUALQUER MEIO CONVENCIONAL OU ELETRÔNICO, PARA FINS DE ESTUDO E PESQUISA, DESDE QUE CITADA A FONTE.

Ficha catalográfica elaborada pela Biblioteca Prof. Dr. Sérgio Rodrigues Fontes da EESC/USP com os dados inseridos pelo(a) autor(a).

Eduardo Graziosi Silva - CRB - 8/8907 


\section{FOLHA DE JULGAMENTO}

Candidato: Tecnólogo TIAGO HENRIQUE DOS SANTOS.

Título da tese: "Uma proposta de estimador neural da velocidade para controle vetorial do motor de indução".

Data da defesa: 13/08/2018.

\section{Comissão Julgadora:}

Prof. Associado Ivan Nunes da Silva

\section{(Orientador)}

(Escola de Engenharia de São Carlos/EESC)

Prof. Dr. Manoel Luis de Aguiar

(Escola de Engenharia de São Carlos/EESC)

Prof. Dr. Bruno Augusto Angélico

(Escola Politécnica/EP-USP)

Prof. Dr. Edson Bim

(Universidade Estadual de Campinas/UNICAMP)

Prof. Dr. Marcelo Favoretto Castoldi (Universidade Tecnológica Federal do Paraná/UTFPR)

\section{Resultado:}
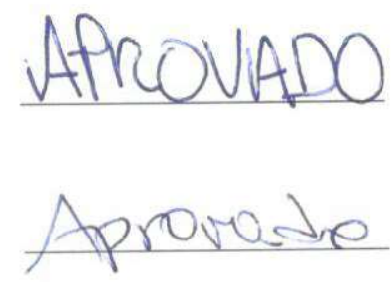

APROVADO

APROVADO

Coordenador do Programa de Pós-Graduação em Engenharia Elétrica:

Prof. Associado Luís Fernando Costa Alberto

Presidente da Comissão de Pós-Graduação:

Prof. Associado Luís Fernando Costa Alberto 

Este trabalho é dedicado à minha mãe Salete, à minha esposa Grazielli, à minha filha Maria Luiza aos meus avós Rosa e João Acácio. 



\section{Agradecimentos}

Primeiramente, eu agradeço a Deus por sempre se fazer presente.

Agradeço à minha esposa Grazielli Bueno, por seu apoio, incentivo e, principalmente pelo seu companheirismo e dedicação. À minha filha Maria Luiza dos Santos, pelos momentos de alegria, aprendizagem como pai e pela sua compreensão ao longo dos momentinhos em que fiquei estudando e não pude dar toda atenção que ela merecia.

À minha mãe, Salete Regina Lugle, que sempre me apoiou em todos os momentos da minha vida, orando para que tudo pudesse acontecer com tranquilidade.

Ao meu orientador, Prof. Dr. Ivan Nunes da Silva, pela sua orientação, ensinamentos, e por suas contribuições para mais essa etapa de minha formação acadêmica e profissional. Agradeço ainda pelos preciosos ensinamentos na elaboração e construção desta pesquisa.

Agradeço ao meu co-orientador, Prof. Dr. Alessandro Goedtel, por ter acreditado e trabalhado incansavelmente ao meu lado. Ainda o agradeço pelos ensinamentos na elaboração e correção dos materiais científicos produzidos ao longo de minha jornada desde o mestrado e também por seus valorosos conselhos.

Aos amigos e parceiros de doutorado, Prof. Msc. Wylliam Salviano Gongora, Profs. Dr. Wagner Fontes Godoy e Dr. Profs. Rodrigo Henrique Cunha Palácios, pelo companherismo, disposição em sempre ajudar, pelos grandes momentos de conversas e principalmente pelo incentivo na pesquisa, minha eterna gratidão.

Aos amigos e parceiros de laboratório, Msc. Clayton Luiz Graciola, Msc. Tiago Drumond Lopes, Murillo Garcia Gentil, Dr. Leonardo Bruno Garcia Campanhol, Msc. Vinicius Dário Bacon, Msc. Gustavo Henrique Bazan e Msc. Bruno Leandro Galvão, pelo apoio e pela amizade.

Ao Dr. Marcelo Suetake e Msc. William César de Andrade Pereira pelo companheirismo e pelas conversas e trocas de informações a cerca da pesquisa.

Ao Instituto Federal do Paraná, que permitiu meu afastamento das atividades, colaborando com este importante passo na minha carreira profissional.

À Universidade Tecnológica Federal do Paraná, por toda a infraestrutura cedida para o desenvolvimento da pesquisa. 
Aos professores da Universidade de São Paulo (USP/EESC/SEL), em especial ao Prof. Dr. Mário Oleskovicz, Prof. Dr. Manoel Luís de Aguiar e Prof. Dr. José Roberto Boffino de Almeida Monteiro pelos ensinamentos e pelo profissionalismo.

Aos funcionários da Universidade de São Paulo (USP/EESC/SEL), em especial a Sra. Marisa Helena R. Vicente Fortulan, pela competência e profissionalismo.

As contribuições do CNPq (Processo 474290/2008-5, 552269/2011-5, 405228/2016-3) e FAPESP (Processo 2011/17610- 0), pelo apoio financeiro sem os quais não seria possível o desenvolvimento desta pesquisa. 
"Se a meta principal de um capitão fosse preservar seu barco, ele o conservaria no porto para sempre." (São Tomás de Aquino)

"Ainda que eu tenha o dom de profetizar e conheça todos os mistérios e toda a ciência; ainda que eu tenha tamanha fé, ao ponto de transportar montes, se não tiver amor, nada serei." (1 Coríntios 13,2.) 



\section{Resumo}

Santos, Tiago Henrique dos UMA PROPOSTA DE ESTIMADOR NEURAL DA VELOCIDADE PARA CONTROLE VETORIAL DO MOTOR DE INDUÇÃO. 156 p. Tese de doutorado - Escola de Engenharia de São Carlos, Universidade de São Paulo, 2018.

A velocidade dos motores de indução é uma grandeza importante em um processo industrial. Entretanto, a medição direta da velocidade em motores de indução pode comprometer o sistema de acionamento e controle, aumentando o custo de implementação. Assim, as técnicas sensorless destinadas a estimar ou prever a velocidade em motores de indução são amplamente investigadas para uso em várias unidades industriais. Essa estratégia, quando baseada nos modelos matemáticos dos motores de indução é, normalmente, dependente dos parâmetros da máquina ou requer outro método que faça uma estimativa ou previsão. Assim, a abordagem alternativa deste trabalho consiste no uso de duas estratégias de implementação de redes neurais artificiais como estimador de velocidade aplicado a duas estratégias de controle do motor de indução orientado pelo campo do estator, controle direto de corrente e controle direto de torque. A velocidade síncrona, as correntes do estator e o torque eletromagnético, que são variáveis utilizadas nos algoritmos de acionamentos orientados no campo eletromagnético, são as entradas dos estimadores neurais propostos. Neste trabalho, resultados de simulação são aplicados no processo de seleção das redes neurais e os resultados experimentais mostram o desempenho de duas estratégias de implementação do estimador neural de velocidade embarcadas em DSP em diferentes metodologias de controle com dois motores de indução de potências diferentes.

Palavras-chave: Estimação de velocidade, motores de indução, redes neurais artificiais, controle orientado ao campo eletromagnético. 



\section{Abstract}

Santos, Tiago Henrique dos A NEURAL SPEED ESTIMATOR PROPOSAL FOR VECTOR CONTROL OF INDUCTION MOTOR. 156 p. Ph.D. Thesis São Carlos School of Engineering, University of São Paulo, 2018.

The induction motor speed is an important quantity in an industrial process. However, the direct measurement of speed on induction motors can compromise the drive and control system, increasing the implementation cost. Thus, sensorless techniques aimed at estimating or predicting the speed in induction motors are widely investigated to be used in industrial plant units. This strategy, when based on the mathematical models of the induction motors is, usually, dependent on the machine parameters or requires another method that makes an estimation or prediction. Thus, the alternative approach of this work consists in the use of two implementation strategies of artificial neural networks as speed estimator applied to two stator field-oriented induction motor control strategies, direct current control and direct torque control. The synchronous speed, the stator currents and the electromagnetic torque, which are quantities used in field-oriented drives, are the inputs of the proposed neural estimators. In this work, simulation results are applied to neural networks selection process and the experimental results show the performance of two implementation strategies of the neural speed estimator embedded in DSP in different control methodologies with two induction motors with different powers.

Keywords: Speed estimation, induction motors, artificial neural networks, field oriented control. 



\section{Lista de ilustrações}

Figura 1 Representação dos sistemas de coordenadas trifásicas e ortogonal. . . . 36

Figura 2 Plano complexo e referência arbritária. . . . . . . . . . . . . . . . . 38

Figura 3 Modelo dinâmico do motor de indução no sistema referencial estacionário $\alpha \beta$ : (a) Circuito equivalente do eixo $\alpha$; (b) Circuito equivalente do eixo $\beta \ldots \ldots \ldots \ldots \ldots$. . . . . . . . . . . . . . . 40

Figura 4 Modelo dinâmico do motor de indução no sistema referencial síncrono $d q$ : (a) Circuito equivalente do eixo $d$; (b) Circuito equivalente do eixo $q$. 42

Figura 5 Diagrama em blocos do controle vetorial direto orientado no fluxo magnético do rotor. . . . . . . . . . . . . . . . . . . . . . 44

Figura 6 Fasores do fluxo de rotor no controle vetorial. . . . . . . . . . . . . 45

Figura 7 Diagrama vetorial do controle vetorial orientado pelo fluxo do estator. . 47

Figura 8 Injeção do sinal de desacoplamento no controle vetorial orientado pelo fluxo do estator. . . . . . . . . . . . . . . . . . . . . . 48

Figura 9 Acionamento do MI pelo controle vetorial orientado pelo fluxo do estator. 49

Figura 10 Fluxo do estator, fluxo do rotor, e correntes do estator nos eixos de

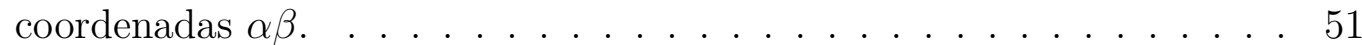

Figura 11 Diagrama do CDT clássico. . . . . . . . . . . . . . . . . . . 52

Figura 12 Diagrama do CDT-SVM orientado pelo fluxo do estator. . . . . . . . . 53

Figura 13 Observador de fluxo com controlador PI baseado no modelo de tensão e corrente. . . . . . . . . . . . . . . . . 56

Figura 14 Sistema p-PLL orientado de fluxo do estator. . . . . . . . . . . . . . 61

Figura 15 Malha do controle de velocidade do CDC . . . . . . . . . . . . . . 62

Figura 16 Malha do controle de fluxo do CDC. . . . . . . . . . . . . . . . 63

Figura 17 Malha dos controles de corrente $i_{d s} i_{q s} \ldots \ldots \ldots$. . . . . . . . . . . . 64

Figura 18 Malha do controle de velocidade do CDT. . . . . . . . . . . . . . . . 65

Figura 19 Malha do controle de fluxo do CDT. . . . . . . . . . . . . . . . . 65

Figura 20 Malha do controle de fluxo do CDC. . . . . . . . . . . . . . . . . 66 
Figura 21 Variáveis candidatas a compor o vetor de entrada do estimador neural a $50 \mathrm{rad} / \mathrm{s}$.

Figura 22 Variáveis candidatas a compor o vetor de entrada do estimador neural a $180 \mathrm{rad} / \mathrm{s} \ldots \ldots \ldots \ldots$. . . . . . . . . . . . . . . . 69

Figura 23 Diagrama em blocos do processamento de dados do método A. . . . . . 70

Figura 24 Diagrama em blocos do processamento de dados do método B. . . . . . 70

Figura 25 Topologia de PMC com entradas atrasadas no tempo. . . . . . . . . . . 74

Figura 26 Rede TDNN como aproximador universal de função. . . . . . . . . . . 75

Figura 27 Processo de geração e uso dos conjuntos de dados no treinamento e validação computacional das RNAs. . . . . . . . . . . . . . . . . . . . . . . . . . . . . . . . 76

Figura 28 Estrutura para o treinamento e validação computacional das RNAs para a estratégia $(A) . \ldots \ldots \ldots$. . . . . . . . . . . . . . . . . . .

Figura 29 Estrutura para o treinamento e validação computacional das RNAs

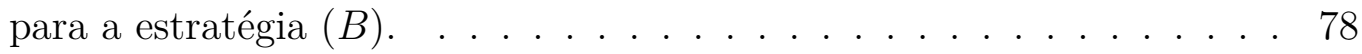

Figura 30 Ilustração da bancada de ensaios experimentais usada nos testes experimentais de execução da tangente hiperbólica. . . . . . . . . . . . . . . . . . . 79

Figura $31 \quad$ Loop principal do algoritmo embarcado no DSP. . . . . . . . . . . . . . 80

Figura 32 Função de ativação tangente hiperbólica. . . . . . . . . . . . . . . . . . 81

Figura 33 Teste 3.1 - tempo de execução de um ciclo usando a biblioteca math.h: a) até a primeira camada escondida, b) após a segunda camada escondida. . 81

Figura 34 Teste 3.1 - Tempo de execução de um ciclo usando a técnica LUT: a) até a primeira camada escondida, b) após a primeira camada escondida.

Figura 35 Teste 3.2 - Tempo de execução da primeira camada escondida: a) usando a biblioteca math.h, b) usando a técnica LUT. . . . . . . . . . . . . . . . . . 83

Figura 36 Resposta do estimador neural de velocidade frente às técnicas de implementação da tangente hiperbólica. . . . . . . . . . . . . . . . . . . . . . . . . 84

Figura $37 \quad$ Estrutura da bancada de testes de máquinas elétricas. . . . . . . . . . . . . . . . . 90

Figura 38 Método de testes das RNAs em bancada experimental. . . . . . . . . . . . . . . . . 90

Figura 39 Resposta da RNA A8 como observador de velocidade com o MI acionado pelo CDC a 90

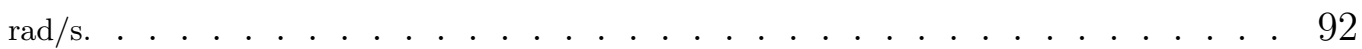

Figura 40 Dinâmica do torque eletromagnético, mecânico e da velocidade síncrona do MI a $90 \mathrm{rad} / \mathrm{s}$ no CDC. . . . . . . . . . . . . . . . . . . . . . . . . . . . . . 92

Figura 41 Resposta da RNA A8 como observador de velocidade com o MI acionado pelo CDT a 90 $\mathrm{rad} / \mathrm{s}$. . . . . . . . . . . . . . . . . . . . . . . . . . . .

Figura 42 Dinâmica do torque eletromagnético, mecânico e da velocidade síncrona do MI a $90 \mathrm{rad} / \mathrm{s}$ no CDT. . . . . . . . . . . . . . . . . . . . . . . . . . 93

Figura 43 Resposta da RNA B3 como observador de velocidade com o MI a 7 rad/s, (a) acionado pelo CDC e (b) acionado pelo CDT. . . . . . . . . . . . . . . . . . . . . . . . . 95 
Figura 44 Resposta da RNA B3 a 5 rad/s usando o fluxo do estator estimado conforme Seção 2.4 com o MI acionado com o CDC. . . . . . . . . . . . . . . . . . . . . 96

Figura 45 Fluxo medido e estimado com o MI a 5 rad/s no CDC. . . . . . . . . . . . . . . . 97

Figura 46 Resposta da RNA B3 a 5 rad/s usando o fluxo calculado do modelo matemático do MI acionado com o CDC. . . . . . . . . . . . . . . . . . . . . . . . 97

Figura 47 Resultado da RNA A8 para o teste experimental 1. . . . . . . . . . . . . . . . . . 99

Figura 48 Resultado da RNA A8 para o teste experimental 3. . . . . . . . . . . . . . . . . . 100

Figura 49 Dinâmica do torque eletromagnético, mecânico e da velocidade síncrona do MI no teste experimental 3........................... 100

Figura 50 Resultado da RNA A8 para o teste experimental 6. . . . . . . . . . . . . . . . . . 101

Figura 51 Resultado da RNA A8 para o teste experimental 8. . . . . . . . . . . . . . . . . 102

Figura 52 Dinâmica do torque eletromagnético, mecânico e da velocidade síncrona do MI no teste experimental 8.......................... 102

Figura 53 Resultado da RNA A8 para o teste experimental 11. . . . . . . . . . . . . . . . 103

Figura 54 Dinâmica do torque eletromagnético, mecânico e da velocidade síncrona do MI no teste experimental 11. . . . . . . . . . . . . . . . . . . . . . . 104

Figura 55 Resultado da RNA A8 para o teste experimental 13. . . . . . . . . . . . . . . . . 105

Figura 56 Dinâmica do torque eletromagnético, mecânico e da velocidade síncrona do MI no teste

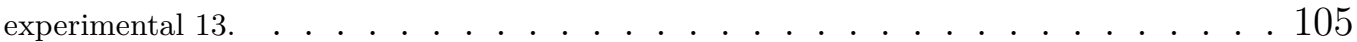

Figura 57 Resultado da RNA A8 para o teste experimental 16. . . . . . . . . . . . . . . . . 106

Figura 58 Dinâmica do torque eletromagnético, mecânico e da velocidade síncrona do MI no teste

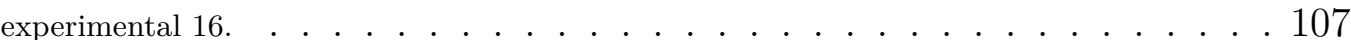

Figura 59 Resultado da RNA A8 para o teste experimental 18. . . . . . . . . . . . . . . . 107

Figura 60 Dinâmica do torque eletromagnético, mecânico e da velocidade síncrona do MI no teste experimental 18. . . . . . . . . . . . . . . . . . . . . . . 108

Figura 61 Resultado da RNA A8 para o teste experimental 21. . . . . . . . . . . . . . . . . . 110

Figura 62 Resultado da RNA A8 para o teste experimental 23. . . . . . . . . . . . . . . . . . 111

Figura 63 Dinâmica do torque eletromagnético, mecânico e da velocidade síncrona do MI no teste experimental 23. . . . . . . . . . . . . . . . . . . . . . . . . 111

Figura 64 Resultado da RNA A8 para o teste experimental 26. . . . . . . . . . . . . . . . . . 112

Figura 65 Resultado da RNA A8 para o teste experimental 28. . . . . . . . . . . . . . . . . 113

Figura 66 Dinâmica do torque eletromagnético, mecânico e da velocidade síncrona do MI no teste experimental 28. . . . . . . . . . . . . . . . . . . . . . . 113

Figura 67 Resultado da RNA A8 para o teste experimental 31. . . . . . . . . . . . . . . . . . 114

Figura 68 Dinâmica do torque eletromagnético, mecânico e da velocidade síncrona do MI no teste experimental 31. . . . . . . . . . . . . . . . . . . . . . . . 115

Figura 69 Resultado da RNA A8 para o teste experimental 33. . . . . . . . . . . . . . . . . 116

Figura 70 Dinâmica do torque eletromagnético, mecânico e da velocidade síncrona do MI no teste experimental 33. . . . . . . . . . . . . . . . . . . . . . . . . . . . . . . . 116 
Figura 71 Resultado da RNA A8 para o teste experimental 36. . . . . . . . . . . . . . 117

Figura 72 Dinâmica do torque eletromagnético, mecânico e da velocidade síncrona do MI no teste experimental $36 . \quad \ldots \ldots \ldots 117$

Figura 73 Resultado da RNA A8 para o teste experimental 38. . . . . . . . . . . . . . . 118

Figura 74 Dinâmica do torque eletromagnético, mecânico e da velocidade síncrona do MI no teste

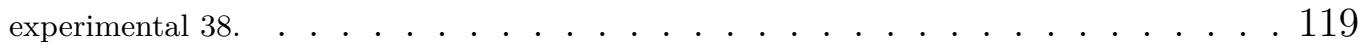

Figura 75 Resultado da RNA A8 para o teste experimental 2. . . . . . . . . . . . . . . 138

Figura 76 Resultado da RNA A8 para o teste experimental 4. . . . . . . . . . . . . . . . 138

Figura 77 Resultado da RNA A8 para o teste experimental 5. . . . . . . . . . . . . . . . . . 139

Figura 78 Resultado da RNA A8 para o teste experimental 7. . . . . . . . . . . . . . . . . . 139

Figura 79 Resultado da RNA A8 para o teste experimental 9. . . . . . . . . . . . . . . . . . 140

Figura 80 Resultado da RNA A8 para o teste experimental 10. . . . . . . . . . . . . . . . . . 140

Figura 81 Resultado da RNA A8 para o teste experimental 12. . . . . . . . . . . . . . . . 141

Figura 82 Resultado da RNA A8 para o teste experimental 14. . . . . . . . . . . . . . . . . 141

Figura 83 Resultado da RNA A8 para o teste experimental 15. . . . . . . . . . . . . . . . . . 142

Figura 84 Resultado da RNA A8 para o teste experimental 17. . . . . . . . . . . . . . . . 142

Figura 85 Resultado da RNA A8 para o teste experimental 19. . . . . . . . . . . . . . . . . . 143

Figura 86 Resultado da RNA A8 para o teste experimental 20. . . . . . . . . . . . . . . . . 143

Figura 87 Resultado da RNA A8 para o teste experimental 22. . . . . . . . . . . . . . . . . 144

Figura 88 Resultado da RNA A8 para o teste experimental 24. . . . . . . . . . . . . . . . 145

Figura 89 Resultado da RNA A8 para o teste experimental 25. . . . . . . . . . . . . . . . . . 145

Figura 90 Resultado da RNA A8 para o teste experimental 27. . . . . . . . . . . . . . . . 146

Figura 91 Resultado da RNA A8 para o teste experimental 29. . . . . . . . . . . . . . . . 146

Figura 92 Resultado da RNA A8 para o teste experimental 30. . . . . . . . . . . . . . . . . 147

Figura 93 Resultado da RNA A8 para o teste experimental 32. . . . . . . . . . . . . . . . . 147

Figura 94 Resultado da RNA A8 para o teste experimental 34. . . . . . . . . . . . . . . . . . 148

Figura 95 Resultado da RNA A8 para o teste experimental 35. . . . . . . . . . . . . . 148

Figura 96 Resultado da RNA A8 para o teste experimental 37. . . . . . . . . . . . . . . . . . 149

Figura 97 Resultado da RNA A8 para o teste experimental 39. . . . . . . . . . . . . . . . . . 149

Figura 98 Resultado da RNA A8 para o teste experimental 40. . . . . . . . . . . . . . 150

Figura 99 Plano complexo com as coordenadas de $G_{p}$. . . . . . . . . . . . . . . 154

Figura 100 Plano complexo com as coordenadas de $C$. . . . . . . . . . . 155 


\section{Lista de tabelas}

Tabela 3.1 Características dos MIs usados neste trabalho. . . . . . . . . . . . . . 61

Tabela 3.2 Parâmetros requeridos para o projeto do controladores PI. . . . . . . . 67

Tabela 3.3 Parâmetros dos controladores PI do CDC e do CDT. . . . . . . . . . . 67

Tabela 3.4 Condições gerais de aquisição de dados das simulações. . . . . . . . . . 77

Tabela 3.5 Parâmetros das RNAs candidatas . . . . . . . . . . . . . . . . . . 77

Tabela 3.6 Testes dos tempos de execução da tangente hiperbólica. . . . . . . . . . 80

Tabela 3.7 Resultados de simulação das RNAs com os dados do MI-2 acionado pelo CDC na estratégia $A$ - Grupo 1.1. . . . . . . . . . . . . . . 85

Tabela 3.8 Resultados de simulação das RNAs com os dados do MI-2 acionado pelo CDT na estratégia $A$ - Grupo 1.2. . . . . . . . . . . . . . 86

Tabela 3.9 Resultados de simulação das RNAs com os dados do MI-2 acionado pelo CDC na estratégia $B$ - Grupo 2.1. . . . . . . . . . . . . . 86

Tabela 3.10 Resultados de simulação das RNAs com os dados do MI-2 acionado pelo CDT na estratégia $B$ - Grupo 2.2. . . . . . . . . . . . . 87

Tabela 4.1 Desempenho das RNAs como observador de velocidade nos testes experimentais implementadas com a estratégia $A$. . . . . . . . . . . . 91

Tabela 4.2 Desempenho das RNAs como observador de velocidade nos testes experimentais implementadas com a estratégia B . . . . . . . . . . . . 94

Tabela 4.3 Pontos de operação da validação experimental da RNA A8. . . . . . . 98

Tabela 4.4 Performance da RNA A8 em regime permanente dos testes experimentais de 1 a 20. . . . . . . . . . . . . . . . . . . . . . . . 109

Tabela 4.5 Pontos de operação da validação experimental da RNA B3. ..... 109

Tabela 4.6 Performance da RNA B3 em regime permanente dos testes experimentais de 21 a $40 \ldots \ldots$. . . . . . . . . . . . . . . . . . . 119 




\section{Lista de Abreviaturas}

$\begin{array}{ll}\text { MI } & \text { Motores de Indução Trifásicos } \\ \text { CE } & \text { Controle Escalar } \\ \text { CDC } & \text { Controle Direto de Corrente } \\ \text { CDT } & \text { Controle Direto de Torque } \\ \text { SI } & \text { Sistemas Inteligentes } \\ \text { RNA } & \text { Redes Neurais Artificiais } \\ \text { LF } & \text { Lógica Fuzzy } \\ \text { SMRA } & \text { Sistema Modelo de Referência Adaptativo } \\ \text { OMD } & \text { Observador de Modos Deslizantes } \\ \text { FEK } & \text { Filtro Extendido de Kalman } \\ \text { FCS-MPC } & \text { Finite Control Set-Model Predective Control } \\ \text { OMD-CL } & \text { Observador de Modos Deslizantes com Camada Limite } \\ \text { FEKROR } & \text { Filtro Extendido de Kalman Robusto de Ordem Reduzida } \\ \text { OE } & \text { Observadores de Estado } \\ \text { SINFA } & \text { Sistema de Inferência Neuro-Fuzzy Adaptativo } \\ \text { FPB } & \text { Filtro Passa-Baixas } \\ \text { PI } & \text { Proporcional Integral } \\ \text { PMC } & \text { Perceptron de Múltiplas Camadas } \\ \text { RPM } & \text { Rotações por Minuto } \\ \text { SVPWM } & \text { Space Vector Pulse Width Modulation } \\ \text { MCC } & \text { Máquina de Corrente Contínua } \\ \text { FCEM } & \text { Força Contra Eletromotriz } \\ \text { CV } & \text { Controle Vetorial } \\ \text { SVM } & \text { Space Vector Modulation } \\ \text { PLL } & \text { Phase Locked Loop } \\ \text { AG } & \text { Algoritmos Genéticos } \\ \text { TDNN } & \text { Time Delay Neural Network } \\ \text { FT } & \text { Função de Transferência } \\ \text { DSP } & \text { Digital Sinais Processor } \\ \text { A/D } & \text { Analógico/Digital } \\ \text { LUT } & \text { Lookup Table } \\ \text { ERM } & \text { Erro Relativo Médio } \\ \text { D/A } & \text { Digital/Analógico } \\ \text { P.O. } & \text { Ponto de Operação } \\ & \end{array}$




\section{Lista de Símbolos}

* Define variável de referência

$\alpha \quad$ Componente real no referencial estacionário

$\beta \quad$ Componente imaginária no referencial estacionário

d Componente direta no referencial síncrono

$q$ Componente em quadratura no referencial síncrono

$s \quad$ Subscrito que define grandeza do estator

$r \quad$ Subscrito que define grandeza do rotor

$i_{s} \quad$ Vetor da corrente do estator

$i_{r} \quad$ Vetor da corrente do rotor

$v_{s} \quad$ Vetor da tensão do estator

$v_{r} \quad$ Vetor da tensão do rotor

$\psi_{s} \quad$ Vetor do fluxo do estator

$\psi_{r} \quad$ Vetor do fluxo do rotor

$R_{s} \quad$ Resistência do estator

$R_{r} \quad$ Resistência do rotor

$L_{s} \quad$ Indutância própria do estator

$L_{r} \quad$ Indutância própria do rotor

$L_{l s} \quad$ Indutância de dispersão do estator

$L_{l r} \quad$ Indutância de dispersão do rotor

$L_{H} \quad$ Indutância de magnetização

$\omega_{e} \quad$ Velocidade síncrona do fluxo eletromagnético estator

$\omega_{r} \quad$ Velocidade na referência do rotor

$\omega_{m e c}$ Velocidade mecânica do rotor

$\omega_{s l} \quad$ Velocidade de escorregamento entre estator e rotor

$\lambda \quad$ Ângulo em de referêncial genérico

$\theta_{e} \quad$ Ângulo do fluxo do estator

$\theta_{r} \quad$ Ângulo do fluxo do rotor

$\theta_{s l}$ ângulo de escorregamento entre estator e rotor 
$T_{e} \quad$ Torque eletromagnético

$T_{L} \quad$ Torque de carga

$B \quad$ Coeficiente de atrito viscoso

$J \quad$ Momento de inércia

$z_{p} \quad$ Número de pares de polos da máquina

$P \quad$ Número de polos da máquina

$T_{s} \quad$ Constante de tempo do estator

$T_{r} \quad$ Constante de tempo do rotor

$\sigma \quad$ Coeficiente de dispersão global

$\wedge \quad$ Define variável estimada

$\Delta \lambda \quad$ Variação do ângulo de carga

$a, b, c \quad$ Define grandezas de fase a, b e c, respectivamente

$x_{j} \quad j$-ésimo sinal de entrada do neurônio

$w_{j} \quad$ Peso associado com o $j$-ésimo sinal de entrada

$b \quad$ Limiar relacionado com o neurônio

$v_{k}(i) \quad$ Resposta ponderada do neurônio $k$-ésimo em relação ao instante $i$

$m \quad$ Número de entradas do neurônio

$\varphi($.$) \quad Função de ativação do neurônio k$-ésimo

$y_{k}(i) \quad$ Sinal de saída do $k$-ésimo neurônio em relação ao instante $i$

$e_{k}(i) \quad$ Sinal do erro associado a $i$-ésima iteração

$d_{k}(i) \quad$ Resposta desejada para o $k$-ésimo neurônio de saída

$E(i) \quad$ Erros quadráticos produzidos pelos neurônios da saída

$p \quad$ Número de neurônios de saída

$\eta \quad$ Constante que determina a taxa de aprendizado do algoritmo backpropagation

$G_{p} \quad$ planta genérica

$\varphi_{p} \quad$ Angulo de fase da planta

$\omega_{c} \quad$ Frequência de cruzamento

$M F_{d} \quad$ Margem de fase desejada

$G_{M A_{c}}(s) \quad$ Malha aberta do sistema compensado

$G_{M A_{P I}}(s)$ Malha aberta do controlador em série com a planta a ser controlada 


\section{Sumário}

1 Introdução $\quad 27$

1.1 Justificativa . . . . . . . . . . . . . . . . . . . . . . . . 30

1.2 Objetivo . . . . . . . . . . . . . . . . . . . . . 31

1.3 Contribuições do Trabalho . . . . . . . . . . . . . . . . . . . . 32

1.4 Organização do Trabalho . . . . . . . . . . . . . . . . . . . . . 32

$2 \quad$ Modelagem e Controle do MI $\quad 35$

2.1 Equações Dinâmicas do Motor de Indução . . . . . . . . . . . . . . . . . . 35

2.2 Controle Vetorial . . . . . . . . . . . . . . . . . . . . . . . . 43

2.2.1 Controle Vetorial Orientado pelo Fluxo do Estator . . . . . . . . . 45

2.3 Controle Direto de Torque . . . . . . . . . . . . . . . . . 49

2.3.1 Controle Direto de Torque com Modulação Vetorial . . . . . . . . 52

2.4 Observador de Fluxo Magnético . . . . . . . . . . . . . . . . . . . . 54

2.5 Conclusões Sobre o Controle do MI . . . . . . . . . . . . . . . 57

$3 \quad$ Estimador Neural de Velocidade do MI $\quad 59$

3.1 Tratamento de Dados para Treinamento e Validação da Proposta . . . . . 60

3.2 Modelagem e Projeto dos Controladores . . . . . . . . . . . . . . . . . . . 62

3.2.1 Modelagem matemática das plantas a serem controladas no CDC . 62

3.2.2 Modelagem matemática das plantas a serem controladas no CDT . 64

3.2.3 Projeto dos controladores PI . . . . . . . . . . . . . . . 66

3.2.4 Análise da composição dos vetores de entrada das RNAs . . . . . . 67

3.3 Estimador Neural de Velocidade . . . . . . . . . . . . . . . . . . 70

3.3.1 Treinamento das redes neurais artificiais . . . . . . . . . . . . . 71

3.3.2 Rede perceptron multicamada . . . . . . . . . . . . . . . 71

3.3.3 Aspectos metodológicos do treinamento da RNA . . . . . . . . . . 75

3.4 Métodos para Implementação da Tangente Hiperbólica . . . . . . . . . . . . 78

3.5 Seleção das RNAs Candidatas com Dados de Simulação . . . . . . . . . . . 84 
3.5.1 Seleção das RNAs para a estratégia de implementação $A \quad$. . . . 85

3.5.2 Seleção das RNAs para a estratégia de implementação $B$. . . . . 85

3.6 Conclusões Sobre a Validação Computacional do Estimador Neural de Velocidade . . . . . . . . . . . . . . . . . . . . . 87

4 Validação Experimental $\quad 89$

4.1 A Bancada Experimental e Seleção das RNAs por Testes Experimentais 89

4.1.1 Seleção da RNA nos CDC e CDT na estratégia de implementação $A 90$

4.1.2 Seleção da RNA nos CDC e CDT na estratégia de implementação $B 94$

4.1.3 A influência do estimador do fluxo magnético do MI na estimação de velocidade . . . . . . . . . . . . . . . . . . 95

4.2 Testes Experimentais com as RNAs Selecionadas Realimentando o Controle de Velocidade no CDC e CDT . . . . . . . . . . . . . . . . . . . . . 98

4.2.1 Testes experimentais com a RNA A8 realimentando o controle de velocidade no CDC e CDT . . . . . . . . . . . . . . . 98

4.2.2 Testes experimentais com as RNA B3 realimentando o controle de velocidade no CDC e CDT . . . . . . . . . . . . . . . . . . 109

4.3 Conclusões Sobre a Validação Experimental do Estimador Neural de Velocidade . . . . . . . . . . . . . . . . . . . . 120

5 Conclusões Gerais e Proposta de Continuidade 123

5.1 Conclusão . . . . . . . . . . . . . . . . . . . . . . . . . . . 123

5.2 Proposta de Continuidade . . . . . . . . . . . . . . . . . . . . . . . 124

5.3 Artigos Publicados . . . . . . . . . . . . . . . . . . . . . . 124

$\begin{array}{ll}\text { Referências } & 127\end{array}$

Apêndices

APÊNDICE A Resultados Complementares dos Testes Experimentais do Capítulo 4

A.0.1 Resultados Complementares dos Testes experimentais com as RNA A8 realimentando o controle de velocidade . . . . . . . . . 137

A.0.2 Resultados Complementares dos Testes experimentais com as RNA B3 realimentando o controle de velocidade . . . . . . . . . . . . . 144 


\section{Introdução}

Os Motores de Indução (MI) são amplamente usados em muitos setores industriais, sendo o principal elemento de conversão de energia elétrica em mecânica motriz. Suas principais características são o baixo custo, a robustez e a confiabilidade (SUETAKE; SILVA; GOEDTEL, 2011; KAN; ZHANG; WANG, 2015; MERABET; TANVIR; BEDDEK, 2017).

As aplicações que incluem o MI podem ser divididas em dois grupos: o primeiro é aquele em que o motor é diretamente acoplado à rede elétrica, sem elemento de controle de velocidade. No segundo, as metodologias de Controle Escalar (CE), Controle Vetorial com Controle Direto de Corrente (CDC) ou com Controle Direto de Torque (CDT) são aplicadas. Dentre os acionamentos de alto desempenho, o CDT destaca-se pela sua simplicidade e rápida resposta do torque eletromagnético (ZHANG et al., 2012). Já o CDC possui rápida resposta dinâmica, baixa ondulação de torque eletromagnético e ampla faixa de velocidade de operação. Para ambas as estratégias de controle e nas diversas aplicações dos setores produtivos, há a necessidade de conhecer a velocidade no eixo da máquina, seja na forma de medida direta ou estimada (KRISHNAN, 2001).

A velocidade no eixo do motor de indução é comumente medida com encoders ópticos, resolvers eletromagnéticos ou tacogeradores. Entretanto, o uso destes dispositivos apresentam certas limitações em suas aplicações, tais como o aumento do custo do dispositivo de acionamento, a redução da robustez mecânica, a baixa imunidade ao ruído, a alteração da inércia da máquina, além de exigir cuidados especiais em ambientes hostis (VAS, 1998; AYDOGMUS; AYDOGMUS, 2015).

As técnicas sensorless são preferidas em muitas aplicações devido ao menor custo e melhor adaptabilidade ao ambiente industrial (YANG et al., 2017a). As principais estratégias de controle sensorless têm como base os estimadores em malha aberta com monitoramento de corrente e tensão do estator, observadores de estado, sistemas de referência com modelos adaptativos e estimadores baseados em Sistemas Inteligentes (SI), os quais advêm principalmente das Redes Neurais Artificiais (RNA) e Lógica Fuzzy (LF) (VAS, 1998; KRAUSE; WASYNCZUK; SUDHOF, 2002; LIMA et al., 2014).

A maioria dos estimadores de velocidade tem origem no modelo matemático do motor 
de indução, onde é necessário o conhecimento preciso dos parâmetros do motor (VASIC; VUKOSAVIC; LEVI, 2003; AMEZQUITA-BROOKS; LICEAGA-CASTRO; LICEAGA-CASTRO, 2014a; KAN; ZHANG; WANG, 2015; SMITH; GADOUE; FINCH, 2016). Muitas estratégias para a estimação de velocidade têm sido propostas; tais como o uso do Sistema Modelo de Referência Adaptativo (SMRA) (YANG et al., 2016; ORLOWSKA-KOWALSKA; DYBKOWSKI, 2010), injeção de sinais de alta frequência (CARUANA; ASHER; SUMNER, 2005), Observador de Modos Deslizantes (OMD) (ZHANG, 2013), Filtro Extendido de Kalman (FEK) (YIN et al., 2013; ANDRIAMALALA et al., 2011)

Em Yang et al. (2016) é apresentado o uso de um OMD aplicado para estimar a velocidade de um MI, onde é observada a sensibilidade do sistema frente a precisão paramétrica. O trabalho de Orlowska-Kowalska e Dybkowski (2010) desenvolveu um novo tipo de SMRA para estimar a velocidade do rotor com controle vetorial do MI. O uso de injeção de sinais de alta frequência na estimação de velocidade obteve bons resultados, como mostra o trabalho de Caruana, Asher e Sumner (2005). Entretanto, os sinais de correntes devem ser medidos com elevadas taxas de aquisição, bem como a exigência de atenção especial nos projetos dos filtros dos sinais envolvidos. Outro método sensorless de acionamento do motor de indução é o Finite Control Set-Model Predective Control (FCSMPC), mostrado em Zbede, Gadoue e Atkinson (2016), onde é aplicada uma abordagem de otimização para minimizar o erro de velocidade ajustando esse sinal no SMRA. Mesmo com a redução da complexidade de implementação devido a não utilização de controlador Proporcional-Integral (PI) e redução da ondulação da velocidade estimada em regime permanente, o trabalho mostra que o sistema é sensível às alterações das resistências do estator e à variação mútua de indutância em baixas velocidades, onde a velocidade estimada apresenta oscilações significativas. Em Zhang (2013) um OMD com Camada Limite (OMD-CL) é usado em um driver sensorless de alta performance de um MI aplicado a um veículo elétrico baseado apenas nas medidas das correntes. O OMD-CL livre de oscilação contribui significativamente na precisão da estimativa de velocidade e do fluxo do rotor, mesmo em condições de baixa velocidade. No trabalho de Yin et al. (2013) um FEK Robusto de Ordem Reduzida (FEKROR) é usado para estimar fluxo e a velocidade de um MI que, embora apresente bons resultados em ampla faixa de velocidade, demanda atenção especial em baixas velocidades de operação.

Os estimadores de velocidade baseados em Observadores de Estado (OE) necessitam o valor exato dos parâmetros da máquina para a correta operação do dispositivo sensorless nas regiões de baixa velocidade do MI (BOSE; WASYNCZUK; SUDHOF, 2002; SMITH; GADOUE; FINCH, 2016). Alguns parâmetros têm seus valores modificados com a operação da máquina, com a temperatura e com o desgaste dos componentes (TOLIYAT; LEVI; RAINA, 2003; SUN et al., 2016; KAN; ZHANG; WANG, 2015). Os métodos que têm como base o modelo matemático do MI requerem maior poder computacional, já que no algoritmo do estimador há a necessidade de resolução de equações diferenciais. Com o objetivo de 
reduzir a dependência paramétrica, muitos trabalhos vêm sendo desenvolvidos usando os SI para estimar parâmetros, variáveis e para controlar o MI. Com destaque aos SI, tem-se as RNAs (SUN et al., 2013; SANTOS et al., 2014; FU; LI, 2015), LF (AZCUE-PUMA; FILHO; RUPPERT, 2014; GDAIM; MTIBAA; MIMOUNI, 2015; TIR; MALIK; ELTAMALY, 2016; WANG; LIU; CHOU, 2018) e Neuro-Fuzzy (UDDIN; HUANG; HOSSAIN, 2014; BOUSSADA; HAMED; SBITA, 2014; LIMA et al., 2014).

O trabalho de Santos et al. (2014) apresenta a aplicação de um estimador neural de velocidade aplicado a um driver escalar no controle de um MI. O treinamento é realizado de forma off-line, onde a RNA tem como entrada as correntes e as tensões do estator no eixo de referência síncrona $(d q)$ e a tensão estimada do barramento CC do inversor. Resultados experimentais são apresentados para validar a proposta e demonstram o desempenho em ampla faixa de operação do MI. No trabalho de Sun et al. (2013), uma RNA é usada como estimador de velocidade de um MI sem mancal mecânico acionado com controle vetorial, onde as correntes, as tensões do estator e a velocidade síncrona são as entradas do estimador.

Maiti et al. (2012) apresenta um acionamento vetorial de um MI com Sistema Modelo de Referência Adaptativo (SMRA) baseado na potência reativa instantânea Q-SMRA. Quando o MI está operando na regeneração, o Q-SMRA apresenta alguns pontos de instabilidade. O trabalho mostra a aplicação da RNA como modelo ajustável, fornecendo o parâmetro de adaptação do Q-SMRA.

Um estimador de velocidade baseado em um Sistema de Inferência Neuro-Fuzzy Adaptativo (SINFA) é apresentado em Lima et al. (2014). O SINFA é treinado baseado em dados de acionamento com controle escalar e posteriormente, controle vetorial orientado pelo fluxo do entreferro, os quais são validadas experimentalmente.

Um estimador neural de velocidade e resistência rotórica de um MI utilizando uma rede Adaline é apresentado em Marei, Shaaban e El-Sattar (2009). Nesta proposta a corrente e a tensão do estator da máquina são medidos no eixo de coordenadas estacionárias trifásica abc. Após a transformação para o eixo de coordenadas estacionárias trifásico $\alpha \beta 0$, esses sinais são utilizados para estimar a corrente, o fluxo e a derivada do fluxo do rotor, sendo essas as variáveis de entrada da RNA. Para a validação do estimador neural de velocidade o mesmo é aplicado em diversas estratégias de controle dos MI, como o controle escalar e o controle vetorial. A validação do estimador é realizada via simulação computacional, a qual demostra a necessidade do uso de Filtro Passa-Baixa (FPB) para obter imunidade a harmônicos das formas de ondas medidas. Testes que demonstram a estabilidade frente a mudança de sentido de rotação e sensibilidade a precisão da estimação do fluxo magnético do MI não foram apresentados.

Um controlador de velocidade usando RNA é apresentado em Fu e Li (2015). Os autores comparam a resposta dinâmica do controlador neural com um controlador PI aplicado ao loop atual em um controle vetorial. Devido às características de aproximação da função 
universal, os testes mostraram um bom desempenho no torque e no desacoplamento do fluxo e na mudança da resistência do rotor.

O trabalho de Oguz e Dede (2011) também apresenta um estimador neural de velocidade de um MI utilizando uma rede Perceptron de Múltiplas Camadas (PMC). As entradas desse estimador utilizam os dados de corrente e tensão de alimentação da máquina. Os conjuntos de dados de treinamento e validação do estimador neural de velocidade são adquiridos com a máquina operando em regime permanente e com a velocidade entre 500 a 1000 RPM. Para controlar as malhas de correntes e de velocidade mecânica são usados controladores PI.

Assim, a contribuição deste trabalho consiste no desenvolvimento de duas estratégias de implementação de estimadores neurais de velocidade aplicado ao MI, onde este é acionado em momentos distintos por dois tipos de controles orientados pelo campo do estator. O inversor de tensão aciona o MI com controle direto de corrente e com controle direto de torque. Uma das estratégias de implementação do estimador neural de velocidade usa como variáveis de entrada as correntes do estator e a velocidade síncrona do campo girante do estator. Na segunda estratégia o torque eletromagnético e a velocidade síncrona do campo girante são utilizados como entradas da RNA. Os dados de treinamento são gerados a partir da simulação do modelo matemático do motor de indução acionado por um driver com Modulação por Largura de Pulso por Vetores Espaciais SVPWM (Space Vector Pulse Width Modulation), onde o referido treinamento é realizado de forma off-line.

Durante o processo de treinamento são geradas as RNAs candidatas a estimador de velocidade. Essas RNAs são testadas via simulação computacional com dados de um segundo MI, a fim de garantir maior generalização dos resultados. A fim de avaliar a robustez dos estimadores, são realizados testes computacionais frente à variação de resistência do estator e do rotor.

As RNAs que obtém o melhores resultados, em cada um das estratégias de implementação são testadas experimentalmente. Nos testes experimentais, as RNAs que obtém os melhores resultados são usadas como estimador neural de velocidade do MI em ambas as estratégias de controle. Com o intuito de garantir a generalização de resultados, os testes experimentais são conduzidos em dois motores com potências distintas.

\section{$1.1 \quad$ Justificativa}

O setor industrial brasileiro consome 40,7\% de toda energia elétrica produzida no país de acordo com o EPE (2014). Neste cenário tem-se, aproximadamente, $62 \%$ da energia consumida no setor industrial brasileiro sendo utilizada em sistemas motrizes, fato este que evidencia a importância do MI nas mais diversas aplicações industriais.

Nas aplicações industriais, os motores de indução trifásicos aparecem como principal 
elemento de conversão eletromecânica de energia, pois as características como baixo custo e robustez tornam o seu uso atrativo. Entretanto, em sistemas de acionamento e controle dessas máquinas, o conhecimento da velocidade com precisão é primordial para o setor produtivo.

Grandezas elétricas tais como corrente e tensão podem ser utilizadas para descrever o comportamento de diversas variáveis do MI. A velocidade em função da corrente e da tensão pode ser mapeada utilizando os padrões das amostras das curvas características destas variáveis. Assim, um conjunto de dados pode ser formado nos mais diversos pontos de operação, delimitando o domínio de abrangência.

As técnicas de estimação de velocidade baseadas nos modelos matemáticos convencionais das máquinas elétricas apresentam limitações, pois essas são sensíveis às variações paramétricas do MI nos diversos regimes de velocidade. Assim, o uso das redes neurais tem por objetivo mapear o comportamento da máquina, incorporando intrinsecamente em sua estrutura as diversas características não lineares apresentadas pelas variáveis envolvidas no processo.

Com a evolução do poder computacional dos processadores digitais para sistemas embarcados, o uso dessa ferramenta alternativa tem se tornado atrativa. Como benefício esperado, destacam-se a redução do custo do sistema de acionamento e controle, a melhoria na resposta dinâmica do sistema frente a mudanças de set-point e perturbações do sistema bem como a menor manutenção de dispositivos mecânicos.

Um método eficiente de estimativa da velocidade do MI para diversas aplicações deve ser capaz de ter precisão satisfatória em ampla faixa de velocidade e de conjugado de carga e ainda ser robusto a variações paramétricas e generalista para diferentes níveis de potência de motores. Além disso, o mesmo estimador deve funcionar de forma adequada independentemente da estratégia de controle.

\subsection{Objetivo}

O objetivo geral deste trabalho consiste em apresentar um método alternativo para a estimativa de velocidade em motores de indução trifásicos acionados por um driver com controle vetorial orientado pelo fluxo do estator do controle direto de corrente e pelo controle direto de torque, utilizando redes neurais artificiais com treinamento supervisionado off-line.

Assim, os objetivos específicos do trabalho são apresentados a seguir:

$\square$ Estudar o estado da arte em relação às aplicações das redes neurais artificiais utilizadas para a estimação de velocidade de motores elétricos trifásicos.

$\square$ Formar um conjunto de dados baseado em simulação computacional para treinamento e validação da RNA para as estratégias de controle vetorial orientado pelo 
fluxo eletromagnético do estator do MI.

$\square$ Realizar as simulações computacionais com as RNAs obtidas para selecionar as melhores candidatas a estimador de velocidade do MI para cada uma das estratégias de implementação.

$\square$ Realizar os experimentos na bancada de ensaio a fim de validar a proposta das duas estratégias de implementação de RNAs nos dois métodos de controles em diferentes MIs.

\subsection{Contribuições do Trabalho}

A proposta deste trabalho contribui com as pesquisas na área de estimação de velocidades dos MIs acionados por inversores de frequência com controle orientado pelo campo eletromagnético, nos seguintes aspectos:

$\square$ Investigar as variáveis disponíveis nas técnicas de acionamento CDC e CDT que contribuem para o mapeamento da velocidade utilizando RNAS.

$\square$ Identificar e avaliar as características de implementação da função tangente hiperbólica em processador digital de sinais.

$\square$ Utilização da Time Delay Neural Network como estimador de velocidade do MI.

$\square$ Implementar duas técnicas de controle vetorial do MI sensorless baseada em duas estratégias de implementação das redes neurais artificiais para a estimativa da velocidade.

$\square$ Desenvolvimento de um estimador neural de velocidade robusto para utilização em diferentes potência de MI.

\subsection{Organização do Trabalho}

Os próximos capítulos deste trabalho estão organizados da seguinte forma:

$\square$ No Capítulo 2 é apresentada a modelagem matemática do motor de indução para uso nas simulações computacionais, bem como as estratégias de controle vetorial orientado pelo fluxo do estator com controle direto de corrente e direto de torque. Ainda, é descrito o método de estimação de fluxo eletromagnético do estator da máquina para a correta operação das técnicas de controle.

$\square$ O Capítulo 3 aborda as técnicas de estimação de velocidade do MI e a apresentação da proposta de estimação da velocidade utilizando RNAs, bem como as estratégias 
de processamento de dados que compõe os vetores de entrada das RNAs. Ainda, neste capítulo, são apresentados os desempenhos de diversas RNAs treinadas com os conjuntos de dados de simulação para ambas as técnicas de controle e acionamentos. Ainda, neste capítulo, é realizada a seleção das RNAs de melhor desempenho e essas redes são posteriormente testadas na bancada experimental.

$\square$ O Capítulo 4 inicia com a seleção das melhores RNAs que podem atuar como um estimador genérico para cada uma das estratégias de implementação em ambos os métodos de controle vetorial orientado pelo fluxo do estator. As RNAs selecionadas em cada estratégia de implementação são testadas experimentalmente como estimador de velocidade do MI na realimentação do CDC e do CDT.

$\square$ Finalmente, no Capítulo 5, as conclusões do trabalho referente aos resultados obtidos, as perspectivas futuras e os trabalhos publicados referente ao trabalho são apresentados. 


\section{Modelagem e Controle do MI}

O controle a laço-fechado da máquina de indução e suas aplicações industriais têm crescido com a evolução da eletrônica de potência e dos sistemas digitais (AMEZQUITABROOKS; LICEAGA-CASTRO; LICEAGA-CASTRO, 2014b). Dessa forma, o controle do MI tem um importante papel nas aplicações de alta precisão na automação industrial (SOUZA et al., 2014).

A variação da velocidade do MI é comumente requerida em sistemas de automação industrial. A velocidade pode ser obtida por meio da medição direta no eixo da máquina, estimação ou predição, onde algumas estratégias são baseadas em modelos matemáticos do MI (ZHAO et al., 2016; ZBEDE; GADOUE; ATKINSON, 2016). Entretanto, a performance do controle e dos observadores de estado são fortemente afetados pelas incertezas paramétrica do motor (ALONGE; D'IPPOLITO; SFERLAZZA, 2014). Assim, as metodologias de estimação de velocidade que aparecem de forma robusta e que possam atuar em ampla faixa de velocidade se tornam alvo de constantes pesquisas.

As técnicas de controle vetorial como o CDC e o CDT possuem as vantagens de rápida resposta dinâmica de torque e ampla faixa de velocidade. Entretanto, diferentemente das Máquina de Corrente Contínua (MCC) onde o fluxo magnético e torque eletromagnético são naturalmente desacopladas, o controle vetorial orientado pelo fluxo magnético do estator possui tais componentes acopladas. A modelagem matemática do MI permite a identificação dos termos de acoplamento em cada uma das estratégia de controle abordada neste trabalho. Assim, neste capítulo, são apresentados os aspectos associados à modelagem do MI, do controle vetorial e do estimador de fluxo magnético do estator.

\subsection{Equações Dinâmicas do Motor de Indução}

De forma geral, os motores de indução são compostos por dois enrolamentos trifásicos, onde a estrutura fixa é denominada estator e a estrutura girante é denominada rotor. $\mathrm{O}$ enrolamento do rotor é comumente substituído por barras paralelas e curto-circuitadas nas extremidades, formando o rotor em gaiola ou também conhecido como gaiola de esquilo. 
Para o circuito elétrico equivalente, é considerado que o enrolamento do estator bem como o do rotor são constituídos por três bobinas de várias espiras. Tais bobinas são espacialmente distribuídas de forma uniforme na estrutura circular do motor. Os polos das bobinas são defasada em $120^{\circ}$ elétricos entre si. Assumindo uma máquina simétrica, as três impedâncias do estator e do rotor são iguais entre si.

O MI é alimentado por tensões trifásicas e equilibradas. As correntes do estator geram o campo eletromagnético que, por sua vez, induz tensão no rotor, produzindo o campo eletromagnético do rotor por meio da circulação das correntes. A interação dos campos produzidos pelo estator e pelo rotor produzem o torque que leva o rotor ao movimento.

Devido às características elétricas e mecânicas do MI, a influência de cada elemento da máquina no comportamento estacionário e principalmente dinâmico é bastante complexa. Com o objetivo de se obter uma simplificação do modelo matemático do MI e a redução do número de variáveis das equações que descrevem o comportamento dinâmico, o sistema de coordenadas trifásicas em um plano ortogonal é usado (HOLTZ, 1995). Assim, o sistema trifásico é substituído pelo sistema ortogonal, onde cada circuito do MI é visto por apenas dois enrolamento defasados em $90^{\circ}$, no estator e no rotor. As características de torque, de potência, de velocidade e do número de polos são mantidas. Como mostra a Figura 1, o novo sistema de coordenadas é denominado $\alpha \beta$, sendo indexados por $\alpha$ e $\beta$. Na referida figura $X_{a}, X_{b}$ e $X_{c}$ são as representações das componentes por fase do sistema trifásico, $\omega$ é a velocidade de rotação das variáveis do sistema trifásico no referencial estacionário, $X_{\alpha}$ e $X_{\beta}$ são as representações das componentes no referencial estacionário bifásico $\alpha \beta$.
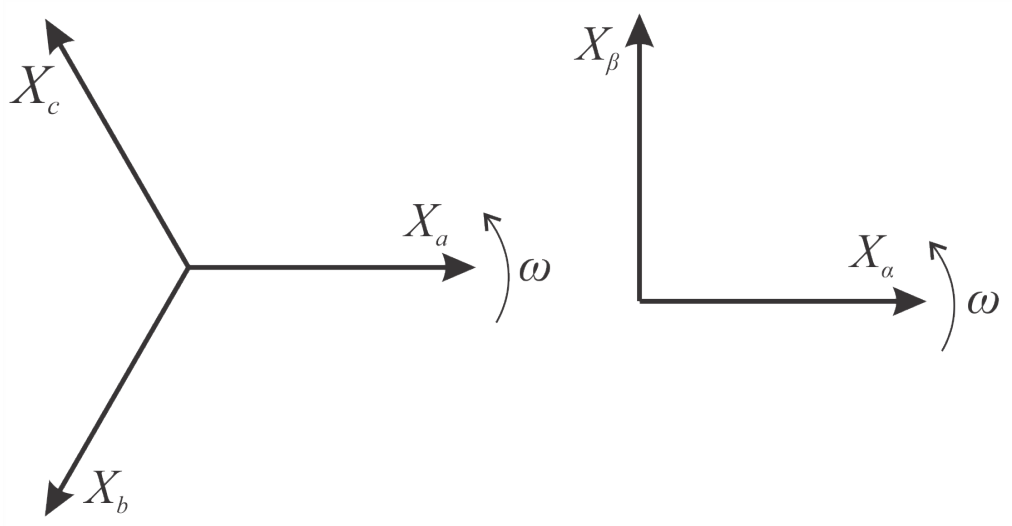

Figura 1 - Representação dos sistemas de coordenadas trifásicas e ortogonal.

O conjugado eletromagnético é produzido pela relação de fluxos e correntes do MI, onde cada grandeza é representada de forma a conter as contribuições de cada fase, com o uso de fasores espaciais. A notação de fasor espacial impõe que o sistema ortogonal seja um plano complexo, onde todas as grandezas neste plano são descritas por uma parte real e outra imaginária. A transformação $\alpha \beta$ para obtenção do plano complexo é dada por 
(1):

$$
f_{\alpha \beta 0}=\left[T_{\alpha \beta 0}\right] f_{a b c}
$$

onde $f$ pode ser as correntes, tensões ou os fluxos do MI. O termo $T_{\alpha \beta 0}$ é a matriz de transformação. A componente de sequência zero "0" possibilita que a matriz de transformação seja bi-direcional, sendo definida por (2):

$$
\left[T_{\alpha \beta 0}\right]=\frac{2}{3}\left[\begin{array}{ccc}
1 & -\frac{1}{2} & -\frac{1}{2} \\
0 & \frac{\sqrt{3}}{2} & -\frac{\sqrt{3}}{2} \\
\frac{1}{2} & \frac{1}{2} & \frac{1}{2}
\end{array}\right]
$$

onde o termo $2 / 3$ é introduzido em (2) para que as grandezas elétricas no referencial estacionário $\alpha \beta$ mantenham as mesmas características de amplitude do sistema trifásicos (FILADELFO, 2016).

As grandezas elétricas trifásicas $\left(f_{a b c}\right)$ podem ser obtidas das componentes ortogonais com o uso da matriz $T_{\alpha \beta 0}$ inversa, dada por (3):

$$
\left[T_{\alpha \beta 0}\right]^{-1}=\left[\begin{array}{ccc}
1 & 0 & 1 \\
-\frac{1}{2} & \frac{\sqrt{3}}{2} & 1 \\
-\frac{1}{2} & -\frac{\sqrt{3}}{2} & 1
\end{array}\right]
$$

Deste modo, as correntes $(\vec{i})$, tensões $(\vec{v})$ e fluxos do motor $(\vec{\psi})$ podem ser descritos no modelo ortogonal complexo $(\alpha \beta)$ a partir das tensões $\left(i_{a b c}\right)$, das correntes $\left(v_{a b c}\right)$ e dos fluxos $\left(\psi_{a b c}\right)$, como segue em $(4),(5)$ e $(6)$ :

$$
\begin{gathered}
\vec{i}=i_{\alpha}+j i_{\beta}=\frac{2}{3}\left[\begin{array}{lll}
1 & a & a^{2}
\end{array}\right]\left[\begin{array}{l}
i_{a} \\
i_{b} \\
i_{c}
\end{array}\right] \\
\vec{v}=v_{\alpha}+j v_{\beta}=\frac{2}{3}\left[\begin{array}{lll}
1 & a & a^{2}
\end{array}\right]\left[\begin{array}{l}
v_{a} \\
v_{b} \\
v_{c}
\end{array}\right] \\
\vec{\psi}=\psi_{\alpha}+j \psi_{\beta}=\frac{2}{3}\left[\begin{array}{lll}
1 & a & a^{2}
\end{array}\right]\left[\begin{array}{l}
\psi_{a} \\
\psi_{b} \\
\psi_{c}
\end{array}\right]
\end{gathered}
$$

onde

$$
a=e^{j 120^{\circ}}=\cos \left(120^{\circ}\right)+j \operatorname{sen}\left(120^{\circ}\right)=-\frac{1}{2}+j \frac{\sqrt{3}}{2}
$$

Nas equações (4), (5) e (6) assume-se que a fase " $a$ " do sistema trifásico esteja em fase com o eixo real do plano complexo. Os termos $a$ e $a^{2}$ indicam a direção das componentes das fases " $b$ " e " $c$ ", respectivamente. Assim, a desloca a fase em $120^{\circ}$ e $a^{2}$ desloca em $240^{\circ}$. 
As grandezas nas expressões fundamentais do MI são normalmente relacionadas ao referencial do estator e do rotor. Para manipular adequadamente tais equações, é importante obter a representação em um único referencial, comum para as grandezas do estator e do rotor. A Figura 2 mostra o plano complexo e os possíveis referenciais que podem ser adotados. O vetor de espaço de tensões de estator tem um deslocamento angular $\alpha^{\prime}$ com relação ao referencial do estator e o vetor de espaço de tensões do rotor tem um deslocamento angular $\beta^{\prime}$ com relação ao referencial do rotor. Neste contexto, o referencial genérico é definido pelos eixos de coordenada $d q$.

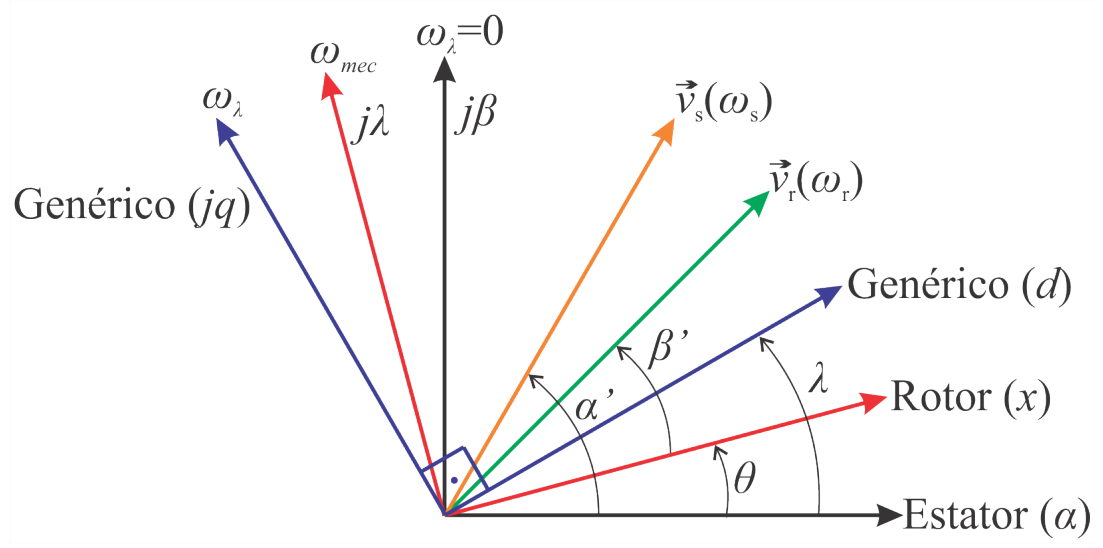

Figura 2 - Plano complexo e referência arbritária.

O referencial genérico pode ser qualquer um daqueles definidos anteriormente. Deste ponto, a velocidade angular $\left(\omega_{\lambda}\right)$ do referencial $\lambda$ é dada pela equação (8):

$$
\omega_{\lambda}=\frac{d}{d t} \lambda
$$

onde

$$
\lambda=\omega_{\lambda} t+\lambda_{0}
$$

Assim, as equações do MI no referencial genérico $\lambda$ são mostradas em (10) à (14):

$$
\begin{gathered}
\vec{v}_{\alpha \beta s}=R_{s} \vec{i}_{\alpha \beta s}+\frac{d}{d t} \vec{\psi}_{\alpha \beta s}+j \omega_{\lambda} \vec{\psi}_{\alpha \beta s} \\
\vec{v}_{\alpha \beta r}=R_{r} \vec{i}_{\alpha \beta r}+\frac{d}{d t} \vec{\psi}_{\alpha \beta r}+j\left(\omega_{\lambda}-z_{p} \omega_{m e c}\right) \vec{\psi}_{\alpha \beta r} \\
\vec{\psi}_{\alpha \beta s}=L_{s} \vec{i}_{\alpha \beta s}+L_{H} \vec{i}_{\alpha \beta r} \\
\vec{\psi}_{\alpha \beta r}=L_{H} \vec{i}_{\alpha \beta s}+L_{r} \vec{i}_{\alpha \beta r} \\
T_{e}=\frac{3}{2} z_{p} \operatorname{Im}\left\{\vec{i}_{\alpha \beta s} \vec{\psi}_{\alpha \beta s}^{*}\right\}
\end{gathered}
$$


onde:

$\vec{v}_{\alpha \beta s}$ é o vetor das tensões do estator em $\operatorname{Volt}(V)$ no referencial estacionário $\alpha \beta$;

$\vec{i}_{\alpha \beta s}$ é o vetor das correntes do estator em Ampère $(A)$ no referencial estacionário $\alpha \beta$;

$\vec{\psi}_{\alpha \beta s}$ é o vetor dos fluxos do estator em Weber $(W b)$ no referencial estacionário $\alpha \beta$;

$\vec{v}_{\alpha \beta r}$ é o vetor das tensões do rotor em $\operatorname{Volt}(V)$ no referencial estacionário $\alpha \beta$;

$\vec{i}_{\alpha \beta s}$ é o vetor das correntes do rotor em Ampère $(A)$ no referencial estacionário $\alpha \beta$;

$\vec{\psi}_{\alpha \beta r}$ é o vetor dos fluxos do rotor em Weber $(W b)$ no referencial estacionário $\alpha \beta$;

$\omega_{m e c}$ é a velocidade mecânica do rotor em $(\mathrm{rad} / \mathrm{s})$;

$z_{p}$ é o número de pares de polos;

$R_{s}$ é a resistência do estator em Ohms $(\Omega)$;

$R_{r}$ é a resistência do rotor em Ohms $(\Omega)$;

$L_{s}$ é a indutância do estator em Henry $(H)$;

$L_{r}$ é a indutância do rotor em Henry $(H)$;

$L_{H}$ é a indutância de magnetização em Henry $(H)$;

$T_{e}$ é o torque eletromagnético em (N.m.).

Com o objetivo de controlar o MI usando a estratégia do controle vetorial orientado no campo eletromagnético do estator e para simplificar o equacionamento, utiliza-se o referencial estacionário $\left(\omega_{\lambda}=0\right)$ (VAS, 1998). O circuito equivalente do MI no referencial estacionário $\alpha \beta$ é mostrado na Figura 3, onde $L_{l s}$ e $L_{l r}$ são as indutâncias de dispersão de estator e de rotor, respectivamente.

Assim, as equações do estator do MI neste referencial se tornam (15) e (16):

$$
\begin{aligned}
& v_{\alpha s}=R_{s} i_{\alpha s}+\frac{d}{d t} \psi_{\alpha s} \\
& v_{\beta s}=R_{s} i_{\beta s}+\frac{d}{d t} \psi_{\beta s}
\end{aligned}
$$

As equações do rotor são dadas por (17) e (18):

$$
\begin{aligned}
& v_{\alpha r}=R_{r} i_{\alpha r}+\frac{d}{d t} \psi_{\alpha r}+z_{p} \omega_{m e c} \psi_{\beta r} \\
& v_{\beta r}=R_{r} i_{\beta r}+\frac{d}{d t} \psi_{\beta r}-z_{p} \omega_{m e c} \psi_{\alpha r}
\end{aligned}
$$

Para o fluxo do estator tem-se as equações (19), (20) e (21):

$$
\begin{gathered}
\psi_{\alpha s}=L_{s} i_{\alpha s}+L_{H} i_{\alpha r} \\
\psi_{\beta s}=L_{s} i_{\beta s}+L_{H} i_{\beta r} \\
\psi_{s}=\sqrt{\psi_{\alpha s}^{2}+\psi_{\beta s}^{2}}
\end{gathered}
$$




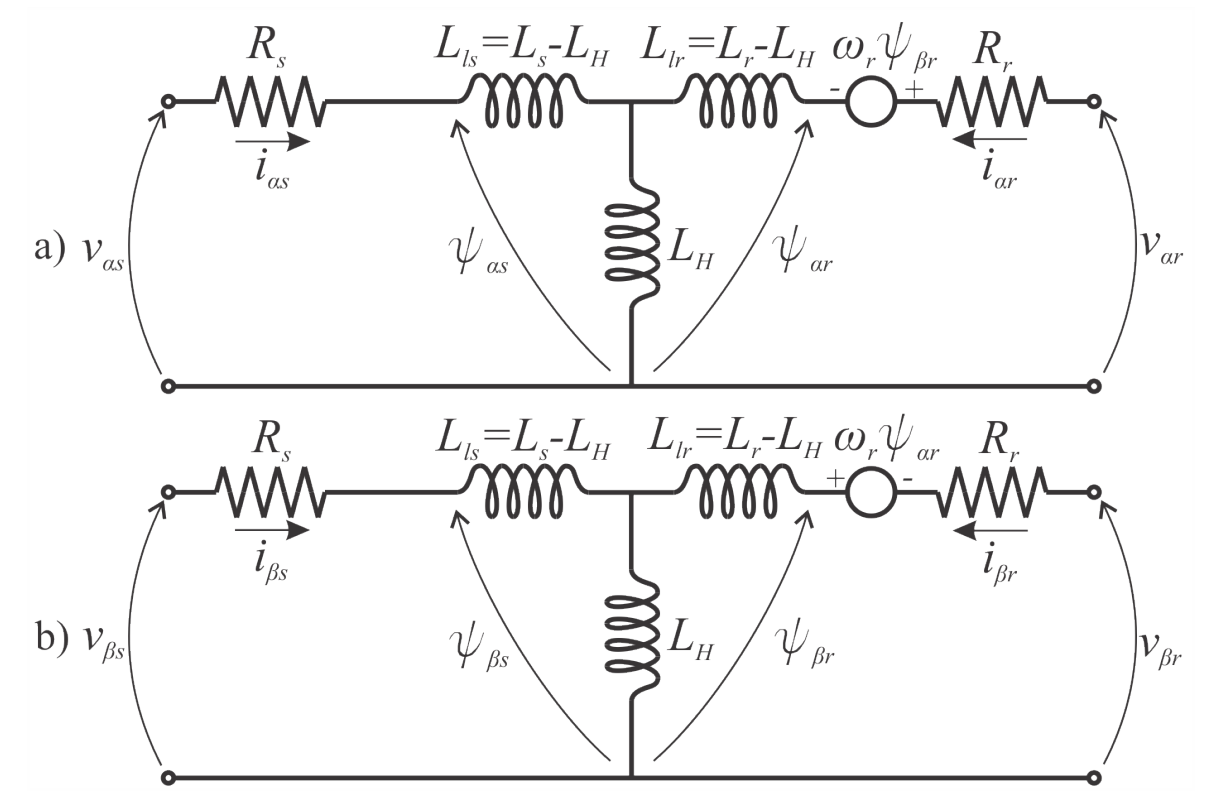

Figura 3 - Modelo dinâmico do motor de indução no sistema referencial estacionário $\alpha \beta$ : (a) Circuito equivalente do eixo $\alpha$; (b) Circuito equivalente do eixo $\beta$.

Fonte: adaptado de Bose, Wasynczuk e Sudhof (2002)

Rearranjando as equações (15) e (16), é possível integrar a f.c.e.m. para se obter os fluxos do estator, como apresentado em (22) e (23):

$$
\begin{aligned}
& \psi_{\alpha s}=\int\left(v_{\alpha s}-R_{s} i_{\alpha s}\right) d t \\
& \psi_{\beta s}=\int\left(v_{\beta s}-R_{s} i_{\beta s}\right) d t
\end{aligned}
$$

Enquanto para o fluxo do rotor tem-se as equações (24), (25) e (26):

$$
\begin{gathered}
\psi_{\alpha r}=L_{r} i_{\alpha r}+L_{H} i_{\alpha s} \\
\psi_{\beta r}=L_{r} i_{\beta r}+L_{H} i_{\beta s} \\
\psi_{r}=\sqrt{\psi_{\alpha r}^{2}+\psi_{\beta r}^{2}}
\end{gathered}
$$

Assim, é possível apresentar as equações de torque dadas por (27), (28) e (29):

$$
\begin{gathered}
T_{e}=\frac{3}{2} z_{p}\left(\psi_{\alpha s} i_{\beta s}-\psi_{\beta s} i_{\alpha s}\right) \\
T_{e}=\frac{3}{2} z_{p}\left(\psi_{\alpha r} i_{\beta r}-\psi_{\beta r} i_{\alpha r}\right) \\
T_{e}=\frac{3}{2} z_{p} L_{H}\left(i_{\alpha r} i_{\beta s}-i_{\beta r} i_{\alpha s}\right)
\end{gathered}
$$


Outra forma de representar o modelo matemático do MI consiste na aplicação da transformada de Park. O intuito do uso da transformada de Park é fazer com que as grandezas variantes no tempo no referencial estacionário $(\alpha \beta)$ se tornem constantes no sistema rotacional $\omega_{\lambda}$. A forma da transformada de Park é dada por (30):

$$
f_{d q 0}=\left[T_{d q 0}\right] f_{\alpha \beta 0}
$$

onde o termo $T_{d q 0}$ é a matriz de transformação, sendo definida pela equação (31):

$$
\left[T_{d q 0}\right]=\left[\begin{array}{cc}
\cos (\theta) & \operatorname{sen}(\theta) \\
-\operatorname{sen}(\theta) & \cos (\theta)
\end{array}\right]
$$

enquanto a matriz inversa de Park é dada por (32):

$$
\left[T_{d q 0}\right]^{-1}=\left[\begin{array}{cc}
\cos (\theta) & -\operatorname{sen}(\theta) \\
\operatorname{sen}(\theta) & \cos (\theta)
\end{array}\right]
$$

Aplicando a transformação de referencial de Park às equações no referencial estacionário do motor de indução se obtém o modelo dinâmico da máquina no sistema de coordenadas síncrona $d q$, apresentado na Figura 4. Este modelo é composto por dois circuitos equivalentes, onde um é relativo ao eixo direto $d$ e o outro relativo ao eixo em quadratura $q$. Assim, as grandezas variantes no tempo no sistema estacionário, aparecem com valores constantes no sistema girando na velocidade síncrona $\left(\omega_{e}\right)$ para o caso da orientação do estator.

Com base no modelo da Figura 4, pode-se escrever as equações para o estator e para o rotor conforme (33) à (36):

$$
\begin{gathered}
v_{d s}=R_{s} i_{d s}+\frac{d}{d t} \psi_{d s}-\omega_{e} \psi_{q s} \\
v_{q s}=R_{s} i_{q s}+\frac{d}{d t} \psi_{q s}+\omega_{e} \psi_{d s} \\
v_{d r}=R_{r} i_{d r}+\frac{d}{d t} \psi_{d r}-\left(\omega_{e}-z_{p} \omega_{m e c}\right) \psi_{q r} \\
v_{q r}=R_{r} i_{q r}+\frac{d}{d t} \psi_{q r}+\left(\omega_{e}-z_{p} \omega_{m e c}\right) \psi_{d r}
\end{gathered}
$$

onde:

$v_{d q s}$ são as tensões do estator em Volt $(V)$ no referencial síncrono $d q$;

$i_{d q s}$ são as correntes do estator em Ampère $(A)$ no referencial síncrono $d q$;

$\psi_{d q s}$ são os fluxos do estator em Weber $(W b)$ no referencial síncrono $d q$;

$v_{d q r}$ são as tensões do rotor em $\operatorname{Volt}(V)$ no referencial síncrono $d q$;

$i_{d q s}$ são as correntes do rotor em Ampère $(A)$ no referencial síncrono $d q$;

$\psi_{d q r}$ são os fluxos do rotor em Weber $(W b)$ no referencial síncrono $d q$. 


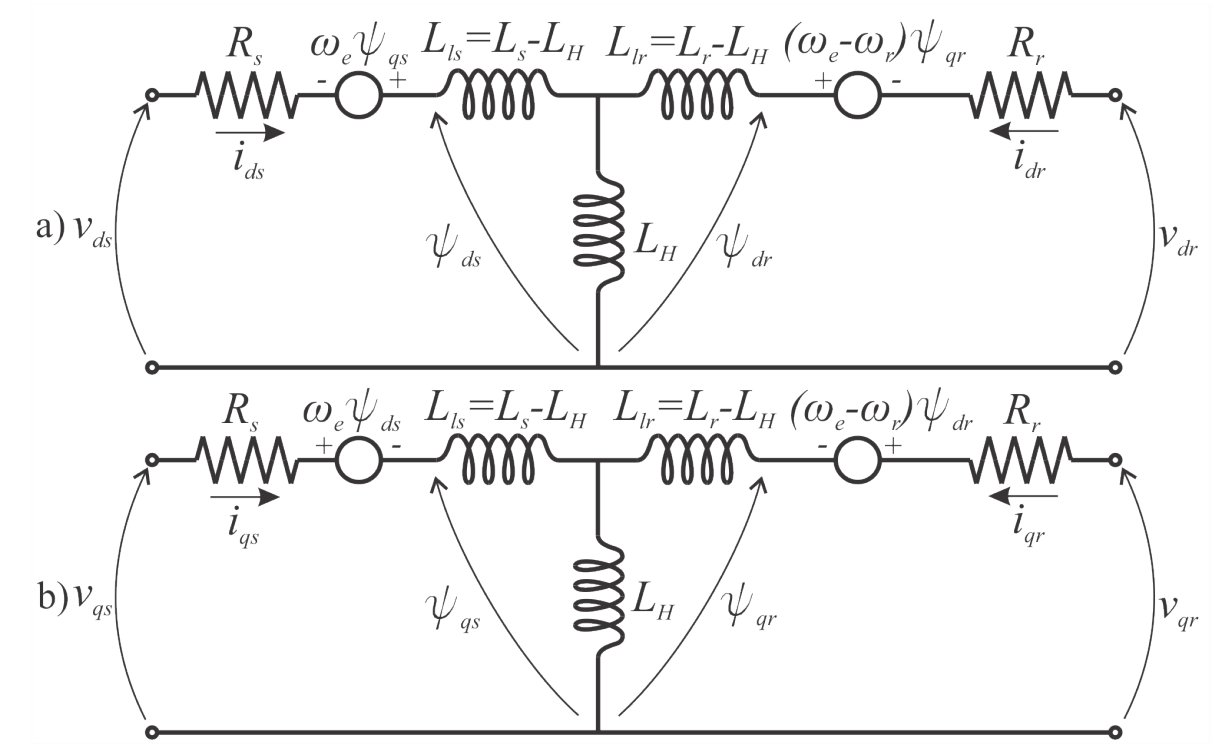

Figura 4 - Modelo dinâmico do motor de indução no sistema referencial síncrono $d q$ : (a) Circuito equivalente do eixo $d$; (b) Circuito equivalente do eixo $q$.

Fonte: adaptado de Bose, Wasynczuk e Sudhof (2002)

As equações para os fluxos no estator são definidas por (37) à (39):

$$
\begin{gathered}
\psi_{d s}=L_{s} i_{d s}+L_{H} i_{d r} \\
\psi_{q s}=L_{s} i_{q s}+L_{H} i_{q r} \\
\psi_{s}=\sqrt{\psi_{d s}^{2}+\psi_{q s}^{2}}
\end{gathered}
$$

Por outro lado, as equações para os fluxos no rotor são descritas por (40) à (42):

$$
\begin{gathered}
\psi_{d r}=L_{r} i_{d r}+L_{H} i_{d s} \\
\psi_{q r}=L_{r} i_{q r}+L_{H} i_{q s} \\
\psi_{r}=\sqrt{\psi_{d r}^{2}+\psi_{q r}^{2}}
\end{gathered}
$$

O torque eletromagnético $\left(T_{e}\right)$ no motor é produzido pela interação entre o fluxo do entreferro $\psi_{H}$ e a força magnetomotriz do rotor que é proporcional a corrente do rotor $I_{r}$. Ainda, na forma vetorial, o torque eletromagnético pode ser obtido por (43):

$$
\vec{T}_{e}=\frac{3}{2} z_{p} \vec{\psi}_{H} \times \vec{I}_{r}
$$


No sistema de coordenada síncrona, obtém-se (44) e (45):

$$
\begin{gathered}
T_{e}=\frac{3}{2} z_{p}\left(\psi_{d s} i_{q s}-\psi_{q s} i_{d s}\right) \\
T_{e}=\frac{3}{2} z_{p} L_{H}\left(i_{q s} i_{d r}-i_{d s} i_{q r}\right)
\end{gathered}
$$

Os parâmetros mecânicos do MI são relacionados ao torque eletromagnético na equação (46):

$$
T_{e}=T_{L}+B \omega_{m e c}+J \frac{d}{d t} \omega_{m e c}
$$

onde $T_{L}$ é o torque da carga $(N . m), B$ é o coeficiente de atrito viscoso (N.m.s) e $J$ é o momento de inércia do eixo do MI $\left(\mathrm{kg} \cdot \mathrm{m}^{2}\right)$. Estas equações são a base para o controle vetorial do MI e serão novamente citas posteriormente.

\subsection{Controle Vetorial}

Além da boa resposta dinâmica de torque e ampla faixa de velocidade, a evolução da eletrônica de digital e de potência fez popularizar o uso do controle vetorial do MI nas aplicações industriais (AMEZQUITA-BROOKS; LICEAGA-CASTRO; LICEAGA-CASTRO, 2014a).

O controle vetorial pode ser implementado em qualquer um dos vetores de referência de fluxo magnético, ou seja, o fluxo do estator, do rotor ou do entreferro. O referencial do fluxo no rotor tem como principal vantagem o desacoplamento natural entre o fluxo e o torque para a alimentação em modo de corrente (VAS, 1998; KAN; ZHANG; WANG, 2015; ZHAO et al., 2016). Entretanto, a dependência paramétrica da constante de tempo do rotor faz dessa técnica bastante sensível à temperatura (GONZALEZ; RIVAS; RODRIGUEZ, 2008; HERNANDEZ, 1999).

As técnicas de controle com orientação no referencial do estator devem ser consideradas nos respectivos circuitos de desacoplamento para o correto funcionamento da estratégia de controle (VAS, 1998). Para as técnicas de controle vetorial que não utilizam sensores invasivos para detecção do fluxo magnético do entreferro, o desafio é a estimação desta variável no referencial selecionado. O controle orientado no fluxo do estator básico tem apenas a dependência da precisão do valor da resistência do estator (BOSE; WASYNCZUK; SUDHOF, 2002). Entretanto, para o correto funcionamento dessa estratégia de controle em ampla faixa de velocidade, as técnicas de estimação do fluxo do estator devem ser aprimoradas, como apresentado nos trabalhos de Idris e Yatim (2002) e Stojić et al. (2015).

O controle vetorial pode ser do tipo direto ou indireto, diferenciando-se basicamente pelo método de determinação do módulo e da posição do vetor fluxo magnético na refe- 
rência selecionada. O controle direto usa a medição do campo magnético ou a estimativa do módulo (ou posição) do vetor magnético a partir de variáveis primárias, tais como as correntes e as tensões do estator. Enquanto no controle indireto, a velocidade de escorregamento $\left(\omega_{s l}\right)$ é obtida com o uso das correntes de referência $i_{d s}{ }^{*}$ e $i_{q s}{ }^{*}$ e dos parâmetros do motor. Somando a velocidade do rotor, medida ou estimada, obtém-se a velocidade do fluxo magnético de referência.

O diagrama em blocos do controle vetorial direto acionado por um inversor fonte de tensão é mostrado na Figura 5. Os valores de referência das correntes $i_{d s}{ }^{*}$ e $i_{q s}{ }^{*}$ no referencial síncrono $(d q)$ são convertidos para o referencial estacionário $(\alpha \beta)$, com o uso do vetores unitários $\cos \left(\theta_{e}\right)$ e $\operatorname{sen}\left(\theta_{e}\right)$ gerado pelo fluxo, no caso do referencial do rotor, $\psi_{d r}$ e $\psi_{q r}$. Neste caso, o vetores de fluxo $\psi_{d r}$ e $\psi_{q r}$ são obtidos por um estimador, baseado no modelo de tensão do MI, com o uso da medição das correntes e das tensões do estator. Os controladores Proporcional e Integral $(P I)$ são opcionais, onde no diagrama da Figura 5 , um controlador atua no ajuste do fluxo do MI gerando a corrente de referência $i_{d s}{ }^{*}$, enquanto o outro controlador é usado para gerar a referência de corrente que controla o torque $\left(i_{q s}{ }^{*}\right)$, para o ajuste da velocidade do MI.

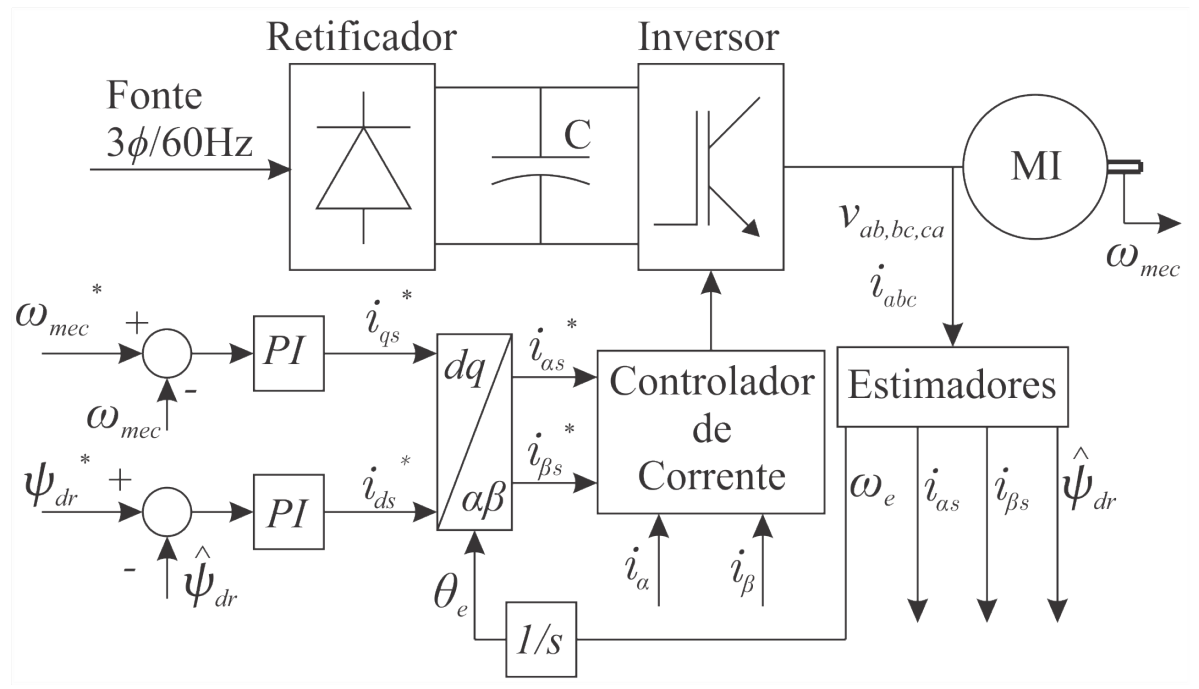

Figura 5 - Diagrama em blocos do controle vetorial direto orientado no fluxo magnético do rotor.

Para o funcionamento do controle vetorial, é necessário o alinhamento entre a corrente $i_{d s}$ com $\psi_{r}$ e a corrente $i_{q s}$ de forma perpendicular, conforme Bose, Wasynczuk e Sudhof (2002). A Figura 6 mostra o alinhamento do vetores de fluxo $\psi_{\alpha r}$ e $\psi_{\beta r}$ no referencial estacionário. Nesta figura, os eixos $d q$ giram na velocidade síncrona $\omega_{e}$ em relação ao referencial estacionário $\alpha \beta$, onde a posição do eixo $d$ em relação a $\alpha$ é $\theta_{e}$. Da Figura 6 é possível extrair as expressões (47) e (48):

$$
\psi_{\alpha r}=\widehat{\psi}_{r} \cos \left(\theta_{e}\right)
$$




$$
\psi_{\beta r}=\widehat{\psi}_{r} \operatorname{sen}\left(\theta_{e}\right)
$$

ou ainda, pode-se escrever (49) à (51):

$$
\begin{gathered}
\cos \left(\theta_{e}\right)=\frac{\psi_{\alpha r}}{\widehat{\psi}_{r}} \\
\operatorname{sen}\left(\theta_{e}\right)=\frac{\psi_{\beta r}}{\widehat{\psi}_{r}} \\
\widehat{\psi}_{r}=\sqrt{\psi_{\alpha r}^{2}+\psi_{\beta r}^{2}}
\end{gathered}
$$

Os sinais de $\operatorname{sen}\left(\theta_{e}\right)$ e $\cos \left(\theta_{e}\right)$, são usados para a orientação dos vetores de corrente do estator na Figura 6. Assim, $\psi_{q r}=0$ e $\psi_{d r}=\widehat{\psi}_{r}$.

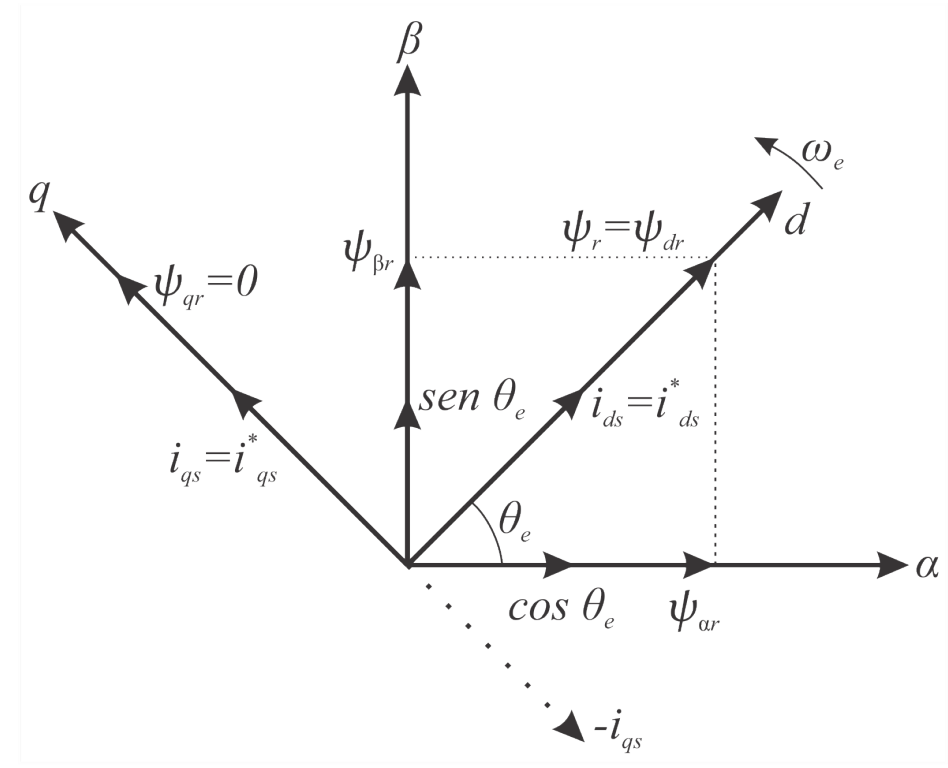

Figura 6 - Fasores do fluxo de rotor no controle vetorial.

\subsubsection{Controle Vetorial Orientado pelo Fluxo do Estator}

Como mencionado anteriormente, o controle vetorial pode ser orientado pelo fluxo do estator, ao custo da utilização de um circuito de desacoplamento (BOSE; WASYNCZUK; SUDHOF, 2002). O controle vetorial direto do fluxo do estator tem como característica a precisa estimação do vetor fluxo, o qual é dependente apenas da resistência do estator $\left(R_{s}\right)$.

Considerando o MI com o rotor em gaiola, onde as suas barras são curto-circuitadas, as tensões $v_{d r}$ e $v_{q r}$ são nulas, fazendo com que as equações (35) e (36) se tornem (52) e (53):

$$
R_{r} i_{d r}+\frac{d}{d t} \psi_{d r}-\left(\omega_{e}-z_{p} \omega_{m e c}\right) \psi_{q r}=0
$$




$$
R_{r} i_{q r}+\frac{d}{d t} \psi_{q r}+\left(\omega_{e}-z_{p} \omega_{m e c}\right) \psi_{d r}=0
$$

Manipulando as equações (52) e (53) pela constante de tempo do rotor $\left(T_{r}=L_{r} / R_{r}\right)$ e a velocidade de escorregamento $\left(\omega_{s l}\right)$, obtêm-se $(54)$ e $(55)$ :

$$
\begin{aligned}
& \left(1+s T_{r}\right) \psi_{d r}-L_{H} i_{d s}-T_{r} \omega_{s l} \psi_{q r}=0 \\
& \left(1+s T_{r}\right) \psi_{q r}-L_{H} i_{q s}+T_{r} \omega_{s l} \psi_{d r}=0
\end{aligned}
$$

onde " $s$ " é o operador diferencial $\left(\frac{d}{d t}\right)$. Nessas equações, o fluxo $\psi_{d r}$ e $\psi_{q r}$ são substituídos por $\psi_{d s}$ e $\psi_{q s}$. Assim, as equações dos fluxos do estator nos eixos de referência $d q$ são escritos por (56) e (57):

$$
\begin{aligned}
& \psi_{d s}=L_{s} i_{d s}+L_{H} i_{d r} \\
& \psi_{q s}=L_{s} i_{q s}+L_{H} i_{q r}
\end{aligned}
$$

ou

$$
\begin{aligned}
& i_{d r}=\frac{\psi_{d s}}{L_{H}}-\frac{L_{s}}{L_{H}} i_{d s} \\
& i_{q r}=\frac{\psi_{q s}}{L_{H}}-\frac{L_{s}}{L_{H}} i_{q s}
\end{aligned}
$$

Substituindo as equações (58) e (59) nas equações (40) e (41), respectivamente, obtêmse $(60)$ e (61):

$$
\begin{aligned}
& \psi_{d r}=\frac{L_{r}}{L_{H}} \psi_{d s}+\left(L_{H}-\frac{L_{s} L_{r}}{L_{H}}\right) i_{d s} \\
& \psi_{q r}=\frac{L_{r}}{L_{H}} \psi_{q s}+\left(L_{H}-\frac{L_{s} L_{r}}{L_{H}}\right) i_{q s}
\end{aligned}
$$

Essas equações relacionam os fluxos do estator e do rotor às correntes do estator. Ainda, essas equações podem ser simplificadas, aplicando as equações (60) e (61) nas equações (54) e (55), respectivamente, e multiplicando ambos os lados por $L_{m} / L_{r}$, obtendo (62) e (63):

$$
\begin{aligned}
& \left(1+s T_{r}\right) \psi_{d s}=\left(1+s \sigma T_{r}\right) L_{s} i_{d s}+\omega_{s l} T_{r}\left(\psi_{q s}-\sigma L_{s} i_{q s}\right) \\
& \left(1+s T_{r}\right) \psi_{q s}=\left(1+s \sigma T_{r}\right) L_{s} i_{q s}-\omega_{s l} T_{r}\left(\psi_{d s}-\sigma L_{s} i_{d s}\right)
\end{aligned}
$$

onde $\sigma=1-L_{H}^{2} / L_{s} L_{r}$. O diagrama vetorial apresentado na Figura 7 ilustra o controle vetorial orientado pelo fluxo do estator. Neste, tem-se que $\psi_{d s}=\psi_{s}, \psi_{q s}=0$ e $\theta_{e}$ é a 
posição do fluxo do estator no eixo $\alpha$ em relação ao eixo síncrono $d$. Portanto, as equações (62) e (63) podem ser reescritas como (64) e (65):

$$
\begin{gathered}
\left(1+s T_{r}\right) \psi_{d s}=\left(1+s \sigma T_{r}\right) L_{s} i_{d s}-\sigma L_{s} T_{r} \omega_{s l} i_{q s} \\
\left(1+s \sigma T_{r}\right) L_{s} i_{q s}=\omega_{s l} T_{r}\left(\psi_{d s}-\sigma L_{s} i_{d s}\right)
\end{gathered}
$$

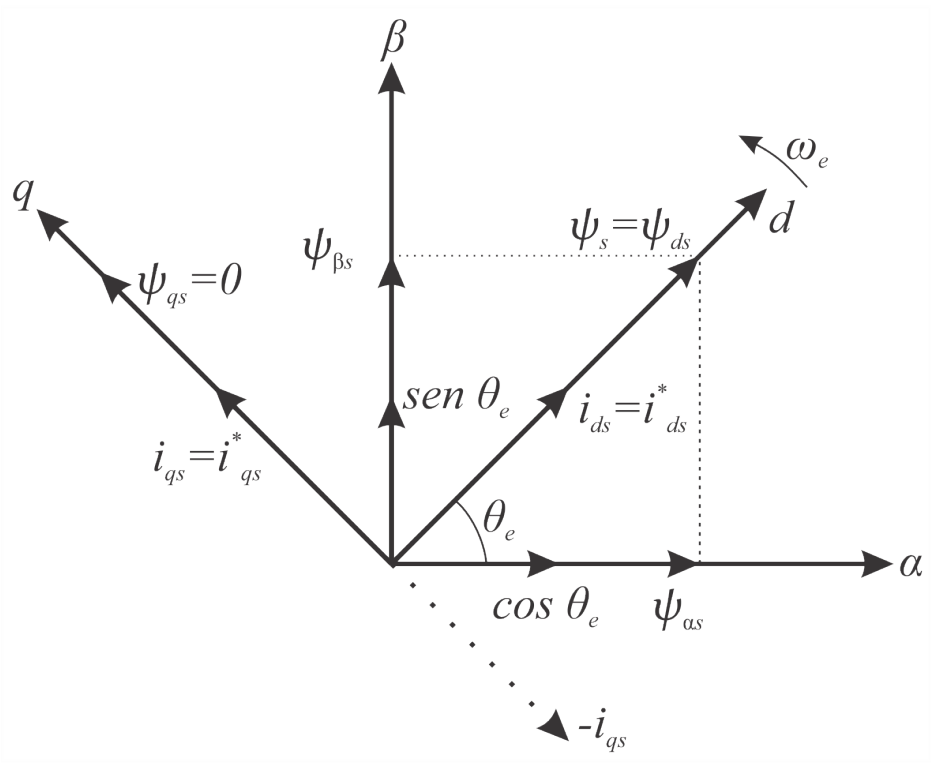

Figura 7 - Diagrama vetorial do controle vetorial orientado pelo fluxo do estator.

Fonte: adaptado de Bose, Wasynczuk e Sudhof (2002)

É importante observar na equação (64) que o fluxo $\psi_{d s}$ está em função da corrente $i_{d s}$ e $i_{q s}$; ou seja, há o efeito de acoplamento entre os eixos. Isso significa que a alteração no comando de torque dado por $i_{q s}$ também afetará o fluxo da máquina. Portanto, esse efeito do acoplamento deve ser eliminado para o correto funcionamento da estratégia de controle.

O circuito de desacoplamento é mostrado no diagrama de blocos da Figura 8, onde o termo de desacoplamento $i_{d q}$ é adicionado na saída do controle de fluxo da máquina para gerar o sinal de comando de referência de corrente $i_{d s}{ }^{*}$ e a referência de fluxo do estator $\psi_{d s}{ }^{*}$. A corrente $i_{d s}{ }^{*}$ pode ser escrita como (66):

$$
i_{d s}^{*}=C\left(\psi_{d s}^{*}-\psi_{d s}\right)+i_{d q}
$$

onde $C=K_{1}+K_{2} / s$, sendo $K_{1}$ e $K_{2}$ os ganhos do controlador PI. Substituindo a equação (66) em (64), tem-se (67):

$$
\left(1+s T_{r}\right) \psi_{d s}=L_{s}\left[\left(1+s \sigma T_{r}\right) C\left(\psi_{d s}^{*}-\psi_{d s}\right)+\left(1+s \sigma T_{r}\right) i_{d q}-\sigma T_{r} \omega_{s l} i_{q s}\right]
$$




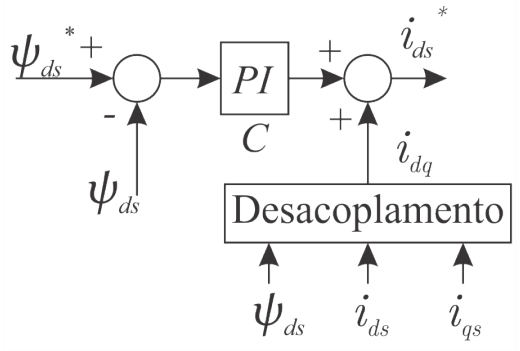

Figura 8 - Injeção do sinal de desacoplamento no controle vetorial orientado pelo fluxo do estator.

Fonte: adaptado de Bose, Wasynczuk e Sudhof (2002)

Para o desacoplamento do controle do fluxo $\psi_{d s}$ com a adição de $i_{d q}$, o resultado dos termos $\left(1+s \sigma T_{r}\right) i_{d q}-\sigma T_{r} \omega_{s l} i_{q s}=0$, é descrito por (68):

$$
i_{d q}=\frac{\sigma T_{r} \omega_{s l} i_{q s}}{\left(1+s \sigma T_{r}\right)}
$$

onde $\omega_{s l}$ pode ser escrita pela equação (65) tem-se (69):

$$
\omega_{s l}=\frac{\left(1+\sigma s T_{r}\right) L_{s} i_{q s}}{T_{r}\left(\psi_{d s}-\sigma L_{s} i_{d s}\right)}
$$

Por meio das equações (68) e (69), o sinal de desacoplamento $i_{d q}$ é dada por (70):

$$
i_{d q}=\frac{\sigma L_{s} i_{q s}^{2}}{\left(\psi_{d s}-\sigma L_{s} i_{d s}\right)}
$$

onde $i_{d q}$ fica em função de fluxo $\psi_{d s}, i_{d s}$ e $i_{q s}$.

A expressão geral para o torque eletromagnético desenvolvido é a seguinte (71):

$$
T_{e}=\frac{3}{2} \frac{P}{2}\left(\psi_{d s} i_{q s}-\psi_{q s} i_{d s}\right)
$$

Com o controle vetorial considera-se o fluxo $\psi_{q s}=0$, então tem-se (72):

$$
T_{e}=\frac{3}{2} \frac{P}{2} \psi_{d s} i_{q s}
$$

A Figura 9 mostra o diagrama em blocos do controle vetorial orientado pelo fluxo do estator, onde, nesse trabalho, é denominado Controle Vetorial com Controle Direto de Corrente (CV-CDC) com o objetivo de diferenciar do Controle Vetorial com Controle Direto de Torque (CV-CDT). A etapa do acionamento eletrônico é representado pelo retificador trifásico em ponte, filtro capacitivo de tensão e o inversor trifásico, cuja função consiste em aplicar a tensão de alimentação ao MI. Neste trabalho a carga mecânica do MI é representada pela máquina de corrente contínua, que por sua vez está configurada como gerador. As tensões e as correntes do MI são utilizadas na etapa de estimação do fluxo eletromagnético e da sua velocidade síncrona. A medição das tensões pode ser substituída pelos sinais de modulação do inversor. Um controlador PI é utilizado para o controle do fluxo do estator, enquanto um segundo controlador PI tem a função de controlar a 
velocidade mecânica do MI, onde as referências de fluxo e de velocidade são $\psi_{d s}{ }^{*}$ e $\omega_{r}{ }^{*}$, respectivamente. A malha de controle do fluxo do estator fornece a corrente de referência $i_{d s}{ }^{*}$, enquanto a malha de velocidade fornece a corrente de referência $i_{q s}{ }^{*}$, após ter sido adicionado o termo de desacoplamento $i_{d q}$. É possível observar que o desacoplamento do controle é dependente de outros parâmetros do MI, mas devido à presença do controlador PI, esse efeito pode ser negligenciado (BOSE; WASYNCZUK; SUDHOF, 2002). A Figura 9 apresenta também o bloco responsável pelo controle de corrente, podendo ser adotadas diversas estratégias para tal finalidade. O bloco denominado Estimadores tem como função estimar o vetor do fluxo eletromagnético do estator, sua velocidade e a posição.

A estratégia para a estimativa de fluxo será abordada na Seção 2.4, enquanto o Capítulo 3 trata da estimativa da velocidade mecânica do MI. Na Seção 2.3 apresentam-se os aspectos da modelagem do CDT.

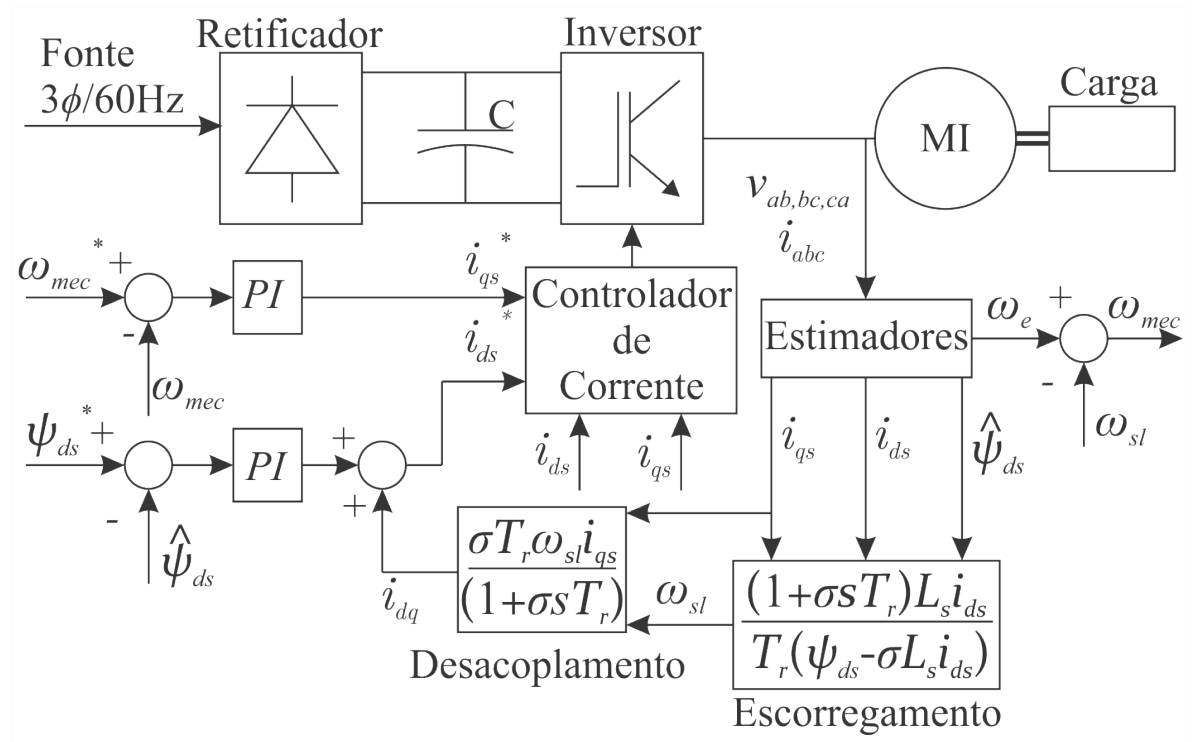

Figura 9 - Acionamento do MI pelo controle vetorial orientado pelo fluxo do estator.

Fonte: adaptado de Bose, Wasynczuk e Sudhof (2002)

\subsection{Controle Direto de Torque}

O controle direto de torque oferece alta performance em relação a sua simplicidade de implementação e rápida resposta de torque eletromagnético. O baixo custo computacional e o bom desempenho dinâmico em médias e altas velocidades motivaram o uso do CDT (VAS, 1998). Essa técnica tem a característica de controlar diretamente o fluxo e o torque, para as máquinas acionadas por inversor fonte de tensão com a devida tabela de chaveamento ou técnica de modulação apropriada.

De forma similar à equação (71), o torque eletromagnético em relação as variáveis do 
estator é dado por (73):

$$
T_{e}=\frac{3}{2} \frac{P}{2} \vec{\psi}_{s} \times \vec{I}_{s}
$$

onde $\vec{\psi}_{s}=\psi_{q s}+j \psi_{d s}$ e $\vec{I}_{s}=i_{q s}+j i_{d s}$. Na forma complexa, os fluxos do estator e do rotor podem ser escritos como (74) e (75):

$$
\begin{aligned}
& \vec{\psi}_{s}=L_{s} \vec{I}_{s}+L_{H} \vec{I}_{r} \\
& \vec{\psi}_{r}=L_{r} \vec{I}_{r}+L_{H} \vec{I}_{s}
\end{aligned}
$$

onde $\vec{I}_{r}$ é o vetor da corrente do rotor.

Eliminando o $\vec{I}_{r}$ da equação (74), tem-se (76):

$$
\vec{\psi}_{s}=\frac{L_{H}}{L_{s}} \vec{\psi}_{r}+L_{s}^{\prime} \vec{I}_{s}
$$

onde $L_{s}^{\prime}=L_{s} L_{r}-L_{H}^{2}$. A equação $(77)$ corresponde a $\vec{I}_{s}$.

$$
\vec{I}_{s}=\frac{1}{L_{s}^{\prime}} \vec{\psi}_{s}-\frac{L_{H}}{L_{r} L_{s}^{\prime}} \vec{\psi}_{r}
$$

Substituindo a equação (77) na equação (73) e simplificando, obtém-se a expressão (78):

$$
\vec{T}_{e}=\frac{3}{2} \frac{P}{2} \frac{L_{H}}{L_{r} L_{s}^{\prime}} \vec{\psi}_{s} \times \vec{\psi}_{r}
$$

Assim, a magnitude do torque é calculada conforme (79):

$$
T_{e}=\frac{3}{2} \frac{P}{2} \frac{L_{H}}{L_{r} L_{s}^{\prime}}\left|\psi_{s}\right| \times\left|\psi_{r}\right| \operatorname{sen}(\lambda)
$$

onde $\lambda$ é o ângulo entre os fluxos. A Figura 10 mostra o diagrama fasorial para a equação (78), indicando os vetores $\vec{\psi}_{s}, \vec{\psi}_{r}$ e $\vec{I}_{s}$ para o desenvolvimento do torque positivo. Mantendo o fluxo do rotor constante e tendo o fluxo do estator aumentado pela tensão do estator $V_{s}$, a mudança do ângulo $\lambda$ é $\Delta \lambda$, e a expressão do torque incremental $\Delta T_{e}$ é dado por (80):

$$
T_{e}=\frac{3}{2} \frac{P}{2} \frac{L_{H}}{L_{r} L_{s}^{\prime}}\left|\psi_{r}\right| \times\left|\vec{\psi}_{s}+\Delta \vec{\psi}_{s}\right| \operatorname{sen}(\Delta \lambda)
$$

O CDT clássico proposto por Takahashi e Noguchi (1986) consiste na comparação dos valores de referência de torque e de fluxo do estator com os valores medidos ou estimados do MI e controlados por meio de comparadores de histerese. O CDT atua independentemente no controle de torque e de fluxo utilizando uma estratégia ótima de seleção do vetor de tensão aplicada ao MI. A representação do CDT, conforme Takahashi e Noguchi 


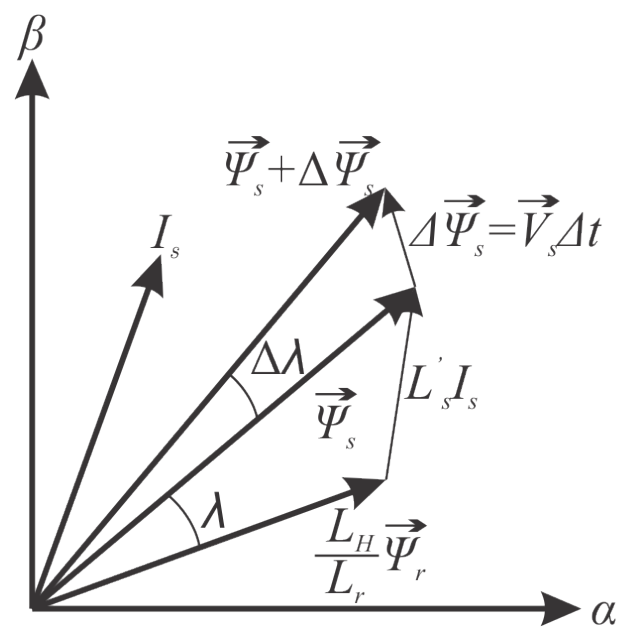

Figura 10 - Fluxo do estator, fluxo do rotor, e correntes do estator nos eixos de coordenadas $\alpha \beta$.

Fonte: adaptado de Bose, Wasynczuk e Sudhof (2002)

(1986), é mostrada na Figura 11. A tensão que impõe o torque eletromagnético do MI é aplicada pelo inversor, onde o padrão de chaveamento obedece uma lógica previamente estabelecida e acionada pelas variáveis de saída dos comparadores de histerese que controlam o fluxo do estator e o torque. De modo similar ao bloco denominado Estimadores mostrados na Figura 9, o CDT possui a estimação do fluxo eletromagnético do estator, da posição e do torque eletromagnético.

Observando a posição espacial do fluxo do estator e o estado dos comparadores de histerese é possível selecionar o vetor ótimo para o chaveamento a partir de uma tabela de regras pré-definidas. Com a devida aplicação dos vetores de tensão, é possível manter os níveis de torque e de fluxo eletromagnéticos dentro dos respectivos valores de referência da banda de histerese. As características da estratégia CDT proposta por Takahashi e Noguchi (1986), são destacadas na sequência (VAS, 1998). As principais vantagens são:

$\square$ Uso do referencial estacionário das variáveis $(\alpha \beta)$;

\ Não utilização do módulo gerador PWM;

$\square$ Controle indireto da corrente;

$\square$ Estrutura independente dos parâmetros do rotor;

$\square$ Rápida resposta do controle de torque;

$\square$ Reduzido número de controladores.

As principais desvantagens são:

$\square$ Frequência de chaveamento variável;

$\square$ Elevada frequência de amostragem dos sinais em aplicações digitais; 


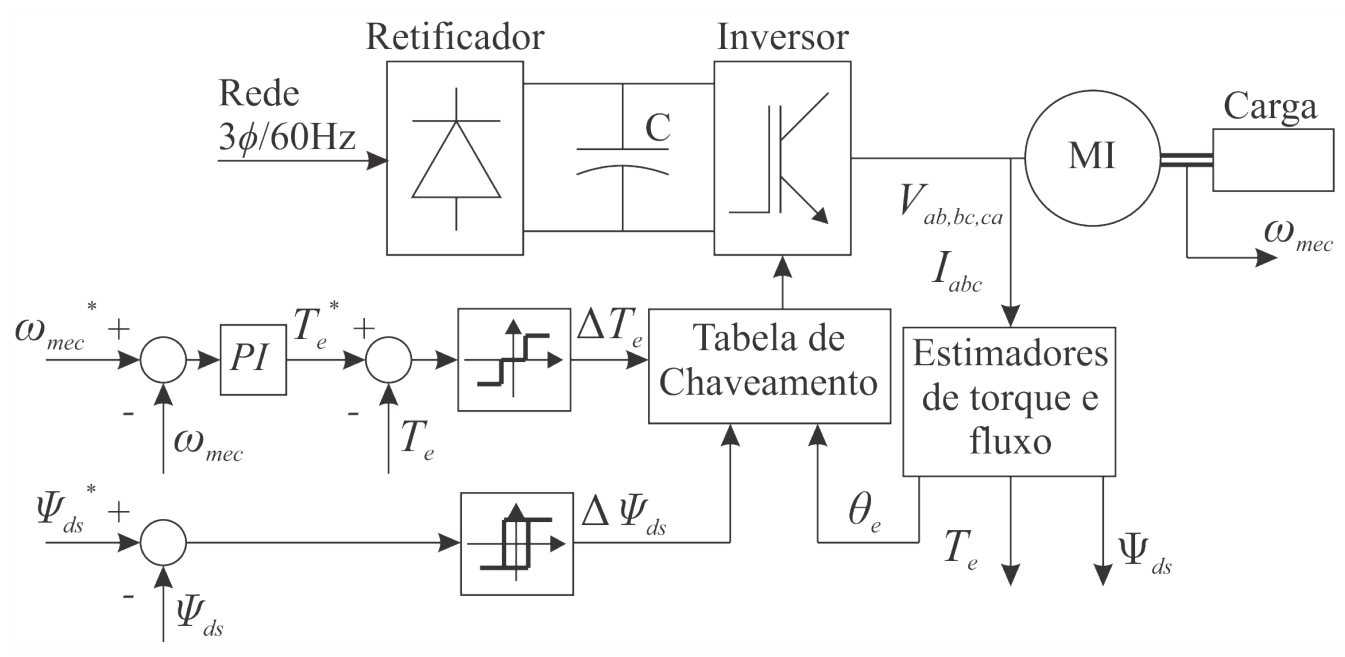

Figura 11 - Diagrama do CDT clássico.

Fonte: adaptado de Takahashi e Noguchi (1986)

Altas perdas de chaveamento;

Elevada ondulação de torque;

Dificuldade de operação em regiões de baixa velocidade e durante a partida.

A seguir é apresentada uma metodologia para atenuar ou mesmo anular algumas das desvantagens elencadas, possibilitando assim, um melhor desempenho do sistema acionado utilizando o CDT.

\subsubsection{Controle Direto de Torque com Modulação Vetorial}

A utilização da modulação por vetores espaciais tem por objetivo atenuar os problemas encontrados do CDT controlado por comparadores de histerese. O uso da modulação Space Vector Modulation (SVM) proporciona ao CDT uma frequência constante de chaveamento, reduzindo a ondulação do torque eletromagnético e melhorando o desempenho na região de baixas velocidades (Xue et al., 1990). Além da modulação SVM, outra alteração na estratégia de controle é a substituição dos comparadores de histerese por controladores PI. O conjunto de alterações implica no aumento no custo computacional para sua implementação, sendo que a modulação SVM representa um acréscimo de $25 \%$ à $30 \%$ do tempo computacional requerido em relação ao CDT clássico (CASADEI et al., 2002).

O CDT-SVM é comumente interpretado de forma similar ao CDC orientado pelo fluxo do estator, sem a utilização dos controladores de corrente (KAZMIERKOWSKI et al., 2011). Para ABU-RUB, STANDO e KAZMIERKOWSKI (2013) a técnica CDT-SVM pode ser vista como a combinação do CDT clássico e o FOC, atenuando as desvantagens básicas e mantendo as vantagens de ambos os métodos. O diagrama em blocos da Figura 12 mostra 
o controle CDT-SVM em malha fechada. O modelo apresentado a seguir tem como base o circuito já apresentado na Figura 3, assim como mostrado nos conceitos fundamentais do controle vetorial.

O CDT mostrado na Figura 12 apresenta três malhas de controle, sendo um controlador para o fluxo eletromagnético do estator, um para o torque eletromagnético e outro para a velocidade mecânica, resultando na tensão a ser sintetizada pelo inversor $\left(v_{d s}{ }^{*} \mathrm{e}\right.$ $\left.v_{q s}{ }^{*}\right)$. Um termo de desacoplamento é utilizado na saída da malha do controle de torque, representado pela adição do termo $\psi_{d s} \times \omega_{e}$. A posição do fluxo do estator $\left(\theta_{e}\right)$ é obtida por meio das componentes $\psi_{\alpha s}$ e $\psi_{\beta s}$, dado pela equação (81). Em regime permanente o controle de fluxo do estator se comporta de forma similar ao CDC orientado pelo fluxo do estator, ou seja, em que $\psi_{d s}=\psi_{s}$ e $\psi_{q s}=0$.

$$
\theta_{e}=\tan ^{-1}\left(\frac{\psi_{\alpha s}}{\psi_{\beta s}}\right)
$$

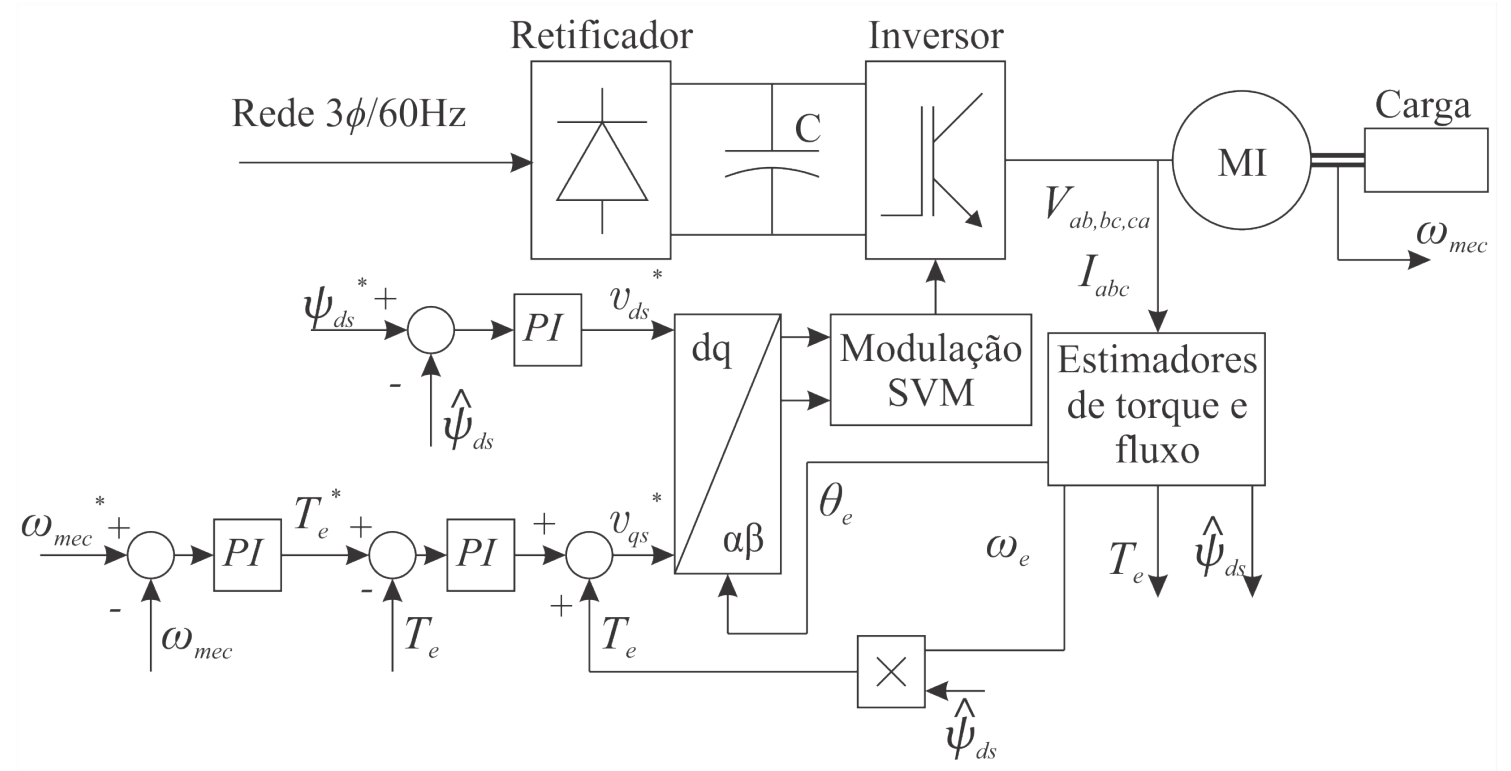

Figura 12 - Diagrama do CDT-SVM orientado pelo fluxo do estator.

A velocidade síncrona $\left(\omega_{e}\right)$ pode ser obtida pelo fluxo do estator no referencial estacionário, como apresentado na equação (82):

$$
\omega_{e}=\frac{d \theta_{e}}{d t}=\frac{\frac{d \psi_{\beta s}}{d t} \psi_{\alpha s}-\frac{d \psi_{\alpha s}}{d t} \psi_{\beta s}}{\left(\psi_{\alpha s}\right)^{2}+\left(\psi_{\beta s}\right)^{2}}
$$

O fluxo do estator no referencial estacionário é calculado por (83) e (84):

$$
\begin{aligned}
& \psi_{\alpha s}=\int\left(v_{\alpha s}-R_{s} i_{\alpha s}\right) d t \\
& \psi_{\beta s}=\int\left(v_{\beta s}-R_{s} i_{\beta s}\right) d t
\end{aligned}
$$


Assim, usando as equações (83) e (84) e substituindo em (82), obtém-se (85):

$$
\omega_{e}=\frac{\left(v_{\beta s}-R_{s} i_{\beta s}\right) \psi_{\alpha s}-\left(v_{\alpha s}-R_{s} i_{\alpha s}\right) \psi_{\beta s}}{\left(\psi_{\alpha s}\right)^{2}+\left(\psi_{\beta s}\right)^{2}}
$$

A tensão do estator escrita com base no circuito equivalente da Figura 3 é dada pelas expressões (86) e (87):

$$
\begin{aligned}
& v_{\alpha s}=R_{s} i_{\alpha s}+\frac{d \psi_{\alpha s}}{d t}-j\left(\omega_{e} \psi_{\beta s}\right) \\
& v_{\beta s}=R_{s} i_{\beta s}+\frac{d \psi_{\beta s}}{d t}+j\left(\omega_{e} \psi_{\alpha s}\right)
\end{aligned}
$$

Novamente, admitindo-se que $\psi_{d s}=\psi_{s}$ e $\psi_{q s}=0$, e com base nas equações (86) e (87), escreve-se as equações do estator do eixo de referência síncrona $d q$ conforme (88) e $(89)$ :

$$
\begin{gathered}
v_{d s}=R_{s} i_{d s}+\frac{d \psi_{d s}}{d t} \\
v_{q s}=R_{s} i_{q s}+j\left(\omega_{e} \psi_{d s}\right)
\end{gathered}
$$

Como resultado, o torque eletromagnético pode ser reescrito conforme apresentado em $(90)$ :

$$
T_{e}=\frac{3}{2} \frac{P}{2} \psi_{d s} i_{q s}
$$

$\mathrm{e}$

$$
i_{q s}=\frac{2}{3} \frac{2}{P} \frac{T_{e}}{\psi_{d s}}
$$

Substituindo a equação (91) na equação (89), resulta em (92):

$$
v_{q s}=\frac{2}{3} \frac{2}{P} R_{s} \frac{T_{e}}{\psi_{d s}}+j\left(\omega_{e} \psi_{d s}\right)
$$

Dessa forma, com o cálculo do erro do fluxo do estator e do torque eletromagnético, é possível obter os vetores da tensão no estator que são aplicados pelo inversor, sendo que esses erros são minimizados com o uso dos controladores PI (LONGJI; RULIN, 2004).

\subsection{Observador de Fluxo Magnético}

Conforme já apresentado, o controle vetorial orientado no fluxo magnético depende da correta estimação do vetor do fluxo do estator durante todo o período de operação do MI. No entanto, existem diversas dificuldades para esta estimação devido a erros em 
processos de medição, variação paramétrica e problemas de drift e off-set de integradores puros.

$\mathrm{O}$ valor do fluxo magnético em um MI pode ser obtido de forma direta, com o uso de bobina exploratória ou sensor de efeito Hall. Entretanto, essa metodologia eleva o custo da máquina devido às alterações na carcaça, diminuindo a confiabilidade e o aumento dos custos de manutenção. Outro caminho é a estimação do fluxo com o uso das variáveis elétricas de tensões e correntes nos terminais da máquina. Dentre os métodos propostos na literatura, destacam-se as técnicas baseadas nos modelos de corrente e de tensão (VAS, 1998; LASCU; ANDREESCU, 2006; LASCU; BOLDEA; BLAABJERG, 2009; WANG et al., 2014).

No modelo de tensão a estimativa de fluxo é realizada no referencial estacionário, integrando a Força Contra Eletromotriz (FCEM), conforme as equações (83) e (84). Essa estratégia de estimação é atraente devido a sua simplicidade, pois necessita apenas de um parâmetro da máquina; a saber: a resistência do estator. A resistência do estator é um parâmetro que varia até $50 \%$ durante a operação do MI (KARANAYIL; RAHMAN; GRANTHAM, 2007). Entretanto, o modelo de tensão apresenta bom desempenho em médias e altas velocidade de operação. Há ainda dois problemas em sua implementação prática: $i$ ) um pequeno offset nos sinais pode causar problemas com o uso do integrador puro e ii) em baixas velocidades de operação o estimador é sensível a erros de medição (HINKKANEN; LUOMI, 2003).

O modelo de corrente apresenta melhores resultados para a estimação em baixas velocidades, possibilitando a estimativa em velocidade zero (KAZMIERKOWSKI et al., 2011). Entretanto, esta estratégia apresenta a desvantagem de ser dependente da constante de tempo do rotor para estimar o fluxo do rotor, parâmetro esse que tende a variar conforme a operação do MI.

Nesse trabalho é usada a proposta de Lascu, Boldea e Blaabjerg (2000), que combina o modelo de corrente e de tensão do MI para a estimação do fluxo do estator. Esta estratégia apresenta a estimativa do fluxo do estator em aplicações de alto desempenho e ampla faixa de velocidade. Mais especificamente, o modelo de corrente a laço aberto proporciona valores precisos em baixa velocidade e é integrado ao modelo de tensão adaptativo. A Figura 13 mostra o diagrama em blocos do estimador baseado no modelo de tensão e corrente do MI. No referido diagrâma, " $\wedge$ " representa as variáveis estimadas.

O modelo de corrente é deduzido das equações (54) e (55), resultando em (93):

$$
\psi_{d q r}=\frac{L_{H}}{1+s T_{r}} i_{d q s}-j \frac{\omega_{s l}}{1+s T r} \psi_{d q r}
$$

Com a devida orientação do fluxo magnético no eixo $d$ a equação (93) é reescrita por (94) e (95):

$$
\psi_{d r}=\frac{L_{H}}{1+s T_{r}} i_{d s}
$$




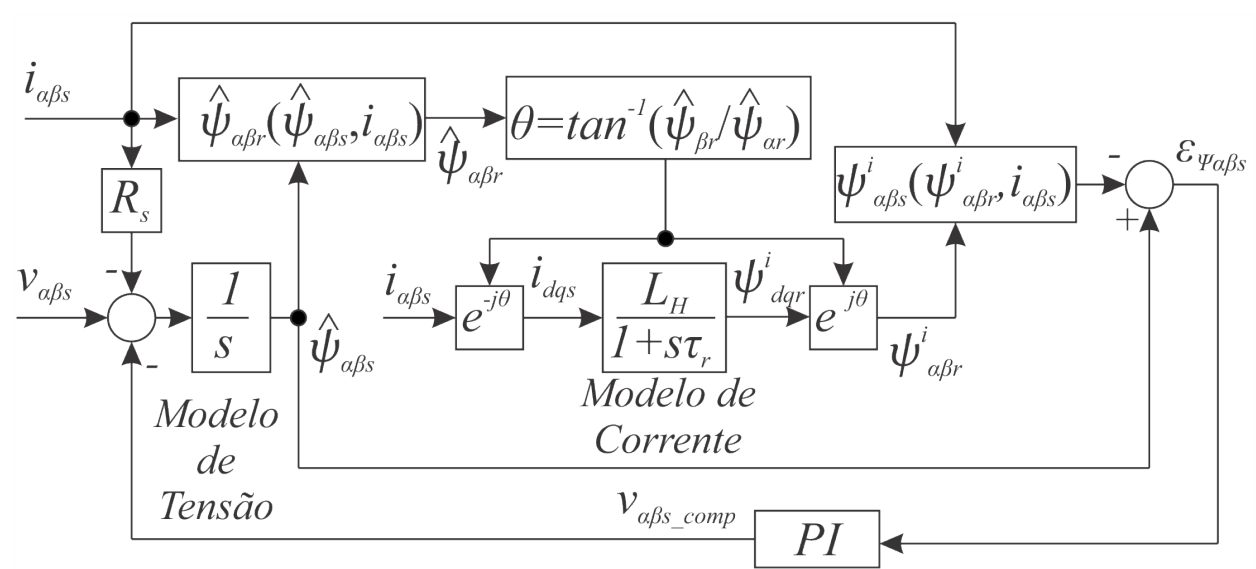

Figura 13 - Observador de fluxo com controlador PI baseado no modelo de tensão e corrente.

$$
\psi_{q r}=0
$$

O fluxo magnético do estator $\left(\psi_{q}^{i}\right)$, com o uso do modelo de corrente de laço-aberto, é obtido pela equação (96):

$$
\vec{\psi}_{s}^{i}=\frac{L_{H}}{L_{r}} \vec{\psi}_{r}^{i}+\frac{L_{s} L_{r}-L_{H}^{2}}{L_{r}} \vec{i}_{s}
$$

sendo $\vec{\psi}_{r}^{i}$ o fluxo estimado do rotor com o uso de (94) e (95) no eixo estacionário.

O modelo de tensão adaptativo é baseado em (22) e (23). Na referência estacionária do estator, o fluxo do estator $\vec{\psi}_{s}$ com o termo compensador é expresso por (97) e (98):

$$
\begin{aligned}
& \psi_{\alpha s}=\int\left(v_{\alpha s}-R_{s} i_{\alpha s}-v_{\alpha \_c o m p}\right) d t \\
& \psi_{\beta s}=\int\left(v_{\beta s}-R_{s} i_{\beta s}-v_{\beta \_c o m p}\right) d t
\end{aligned}
$$

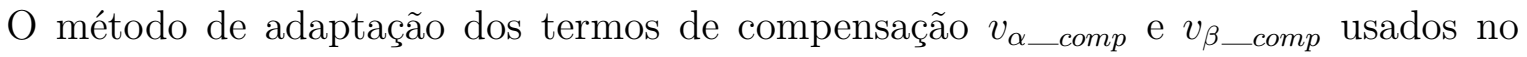
estimador de fluxo magnético de Lascu, Boldea e Blaabjerg (2000) é o controlador PI. O objetivo do controlador $P I$ é a compensação do erro do integrador puro devido ao drift e o off-set, e manter a precisão da estimação do fluxo magnético quando o MI é acionado em baixas velocidades, mesmo sob variação da resistência do $R_{s}$. Assim, o termo de compensação é dado por (99) e (100):

$$
\begin{aligned}
& U_{\alpha \_ \text {comp }}=\left(K_{P}+\frac{K_{I}}{s}\right)\left(\psi_{\alpha s}-\psi_{\alpha s}^{i}\right) \\
& U_{\beta \_c o m p}=\left(K_{P}+\frac{K_{I}}{s}\right)\left(\psi_{\beta s}-\psi_{\beta s}^{i}\right)
\end{aligned}
$$


Os ganhos do controlador $K_{P}$ e $K_{I}$ são calculados de modo que, em frequência zero, o modelo de corrente é priorizado, enquanto em altas frequências o modelo de tensão prevalece. Assim, os ganhos podem ser obtidos conforme (101) e (102):

$$
\begin{gathered}
K_{P}=\omega_{1}+\omega_{2} \\
K_{I}=\omega_{1} \omega_{2}
\end{gathered}
$$

Na prática, valores de $2 \leq \omega_{1} \leq 5 \mathrm{rad} / \mathrm{s}$ e $20 \leq \omega_{2} \leq 30 \mathrm{rad} / \mathrm{s}$ podem ser adotados para uma transição suave entre os dois modelos do estimador de fluxo em malha fechada (LASCU; BOLDEA; BLAABJERG, 2000). A sensibilidade paramétrica do observador é apresentada em Jansen, Lorenz e Novotny (1994).

\subsection{Conclusões Sobre o Controle do MI}

Este capítulo abordou os aspectos do controle vetorial orientado pelo fluxo do estator com CDC e do CDT-SVM a partir no modelo dinâmico do MI. Em seguida foram apresentados os aspectos medotológicos para obtenção do fluxo do estator e o desacoplamento do torque eletromagnético, sendo essa baseada no modelo de corrente e de tensão da máquina de indução. No próximo capítulo é proposta uma metodologia alternativa as tradicionais para estimação da velocidade no eixo do MI com o uso das RNAs, quando a máquina de indução é acionada pelas técnicas de controle CDC e CDT. 


\section{Estimador Neural de Velocidade do MI}

O uso das técnicas sensorless no controle de máquinas elétricas é hoje uma realidade em diversos drivers comerciais de aplicações industriais, como a linha CFW11 da WEG e a ACS880 da ABB, por exemplo. Isso reduz consideravelmente o custo de implementação dos sistemas de controle, uma vez que os sensores de velocidade com precisão e nível de ruído satisfatório possuem custo elevado.

Diversas técnicas de estimação de velocidade vêm sendo apresentadas a fim de ser possível estimar essa variável com robustez em ampla faixa de operação do MI. Na literatura são encontrados trabalhos publicados que utilizam o modelo matemático do MI para a implementação do estimador de velocidade (ZHAO et al., 2016; ZBEDE; GADOUE; ATKINSON, 2016). Entretanto, a performance do estimador é dependente da fidelidade dos parâmetros utilizados com relação ao valores físicos reais da máquina (ALONGE; D'IPPOLITO; SFERLAZZA, 2014; AMEZQUITA-BROOKS; LICEAGA-CASTRO; LICEAGA-CASTRO, 2014a; KAN; ZHANG; WANG, 2015; SMITH; GADOUE; FINCH, 2016). Por esses parâmetros serem variáveis com o tempo de operação da máquina, os mesmos devem ser constantemente atualizados. Dentre as técnicas de atualização dos parâmetros do MI destacam-se as de Modelo de Referência Adaptativa, como apresentado em Comanescu (2009), Jevremovic et al. (2010), Alonge et al. (2016) e Smith, Gadoue e Finch (2016).

Outros autores apresentam a aplicação de técnicas baseadas em sistemas inteligentes para a estimação da velocidade do MI. Tais técnicas vêm se apresentando promissoras, como descrito nos trabalhos de Gadoue, Giaouris e Finch (2013) e Maiti et al. (2012), onde as redes neurais artificiais são usadas em complemento ao sistema de modelo adaptativo.

Neste trabalho as RNAs são aplicadas na estimação da velocidade do MI utilizandose variáveis comuns às técnicas de controle vetorial orientado no campo magnético do estator. Primeiramente, são investigadas as correlações dos sinais do MI e das técnicas de controle que mostram o comportamento característico da velocidade, a fim de facilitar o mapeamento a ser realizado pela RNA. A estratégia de obtenção das variáveis que são utilizadas no processo de treinamento e validação da RNA são apresentadas neste capítulo. Em seguida, são apresentados os resultados obtidos via simulações computacionais, onde 
os resultados obtidos são usados para a seleção das RNAs usados posteriormente na bancada experimental.

\subsection{Tratamento de Dados para Treinamento e Vali- dação da Proposta}

As simulações são executadas para formar um conjunto de dados, o qual é usado no processo de treinamento e validação computacional. Para isso, as configurações do motor de indução e do método de acionamento foram previamente apresentados. De forma a adquirir os dados de simulação com uma fidelidade satisfatória dos modelos matemáticos em relação aos dados reais, algumas considerações foram seguidas, tais como:

\ A simulação do modelo do MI, bem como os dispositivos de eletrônica de potência, foram executadas em tempo contínuo no ambiente Matlab/Simulink.

$\square$ Foram utilizados Filtros Passa-Baixas (FPB) de primeira ordem com frequência de corte de $1 \mathrm{kHz}$ no condicionamento dos sinais das tensões e correntes;

$\square$ A taxa de amostragem dos conversores Analógico/Digital (A/D) e do processamento dos algoritmos das estratégias de controle foi de vinte mil amostras por segundo (20k samples/s).

As tensões sintetizadas pelo inversor fonte de tensão trifásico e as correntes drenadas pela máquina, devido às características do chaveamento do inversor, possuem um elevado nível de ruído. A fim de contornar esse efeito, é utilizado um FPB de primeira ordem ajustado para uma frequência de corte de $1 \mathrm{kHz}$. Esses sinais, agora com características senoidais, precisam ser pré-processados de forma a extrair as informações que possam ser utilizadas para mapear a velocidade do MI em função dessas variáveis. Esse préprocessamento é mostrado na seção 3.2.4.

Alguns trabalhos que utilizam a tensão e/ou a corrente do MI como variável de entrada dos estimadores são apresentados em Oguz e Dede (2011), Marei, Shaaban e El-Sattar (2009) e em Santos et al. (2014) os quais utilizam essas variáveis nos eixos de coordenadas estacionária e síncrona, respectivamente, nas aplicações dos seus estimadores.

Neste trabalho, para converter as variáveis do eixo estacionário $(\alpha \beta 0)$ para síncrono $(d q 0)$ é utilizado um PLL (Phase Locked Loop), cuja função é gerar os vetores unitários seno e cosseno e a velocidade síncrona do campo girante $\left(\omega_{e}\right)$ (BIERHOFF, 2017), de forma similar ao usado em Yang et al. (2017b). Nos sistemas elétricos trifásicos equilibrados o eixo 0 é nulo, sendo então desconsiderado nas modelagens. O sistema PLL utilizado neste trabalho é o p-PLL descrito em Silva et al. (2009) e usado em Santos et al. (2014), conforme a Figura 14. O ponto de referência $p^{*}$ é nulo a fim de obter os vetores seno 
e cosseno utilizados na transformação dos eixos de referência estacionária em síncrona, onde o fluxo em quadratura deve ser nulo $\left(\psi_{q}=0\right)$, conforme apresentado no Capítulo 2. Os vetores fictícios $\left(\psi_{\alpha}^{\prime}\right.$ e $\left.\psi_{\beta}^{\prime}\right)$ são alinhados aos vetores de referência de sincronismo $\left(\hat{\psi}_{\alpha}\right.$ e $\hat{\psi}_{\beta}$ ) com o uso de um controlador PI. Outra vantagem do uso do PLL é a atenuação, pelo controlador PI, de possíveis distúrbios nos vetores seno e cosseno gerados, que são oriundos do fluxo magnético de entrada.

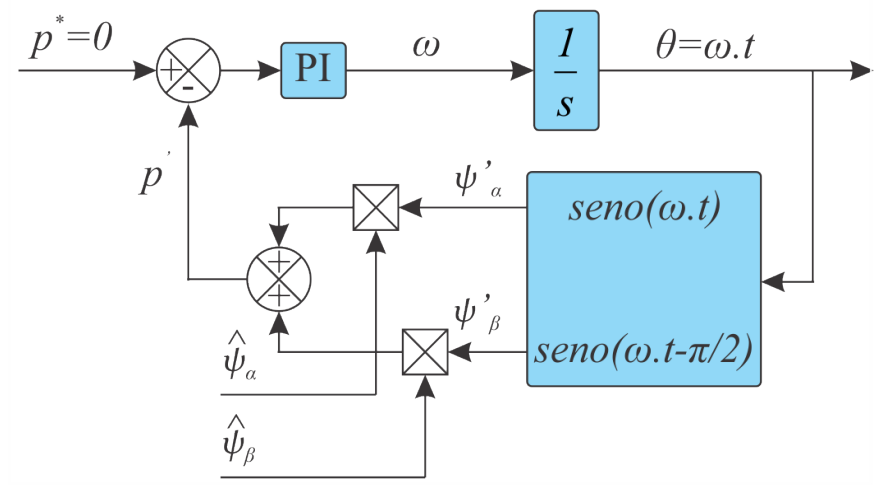

Figura 14 - Sistema p-PLL orientado de fluxo do estator.

As redes neurais artificiais têm se mostrado eficientes nas mais diversas aplicações na engenharia. Nesse trabalho uma estrutura neural é aplicada na estimação de velocidade de um motor de indução trifásico quando este é acionado por um inversor de frequência com o CDC e pelo CDT. Para ser possível avaliar a generalização de resultados são usados dois MIs, sendo um utilizado para a composição do banco de dados para o treinamento (MI-1) e o outro para a validação computacional (MI-2). As características dessas máquinas são apresentadas na Tabela 3.1, que também apresenta as características do MI-3, que juntamente ao IM-2, são usadas nos testes experimentais no Capítulo 4.

Tabela 3.1 - Características dos MIs usados neste trabalho.

\begin{tabular}{c|c|c|c}
\hline \multicolumn{4}{c}{ Linha Standard - IV Polos - $60 \mathrm{~Hz}-220 / 380 \mathrm{~V}$} \\
\hline & MI-1 & MI-2 & MI-3 \\
\hline Potência $(C V)$ & 1 & 1 & 2 \\
\hline Resistência do Estator $(\Omega)$ & 7,32 & 10,5 & 4,6 \\
\hline Resistência do Rotor $(\Omega)$ & 2,78 & 5,49 & 3,67 \\
\hline Indutância do Estator $(H)$ & 0,14995 & 0,443887 & 0,172414 \\
\hline Indutância do Rotor $(H)$ & 0,14644 & 0,443887 & 0,172414 \\
\hline Indutância de Magnetização $(H)$ & 0,141 & 0,424 & 0,159 \\
\hline Corrente Nominal do Estator $(A)$ & $3,02 / 1,75$ & $3,02 / 1,75$ & $6,01 / 3,46$ \\
\hline Momento de Inércia do Rotor $\left(\mathrm{kg} \cdot \mathrm{m}^{2}\right)$ & $2,71 \cdot 10^{-3}$ & $2,71 \cdot 10^{-3}$ & $2,85 \cdot 10^{-3}$ \\
\hline Escorregamento Nominal $(\%)$ & 3,8 & 3,8 & 3,6 \\
\hline Torque Nominal $(N . m)$ & 4,1 & 4,1 & 8,2 \\
\hline
\end{tabular}

Conhecidas as características dos MIs usados nos procedimentos de treinamento e 
de validações computacionais e experimentais, o próximo passo consiste na sintonia dos controladores PI usados no CDC e CDT.

\subsection{Modelagem e Projeto dos Controladores}

Nesta seção são apresentadas a modelagem matemática das plantas a serem controladas, na forma de funções de transferência, em ambas as estratégias de acionamento. Os modelos matemáticos são obtidos com base nas equações do CDC e do CDT.

\subsubsection{Modelagem matemática das plantas a serem controladas no CDC}

No CDC usado neste trabalho há quatro malhas de controle, sendo uma de velocidade, uma de fluxo do estator e duas de corrente do estator. Cada uma das malhas de controle são analisadas separadamente.

A malha de velocidade tem como base o modelo eletromecânico do MI, descrito pela equação (46). Considerando apenas os termos referentes ao MI e desconsiderando o coeficiente de atrito viscoso $(B)$, a equação (46) é reescrita, como (103):

$$
T_{e}=J \frac{d}{d t} \omega_{m e c}
$$

A partir de (103) a função de transferência da malha de velocidade é dada por (104):

$$
\frac{\omega_{m e c}(s)}{T_{e}(s)}=\frac{1}{J s}
$$

O torque eletromagnético $\left(T_{e}\right)$ é relacionado com a corrente $i_{q s}$, como descrito em (72). No acionamento CDC, bem como no CDT, o controle de velocidade é acionado com o fluxo do estator estabelecido, no caso deste trabalho, em 0,75 Wb. Deste modo, $\left(T_{e}\right)$ fica relacionado com a corrente $i_{q s}$ pela constante $k_{T}$, resultando em (105):

$$
T_{e}=k_{T} i_{q s}
$$

onde $k_{T}=\frac{3}{2} \frac{z_{p}}{2} \psi_{d s}$. Assim, a composição da malha do controle de velocidade do CDC é mostrada na Figura 15.

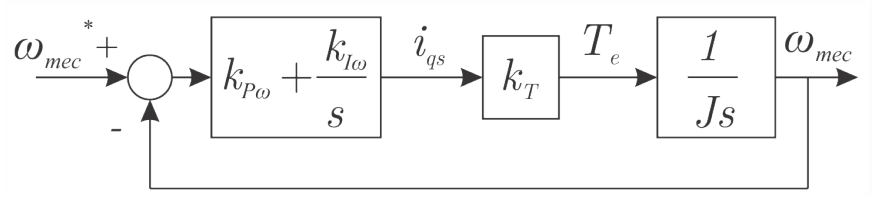

Figura 15 - Malha do controle de velocidade do CDC.

onde $k_{P_{\omega}}$ e $k_{I \omega}$ são os ganhos proporcional e integral do controlador PI, respectivamente. 
A equação (67) representa matematicamente a malha de controle de fluxo do estator. O termo de desacoplamento descrito pela equação (68) faz $\left(1+s \sigma T_{r}\right) L_{s} i_{d q}(s)-$ $\sigma T_{r} \omega_{s l} L_{s} i_{q s}^{*}(s)=0$, o que resulta na função de transferência descrita na equação (106).

$$
\frac{\psi_{d s}(s)}{i_{d s}(s)}=\frac{\left(\sigma T_{r} s+1\right) L_{s}}{\left(T_{r} s+1\right)}
$$

Rearranjando (106) obtém-se (107):

$$
\frac{\psi_{d s}(s)}{i_{d s}(s)}=\frac{\left(s+\frac{1}{T_{r} \sigma}\right) \sigma L_{s}}{\left(s+\frac{1}{T_{r}}\right)}
$$

A malha do controle de fluxo do estator do CDC considerando o termo de desacoplamento é mostrada na Figura 16.

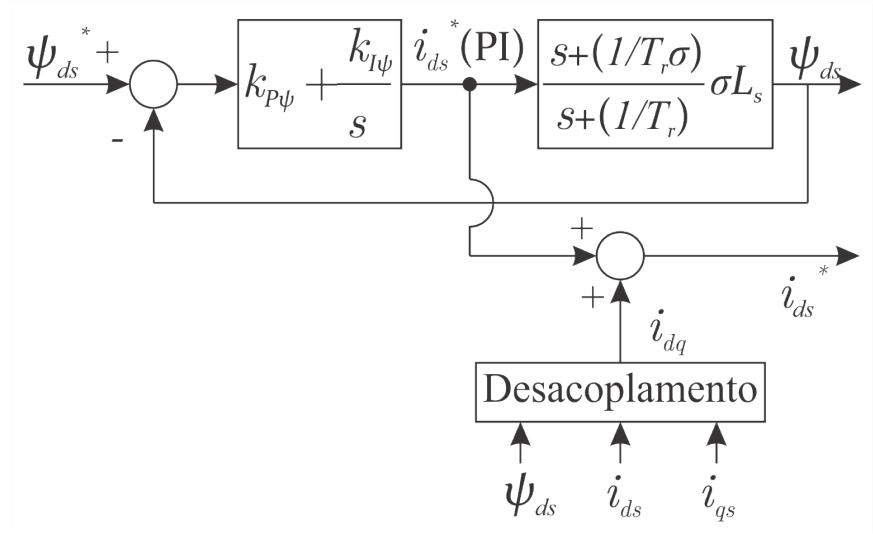

Figura 16 - Malha do controle de fluxo do CDC.

Por fim, há duas malhas de controle de corrente, sendo uma no eixo de referência síncrona $d$ e outra em $q$. As funções de transferência das malhas de corrente têm como base as equações de tensão do estator (33) e (34). Substituindo a corrente $i_{d r}$ da equação (37) em (40) e isolando $\psi_{d s}$, obtém-se (108):

$$
\psi_{d s}=\frac{L_{H}}{L_{r}} \psi_{d r}+\sigma L_{s} i_{d s}
$$

Considerando as condições do controle vetorial, onde $\psi_{q r}=0$, isolando $i_{q r}$ de (41) e substituindo em (38), obtém-se (109):

$$
\psi_{q s}=\sigma L_{s} i_{q s}
$$

Substituindo (108) e (109) em (33) e (34), as equações de tensão do estator são reescritas em (110) e (111).

$$
v_{d s}=\underbrace{R_{s} i_{d s}+\sigma L_{s} \frac{d}{d t} i_{d s}}_{v_{d s}^{\prime}}+\underbrace{\frac{L_{H}}{L_{r}} \frac{d}{d t} \psi_{d r}-\omega_{e} \sigma L_{s} i_{q s}}_{v_{d s}, \text { dist. }}
$$




$$
v_{q s}=\underbrace{R_{s} i_{q s}+\sigma L_{s} \frac{d}{d t} i_{q s}}_{v_{q s}^{\prime}}+\underbrace{\omega_{e} \frac{L_{H}}{L_{r}} \frac{d}{d t} \psi_{d r}+\omega_{e} \sigma L_{s} i_{d s}}_{v_{q s}, \text { dist. }}
$$

A equação (110) é simplificada, considerando somente os termos dependentes de $i_{d s}$ e $\frac{d}{d t} i_{d s}$ contidos em $v_{d s}^{\prime}$. Os termos dependentes de $\psi_{d r}$ e $i_{d s}$ são considerados distúrbios. As mesmas considerações são feitas em (111). Dessa forma, as equações (110) e (111) são reescritas como (112) e (113):

$$
\begin{aligned}
& v_{d s}=R_{s} i_{d s}+\sigma L_{s} \frac{d}{d t} i_{d s} \\
& v_{q s}=R_{s} i_{q s}+\sigma L_{s} \frac{d}{d t} i_{q s}
\end{aligned}
$$

As malhas dos controles de corrente $i_{d s}$ e $i_{q s}$ do CDC são mostradas na Figura 17.

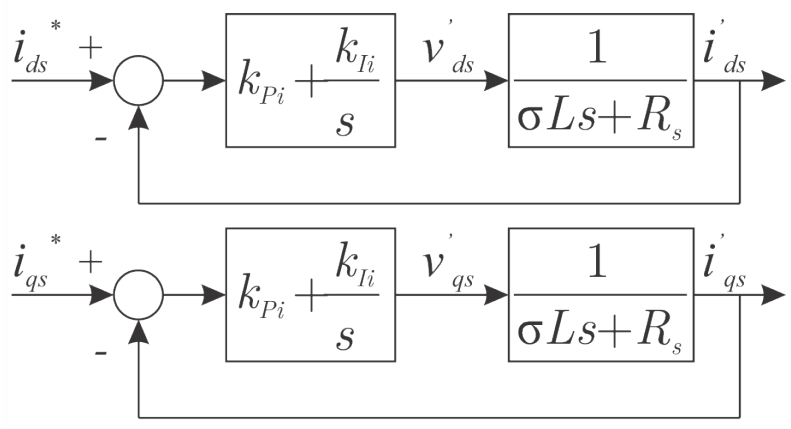

Figura 17 - Malha dos controles de corrente $i_{d s} i_{q s}$.

Obtidas as quatro malhas de controle para o acionamento do MI pelo CDC, uma estratégia de sintonia dos ganhos dos controladores PI é aplicada, conforme parâmetros de projeto mostrados na Seção 3.2.3.

\subsubsection{Modelagem matemática das plantas a serem controladas no CDT}

No CDT usado neste trabalho há três malhas de controle, sendo uma de velocidade, uma de fluxo do estator e uma de torque eletromagnético. Assim, como no feito no CDC, cada uma das malhas de controle são analisadas separadamente.

A malha de velocidade do CDT é similar ao obtido no CDC, onde devido à saída do PI de velocidade ser o torque eletromagnético de referência, a diferença ao CDC se limita a exclusão da constante $k_{T}$ mostrada na Figura 15. A função de transferência é descrita em (104) e a malha de controle é mostrada na Figura 18.

A malha do controle de fluxo é obtida da equação (88), em que as perdas em $R_{s}$ são consideradas distúrbios e o fluxo $\psi_{d s}$ é relacionado a tensão $v_{d s}$ por meio de um integrador. A malha de controle do fluxo do estator é mostrado na Figura 19. 


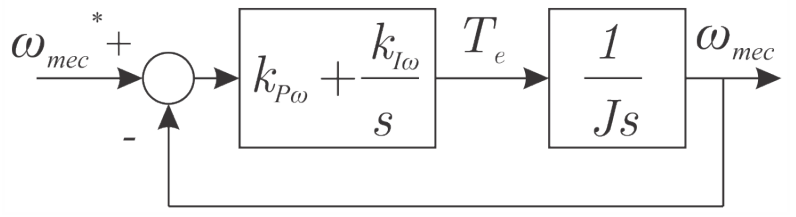

Figura 18 - Malha do controle de velocidade do CDT.

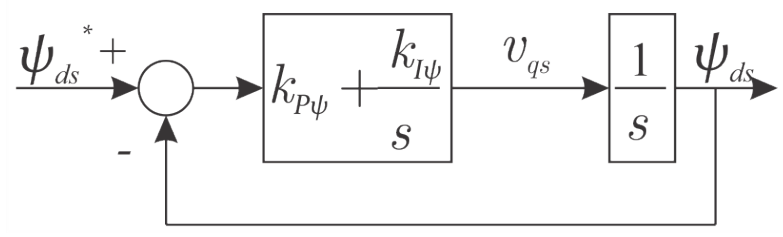

Figura 19 - Malha do controle de fluxo do CDT.

A obtenção da malha de controle de torque do MI tem como base as expressões (33) a (41), obtendo (114):

$$
\left[\left(R_{s} L_{r}+R_{r} L_{s}\right)+\sigma L_{s} R_{r} s\right] i_{q s}=L_{r} v_{q s}-L_{r} \psi_{s} \omega_{r}+i_{d s} \sigma L_{s} R_{r}\left(\omega_{e}-\omega_{r}\right)
$$

O último termo à direita de (114) $\left(i_{d s} \sigma L_{s} R_{r}\left(\omega_{e}-\omega_{r}\right)\right)$ pode ser desprezado conforme Zelechowski (2005). Assim, obtém-se a equação (115).

$$
\left[\left(R_{s} L_{r}+R_{r} L_{s}\right)+\sigma L_{s} R_{r} s\right] i_{q s}=L_{r} v_{q s}-L_{r} \psi_{s} \omega_{r}
$$

Multiplicando-se ambos os lados de (115) por $s$ e substituindo $\omega_{r}$ por $z_{p} \omega_{m e c}$, obtém-se (116):

$$
\left[\left(R_{s} L_{r}+R_{r} L_{s}\right) s+\sigma L_{s} R_{r} s^{2}\right] i_{q s}=L_{r} s v_{q s}-L_{r} \psi_{s} s \omega_{m e c}
$$

Desprezando o atrito viscoso e o torque de carga de (46), assumidos como incerteza ou ruídos, obtém-se $T_{e}=J s \omega_{m e c}$. Ainda, isolando $i_{q s}$ de (90), obtém-se (117):

$$
i_{q s}=\frac{2 T_{e}}{3 z_{p} \psi_{d s}}
$$

Substituindo (117) e $\omega_{m e c}$ por $T_{e} / J s$ em (116), tem-se a equação (118):

$$
\left[\left(R_{s} L_{r}+R_{r} L_{s}\right) s+\sigma L_{s} R_{r} s^{2}\right] \frac{2 T_{e}}{3 z_{p} \psi_{d s}}=L_{r} s v_{q s}-L_{r} \psi_{s} z_{p} \frac{T_{e}}{J}
$$

Rearranjando (118) para obter relação $T_{e} / v_{q s}$, deduz-se (119):

$$
\frac{T_{e}}{v_{q s}}=\frac{\frac{3 z_{p} \psi_{s} L_{r}}{2} s}{\left(R_{s} L_{r}+R_{r} L_{s}\right) s+\sigma L_{s} R_{r} s^{2}+\frac{3 L_{r} \psi_{s}^{2} z_{p}^{2}}{2 J}}
$$


Dividindo (119) por 1/ $\left(\sigma L_{s} R_{r}\right)$, obtém-se a função de transferência dada pela equação (120):

$$
G_{T e}(s)=\frac{T_{e}}{v_{q s}}=\frac{\frac{3 z_{p} \psi_{s}}{2 \sigma L_{s}} s}{s^{2}+\frac{\left(L_{s} R_{r}+L_{r} R_{s}\right)}{\sigma L_{s} R_{r}} s+\frac{3 z_{p}^{2} \psi_{d s}^{2}}{2 \sigma L_{s} J}}
$$

A malha do controle de torque do MI e considerando o fluxo do estator como constante resulta na Figura 20. Obtidas todas as funções de transferências pertinentes às estratégias de controle, o próximo passo é o projeto dos controladores PIs.

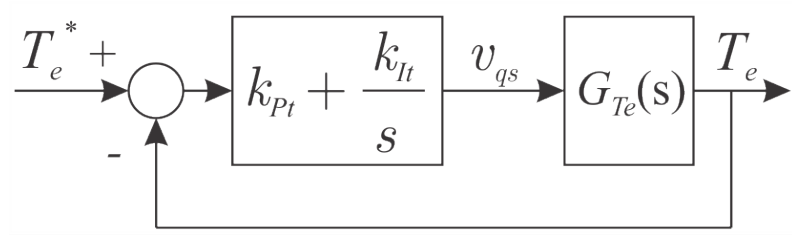

Figura 20 - Malha do controle de fluxo do CDC.

A seguir, na Seção 3.2.3, são apresentados os parâmetros de sintonia dos ganhos dos controladores PI.

\subsubsection{Projeto dos controladores PI}

O método do projeto dos controladores PI descritos na Seção 3.2.1 e na Seção 3.2.2 é o da resposta em frequência, cujo procedimento é demonstrado em Angélico, Campanhol e Silva (2014), Campanhol (2012) e reproduzido no Anexo A.

Obtidas as funções de transferência das plantas a serem controladas, a frequência de cruzamento $\left(\omega_{c}\right)$ e a margem de fase $\left(M F_{d}\right)$ são parâmetros requeridos para o projeto. A Tabela 3.2 mostra a frequência de cruzamento e a margem de fase para cada um dos controladores usados no CDC e no CDT, e para cada um dos MIs acionados via simulação computacional e experimentalmente.

Aplicando-se os parâmetros de $\omega_{c}$ e $M F_{d}$ no procedimento de sintonia descrito no Anexo A, cujas funções de transferência foram apresentadas na Seção 3.2.1 e na Seção 3.2.2, com base nas características dos MIs apresentadas na Tabela 3.1, resultam nos ganhos $\left(K_{P}\right)$ e $\left(K_{I}\right)$ mostrados na Tabela 3.3.

A influência das respostas dinâmicas dos sistemas de controle têm influência do limitador de corrente, no caso do CDC, e o limitador de torque do CDT. Neste trabalho os saturadores têm o valores definidos com $150 \%$ do valor nominal em todos os MIs, a fim de garantir que tanto a corrente, bem como o torque de partida fiquem limitados. 
Tabela 3.2 - Parâmetros requeridos para o projeto do controladores PI.

\begin{tabular}{|c|c|c|c|c|}
\hline & \multicolumn{2}{|c|}{$\mathrm{CDC}$} & \multicolumn{2}{|c|}{ CDT } \\
\hline MI-1 & $\omega_{c}(\mathrm{rad} / \mathrm{s})$ & $M F_{d}$ & $\omega_{c}(\mathrm{rad} / \mathrm{s})$ & $M F_{d}$ \\
\hline PI correntes $i_{d s}$ e $i_{q s}$ & $2,5 \mathrm{k}$ & $75^{\circ}$ & - & \\
\hline PI fluxo do estator & 62,83 & $85^{\circ}$ & $2,51 \mathrm{k}$ & $80^{\circ}$ \\
\hline PI velocidade & 125,6 & $80^{\circ}$ & 125,6 & $80^{\circ}$ \\
\hline PI torque & - & & $2,51 \mathrm{k}$ & $80^{\circ}$ \\
\hline MI-2 & \multicolumn{2}{|c|}{$\mathrm{CDC}$} & \multicolumn{2}{|c|}{$\mathrm{CDT}$} \\
\hline PI correntes $i_{d s}$ e $i_{q s}$ & $1,25 \mathrm{k}$ & $80^{\circ}$ & - & \\
\hline PI fluxo do estator & 62,8 & $85^{\circ}$ & $2,51 \mathrm{k}$ & $80^{\circ}$ \\
\hline PI velocidade & 125,6 & $10^{\circ}$ & 125,6 & $80^{\circ}$ \\
\hline PI torque & - & - & $2,51 \mathrm{k}$ & $80^{\circ}$ \\
\hline MI-3 & \multicolumn{2}{|c|}{$\mathrm{CDC}$} & \multicolumn{2}{|c|}{ CDT } \\
\hline PI correntes $i_{d s}$ e $i_{q s}$ & $1,25 \mathrm{k}$ & $80^{\circ}$ & - & \\
\hline PI fluxo do estator & 62,83 & $85^{\circ}$ & $2,51 \mathrm{k}$ & $80^{\circ}$ \\
\hline PI velocidade & 125,6 & $80^{\circ}$ & 125,6 & $80^{\circ}$ \\
\hline PI torque & - & - & $2,51 \mathrm{k}$ & $80^{\circ}$ \\
\hline
\end{tabular}

Tabela 3.3 - Parâmetros dos controladores PI do CDC e do CDT.

\begin{tabular}{c|c|c|c|c}
\hline & \multicolumn{2}{|c|}{ CDC } & \multicolumn{2}{c}{ CDT } \\
\hline MI-1 & $K_{p}(\Omega)$ & $K_{i}(\Omega / s)$ & $K_{p}(\Omega)$ & $K_{i}(\Omega / s)$ \\
\hline PI correntes $i_{d s}$ e $i_{q s}$ & 32,5 & $40,1 \mathrm{k}$ & - & - \\
\hline PI fluxo do estator & 17,0 & 873,8 & $2,47 \mathrm{k}$ & $1,1 \mathrm{M}$ \\
\hline PI velocidade & 0,15 & 3,3 & 0,33 & 7,4 \\
\hline PI torque & - & - & 7,8 & $3,75 \mathrm{k}$ \\
\hline MI-2 & \multicolumn{2}{|c|}{ CDC } & \multicolumn{2}{c}{ CDT } \\
\hline PI correntes $i_{d s}$ e $i_{q s}$ & 46,3 & $23,6 \mathrm{k}$ & - & - \\
\hline PI fluxo do estator & 8,14 & 431,5 & $2,47 \mathrm{k}$ & $1,1 \mathrm{M}$ \\
\hline PI velocidade & 0,15 & 3,3 & 0,33 & 7,4 \\
\hline PI torque & - & - & 21,3 & $10,18 \mathrm{k}$ \\
\hline MI-3 & \multicolumn{3}{|c|}{ CDC } & \multicolumn{2}{c}{ CDT } \\
\hline PI correntes $i_{d s}$ e $i_{q s}$ & 31,1 & $12,7 \mathrm{k}$ & - & - \\
\hline PI fluxo do estator & 11,1 & 766,4 & $2,47 \mathrm{k}$ & $1,1 \mathrm{M}$ \\
\hline PI velocidade & 0,16 & 3,5 & 0,35 & 7,8 \\
\hline PI torque & - & - & 14,2 & $6,5 \mathrm{k}$ \\
\hline Estimador de fluxo & 32,0 & 60,0 & 32,0 & 60,0 \\
\hline PI & 32,0 \\
\hline
\end{tabular}

\subsubsection{Análise da composição dos vetores de entrada das RNAs}

Para avaliar as variáveis do sistema de acionamento do MI que podem contribuir para o mapeamento da velocidade mecânica usando as RNAs, são executadas as simulações em diferentes níveis de velocidade e observados os comportamentos das possíveis variáveis de entrada do estimador. Para isso, o CDC foi adotado para o acionamento, onde o MI-1 aciona dois níveis de velocidade arbitrários, $50 \mathrm{rad} / \mathrm{s}$ e $180 \mathrm{rad} / \mathrm{s}$ (Figura 21 e Figura 
22, respectivamente), com variação de carga mecânica no eixo de 0 N.m e 4,1 N.m. O CDT também poderia ser adotado para essa análise sem nenhuma alteração do método. Nas figuras oriundas destes testes há alterações das escalas de corrente, fluxo magnético e torque eletromagnético, a fim de facilitar a visualização.

Observando a Figura 21 é possível analisar que até o instante $t=0,07 \mathrm{~s}$ a malha de velocidade mantém a rotação do MI a $0 \mathrm{rad} / \mathrm{s}$, para estabelecer o fluxo magnético nominal. Nesse primeiro intervalo de tempo a componente do eixo direto da corrente tem seu valor nominal. Após esse instante, a máquina inicia a aceleração, estabelecendo o torque eletromagnético nominal do MI. Esse fenômeno é também observado pela componente $I_{q s}$. Ainda, o fluxo magnético uma vez estabelecido tem seu valor inalterado, assim como a tensão $\left(V_{d s}\right)$, o que evidencia sua reduzida contribuição para descrever a dinâmica de aceleração da máquina. Conforme o MI se aproxima da velocidade de referência, os níveis de corrente e de tensão em quadratura e de torque eletromagnético são reduzidos, evidenciando a velocidade de escorregamento $\left(\omega_{s l}\right)$ frente a velocidade síncrona.

Quando é aplicado o torque de carga nominal no eixo do motor em 0,5 s na Figura $21 \mathrm{e}$ $0,7 s$ na Figura 22, o escorregamento aumenta, como evidenciam os níveis das variáveis $\omega_{e}$, $T_{e}, V_{q s}, i_{d s}$ e $i_{q s}$. Dentre essas variáveis, a componente de tensão $V_{q s}$ possui o inconveniente da necessidade da medição direta ou pela estimação, usando a tensão do barramento de Corrente Contínua $(C C)$ do inversor e o sinais de modulação. Neste contexto, a velocidade síncrona do campo magnético do estator está relacionada à velocidade mecânica. Ainda, tem-se $T_{e}, i_{d s}$ e $i_{q s}$ sensíveis as alterações de velocidade de escorregamento $\left(\omega_{s l}\right)$, sendo todas estas variáveis candidatas a compor o vetor de entrada da RNA. Como já descrito na Seção 2.2, o torque eletromagnético é controlado via malha da corrente $i_{q s}$. Assim, usar as duas variáveis do eixo de quadratura na mesma RNA seria redundante.

Com a análise do comportamento das variáveis do sistema de acionamento do MI com CDC é possível encontrar duas possibilidades evidentes para compor o vetor de entrada da RNA; a saber: no método $A$ o vetor de entrada composto por $\omega_{e}, i_{d s}$ e $i_{q s}$ e no método $B$ é formado por $\omega_{e}$ e $T_{e}$.

A Figura 23 apresenta o diagrama em blocos do sistema de tratamento de dados das grandezas corrente e velocidade síncrona do MI usado no método $A$, enquanto a Figura 24 apresenta o diagrama em blocos do sistema de tratamento de dados das grandezas torque eletromagnético e velocidade síncrona do MI usado no método $B$.

O modelo matemático do MI e seus parâmetros são representados pelo bloco MI, onde esse é acionado pelo inversor com uma das estratégias de CDC ou CDT. Durante o acionamento, as variáveis de corrente e de tensão são convertidas do referencial estacionário $a b c$ para $\alpha \beta$, onde seguem para o estimador de fluxo do estator e consequentemente, do torque eletromagnético. Orientado pelo vetores do fluxo do estator, o PLL gera os vetores unitários seno e cosseno que são usados para mudança de orientação do referencial estacionários para síncrono, e também detecta a velocidade síncrona do campo girante do 


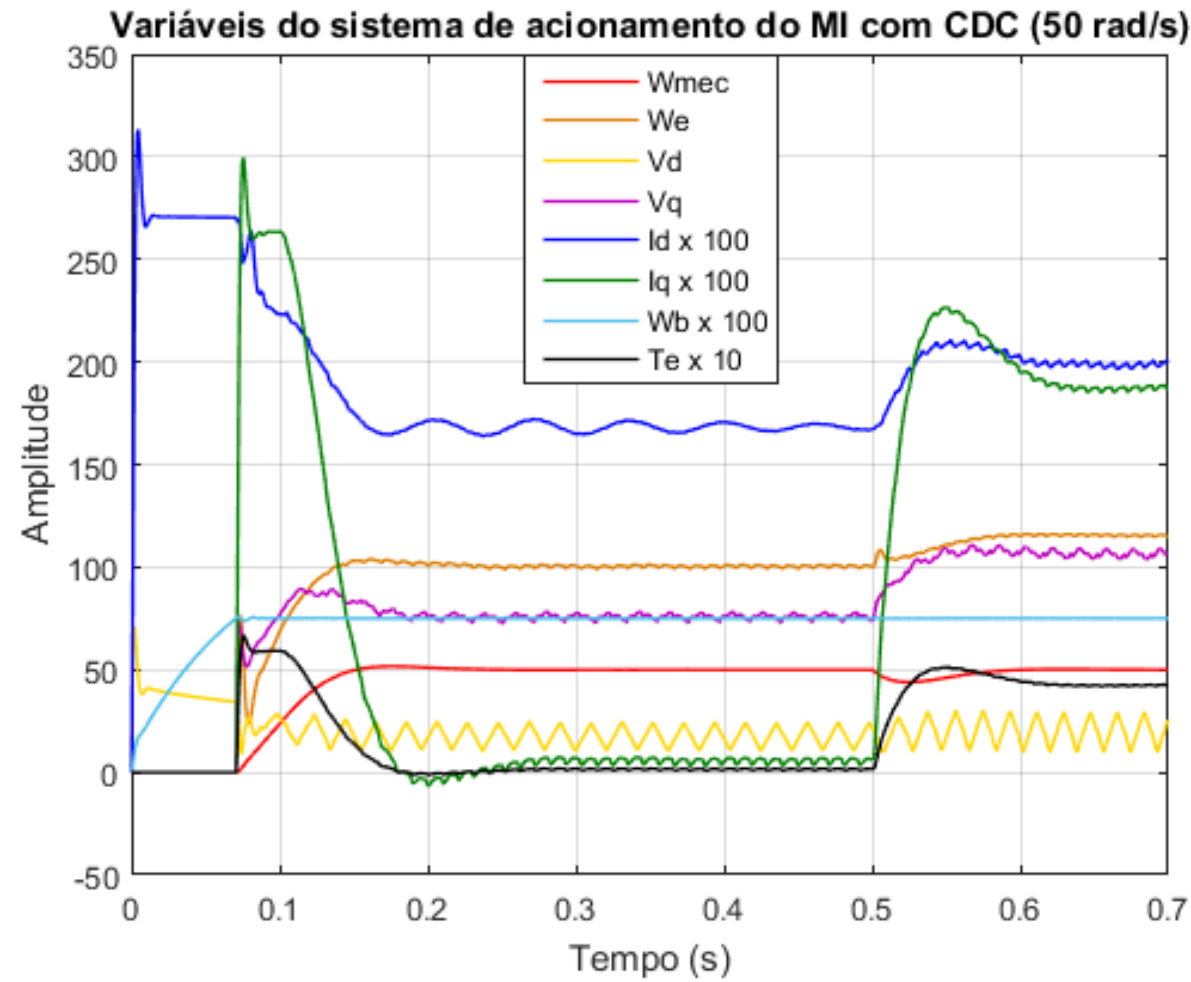

Figura 21 - Variáveis candidatas a compor o vetor de entrada do estimador neural a $50 \mathrm{rad} / \mathrm{s}$.

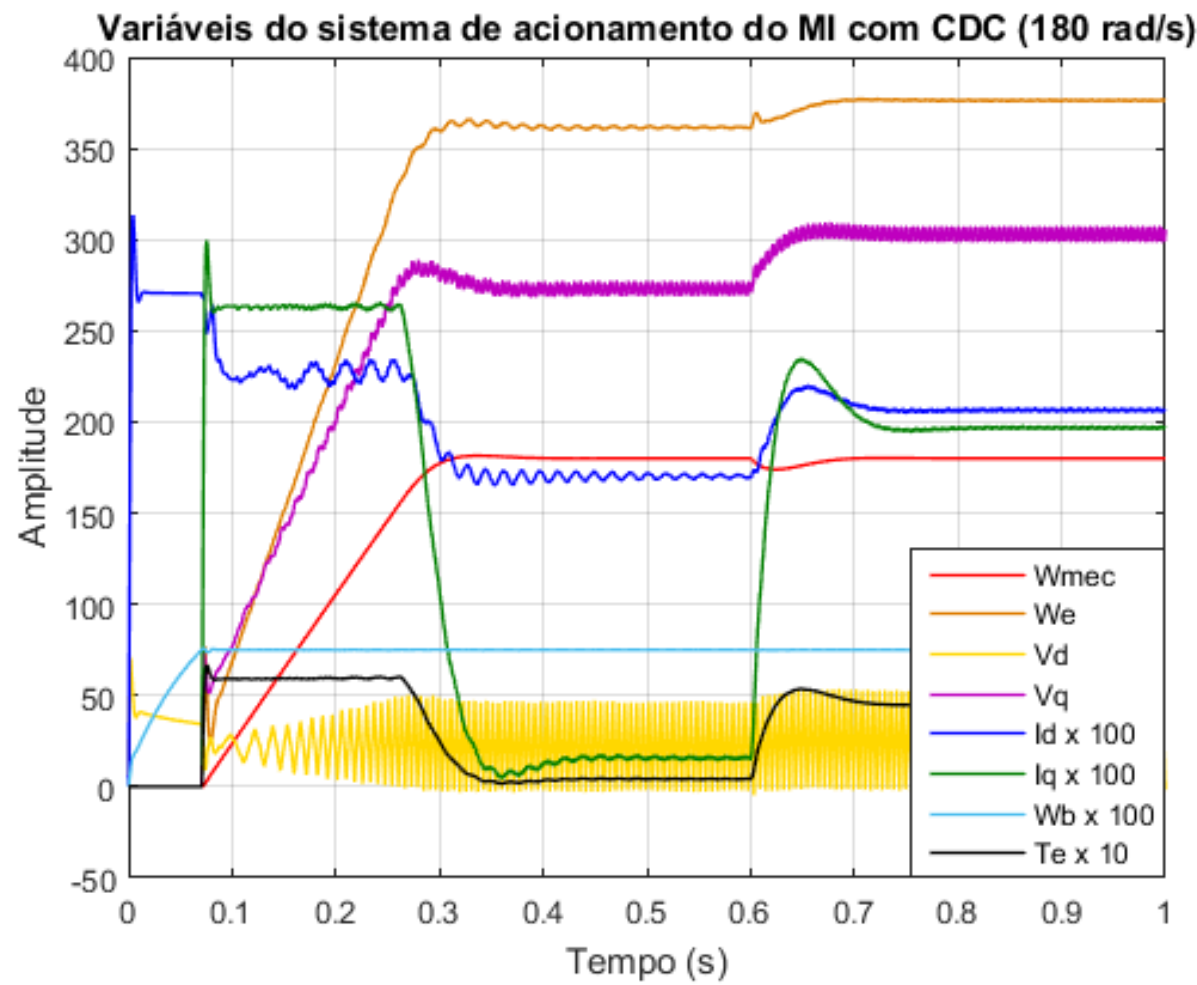

Figura 22 - Variáveis candidatas a compor o vetor de entrada do estimador neural a $180 \mathrm{rad} / \mathrm{s}$. 


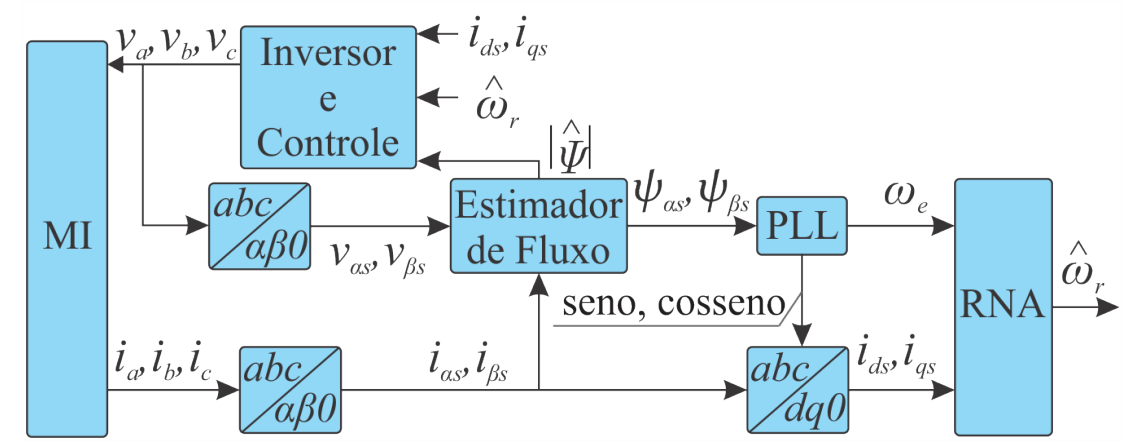

Figura 23 - Diagrama em blocos do processamento de dados do método A.

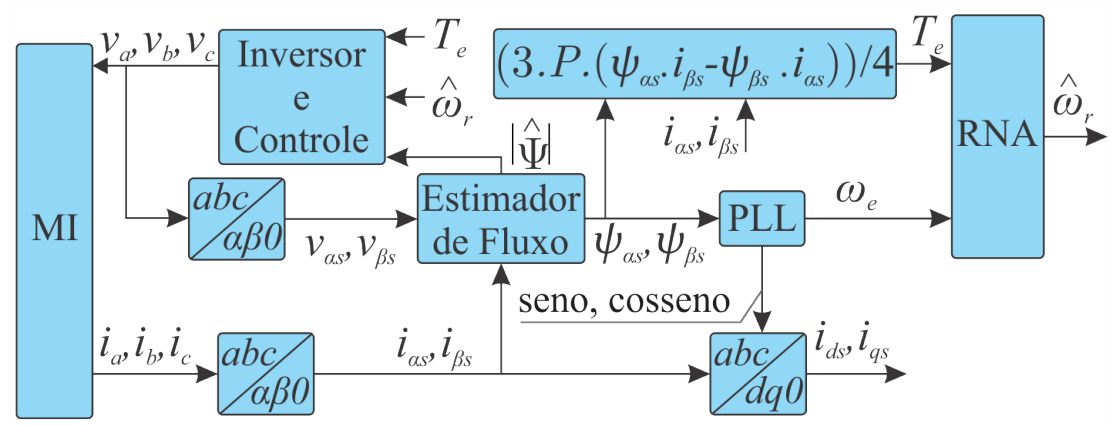

Figura 24 - Diagrama em blocos do processamento de dados do método B.

\subsection{Estimador Neural de Velocidade}

Por anos o desenvolvimento de sistemas autônomos com capacidade de aprender e se adaptar têm sido o objetivo de diversos cientistas. Embora as primeiras pesquisas na área de sistemas inteligentes foram publicadas há mais de 50 anos, resultados que colocaram em destaque essa linha de pesquisa apareceram no início dos anos 1990, onde a tecnologia proporcionou a implementação das técnicas computacionais envolvidas (NUNES; SPATTI; FLAUZINO, 2010).

A inteligência computacional é um conjunto de técnicas de modelagem e computação que são também denominadas como Sistemas Inteligentes ou Soft Computing (ZADEH, 1994). Dentre as ferramentas constituintes da inteligência computacional destacam-se as RNAs, a Lógica Nebulosa (Fuzzy Logic) e os Algoritmos Genéticos (AG).

As RNAs são modelos matemáticos que utilizam processamento paralelo, e tem a capacidade de se adaptar com um grande número de unidades simples de processamento. Ainda, as redes são modeladas de forma a mapear algumas características biológicas do neurônio.

Com a aplicação das redes neurais artificiais, é possível desenvolver sistemas capazes de realizar a predição sobre o comportamento de um processo, classificação de padrões, controle de processos, aproximador universal de funções entre outras.

As aplicações que envolvem as redes neurais artificiais são crescentes, possibilitando uma alternativa aos métodos convencionais com o aumento do poder computacional dos 
microprocessadores. Várias pesquisas têm mostrado seu desempenho no tratamento das não linearidades de sistemas dinâmicos, cujo equacionamento é árduo ou com níveis significativos de particularidades, devido às suas capacidades de mapeamento e aproximações a sistemas lineares.

Devido à característica não linear da velocidade mecânica do MI frente às variáveis elétricas e dos parâmetros físicos da máquina, as RNAs tornam-se uma ferramenta compatível para a aplicação desse problema.

\subsubsection{Treinamento das redes neurais artificiais}

As redes neurais têm a capacidade de aprendizado, ou seja, aplica-se um processo de treinamento no qual a rede aprende a relação entre as entradas e saídas de um determinado sistema por meio do ajuste dos seus pesos sinápticos. O processo de treinamento é dividido em duas categorias: supervisionado e não supervisionado.

No processo de treinamento supervisionado os padrões de dados de entrada são apresentados à rede e a saída é calculada. A diferença entre a resposta da rede em relação à saída desejada é utilizada como parâmetro de ajuste dos pesos sinápticos. Esse processo se repete para todos os padrões apresentados à rede ciclicamente até que o erro tenha um valor aceitável. Diz-se então que um supervisor monitora a resposta da rede referente a um padrão de dados de entrada, atuando quando esta difere de um valor esperado.

No treinamento não supervisionado, não há um valor de saída previamente conhecido para um dado padrão de entrada. Nesse processo, a rede deve se auto-organizar de forma a identificar os subconjuntos de dados que o caracteriza. Os pesos sinápticos, bem como os limiares dos neurônios, são ajustados de forma a melhor representar as saídas com relação às características dos dados de entrada.

Existem diversas arquiteturas de redes onde cada uma delas possui um algoritmo de treinamento próprio. Neste trabalho é utilizada a rede Perceptron Multicamada, a qual possui como uma de suas propriedades a capacidade de generalização de soluções quando atuando como aproximador universal de funções. Em outras palavras, ela aprende por meio de um conjunto de padrões de entrada e generaliza resultados para padrões de entradas desconhecidos aos utilizados no processo de treinamento.

\subsubsection{Rede perceptron multicamada}

A proposta de McCulloch e Pitts em 1943 introduz o conceito de redes neurais como elementos computacionais. Posteriormente, em 1949, Hebb apresenta a primeira regra de aprendizagem auto-organizada (ROSENBLATT, 1958). Em 1958, Frank Rosenblatt propõe o perceptron com aprendizagem supervisionada. A estrutura de um neurônio perceptron é constituída por um elemento processador com pesos sinápticos ajustáveis. Esta rede, com um único elemento processador, é capaz de apenas realizar a classificação de padrões 
linearmente separáveis (HAYKIN, 2001). Esse fato desencorajou os pesquisadores a dar continuidade aos estudos do perceptron, uma vez que a convergência do algoritmo não era garantida.

Em 1963 o trabalho de Levenberg e Marquardt propõe uma alteração do método dos mínimos quadráticos de Gauss-Newton, usados comumente em problemas de otimização, por introdução de uma taxa variável somada ao produto da matriz Jacobiana pela sua transposta que resulta da derivada do erro (HAGAN; MENHAJ, 1994). O algoritmo backpropagation trabalha com a hipótese de que ocorre uma variação negativa do erro a cada iteração. Com a alteração proposta por Levenberg e Marquardt o algoritmo ficou flexível, podendo variar a taxa de erro apresentada a cada iteração, resolvendo assim o problema de convergência.

O algoritmo Backpropagation é utilizado no treinamento das redes perceptrons multicamadas, podendo ser dividido em duas etapas; a saber: Passo Forward e Passo Backward.

$\square$ Passo Forward - Um padrão de dados é apresentado às entradas da rede e às saídas de cada neurônio e propaga até a entrada seguinte de forma a obter a saída da rede.

$\square$ Passo Backward - Faz o caminho oposto, ou seja, a partir da saída, calcula-se o erro que será propagado para os neurônios das camadas anteriores. Com o erro calculado, são executados os ajustes dos pesos sinápticos associados às entrada de cada neurônio.

O erro na saída da rede é usado no processo de ajuste dos pesos e limiares, conforme demonstrado em Haykin (2001), Nunes, Spatti e Flauzino (2010). Expandindo o equacionamento para $i$ amostras, obtém-se a expressão (121):

$$
\begin{gathered}
v_{k}(i)=\sum_{j=1}^{m} x_{j} \cdot w_{j}+b_{k} \\
y_{k}(i)=\varphi_{k}\left(v_{k}(i)\right)
\end{gathered}
$$

onde:

$m$ é o número de entradas do neurônio;

$w_{j}$ é o peso associado com a $j$-ésima entrada;

$b$ é o limiar de ativação associado ao neurônio;

$x_{j}$ é a $j$-ésima entrada do neurônio;

$v_{k}(i)$ é a resposta ponderada do $k$-ésimo neurônio em relação ao instante $i$;

$\varphi_{k}($.$) é a função de ativação do k$-ésimo neurônio;

$y_{k}(i)$ é a saída do neurônio do $k$-ésimo neurônio em relação ao instante $i$.

Cada neurônio artificial computa os sinais da entrada à saída e as funções de ativação não lineares são normalmente usadas, tais como a função logística e a tangente hiperbólica. O erro produzido pelo $k$-ésimo neurônio de saída quando a ele é apresentado o $i$-ésimo 
vetor de entrada relacionado com os pesos $\left(w_{k}\right)$ do $k$-ésimo neurônio é usado para o ajuste dos pesos sinápticos. Este erro é calculado por:

$$
e_{k}(i)=d_{k}(i)-y_{k}(i)
$$

onde $d_{k}(i)$ é a saída desejada do $k$-ésimo neurônio de saída.

Com a soma de todos os erros quadráticos produzidos por todos os neurônios de saída da rede em relação à $i$-ésima iteração, tem-se:

$$
E(i)=\frac{1}{2} \sum_{k=1}^{p} e_{k}^{2}(i)
$$

onde $p$ é o número de neurônios de saída.

Para uma configuração ótima dos pesos sinápticos, $E(i)$ é minimizado pelo ajuste dos pesos $w_{k j}$. Os pesos associados à camada de saída da rede são ajustados conforme a expressão (125):

$$
E_{k j}(i+1) \leftarrow w_{k j}(i)-\eta \frac{\partial E(i)}{\partial w_{k j}(i)}
$$

onde $w_{k j}$ é o peso que conecta o $k$-ésimo neurônio da camada de saída ao $j$-ésimo neurônio da camada anterior e $\eta$ é a constante que determina a taxa de aprendizado do algoritmo de retropropagação. De forma análoga, são feitos os ajustes dos pesos pertencentes às camadas ocultas. O algoritmo de correção é detalhado em Haykin (2001) e em Nunes, Spatti e Flauzino (2010).

O algoritmo de retropropagação tende a um tempo longo de convergência, o que aumenta o esforço computacional. Neste trabalho foi utilizado o algoritmo de LevenbergMarquardt (HAGAN; MENHAJ, 1994), pois é um método utilizado e incorporado ao algoritmo de retropropagação.

Esse algoritmo utiliza um método de gradiente descendente de segunda ordem, com base no método dos mínimos quadrados para modelos não lineares. Esse método também é apresentado em Haykin (2001) e Nunes, Spatti e Flauzino (2010).

A característica de aproximador universal de funções, mesmo as não lineares, mostra que as PMCs atendem ao objetivo de estimação de sinais, como é o caso deste trabalho. As redes PMC de entradas atrasadas no tempo Time Delay Neural Network (TDNN) também são de arquitetura feedforward. A TDNN tem sido usada devido a sua habilidade de mapear sistemas dinâmicos usando o histórico dos sinais de entrada (MARQUES et al., 2005; KAISER, 1994). Com essa característica de sinais de entrada, o sinal estimado apresenta robustez frente a ruídos comumente encontrado em sistemas elétricos de potência, pois o estimador não é dependente apenas de valores instantâneos dos sinais de entrada.

As redes PMC de entradas atrasadas no tempo Time Delay Neural Network (TDNN) também são de arquitetura feedforward. Essa rede foi primeiramente apresentada por 
Lang e Hinton (1988) e Waibel et al. (1989). A rede calcula sua saída em função de valores de entradas anteriores, ou seja:

$$
x(t)=f\left(x(t-1), x(t-2), \ldots, x\left(t-n_{p}\right)\right)
$$

onde $n_{p}$ é a ordem dos atrasos do preditor.

Desse modo, uma PMC aplicada em processos variantes no tempo tem configuração conforme apresentada na Figura 25. Nota-se que os atrasos são aplicados somente na camada de entrada, denominada de TDNN com configuração focada (focused time-lagged feedforward network) (NUNES; SPATTI; FLAUZINO, 2010), diferentemente ao TDNN apresentado por Waibel et al. (1989), onde ocorre a inserção dos atrasos em todas as camadas da rede. O atraso das variáveis de entrada garante que a saída dependa do comportamento temporal do processo.

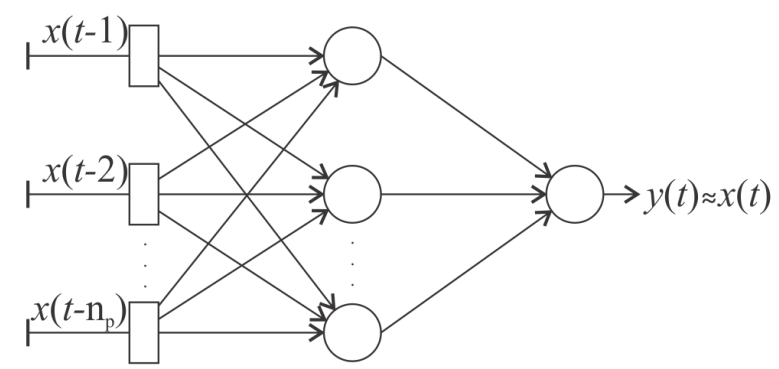

Figura 25 - Topologia de PMC com entradas atrasadas no tempo.

Fonte: Nunes, Spatti e Flauzino (2010)

A resposta da rede representada na Figura 25 mostra que a PMC recebe as $n_{p}$ entradas $\left\{x(t-1), x(t-2), \ldots, x\left(t-n_{p}\right)\right\}$, e então, ela prediz qual seria a resposta $x(t)$, apresentado por $y(t)$. Durante o processo de treinamento, o algoritmo tem como objetivo ajustar os pesos sinápticos visando minimizar o erro $E(t)$ entre $x(t)$ e $y(t)$. Embora o processo de treinamento seja similar ao PMC convencional e o aprendizado é feito de maneira idêntica, deve-se tomar o cuidado com a forma que os dados são apresentados a rede (NUNES; SPATTI; FLAUZINO, 2010).

Consta na literatura pesquisada o uso da TDNN como preditor em sistemas variantes no tempo. A proposta desse trabalho consiste no uso da TDNN com atraso focado, apresentado em (NUNES; SPATTI; FLAUZINO, 2010), com treinamento supervisionado a fim de estimar a velocidade do motor de indução trifásico quando este é acionado por um driver com CDC e CDT. Para isso, a rede TDNN opera como um aproximador universal de funções. Dessa forma, foram realizadas duas modificações na TDNN. A primeira modificação é no vetor das variáveis de entrada, que tem como primeira amostra o valor atual da variável, e não mais a entrada com um atraso de uma amostra $(x(t-1))$. Como um aproximador de funções, a segunda alteração é no sentido de que a saída da rede apresenta a velocidade estimada do MI. A Figura 26 mostra a TDNN na configuração descrita. 
O metodologia de treinamento é similar a rede TDNN como preditor. Entretanto, deve ser observado que os vetores de entrada são compostos também com a amostra atual da variável e a saída desejada. Neste trabalho a variável de saída é a velocidade estimada do eixo.

A TDNN apresentada desempenha o papel de aproximador universal de funções. Neste trabalho os atrasos amostrais utilizados no estimador de velocidade também contribui para minimizar os efeitos de uma possível variação repentina da corrente elétrica e também dos ruídos dos sinais de entrada, ou seja, a TDNN também atua como um filtro das variáveis de entrada. A metodologia que descreve a maneira como os dados de treinamento e validação são adquiridos e tratados também são etapas importante para que as redes neurais, de uma forma geral, tenham um desempenho satisfatório.

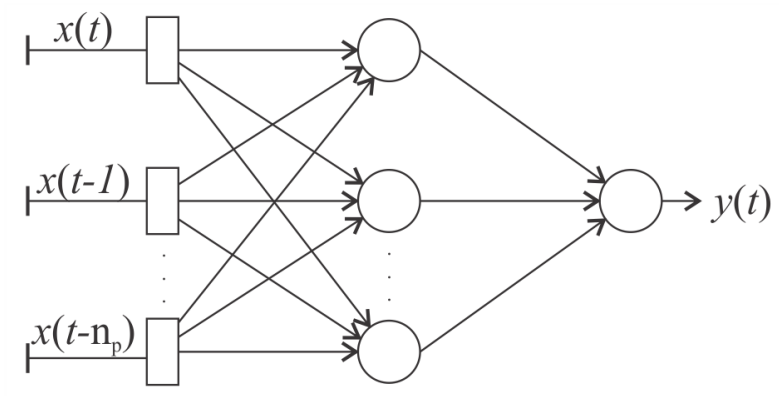

Figura 26 - Rede TDNN como aproximador universal de função.

Fonte: Nunes, Spatti e Flauzino (2010)

\subsubsection{Aspectos metodológicos do treinamento da RNA}

As redes neurais artificiais têm se mostrado eficiente nas mais diversas aplicações na engenharia. Nesse trabalho uma estrutura neural é aplicada na estimação de velocidade de um motor de indução trifásico quando este é acionado por um inversor de frequência com duas estratégias de controle vetorial: o CDC e o CDT. O modelo do MI utilizado nas simulações, tanto na geração dos dados de treinamento bem como para a validação computacional, é apresentado em Ong (1998) e Bose, Wasynczuk e Sudhof (2002). O mesmo conjunto de dados gerados nas simulações são usados para treinar as RNAs nas duas estratégias de implementação da RNA.

Para compor o conjunto de dados de treinamento foram realizadas diversas simulações do modelo matemático do MI-1 implementado no ambiente Matlab/Simulink. As simulações realizadas compreendem o MI operando numa faixa de $0 \mathrm{rad} / \mathrm{s}$ à $180 \mathrm{rad} / \mathrm{s}$, variando com o passo de $5 \mathrm{rad} / \mathrm{s}$ na faixa de 0 à $20 \mathrm{rad} / \mathrm{s}$ e $10 \mathrm{rad} / \mathrm{s}$ na faixa entre 30 à 180 $\mathrm{rad} / \mathrm{s}$, totalizando 21 referências de velocidades para cada sentido de rotação, da partida ao regime permanente. Observa-se que na região de baixas frequências tem-se um menor intervalo entre as referências de velocidade com o objetivo obter uma maior concentração de dados, devido à dificuldade encontrada no mapeamento da resposta dinâmica de 
velocidade nessa região de operação. Ainda, para cada ponto de operação de frequência, foram utilizados 5 valores de conjugado resistente de carga, variando de 0,1 N.m à 4,1 N.m com incremento de 1 N.m. As simulações são também realizadas para o sentido negativo de rotação, para operação em dois quadrantes. Dessa forma, foram executadas 210 simulações para compor o conjunto de dados de treinamento e teste. Após esse processo, as RNAs treinadas são também validadas no MI-2. Este processo é mostrado na Figura 27. A Tabela 3.4 mostra as condições gerais de simulação para compor o conjunto de treinamento das RNAs.

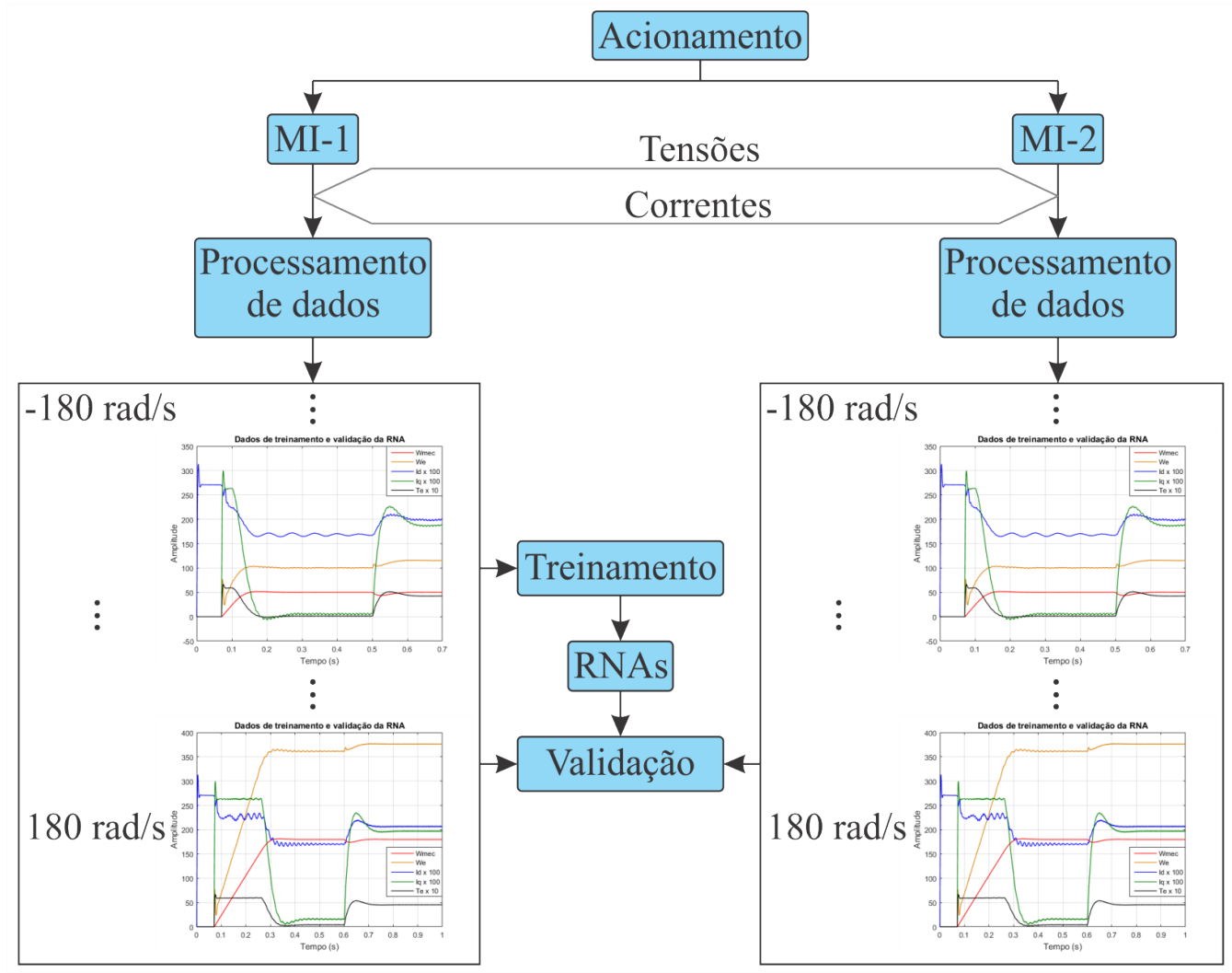

Figura 27 - Processo de geração e uso dos conjuntos de dados no treinamento e validação computacional das RNAs.

Para que a RNA mapeie todo o comportamento dinâmico do sistema de dados durante a aceleração e desaceleração do MI utiliza-se um maior número de dados frente ao regime permanente. Para cada referência de velocidade é aplicado o mesmo tempo de simulação, onde a proporção de amostras durante a aceleração/desaceleração varia de $70 \%$ à $75 \%$ em relação ao total de amostras. Essa diferença de densidade de amostras entre a dinâmica de aceleração/desaceleração do MI e o regime permanente se deve a maior dificuldade de mapeamento no treinamento da RNA durante esses intervalos de tempo. Fazendo-se uso desse procedimento tem-se o reforço do treinamento da RNA durante os transitórios. Os dados não utilizados durante o treinamento são destinados ao processo de validação da RNA.

De posse desses dados, foram realizados atrasos amostrais de ordem quatro nas variá- 
veis de entrada das RNAs, formando o conjunto de treinamento, constituída por quatro variáveis de entrada, onde cada uma é composta por $\{x(t) ; x(t-1) ; x(t-2) ; \cdots ; x(t-n)\}$, ou seja, para cada entrada da RNA são utilizados seus valores atuais e as amostras atrasadas no tempo, até à ordem de atraso desejada.

Tabela 3.4 - Condições gerais de aquisição de dados das simulações.

\begin{tabular}{l|l}
\hline Região de operação & $0-180 \mathrm{rad} / \mathrm{s}$ \\
\hline Intervalo de frequências de operação & $5 \mathrm{rad} / \mathrm{s}$ operando de $0-20 \mathrm{rad} / \mathrm{s}$ \\
\hline Intervalo de frequências de operação & $10 \mathrm{rad} / \mathrm{s}$ operando de $30-180 \mathrm{rad} / \mathrm{s}$ \\
\hline Total de frequências de operação & 21 \\
\hline Intervalos de conjugado de carga & $1 \mathrm{~N} . \mathrm{m}$ variando de $0,1-4,1 \mathrm{~N} . \mathrm{m}$ \\
\hline Região de operação do estimador & $0 \mathrm{rad} / \mathrm{s}$ a $180 \mathrm{rad} / \mathrm{s}$ \\
\hline Total de simulações & 210 \\
\hline
\end{tabular}

Durante o processo de treinamento foram testadas outras ordens de atraso, por exemplo, atraso de ordem 3 houve lentidão da convergência do processo de treinamento e resultados de generalização insatisfatórios. Com atrasos de ordem muito elevada o treinamento tende ao overfitting, além de aumentar a quantidade de memória exigida para a implementação da RNA em sistemas embarcados. Para isso foram realizados testes com RNAs TDNN de ordem 4 e 5. Para cada ordem de atraso, foram geradas duas RNAs candidatas, que têm suas performances avaliadas via simulação computacional. O mesmo procedimento é realizado com as duas estratégias de implementação das RNAs, para cada um das estratégias de controle. Assim, na estratégia de implementação $(A)$ são treinadas oito RNAs, sendo quatro para o MI acionado via CDC e outras quatro quando acionado via CDT, onde para cada estratégia de acionamento as RNAs são duas TDNN de ordem 4 e duas de ordem 5. O mesmo formato é considerado para a estratégia de implementação $(B)$. Dentre as diversas estruturas de RNAs testadas, a que obteve melhor performance é aquela composta por três camadas, onde há cinco neurônios na primeira camada escondida e nove neurônios na segunda camada escondida. A síntese da estrutura das RNAs candidatas é mostrada na Tabela 3.5.

Tabela 3.5 - Parâmetros das RNAs candidatas

\begin{tabular}{ll}
\hline Arquitetura da rede & Perceptron multicamadas \\
\hline Tipo de treinamento & Supervisionado - offline \\
\hline Número de camadas & 3 \\
\hline Número de neurônios da $1^{\text {a }}$ camada escondida & 5 \\
\hline Número de neurônios da $2^{\text {a }}$ camada escondida & 9 \\
\hline Algoritmo de treinamento & Levenberg-Marquardt backpropagation \\
\hline Algoritmo de treinamento & $1.10^{-2}$ \\
\hline Erro quadrático requerido & $5.10^{-6}$ \\
\hline Função de ativação da camada escondida & Tangente hiperbólica \\
\hline Função de ativação da camada saída & Linear \\
\hline
\end{tabular}


Para que o estimador proposto seja generalista com relação à potência do motor de indução acionado, foi adotada a normalização com os valores máximos de todas as variáveis de entrada e saída. Dessa forma, objetiva-se que o estimador tenha performance satisfatória mesmo para uma máquina cujos parâmetros sejam diferentes daqueles usados nas simulações.

A estrutura do conjunto inversor fonte de tensão com as estratégias de controle, processamento de dados e estimador neural de velocidade são apresentadas na Figura 28 para a estratégia de implementação $(A)$, e na Figura 29 para a estratégia de implementação $(B)$.

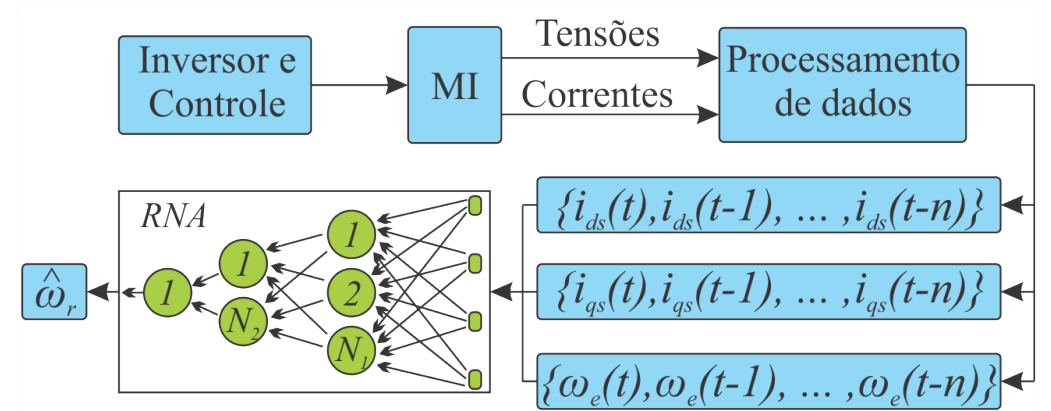

Figura 28 - Estrutura para o treinamento e validação computacional das RNAs para a estratégia $(A)$.

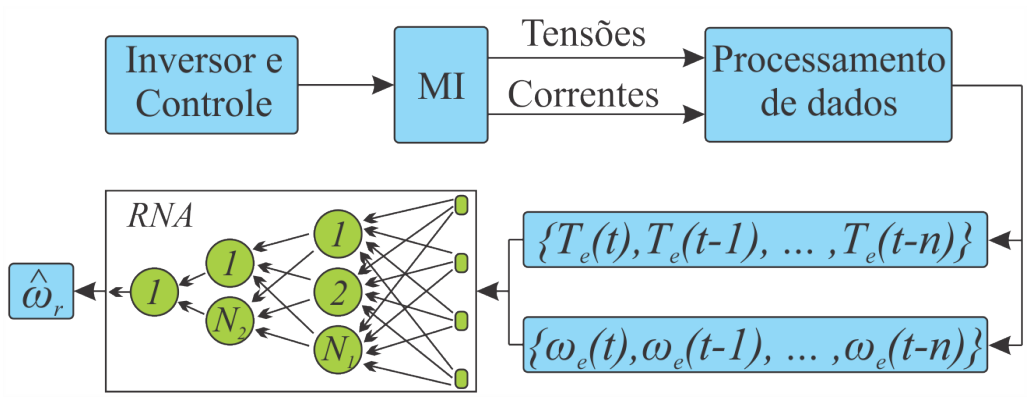

Figura 29 - Estrutura para o treinamento e validação computacional das RNAs para a estratégia $(B)$.

Após a execução das simulações computacionais são formados os dois conjuntos de dados para treinamento e validação. De posse desses conjuntos são treinadas diversas RNAs para que se possa avaliar a de melhor desempenho em cada uma das estratégias de implementação.

\subsection{Métodos para Implementação da Tangente Hi- perbólica}

A metodologia de implementação do neurônio artificial no DSP (Digital Sinais Processor) deve ser avaliado, pois os neurônios das camadas escondidas utilizam a função de ativação tangente hiperbólica. Esta função pode ser complexa de ser executada em 
sistemas embarcados em poucos ciclos de máquina do processador. Assim, alguns testes são conduzidos; a saber: $i$ ) método de implementação dos neurônios artificiais e $i i$ ) testes experimentais do tempo de execução dos neurônios artificiais embarcados em DSP.

Os testes experimentais são conduzidos com o algoritmo de controle CDT no MI-2 e de uma das RNAs treinadas e implementadas no kit de experimentos de DSP TMS320F28335 com a CPU de 150 MIPS em ponto flutuante, $512 \mathrm{kB}$ de memória flash e com o conversor analógico configurado a realizar aquisições de sinais com resolução de 12 bits. O algoritmo de controle é síncrono à interrupção do conversor A/D, onde cada ciclo dura $50 \mathrm{us}(20 \mathrm{ks} / \mathrm{s})$.

Já a RNA é executada em duas etapas, onde na primeira etapa são processados os dados até a saída da primeira camada escondida, enquanto no ciclo seguinte do loop os dados são processados a partir da segunda camada escondida até a saída da RNA. Dessa forma, a velocidade estimada é atualizada a cada dois ciclos do loop principal, ou seja, a uma taxa de $10 \mathrm{ks} / \mathrm{s}$. A Figura 30 mostra a bancada de ensaio usada nos testes experimentais de execução da tangente hiperbólica.

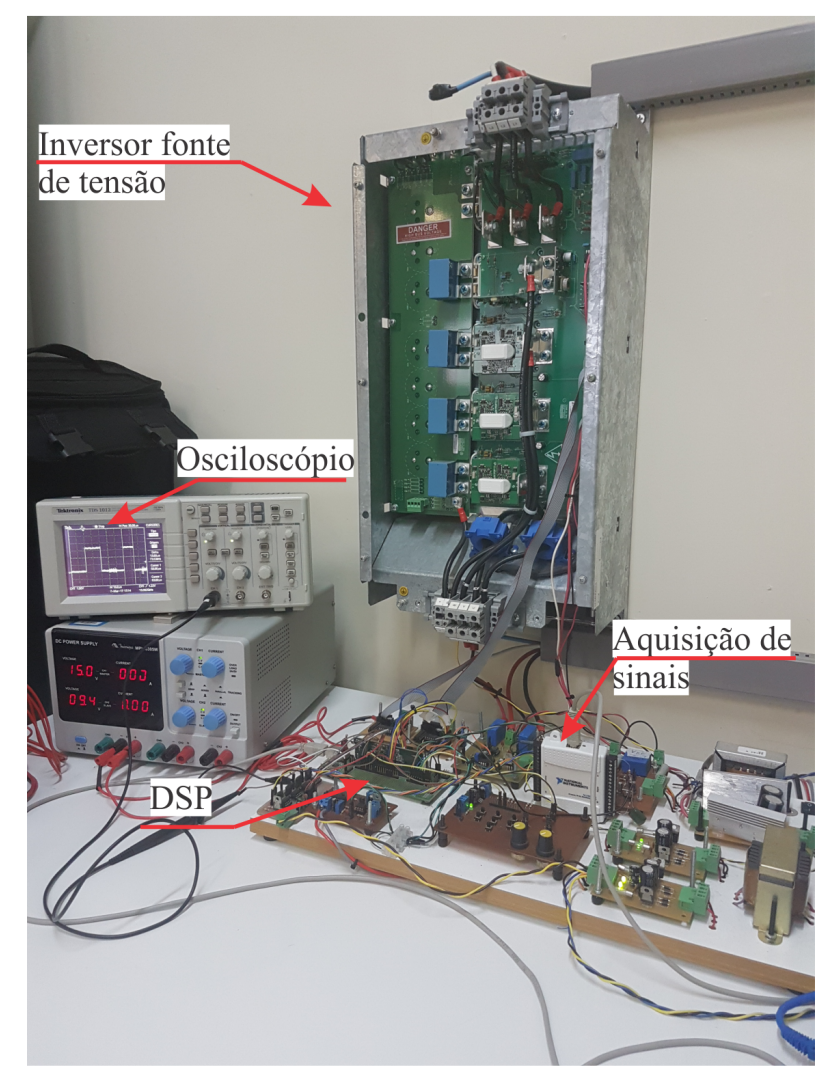

Figura 30 - Ilustração da bancada de ensaios experimentais usada nos testes experimentais de execução da tangente hiperbólica.

Para observar o tempo gasto na execução de uma determinada parte do código é usada uma saída digital do DSP como indicador. O nível lógico alto indica o início de processamento do código avaliado, enquanto o nível lógico baixo indica o término. A medição do tempo de execução é feita com o uso de um osciloscópio, medindo-se largura desse pulso. A Figura 31 mostra a sequência de execução do loop principal no DSP. 
A função de ativação das camadas escondidas da RNA é a tangente hiperbólica, que nesse trabalho é implementada de duas formas, chamando a função tanh com o uso da biblioteca math.h e o uso da técnica lookup table (LUT). A biblioteca math.h tem como vantagem a precisão dos resultados das funções trigonométricas com reduzido uso de memória. Entretanto, a quantidade de instruções que a máquina executa pode ser significativamente elevada. Na técnica LUT, o domínio da saída de uma função ou uma parcela dele em caso de funções simétricas, é armazenado em um vetor e a entrada da função é usada apenas para o cálculo da posição do vetor que contém o valor de retorno da função. Embora o uso de uma tabela com valores definidos são rapidamente acessíveis, a memória alocada para o armazenamento do vetor é atrelado a precisão pretendida da resposta da função, conforme será mostrado pelos dados de simulação.

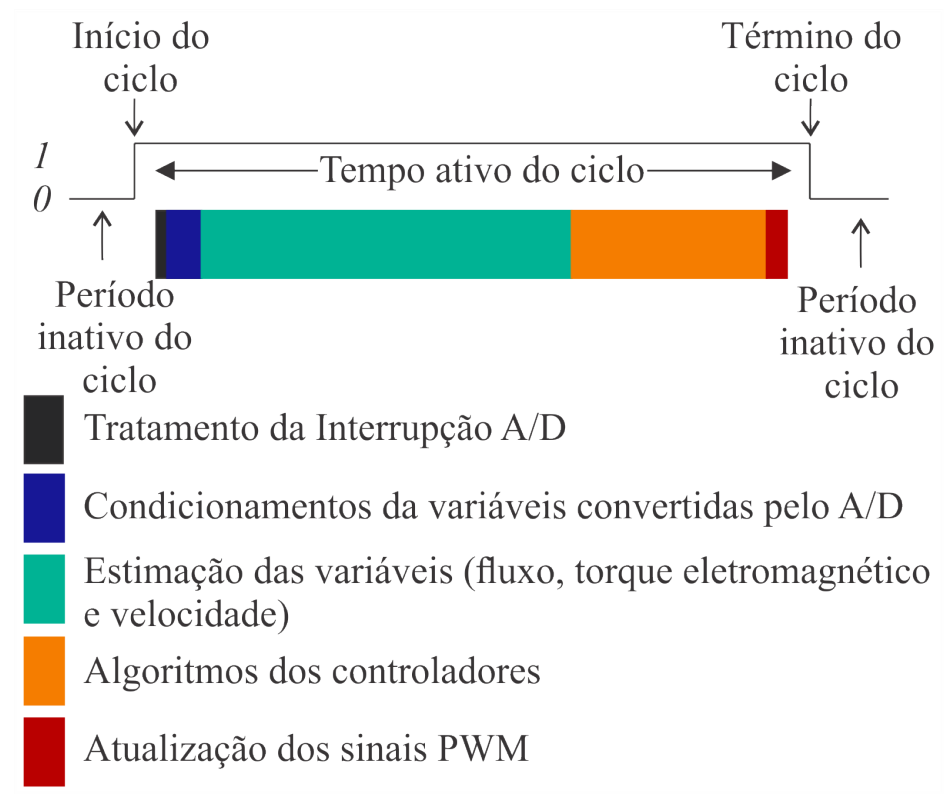

Figura 31 - Loop principal do algoritmo embarcado no DSP.

Devido a simetria da função tangente hiperbólica, conforme mostra a Figura 32, apenas o intervalo positivo (ou negativo) precisa ser usado para representar o domínio da função. Assim, se o valor de entrada $v$ é positivo, a saída da função é positiva, caso contrário atribui-se sinal negativo ao vetor com os valores de saída da função. Com esse artifício é possível dobrar a resolução da saída da função para uma mesma quantidade de memória do DSP.

Os testes experimentais mostram que os tempos de execução do algoritmo embarcado no DSP são executados conforme mostrado na Tabela 3.6.

Tabela 3.6 - Testes dos tempos de execução da tangente hiperbólica.

\begin{tabular}{c|c}
\hline Teste & Tempo de execução \\
\hline 3.1 & Um ciclo do loop principal \\
\hline 3.2 & Primeira camada escondida \\
\hline
\end{tabular}




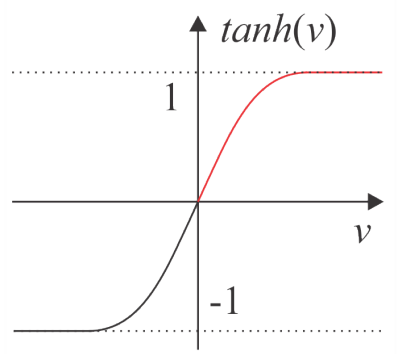

Figura 32 - Função de ativação tangente hiperbólica.

O tempo usado pelo DSP para executar um ciclo do loop principal para o Teste 3.1, considerando o uso da biblioteca math.h para o cálculo da função de ativação, é mostrado na Figura 33. O DSP levou $54 \mu s$ para executar todo o algoritmo de acionamento e a RNA até a primeira camada escondida. No segundo ciclo, O DSP levou $77 \mu s$ para executar o algoritmo de acionamento e a RNA é processada à partir da segunda camada escondida até a saída do estimador neural. Em ambos os ciclos, o tempo de execução foi superior ao limite estabelecido para o correto funcionamento do acionamento do MI (50 $\mu \mathrm{s})$.

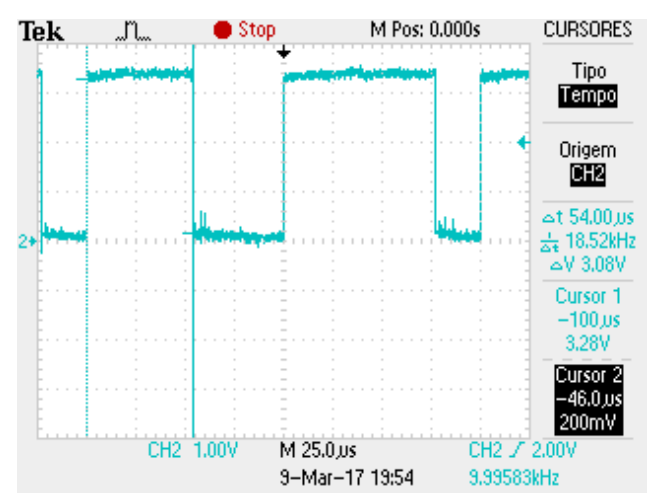

(a)

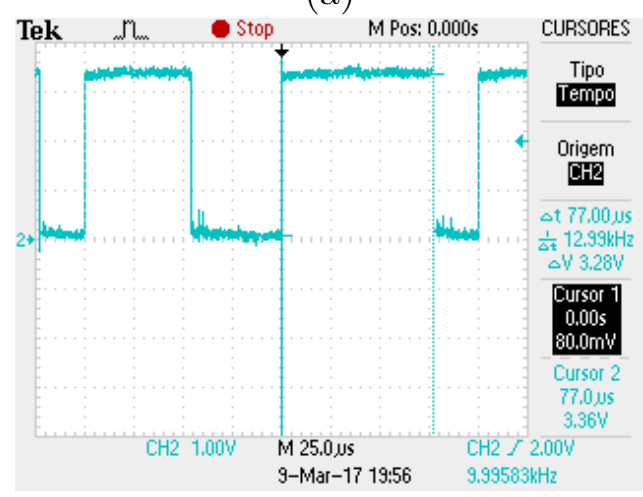

(b)

Figura 33 - Teste 3.1 - tempo de execução de um ciclo usando a biblioteca math.h: a) até a primeira camada escondida, b) após a segunda camada escondida.

Quando o método de implementação da função tangente hiperbólica é o LUT, o tempo usado para executar um ciclo do loop principal é significativamente reduzido, conforme mostra a Figura 34. O tempo de execução é 59,259 \% (32 $\mu s)$ menor considerando a 
primeira camada escondida da RNA, enquanto o ciclo que calcula da segunda camada escondida até a saída tem redução de 49,87 \% (38,4 $\mu s)$.

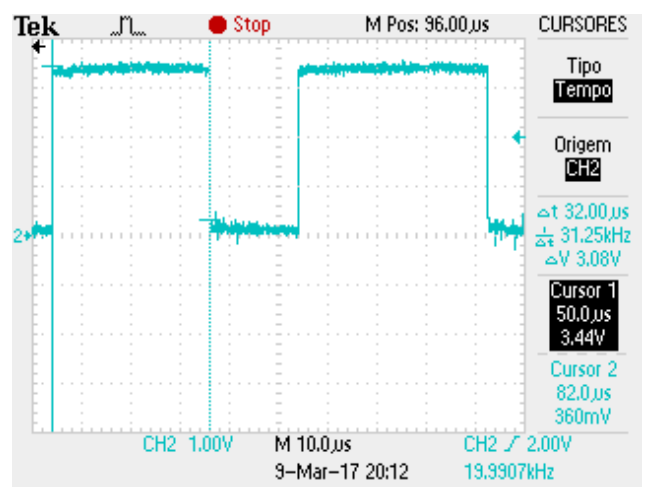

(a)

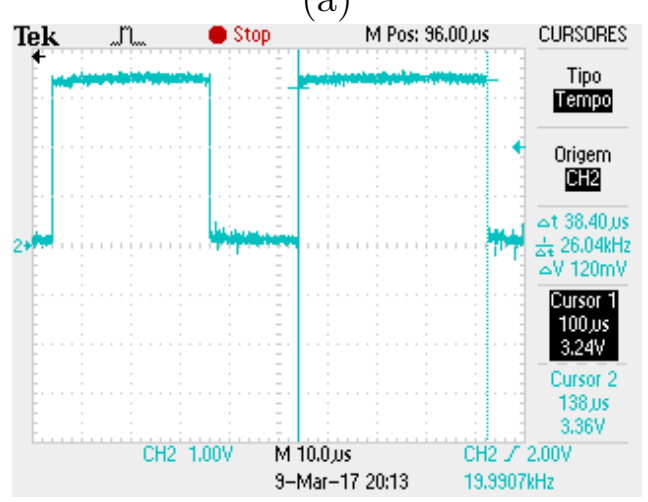

(b)

Figura 34 - Teste 3.1 - Tempo de execução de um ciclo usando a técnica LUT: a) até a primeira camada escondida, b) após a primeira camada escondida.

No Teste 3.2 o tempo de execução dos cinco neurônios da primeira camada escondida é de 35,0 $\mu s$ e 13,6 $\mu s$ usando a biblioteca math.h e a técnica LUT, respectivamente, como mostra a Figura 35 .

Como mostram os resultados experimentais, a estratégia usada no cálculo da função de ativação tangente hiperbólica deve ser levada em conta em sistemas embarcados, influenciando diretamente no tempo de execução do algoritmo.

Uma vez mostrado que o uso da técnica LUT para a função de ativação apresenta vantagem em relação ao tempo de processamento da RNA, a precisão da saída do estimador é também avaliada. Com o objetivo de avaliar o desempenho do estimador neural entre tais estratégicas de implementação da função de ativação, realizou-se um teste computacional considerando o MI a $5 \mathrm{rad} / \mathrm{s}$ em regime permanente com conjugado nominal.

O método quantitativo usado para a avaliação do estimador foi o cálculo do Erro Relativo Médio (ERM). O ERM foi calculado pela relação entre a saída do estimador neural e a velocidade medida no eixo do MI, utilizando a equação (127):

$$
E R M=\frac{1}{n} \sum_{i=1}^{n} e(i)
$$




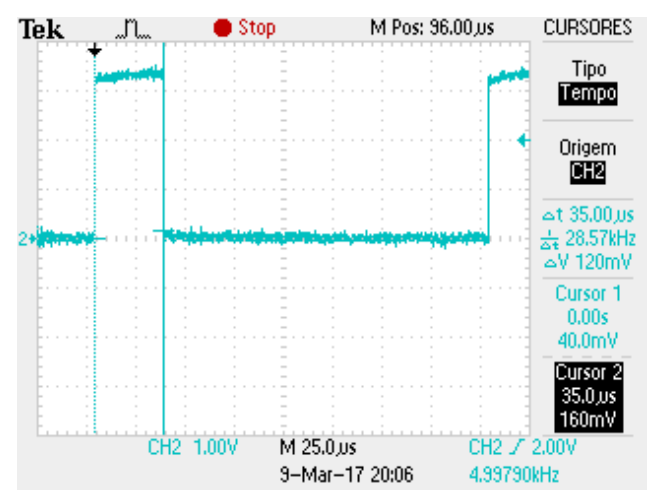

(a)

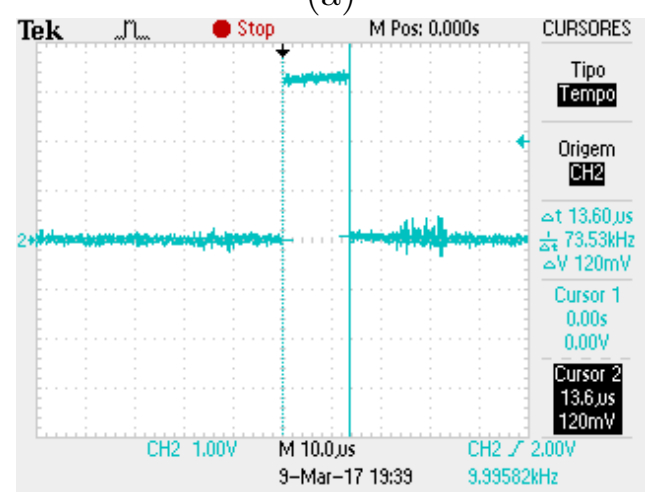

(b)

Figura 35 - Teste 3.2 - Tempo de execução da primeira camada escondida: a) usando a biblioteca math.h, b) usando a técnica LUT.

onde $n$ é o número de amostras, $e(i)$ representa o erro entre o valor medido e o valor estimado para a $i$-ésima amostra.

O desempenho do estimador neural, frente a velocidade medida no eixo da máquina, é avaliado usando a biblioteca math.h e a técnica LUT com quatro mil e cinco mil pontos de resoluções na discretização da função de ativação dos neurônios das camadas escondidas, conforme mostra a Figura 36. O ERM em regime permanente da RNA é de 1,562\% e $0,029 \mathrm{rad} / \mathrm{s}$ de desvio padrão, quando usada a biblioteca math.h. Quando é usado a técnica LUT com discretização da função tangente hiperbólica com quatro mil pontos o ERM de 5,964\% e 0,231 rad/s de desvio padrão. Elevando a quantidade de pontos que representam a saída da função de ativação o ERM obtido é de 5,421\% e 0,196 rad/s de desvio padrão.

Os resultados de simulação mostram que quanto maior é a resolução da função de ativação maior é a precisão da RNA. Entretanto, deve-se considerar o espaço na memória disponível no hardware para alocar a tabela de resultados. Neste trabalho a função tangente hiperbólica foi implementada com a técnica LUT com 5000 pontos de discretização. 

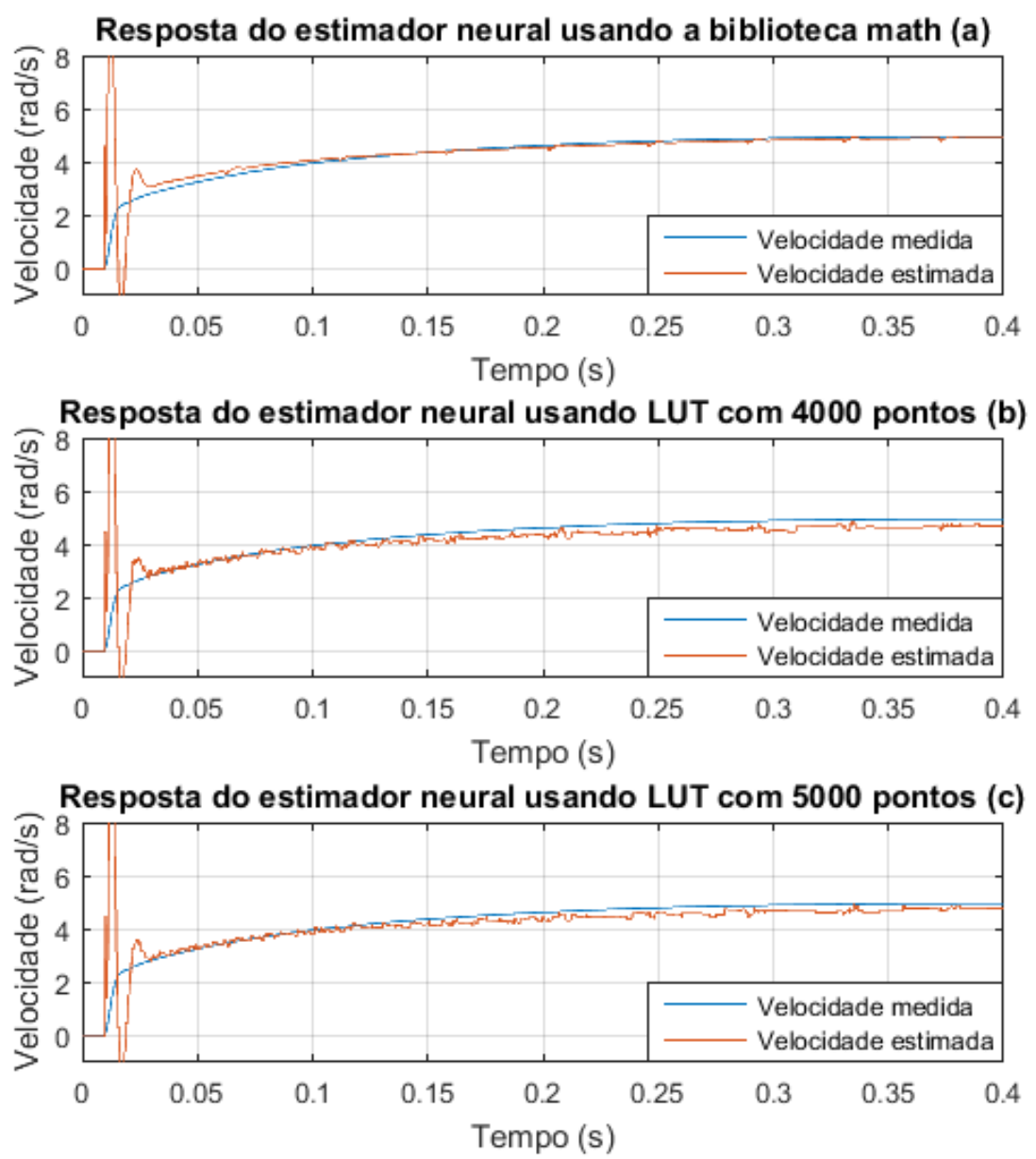

Figura 36 - Resposta do estimador neural de velocidade frente às técnicas de implementação da tangente hiperbólica.

\subsection{Seleção das RNAs Candidatas com Dados de Si- mulação}

Após o treinamento das RNAs candidatas as mesmas são validadas via simulação computacional. Neste processo as RNAs são avaliadas em diferentes níveis de velocidade e o mesmo padrão de testes são usados nas duas estratégias de implementação. Os resultados de cada estimador são usados a fim de classificar o de melhor desempenho, que são na sequência validados experimentalmente.

A fim de avaliar as RNAs que serão usadas como estimadores de velocidade do MI, em cada uma das estratégias de implementação das RNA, foram treinados dois grupos com quatro RNAs cada, onde cada grupo contém duas TDNN de ordem 4 e duas de ordem 5 . Esse procedimento é feito para os dois métodos de controle vetorial.

O desempenho das RNAs foram avaliados com relação ao ERM. Assim, os testes são conduzidos em três níveis de velocidade, $5 \mathrm{rad} / \mathrm{s}, 90 \mathrm{rad} / \mathrm{s}$ e $180 \mathrm{rad} / \mathrm{s}$, com o MI acionando 
uma carga com conjugado nominal em regime permanente.

\subsubsection{Seleção das RNAs para a estratégia de implementação $A$}

Uma vez mostrado que o uso da técnica LUT para a implementação da função de ativação apresenta vantagem em relação ao tempo de processamento da RNA, a precisão da saída usando essa técnica é também avaliada. O MI-2 é usado neste processo de seleção. Na estratégia de implementação $A$, são formados dois grupos de RNAs que passaram pelo processo de treinamento. O Grupo 1.1 é formado por RNAs treinadas com os dados obtidos do MI-1 acionado pelo CDC, e o Grupo 1.2 é composto por RNAs treinadas com os dados obtidos com o MI-1 acionado pelo CDT.

As Tabelas 3.7 e 3.8 mostram os resultados de simulação das RNAs com os dados do MI acionado pelo CDC e CDT, respectivamente. O ERM é calculado em regime permanente.

Tabela 3.7 - Resultados de simulação das RNAs com os dados do MI-2 acionado pelo CDC na estratégia A - Grupo 1.1.

\begin{tabular}{|c|c|c|}
\hline Técnica de implementação & Biblioteca math.h & LUT 5000 pontos \\
\hline Candidatas & \multicolumn{2}{|c|}{ ERM $(\%)$ a $5 \mathrm{rad} / \mathrm{s}$} \\
\hline RNA A1 $-4^{\mathrm{a}}$ ordem & 5,214 & 5,381 \\
\hline RNA A2 $-4^{\mathrm{a}}$ ordem & 6,031 & 4,829 \\
\hline RNA A3 $-5^{\mathrm{a}}$ ordem & 2,480 & 9,335 \\
\hline RNA A4 $-5^{\mathrm{a}}$ ordem & 4,719 & 2,593 \\
\hline Candidatas & \multicolumn{2}{|c|}{$\operatorname{ERM}(\%)$ a $90 \mathrm{rad} / \mathrm{s}$} \\
\hline RNA A1 $-4^{\mathrm{a}}$ ordem & 0,136 & 0,698 \\
\hline RNA A2 $-4^{\text {a }}$ ordem & 0,118 & 0,655 \\
\hline RNA A3 - $5^{\mathrm{a}}$ ordem & 0,117 & 0,188 \\
\hline RNA A4 - $5^{\mathrm{a}}$ ordem & 0,120 & 0,328 \\
\hline Candidatas & \multicolumn{2}{|c|}{$\operatorname{ERM}(\%)$ a $180 \mathrm{rad} / \mathrm{s}$} \\
\hline RNA A1 $-4^{\mathrm{a}}$ ordem & 0,097 & 0,237 \\
\hline RNA A2 - $4^{\mathrm{a}}$ ordem & 0,095 & 0,167 \\
\hline RNA A3 $-5^{\mathrm{a}}$ ordem & 0,078 & 0,066 \\
\hline RNA A4 - $5^{\mathrm{a}}$ ordem & 0,080 & 0,048 \\
\hline
\end{tabular}

Para cada ordem de atraso da TDNN é selecionada a RNA que possui o menor ERM em cada uma das velocidades de teste, considerando a técnica LUT para a execução da tangente hiperbólica. Assim, na estratégia $A$ com o CDC a RNA A2 e a RNA A4 obtiveram os melhores desempenhos, enquanto no CDT a RNA A5 e a RNA A8 obtiveram os menores ERM.

\subsubsection{Seleção das RNAs para a estratégia de implementação $B$}

De maneira similar, as Tabelas 3.9 e 3.10 mostram os resultados de simulação das RNAs com os dados do MI acionado pelo CDC e CDT respectivamente, usando a estra- 
Tabela 3.8 - Resultados de simulação das RNAs com os dados do MI-2 acionado pelo CDT na estratégia A - Grupo 1.2 .

\begin{tabular}{c|c|c}
\hline Técnica de implementação & Biblioteca math.h & LUT 5000 pontos \\
\hline Candidatas & \multicolumn{2}{|c}{ ERM $(\%)$ a $5 \mathrm{rad} / \mathrm{s}$} \\
\hline RNA A5 $-4^{\mathrm{a}}$ ordem & 7,112 & 10,015 \\
\hline RNA A6 - 4 ordem & 4,810 & 13,236 \\
\hline RNA A7 $-5^{\mathrm{a}}$ ordem & 4,903 & 3,905 \\
\hline RNA A8 $-5^{\mathrm{a}}$ ordem & 4,228 & 3,939 \\
\hline Candidatas & \multicolumn{2}{|c}{ ERM $(\%)$ a $90 \mathrm{rad} / \mathrm{s}$} \\
\hline RNA A5 $-4^{\mathrm{a}}$ ordem & 0,091 & 0,221 \\
\hline RNA A6 $-4^{\mathrm{a}}$ ordem & 0,233 & 0,922 \\
\hline RNA A7 $-5^{\mathrm{a}}$ ordem & 0,122 & 0,295 \\
\hline RNA A8 $-5^{\mathrm{a}}$ ordem & 0,078 & 0,181 \\
\hline Candidatas & ERM $(\%) \mathrm{a} 180 \mathrm{rad} / \mathrm{s}$ \\
\hline RNA A5 $-4^{\mathrm{a}}$ ordem & 0,052 & 0,127 \\
\hline RNA A6 - 4 ${ }^{\mathrm{a}}$ ordem & 0,147 & 0,397 \\
\hline RNA A7 $-5^{\mathrm{a}}$ ordem & 0,061 & 0,196 \\
\hline RNA A8 $-5^{\mathrm{a}}$ ordem & 0,044 & 0,054 \\
\hline
\end{tabular}

tégia de implementação $B$. O Grupo 2.1 é formado por RNAs treinadas com os dados obtidos do MI-1 acionado pelo CDC, e o Grupo 2.2 é composto por RNAs treinadas com os dados obtidos com o MI-1 acionado pelo CDT. Buscando as RNAs de melhor desempenho, a RNA B2 e a RNA B3, bem como a RNA B6 e a RNA B8 no CDC e CDT, são selecionadas.

Tabela 3.9 - Resultados de simulação das RNAs com os dados do MI-2 acionado pelo CDC na estratégia $B$ - Grupo 2.1.

\begin{tabular}{c|c|c}
\hline Técnica de implementação & Biblioteca math.h & LUT 5000 pontos \\
\hline Candidatas & \multicolumn{2}{|c}{ ERM $(\%)$ a $5 \mathrm{rad} / \mathrm{s}$} \\
\hline RNA B1 $-4^{\mathrm{a}}$ ordem & 7,125 & 3,755 \\
\hline RNA B2 $-4^{\mathrm{a}}$ ordem & 1,876 & 5,747 \\
\hline RNA B3 $-5^{\mathrm{a}}$ ordem & 4,722 & 4,831 \\
\hline RNA B4 $-5^{\mathrm{a}}$ ordem & 1,424 & 0,047 \\
\hline Candidatas & \multicolumn{1}{|c}{ ERM $(\%)$ a $90 \mathrm{rad} / \mathrm{s}$} \\
\hline RNA B1 $-4^{\mathrm{a}}$ ordem & 0,085 & 0,187 \\
\hline RNA B2 $-4^{\mathrm{a}}$ ordem & 0,077 & 0,198 \\
\hline RNA B3 $-5^{\mathrm{a}}$ ordem & 0,085 & 0,082 \\
\hline RNA B4 $-5^{\mathrm{a}}$ ordem & 0,097 & 0,114 \\
\hline Candidatas & ERM $(\%) \mathrm{a} 180 \mathrm{rad} / \mathrm{s}$ \\
\hline RNA B1 $-4^{\mathrm{a}}$ ordem & 0,082 & 0,092 \\
\hline RNA B2 $-4^{\mathrm{a}}$ ordem & 0,066 & 0,085 \\
\hline RNA B3 $-5^{\mathrm{a}}$ ordem & 0,063 & 0,083 \\
\hline RNA B4 $-5^{\mathrm{a}}$ ordem & 0,093 & 0,087 \\
\hline
\end{tabular}

Após a seleção das RNAs de melhor desempenho com os dados de simulação em cada uma das estratégias de implementação, tanto as TDNN de $4^{\mathrm{a}}$ e $5^{\mathrm{a}}$ ordem, essas são 
Tabela 3.10 - Resultados de simulação das RNAs com os dados do MI-2 acionado pelo CDT na estratégia $B$ - Grupo 2.2.

\begin{tabular}{c|c|c}
\hline Técnica de implementação & Biblioteca math.h & LUT 5000 pontos \\
\hline Candidatas & \multicolumn{2}{|c}{ ERM $(\%)$ a $5 \mathrm{rad} / \mathrm{s}$} \\
\hline RNA B5 $-4^{\mathrm{a}}$ ordem & 1,037 & 54,031 \\
\hline RNA B6 $-4^{\mathrm{a}}$ ordem & 1,021 & 4,003 \\
\hline RNA B7 $-5^{\mathrm{a}}$ ordem & 1,938 & 7,287 \\
\hline RNA B8 $-5^{\mathrm{a}}$ ordem & 1,103 & 5,201 \\
\hline Candidatas & \multicolumn{2}{|c}{ ERM $(\%)$ a $90 \mathrm{rad} / \mathrm{s}$} \\
\hline RNA B5 $-4^{\mathrm{a}}$ ordem & 0,091 & 0,838 \\
\hline RNA B6 $-4^{\mathrm{a}}$ ordem & 0,202 & 0,474 \\
\hline RNA B7 $-5^{\mathrm{a}}$ ordem & 0,058 & 0,316 \\
\hline RNA B8 $-5^{\mathrm{a}}$ ordem & 0,130 & 0,142 \\
\hline Candidatas & ERM $(\%) \mathrm{a} 180 \mathrm{rad} / \mathrm{s}$ \\
\hline RNA B5 $-4^{\mathrm{a}}$ ordem & 0,061 & 0,832 \\
\hline RNA B6 $-4^{\mathrm{a}}$ ordem & 0,061 & 0,133 \\
\hline RNA B7 $-5^{\mathrm{a}}$ ordem & 0,04 & 0,161 \\
\hline RNA B8 $-5^{\mathrm{a}}$ ordem & 0,076 & 0,066 \\
\hline
\end{tabular}

testadas experimentalmente no Capítulo 4 em duas condição; a saber: como observador de velocidade do MI e na realimentação das estratégias de controle CDC e CDT.

\subsection{Conclusões Sobre a Validação Computacional do Estimador Neural de Velocidade}

Os parâmetros dos controladores foi usado o método de resposta em frequência, determinada pela margem de fase e a frequência de cruzamento em 0dB. A resposta dinâmica do CDC e do CDT é também dependente dos níveis usados nos saturadores de saída de cada controlador de corrente, de velocidade e de torque eletromagnético.

Foram selecionados duas estratégia de implementação do estimador de velocidade usando a perceptron TDNN, onde em cada uma das estratégias são usados diferentes variáveis que compõem o vetor de entrada das RNAs. A seleção das variáveis foi baseada no comportamento dinâmico dessas, no decorrer do acionamento do MI.

O método de implementação da tangente hiperbólica, como função de ativação dos neurônios da camada escondida da RNA, é avaliado. A técnica LUT se mostrou mais adequada devido ao seu reduzido tempo execução no DSP, e ter o desempenho satisfatório, sendo dependente da quantidade de memória disponível para armazenar o vetor com a saída da função. Assim, a técnica LUT com 5000 pontos de discretização é usada nos testes experimentais mostrados no Capítulo 4.

Após o treinamento de diversas TDNN de quarta e quinta ordem, essas foram testadas a fim de se obter o estimador com o menor ERM em regime permanente. O próximo passo 
é testar as estratégias de controle com as RNAs em bancada experimental. 


\section{Validação Experimental}

A validação experimental da proposta é realizada em duas etapas. Primeiramente são realizados os testes do sistema com o estimador atuando como observador de velocidade a fim de selecionar a melhor RNA dentre as quatro candidatas, de cada método de implementação, definidas nos testes computacionais. No segundo momento são apresentados os resultados obtidos com o estimador neural selecionado nas duas estratégias de controle realimentado com a velocidade estimada.

\subsection{A Bancada Experimental e Seleção das RNAs por Testes Experimentais}

Neste trabalho a experimentação prática visa confrontar os resultados obtidos via simulação de um modelo matemático com a dinâmica do sistema físico. Nesse propósito, essa seção é dedicada a descrição dos principais componentes do laboratório de ensaios envolvidos no processo de aquisição de dados experimentais.

A Figura 37 mostra a bancada de ensaios usada nos testes, a qual é composta de uma máquina de corrente contínua com um tacogerador acoplado mecanicamente ao motor de indução por um torquímetro girante. A máquina de corrente contínua é configurada como gerador, com o objetivo de impor torque de carga no eixo do MI.

A aquisição de dados é realizado pelo NI USB-6009 da National Instruments, que adquire sinais do tacogerador, do sensor de torque mecânico, da velocidade síncrona e estimada provida pelo DSP via conversor Digital para Analógico (D/A). Os dados adquiridos são formatados para representação gráfica e avaliação da performance do estimador com o uso do software Matlab.

Com o objetivo de se obter um estimador neural de velocidade genérico para o MI acionado pelo CDC e CDT, os dois métodos de implementação das RNAs selecionadas com os dados de simulação são primeiramente avaliados como observador de velocidade. Posteriormente, a RNA que obtém a melhor performance nas duas estratégias de controle 
é selecionada como o estimador neural de velocidade do MI, sendo essa RNA avaliada posteriormente como fonte do sinal de velocidade na realimentação da malha de controle de velocidade. A Figura 38 mostra o diagrama em blocos do método de testes das RNAs.

Os testes são conduzidos com o inversor fonte de tensão com frequência de chaveamento de $10 \mathrm{kHz}$.

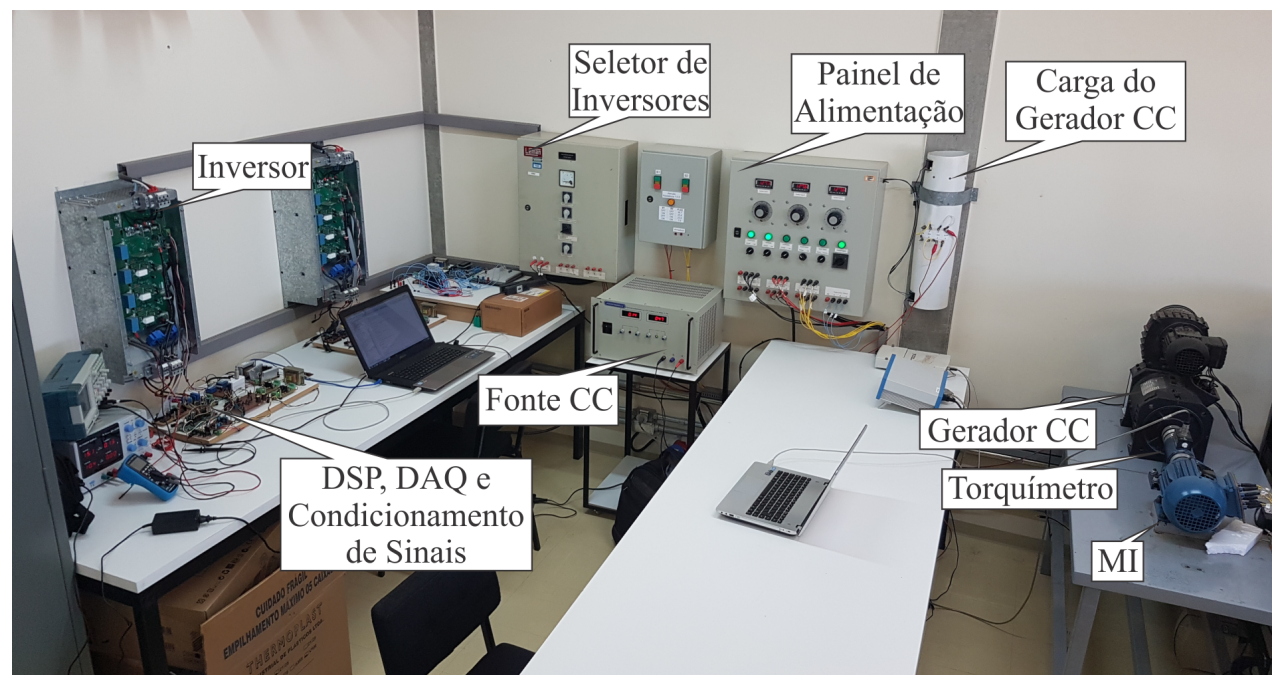

Figura 37 - Estrutura da bancada de testes de máquinas elétricas.

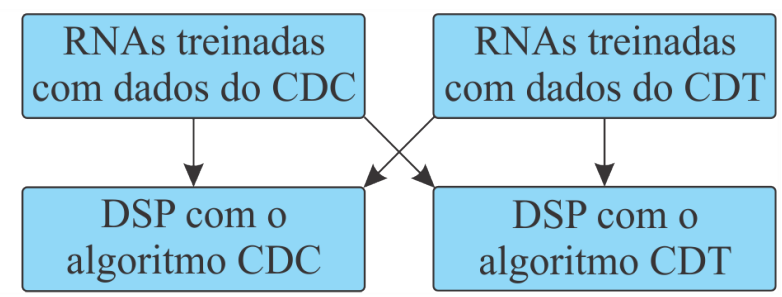

Figura 38 - Método de testes das RNAs em bancada experimental.

Este processo visa selecionar o estimador neural de velocidade de melhor capacidade de generalização de respostas. Assim, as RNAs treinadas com dados oriundos das simulações do MI-1 acionado pelo CDC, bem como pelo CDT, são testadas como observador de velocidade em ambas as estratégias de controle com o MI-2. O procedimento é executado em ambos os métodos de implementação da RNA.

\subsubsection{Seleção da RNA nos CDC e CDT na estratégia de imple- mentação $A$}

Os testes são conduzidos em três níveis diferentes de velocidade, $7 \mathrm{rad} / \mathrm{s}, 90 \mathrm{rad} / \mathrm{s}$ e $180 \mathrm{rad} / \mathrm{s}$, onde as RNAs são usadas como observadores. As entradas das RNAs avaliadas na estratégia $A$ são $\omega_{e}, i_{d}$ e $i_{q}$. A Tabela 4.1 mostra os resultados de ERM obtidos de cada uma das RNAs candidatas nos testes experimentais executados. É possível observar na referida tabela que a RNA A8 obteve o menor ERM na maioria dos testes executados. 
Entretanto, de forma geral, observa-se que os resultados dos testes mostram que as RNAs têm seus desempenhos reduzidos em baixa rotação, como o teste com o MI acionado a 7 $\mathrm{rad} / \mathrm{s}$, onde o ERM obtido pela RNA A8 é de 17,641\% no CDC e 16,415\% no CDT.

Tabela 4.1 - Desempenho das RNAs como observador de velocidade nos testes experimentais implementadas com a estratégia $A$.

\begin{tabular}{c|c|c}
\hline & ERM (\%) no CDC & ERM (\%) no CDT \\
\hline$\omega_{m e c}{ }^{*}=7 \mathrm{rad} / \mathrm{s}$ & \multicolumn{2}{|c}{ RNAs treinada com dados do CDC } \\
\hline RNA A2 $-4^{\mathrm{a}}$ ordem & 19,498 & 22,698 \\
\hline RNA A4 $-5^{\mathrm{a}}$ ordem & 21,608 & 20,724 \\
\hline & \multicolumn{2}{|c}{ RNAs treinada com dados do CDT } \\
\hline RNA A5 $-4^{\mathrm{a}}$ ordem & 18,276 & 18,976 \\
\hline RNA A8 $-5^{\mathrm{a}}$ ordem & 17,641 & 16,415 \\
\hline$\omega_{\text {mec }}{ }^{*}=90$ rad/s & RNAs treinada com dados do CDC \\
\hline RNA A2 $-4^{\mathrm{a}}$ ordem & 1,819 & 2,295 \\
\hline RNA A4 $-5^{\mathrm{a}}$ ordem & 1,866 & 2,265 \\
\hline & RNAs treinada com dados do CDT \\
\hline RNA A5 $-4^{\mathrm{a}}$ ordem & 1,801 & 2,328 \\
\hline RNA A8 $-5^{\mathrm{a}}$ ordem & 1,713 & 2,326 \\
\hline$\omega_{\text {mec }}{ }^{*}=180$ rad $/ \mathrm{s}$ & RNAs treinada com dados do CDC \\
\hline RNA A2 $-4^{\mathrm{a}}$ ordem & 1,036 & 1,378 \\
\hline RNA A4 $-5^{\mathrm{a}}$ ordem & 1,021 & 1,415 \\
\hline & \multicolumn{2}{|c|}{ RNAs treinada com dados do CDT } \\
\hline RNA A5 $-4^{\mathrm{a}}$ ordem & 1,016 & 1,590 \\
\hline RNA A8 $-5^{\mathrm{a}}$ ordem & 1,014 & 1,571 \\
\hline
\end{tabular}

Em médias e altas velocidades o desempenho melhora significativamente. Nos testes a $90 \mathrm{rad} / \mathrm{s}$, a RNA A8 obteve ERM de 1,713\% e 2,326\% no CDC e no CDT, respectivamente. A Figura 39 mostra a resposta do estimador neural de velocidade como observador com o MI acionado pelo CDC com torque nominal a $90 \mathrm{rad} / \mathrm{s}$. Pode-se notar que há alguns picos na velocidade estimada durante o período de estabelecimento do fluxo magnético. Uma vez estabelecido o fluxo nominal, a malha de velocidade é ativada para alcançar a velocidade de referência. As dinâmicas do torque eletromagnético e mecânico, bem como a velocidade síncrona são mostradas na Figura 40, onde no instante 56 ms é possível observar o momento em que a malha de controle de velocidade é acionada. O torque eletromagnético é calculado pela equação (27), usando o fluxo eletromagnético estimado, como mostrado na Figura 24. A velocidade estimada pela RNA A8 e medida no eixo do MI-2 no acionamento CDT a $90 \mathrm{rad} / \mathrm{s}$ é mostrada na Figura 41, enquanto as respostas dinâmicas dos torques mecânicos e eletromagnético e da velocidade síncrona são mostradas nas Figuras 42. O tempo necessário para o estabelecimento do fluxo foi de 56 ms no acionamento CDC e de $4 \mathrm{~ms}$ no CDT. O tempo de aceleração do MI no acionamento CDT também foi menor devido ao maior torque eletromagnético em relação ao CDC, uma vez que neste último há limitação da corrente $i_{q s}$. 


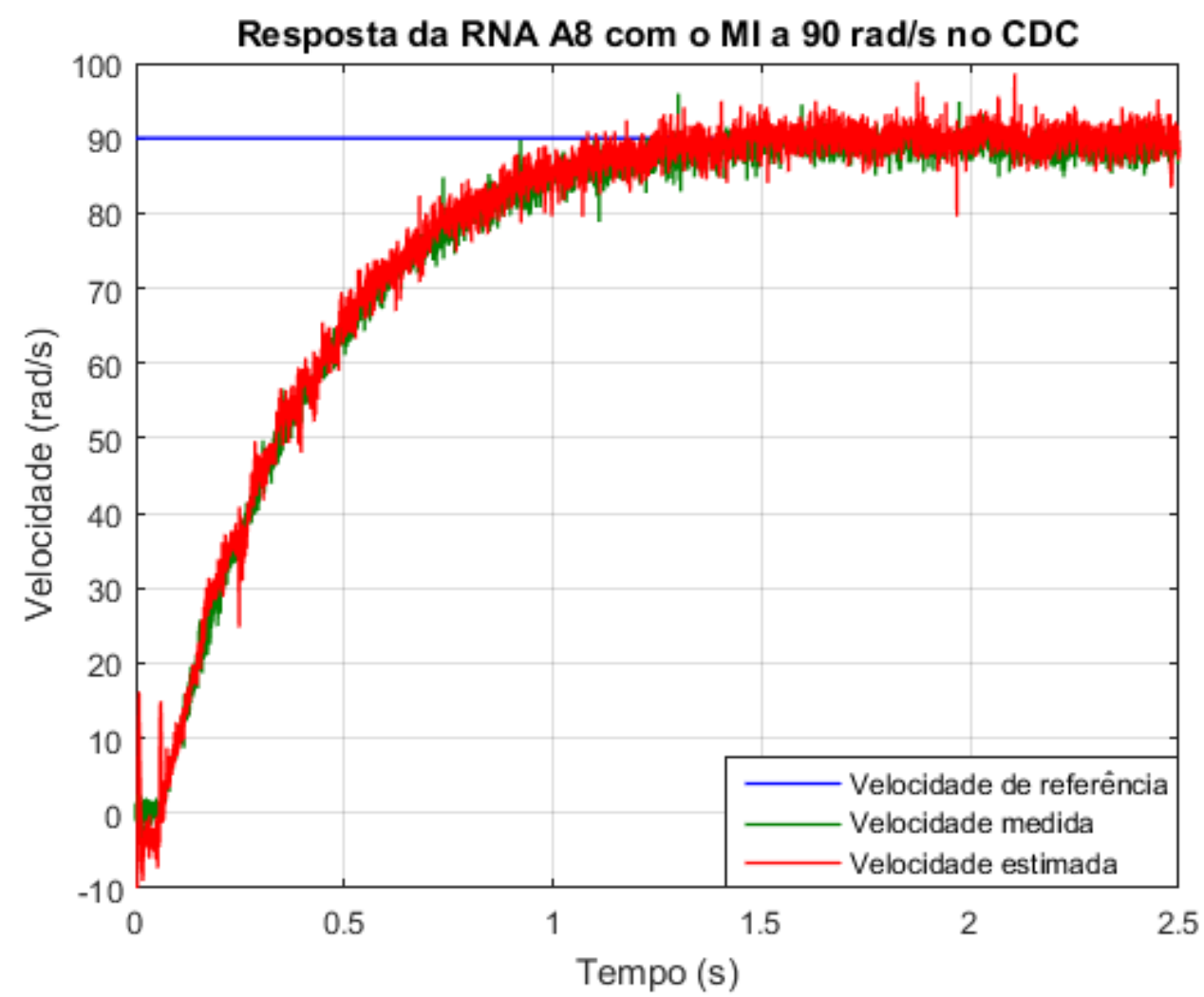

Figura 39 - Resposta da RNA A8 como observador de velocidade com o MI acionado pelo CDC a $90 \mathrm{rad} / \mathrm{s}$.
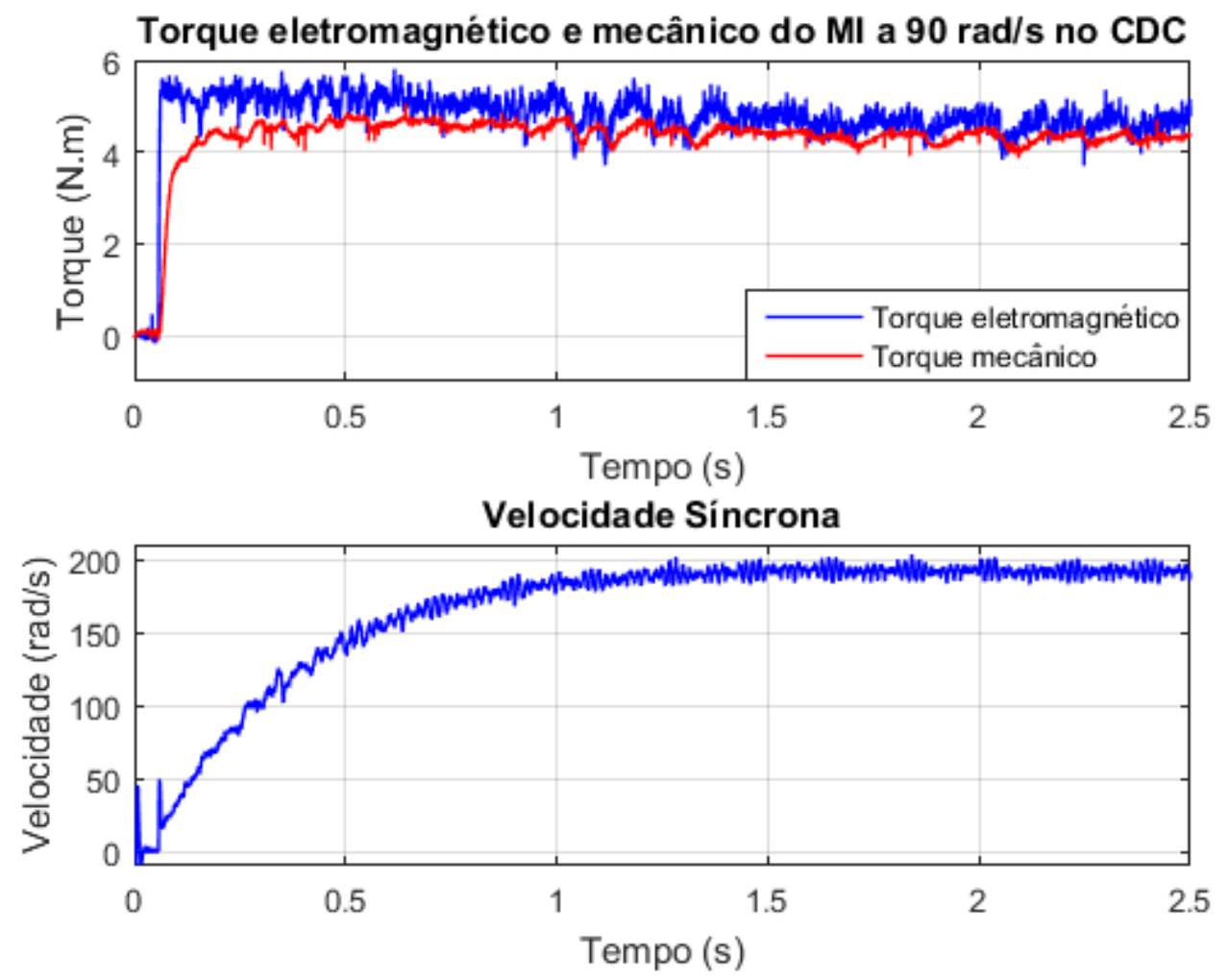

Figura 40 - Dinâmica do torque eletromagnético, mecânico e da velocidade síncrona do MI a 90 rad/s no CDC. 


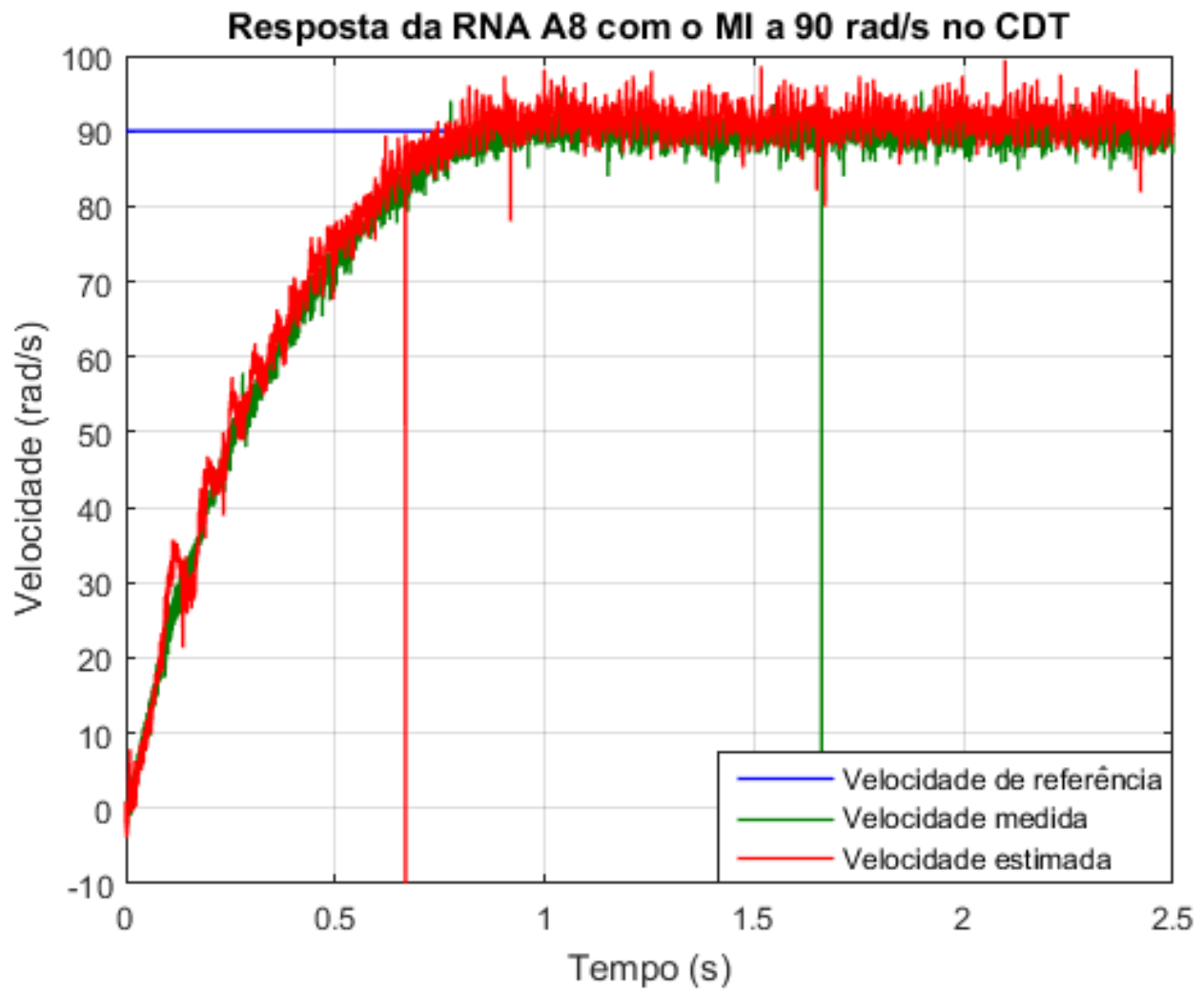

Figura 41 - Resposta da RNA A8 como observador de velocidade com o MI acionado pelo CDT a $90 \mathrm{rad} / \mathrm{s}$.
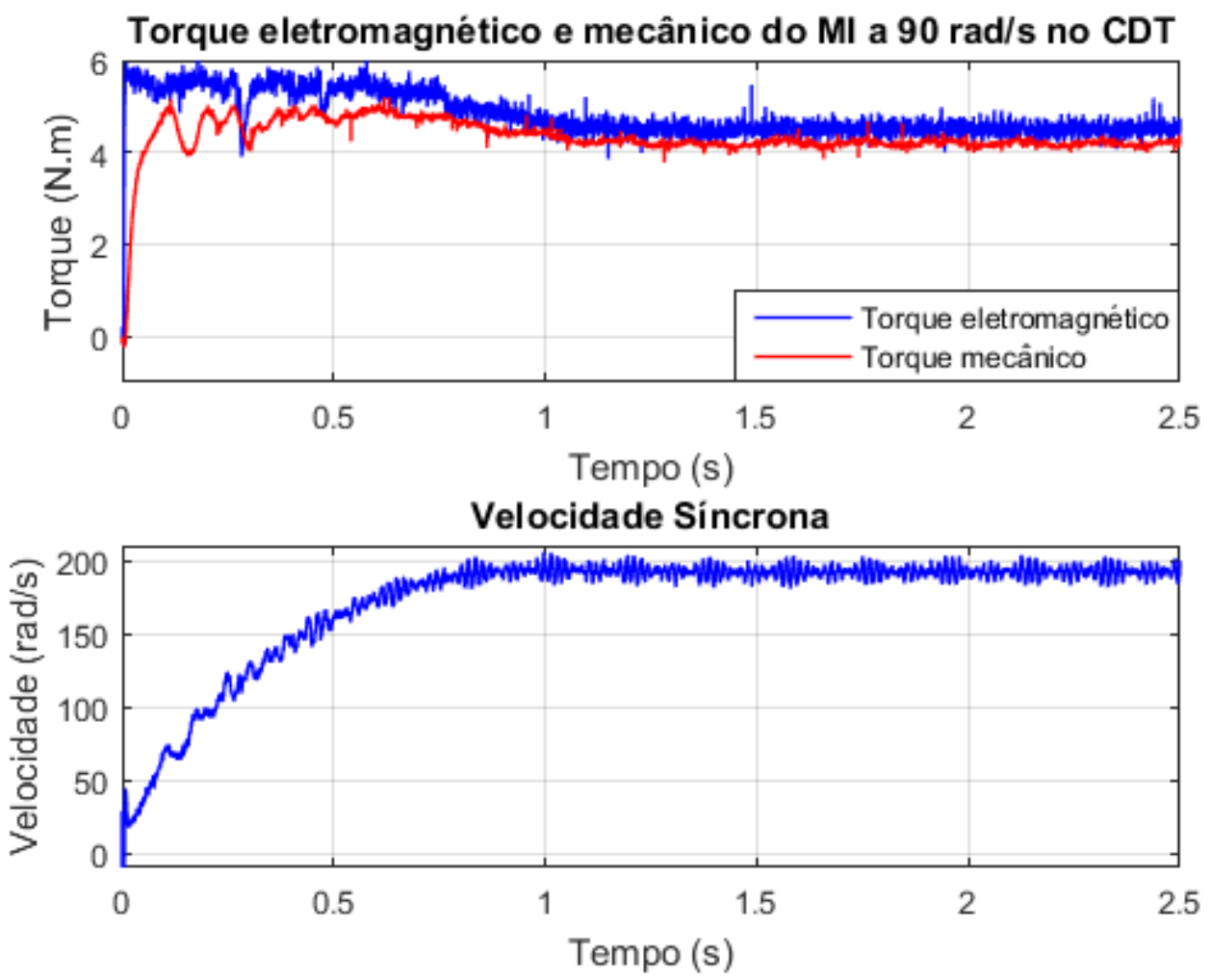

Figura 42 - Dinâmica do torque eletromagnético, mecânico e da velocidade síncrona do MI a 90 rad/s no CDT. 


\subsubsection{Seleção da RNA nos CDC e CDT na estratégia de imple- mentação $B$}

A estratégia de implementação $B$ tem por objetivo testar um segundo conjunto de entradas para o estimador neural de velocidade. Neste caso, as entradas das RNAs testadas como observadores de velocidade são $\omega_{e}$ e $T_{e}$. Assim, os testes são conduzidos nos mesmos níveis de velocidade da estratégia de implementação $A$ e os resultados são mostrados na Tabela 4.2. O estimador de velocidade de melhor desempenho como observador nos testes experimentais foi a RNA B3. Os piores resultados foram obtidos em baixa velocidade, onde em $7 \mathrm{rad} / \mathrm{s}$ o ERM obtido pela RNA B3 foi de 21,004\% (1,47 rad/s) no CDC e 20,808\% (1,45 rad/s) no CDT. Os resultados da RNA B3 a $7 \mathrm{rad} / \mathrm{s}$ no CDC, bem como no CDT, são apresentados na Figura 43. O nível de ruído originado pelo chaveamento do inversor fonte de tensão tem seu nível acentuado nestes testes, mas é possível identificar os picos da velocidade estimada durante o período de estabelecimento do fluxo de referência em ambas as estratégias de controle. Nos testes efetuados com o MI-2 a 90rad/s, bem como a $180 \mathrm{rad} / \mathrm{s}$ o ERM é significativamente menor, assim como é observado na estratégia de implementação $A$.

Tabela 4.2 - Desempenho das RNAs como observador de velocidade nos testes experimentais implementadas com a estratégia $B$.

\begin{tabular}{|c|c|c|}
\hline & ERM (\%) no CDC & ERM $(\%)$ no CDT \\
\hline$\omega_{m e c}{ }^{*}=7 \mathrm{rad} / \mathrm{s}$ & \multicolumn{2}{|c|}{ RNAs treinada com dados do CDC } \\
\hline RNA B2 - 4a ordem & 19,846 & 22,064 \\
\hline \multirow[t]{2}{*}{ RNA B3 - 5a ordem } & 21,004 & 20,808 \\
\hline & \multicolumn{2}{|c|}{ RNAs treinada com dados do CDT } \\
\hline RNA B6 - 4a ordem & 22,584 & 20,973 \\
\hline RNA B8 - 5a ordem & 23,429 & 23,027 \\
\hline$\omega_{m e c}{ }^{*}=90 \mathrm{rad} / \mathrm{s}$ & \multicolumn{2}{|c|}{ RNAs treinada com dados do CDC } \\
\hline RNA B2 - 4a ordem & 2,519 & 2,559 \\
\hline \multirow[t]{2}{*}{ RNA B3 - 5a ordem } & 2,354 & 2,198 \\
\hline & \multicolumn{2}{|c|}{ RNAs treinada com dados do CDT } \\
\hline RNA B6 - 4a ordem & 3,470 & 3,258 \\
\hline RNA B8 - 5a ordem & 2,384 & 2,332 \\
\hline$\omega_{m e c}{ }^{*}=180 \mathrm{rad} / \mathrm{s}$ & \multicolumn{2}{|c|}{ RNAs treinada com dados do CDC } \\
\hline RNA B2 - 4a ordem & 1,145 & 1,144 \\
\hline \multirow[t]{2}{*}{ RNA B3 - 5a ordem } & 1,033 & 1,101 \\
\hline & \multicolumn{2}{|c|}{ RNAs treinada com dados do CDT } \\
\hline RNA B6 - 4a ordem & 1,452 & 1,399 \\
\hline RNA B8 - 5a ordem & 1,238 & 1,236 \\
\hline
\end{tabular}

Algumas observações podem ser inferidas analisando a Tabela 4.1 e a Tabela 4.2; a saber: o ERM do estimador neural de velocidade treinado e implementado pelo método $A$ tem melhor desempenho do que o método $B$, quando o MI é acionado a $7 \mathrm{rad} / \mathrm{s}$ em ambas as estratégias de controle. Nos testes feitos com o MI-2 à $90 \mathrm{rad} / \mathrm{s}$ os dois 

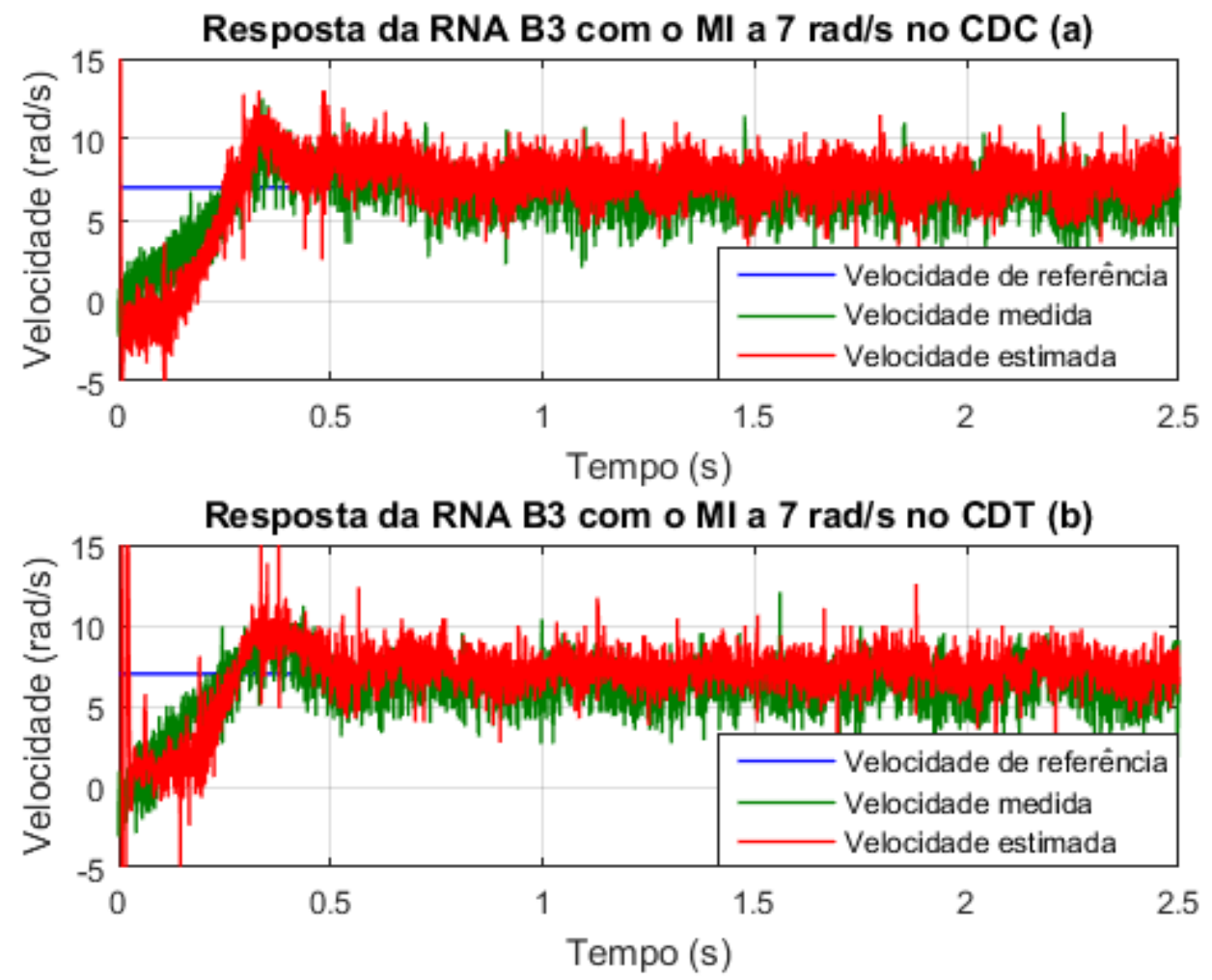

Figura 43 - Resposta da RNA B3 como observador de velocidade com o MI a $7 \mathrm{rad} / \mathrm{s}$, (a) acionado pelo CDC e (b) acionado pelo CDT.

métodos de implementação têm desempenho similar no CDT, embora o método $A$ tem melhor desempenho no CDC. Quando os testes são executados com o MI-2 a $180 \mathrm{rad} / \mathrm{s}$ a estratégia $B$ teve desempenho melhor em relação à estratégia $A$ no $\mathrm{CDT}$ e desempenho similar em ambas os métodos de implementação das RNAs no CDC. Assim, as RNAs A8 e B3 são selecionadas para os testes a laço fechado.

\subsubsection{A influência do estimador do fluxo magnético do MI na estimação de velocidade}

Os resultados experimentais mostrados na Tabela 4.1 e Tabela 4.2 demonstram que as metodologias propostas de estimação de velocidade podem ser aplicadas em acionamentos de alto desempenho como o CDC e o CDT. Entretanto, em baixas velocidades $\left(\omega_{m e c} \leq\right.$ $10 \mathrm{rad} / \mathrm{s}$ ), o erro apresentado pode ser significativo em sistemas que necessitam de muita precisão nessa faixa de velocidade.

Neste trabalho não foi avaliado o desempenho do estimador de fluxo do estator frente ao valor real no MI. Assim, o possível erro no estimador de fluxo e consequentemente no torque eletromagnético prejudica o desempenho do estimador em baixas velocidades. A fim de representar a influência do erro do estimador de fluxo na estimativa de velocidade, um teste computacional foi realizado com o MI a $5 \mathrm{rad} / \mathrm{s}$ com o acionamento CDC, onde as componentes do fluxo do estator são analisadas. 
Primeiramente o teste foi conduzido com o CDC usando o fluxo estimado tanto no controle, bem como no cálculo do torque eletromagnético, conforme equações (97) e (98), de onde se obtém a resposta do estimador como mostra a Figura 44. O ERM obtido neste teste é de 7,314\%. As componentes do fluxo estimado e o medido são apresentadas na Figura 45, onde é possível observar o deslocamento de fase e de amplitude.

Quando o fluxo magnético obtido do modelo matemático do MI, conforme as equações (22) e (23), é usado no controle e no cálculo do torque eletromagnético, o ERM obtido é de 1,645\%, com a resposta do estimador de velocidade mostrado na Figura 46.

Estes testes computacionais demostram que o erro do estimador de fluxo interfere no sistema de controle, bem como na obtenção de variáveis usadas como entrada das RNAs.

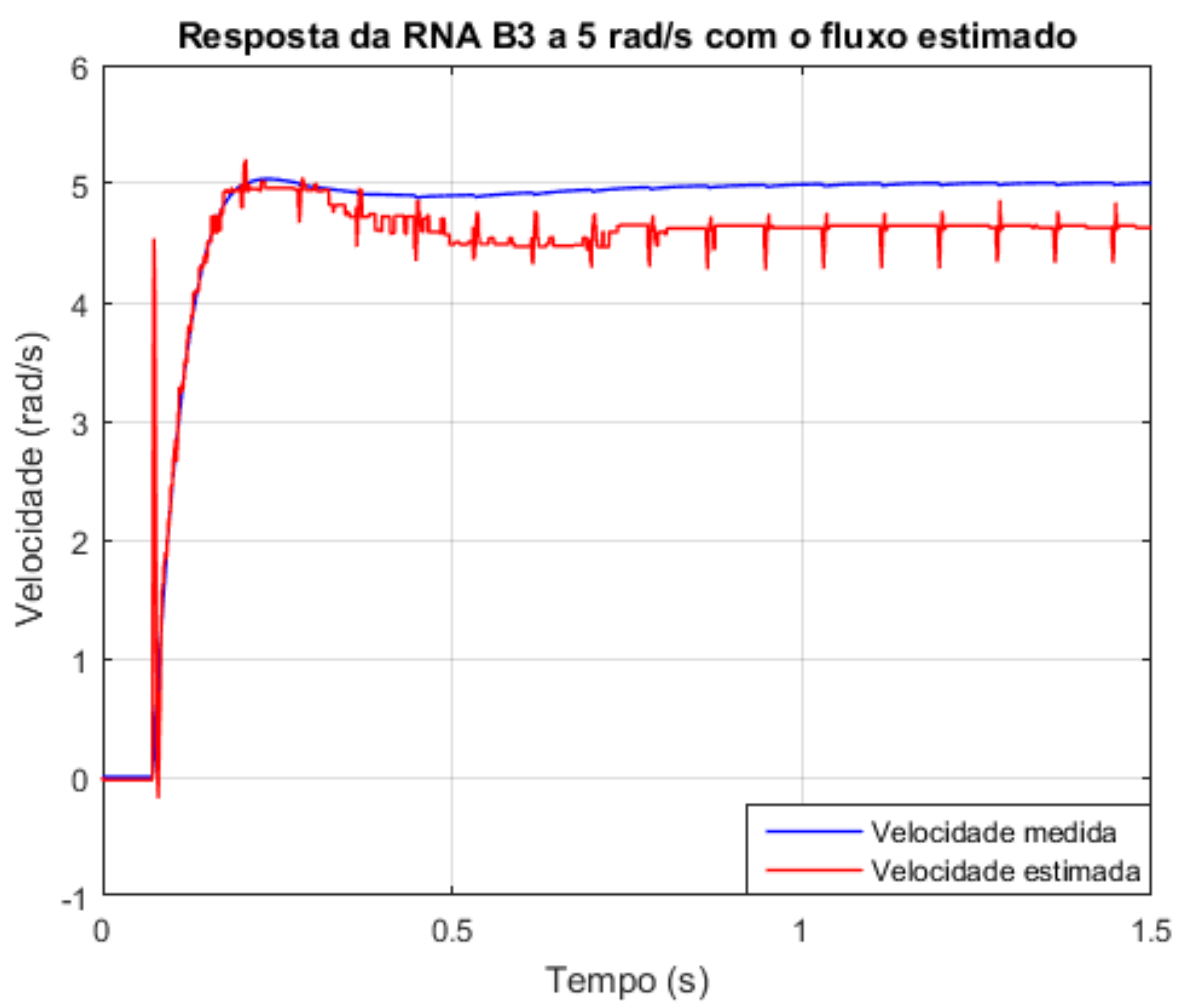

Figura 44 - Resposta da RNA B3 a 5 rad/s usando o fluxo do estator estimado conforme Seção 2.4 com o MI acionado com o CDC. 


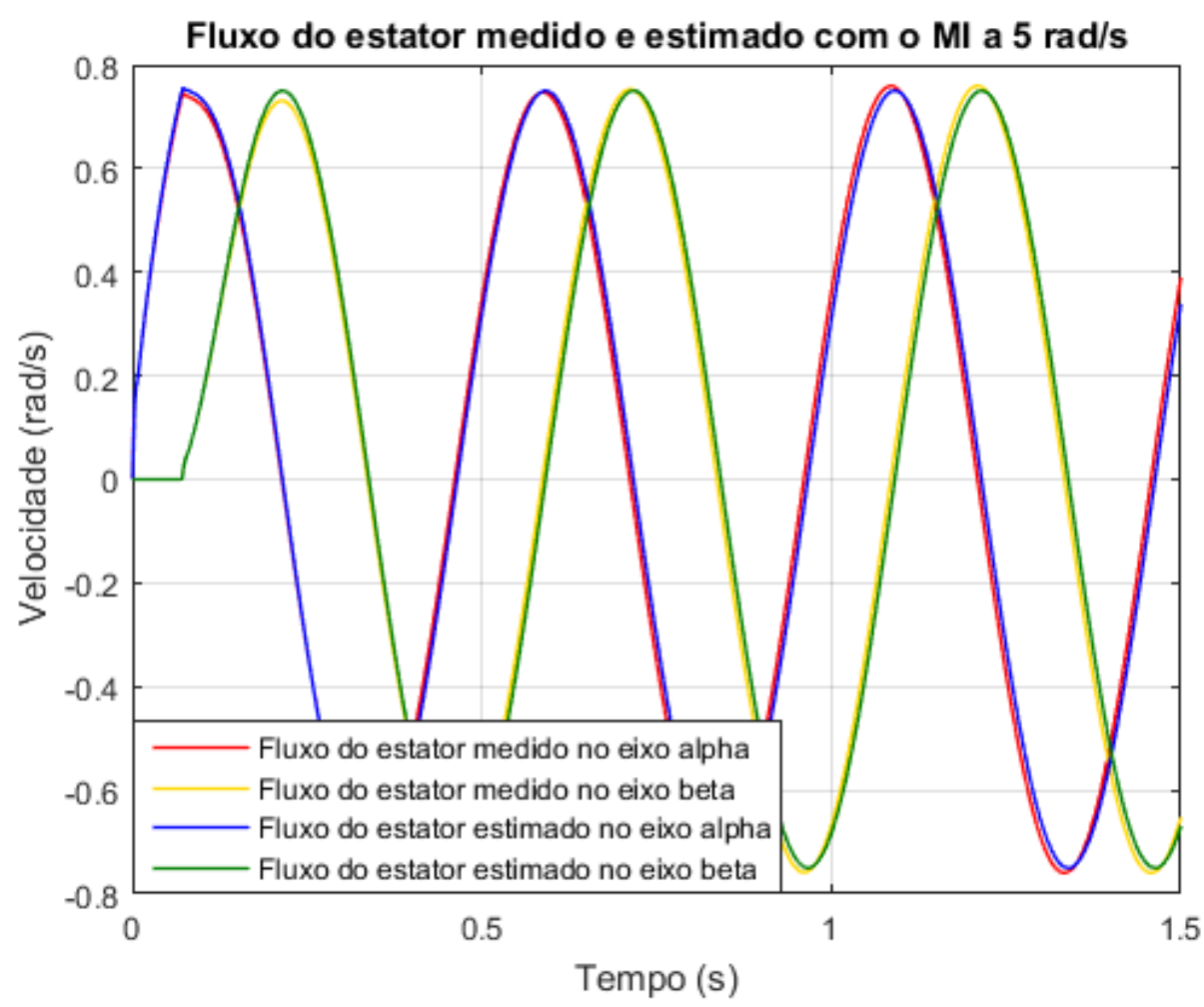

Figura 45 - Fluxo medido e estimado com o MI a $5 \mathrm{rad} / \mathrm{s}$ no CDC.

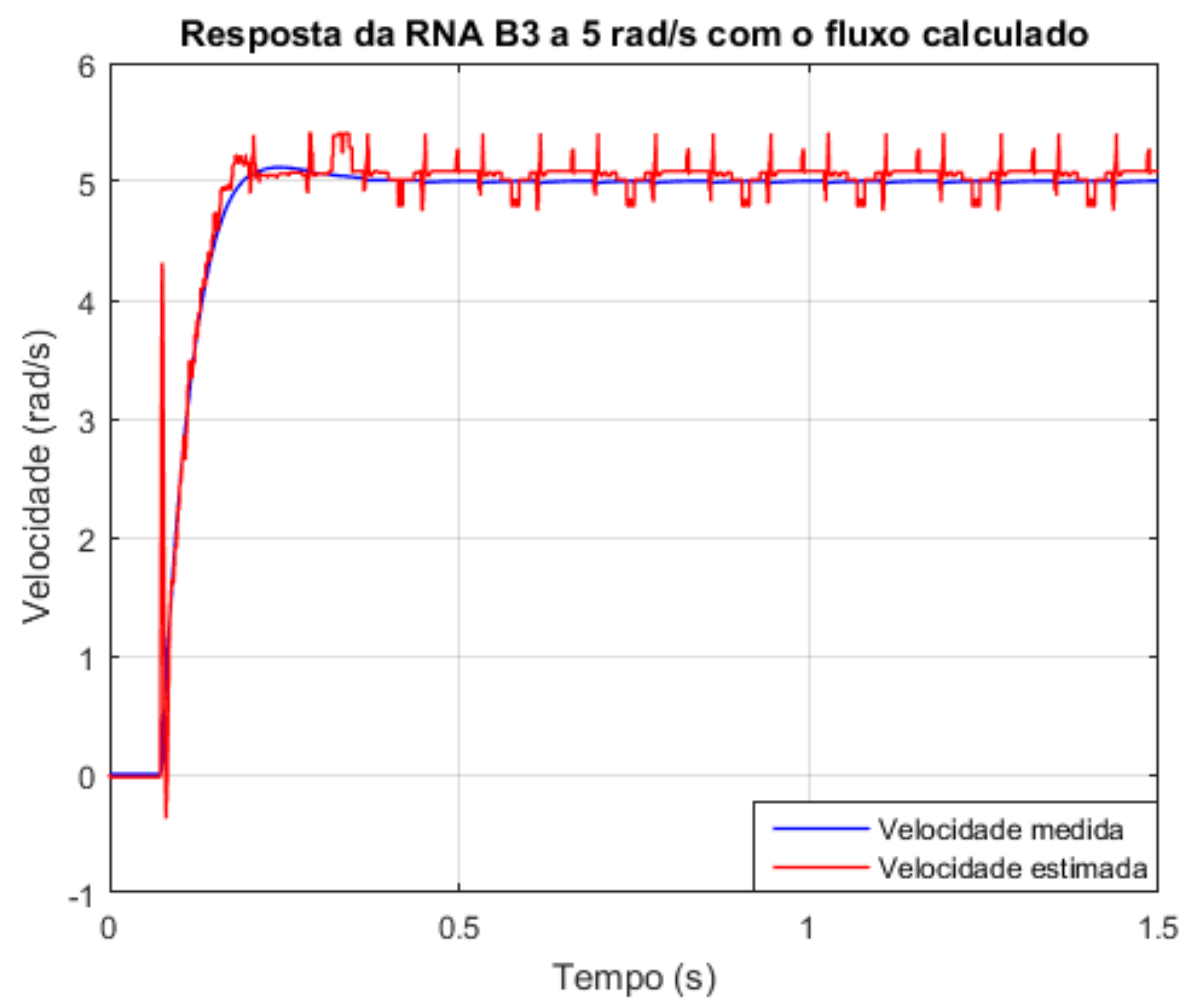

Figura 46 - Resposta da RNA B3 a 5 rad/s usando o fluxo calculado do modelo matemático do MI acionado com o CDC. 


\subsection{Testes Experimentais com as RNAs Seleciona- das Realimentando o Controle de Velocidade no CDC e CDT}

A velocidade do motor de indução pode ser aplicada na medição indireta de importantes variáveis no setor industrial, como exemplo, a vazão em máquinas de bombeamento de fluídos e volume de produção. Entretanto, no acionamento do MI esta variável é usada na malha de controle, onde a velocidade pode ser obtida por meio de medição, estimação ou predição. Na sequência, as RNAs selecionadas na Seção 4.1.1 e na Seção 4.1.2 têm seus desempenhos avaliados na realimentação do sistema de controle de velocidade no CDC e no CDT.

\subsubsection{Testes experimentais com a RNA A8 realimentando o con- trole de velocidade no CDC e CDT}

Esta seção apresenta os resultados obtidos pelo estimador neural de velocidade implementado com a RNA A8 quando este é o elemento de realimentação das estratégias do CDC e do CDT. Os testes são executados com os motores MI-2 e MI-3 em diversas condições de conjugado de carga mecânica e níveis de velocidade, conforme os Pontos de Operação (P.O.) mostrados na Tabela 4.3.

Tabela 4.3 - Pontos de operação da validação experimental da RNA A8.

\begin{tabular}{c|c|c|c|c|c|c|c}
\hline \multicolumn{2}{c|}{ Testes } & \multicolumn{3}{c|}{$\begin{array}{c}\text { Pontos de Operação } \\
\text { (rad/s) }\end{array}$} & \multicolumn{3}{c}{$\begin{array}{c}\text { Torque de Carga } \\
\text { (N.m) }\end{array}$} \\
\hline CDC MI-2 & CDT MI-2 & P.O.1 & P.O.2 & P.O.3 & P.O.1 & P.O.2 & P.O.3 \\
\hline 1 & 6 & 8 & - & - & 1,0 & - & - \\
\hline 2 & 7 & 55 & - & - & 4,1 & - & - \\
\hline 3 & 8 & 7 & 75 & 155 & 0,3 & 2,4 & 4,0 \\
\hline 4 & 9 & 125 & -125 & - & 3,6 & $-3,6$ & - \\
\hline 5 & 10 & -10 & 45 & - & $-0,6$ & 2,7 & - \\
\hline CDC MI-3 & CDT MI-3 & P.O.1 & P.O.2 & P.O.3 & P.O.1 & P.O.2 & P.O.3 \\
\hline 11 & 16 & 8 & - & - & 1,3 & - & - \\
\hline 12 & 17 & 55 & - & - & 7,35 & - & - \\
\hline 13 & 18 & 7 & 75 & 155 & 0,6 & 4,9 & 8,7 \\
\hline 14 & 19 & 125 & -125 & - & 7,6 & $-8,2$ & - \\
\hline 15 & 20 & -10 & 45 & - & $-1,75$ & 6,0 & - \\
\hline
\end{tabular}

O Teste 1 é realizado com o MI-2 acionado com o CDC a $8 \mathrm{rad} / \mathrm{s}$ com 1 N.m. de conjugado de carga em regime permanente, onde a velocidade medida no eixo da máquina e a estimada pela RNA A8 são mostradas na Figura 47. O estimador é estável durante todo o teste, possibilitando o funcionamento adequado do controlador de velocidade e o erro obtido entre a velocidade estimada e a medida foi de $0,79 \mathrm{rad} / \mathrm{s}$. 


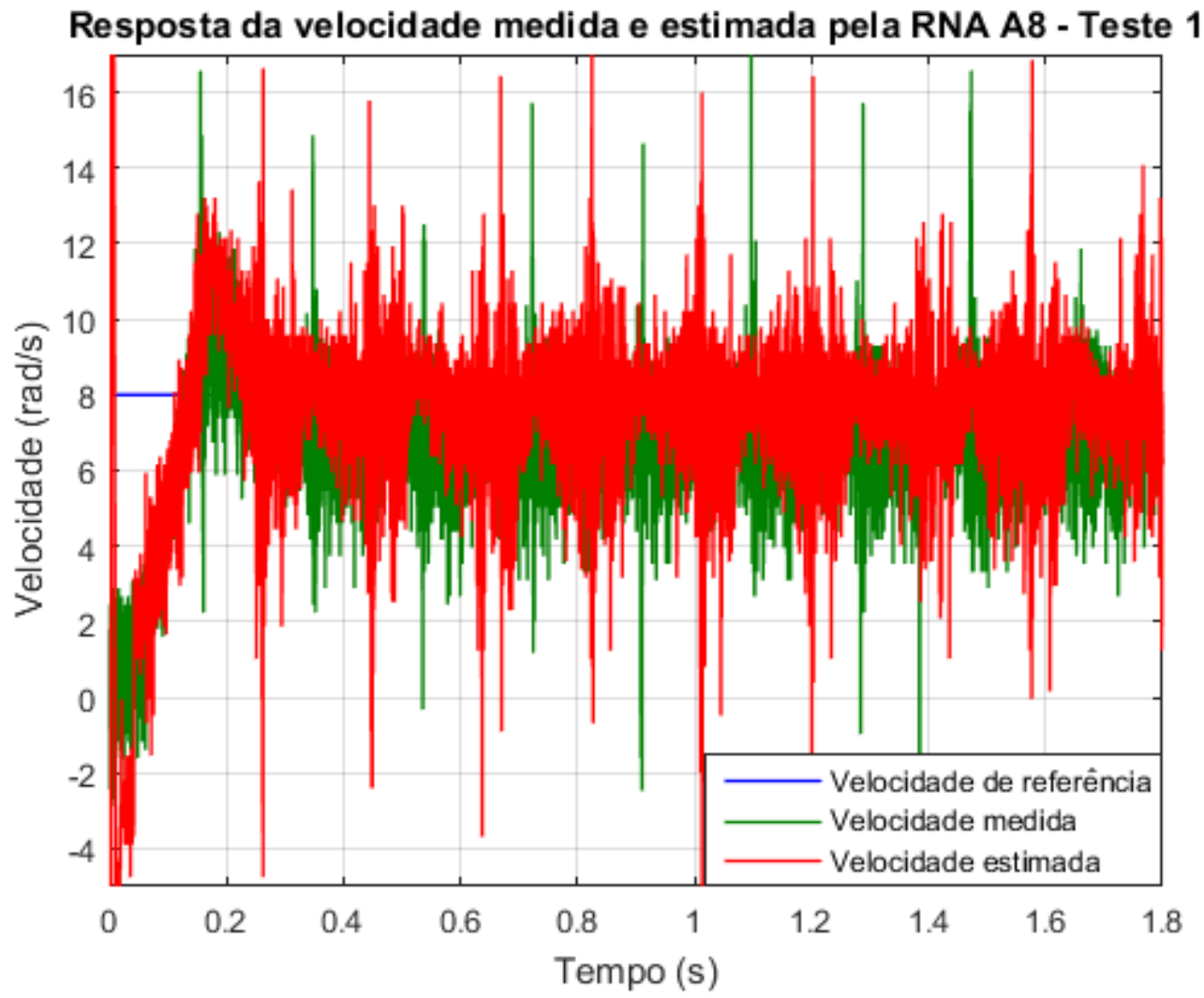

Figura 47 - Resultado da RNA A8 para o teste experimental 1.

O Teste 3 mostra o desempenho da RNA A8 em três níveis diferentes de velocidade. Nesse teste é aplicada uma sequência de degraus de velocidade de $7 \mathrm{rad} / \mathrm{s}, 75 \mathrm{rad} / \mathrm{s}$ e $155 \mathrm{rad} / \mathrm{s}$, fazendo com que o torque de carga seja de 0,3 N.m., 2,4 N.m. e 4,0 N.m., em regime permanente, de acordo com a velocidade aplicada. Os erros de estimativa calculados em regime permanente no Teste 3 em cada nível de velocidade foram de 1,81 $\mathrm{rad} / \mathrm{s}, 0,51 \mathrm{rad} / \mathrm{s}$ e 1,27 rad/s. De forma similar ao observado no Teste 1 , a dinâmica do torque eletromagnético mostrada na Figura 49 durante o primeiro segundo do experimento demonstra que a velocidade estimada é superior à velocidade de referência, como mostra a Figura 49. Ainda neste teste, a velocidade é elevada para $75 \mathrm{rad} / \mathrm{s}$ até $2,5 \mathrm{~s}$ e posteriormente a $155 \mathrm{rad} / \mathrm{s}$. Os picos presentes na velocidade síncrona no instante $0 \mathrm{~s}$ e $1 s$ mostrados na Figura 49 tem suas influências refletidas instantaneamente nos picos na velocidade estimada, como mostra a Figura 48.

Os testes de 1 a 5 mostram que a saída da RNA A8 permanece estável quando esta realimenta a malha de controle de velocidade no CDC com o MI-2. Na sequência, a estratégia de controle é substituída pelo CDT e são conduzidos os testes de 6 a 10. Para efeito de comparação, os gráficos do Teste 6 e do Teste 8 são mostrados nesta seção. 


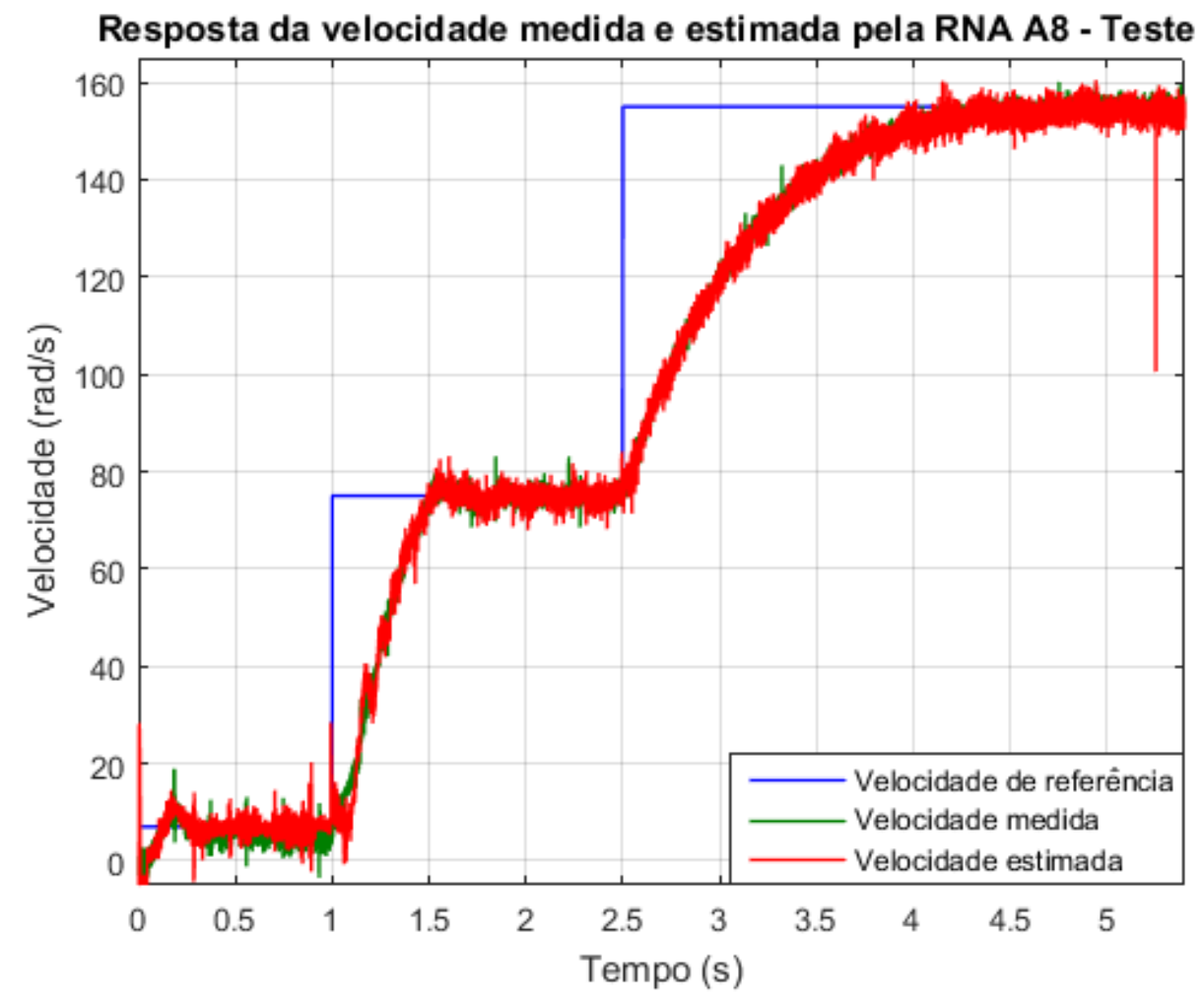

Figura 48 - Resultado da RNA A8 para o teste experimental 3.
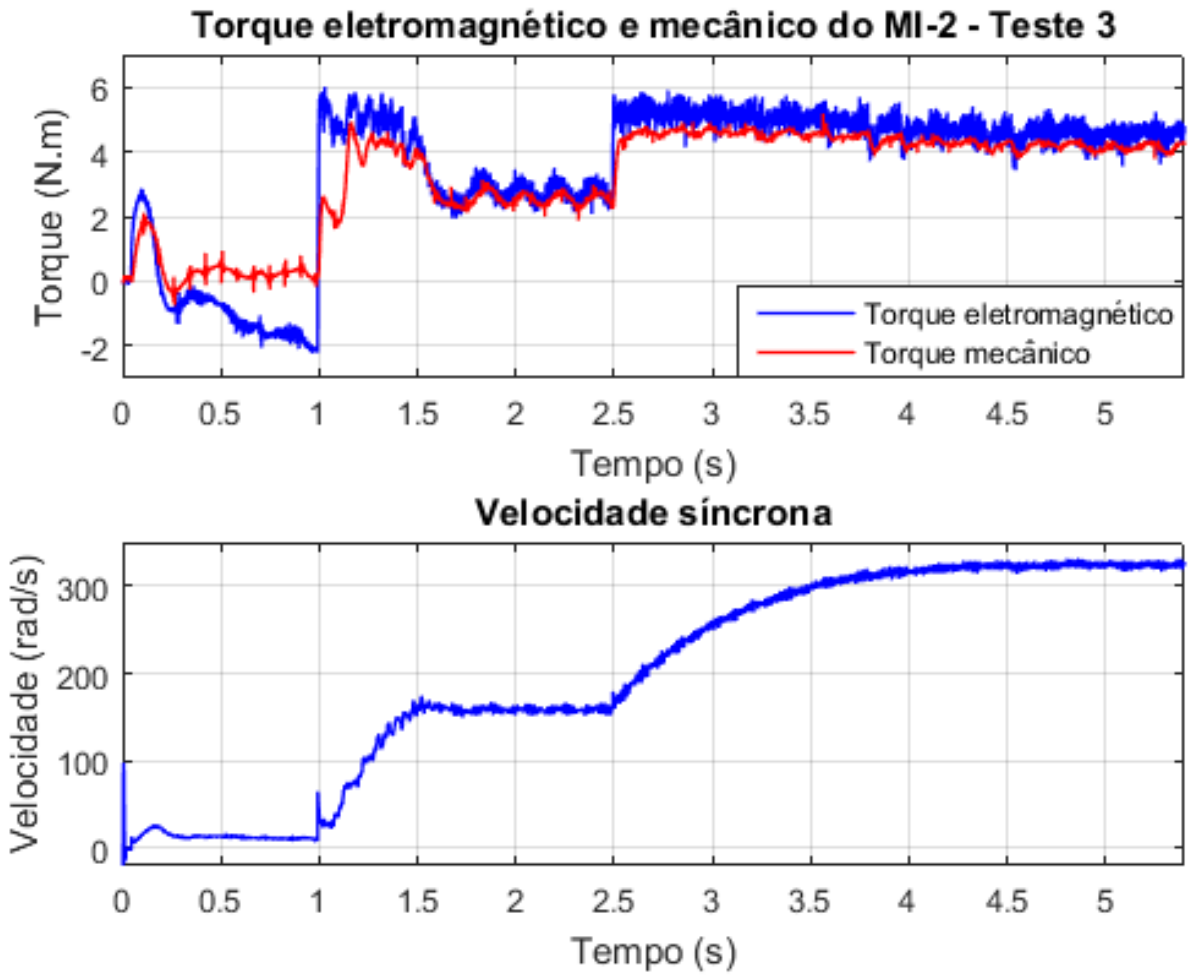

Figura 49 - Dinâmica do torque eletromagnético, mecânico e da velocidade síncrona do MI no teste experimental 3. 
No Teste 6 o MI-2 é novamente acionado a $8 \mathrm{rad} / \mathrm{s}$, onde o erro obtido entre a velocidade estimada e a velocidade medida é de 0,49 rad/s. A Figura 50 mostra os gráficos das velocidades associados ao Teste 6 .

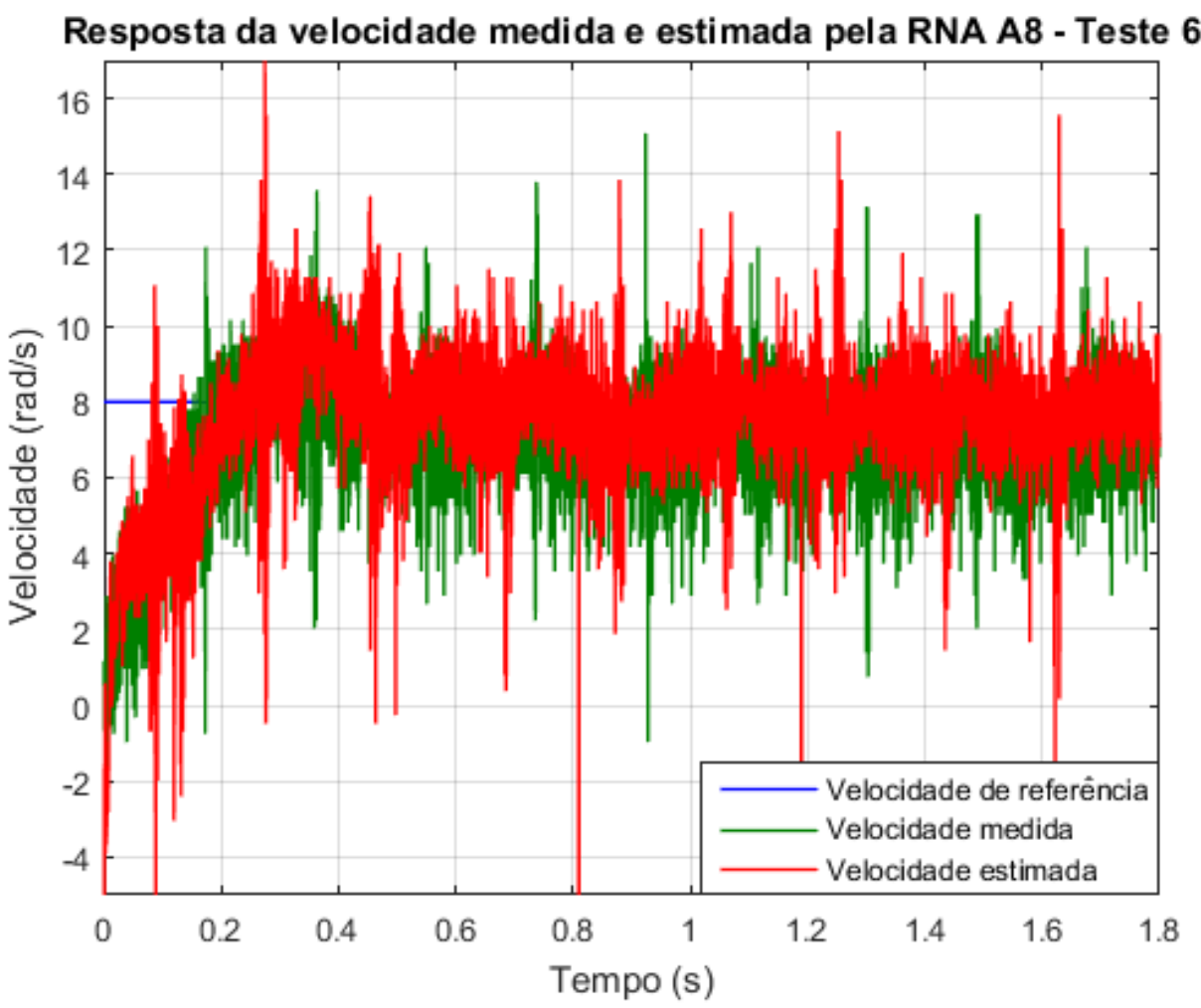

Figura 50 - Resultado da RNA A8 para o teste experimental 6.

Seguindo a mesma metodologia de comparação, a Figura 51 mostra a resposta da RNA A8 para o Teste 8 . Nas velocidades de $7 \mathrm{rad} / \mathrm{s}$ e $75 \mathrm{rad} / \mathrm{s}$ o desempenho dinâmico deste teste é similar ao observado no Teste 3. Entretanto, nota-se um desempenho dinâmico melhor quando o degrau de $155 \mathrm{rad} / \mathrm{s}$ é aplicado no Teste 8 em relação ao observado no Teste 3, onde o MI-2 chega ao regime permanente aos $4 s$ e $5 s$, respectivamente. O erro de estimação da RNA A8 no Teste 8 em regime permanente nos três níveis de velocidades é de 1,05 rad/s, 0,09 rad/s e 0,21 rad/s, na sequência de degraus aplicados. O comportamento dinâmico dos torques eletromagnético e mecânico, bem como o da velocidade síncrona são apresentados na Figura 52. Neste teste, ilustrado pela referida figura, é possível confirmar a similaridade nos Testes 3 e 8 com torque de carga de 0,3 N.m. e 2,4 N.m. bem como desempenho superior do CDT quando o $T_{L}$ aplicado ao eixo da máquina de 4 N.m.

A fim de avaliar a robustez do estimador neural de velocidade implementado com a RNA A8 são realizados testes em uma máquina de maior potência, o MI-3 de 2 CV. Para isso, os parâmetros do MI usados no estimador de fluxo magnético do estator são atualizados para as características do MI-3, conforme a Tabela 3.1. Os ganhos dos controladores PIs de ambas as estratégias de controle também são substituídos, conforme os parâmetros apresentados na Tabela 3.3. Para a implementação da RNA A8 na estimativa de 


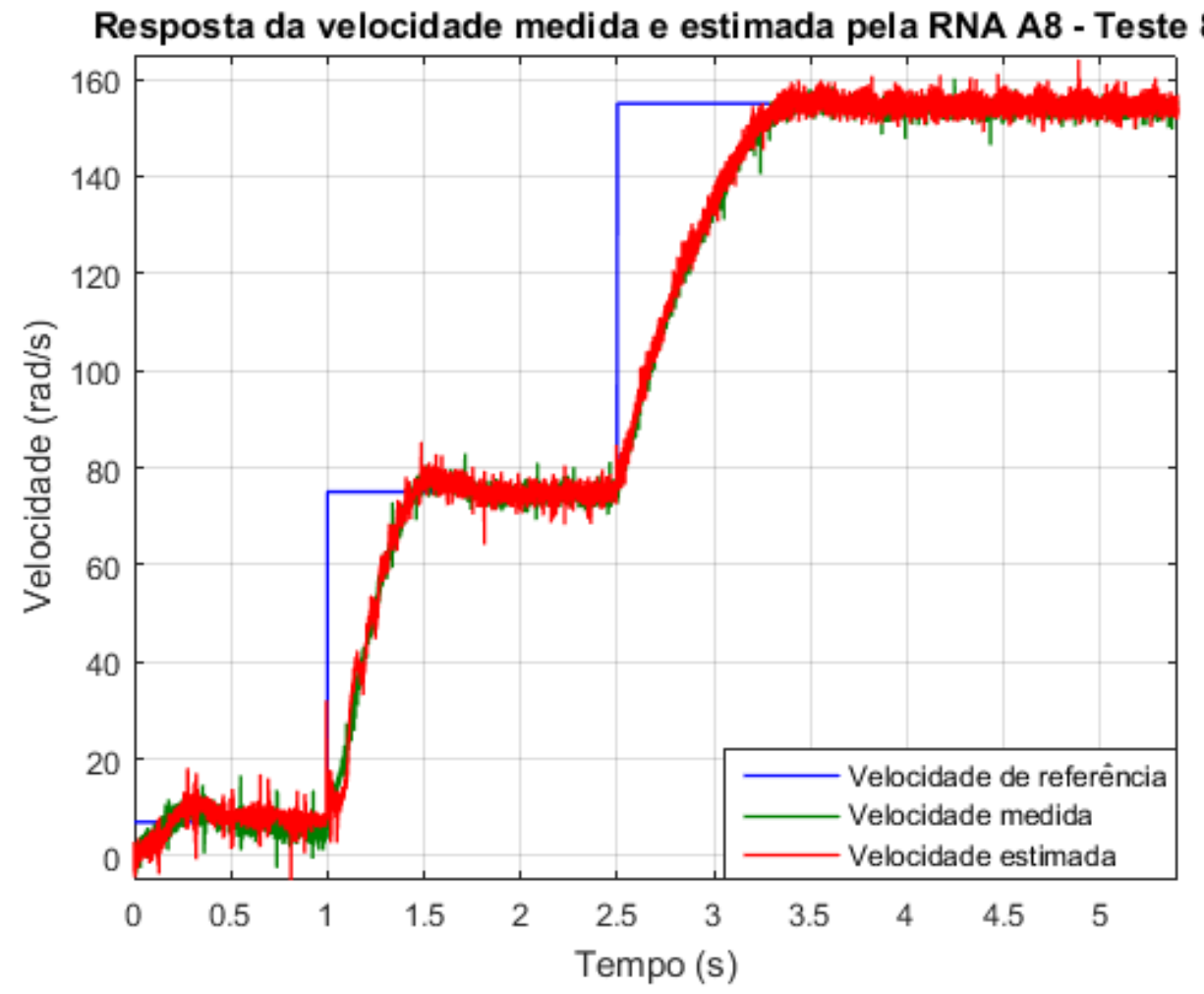

Figura 51 - Resultado da RNA A8 para o teste experimental 8.
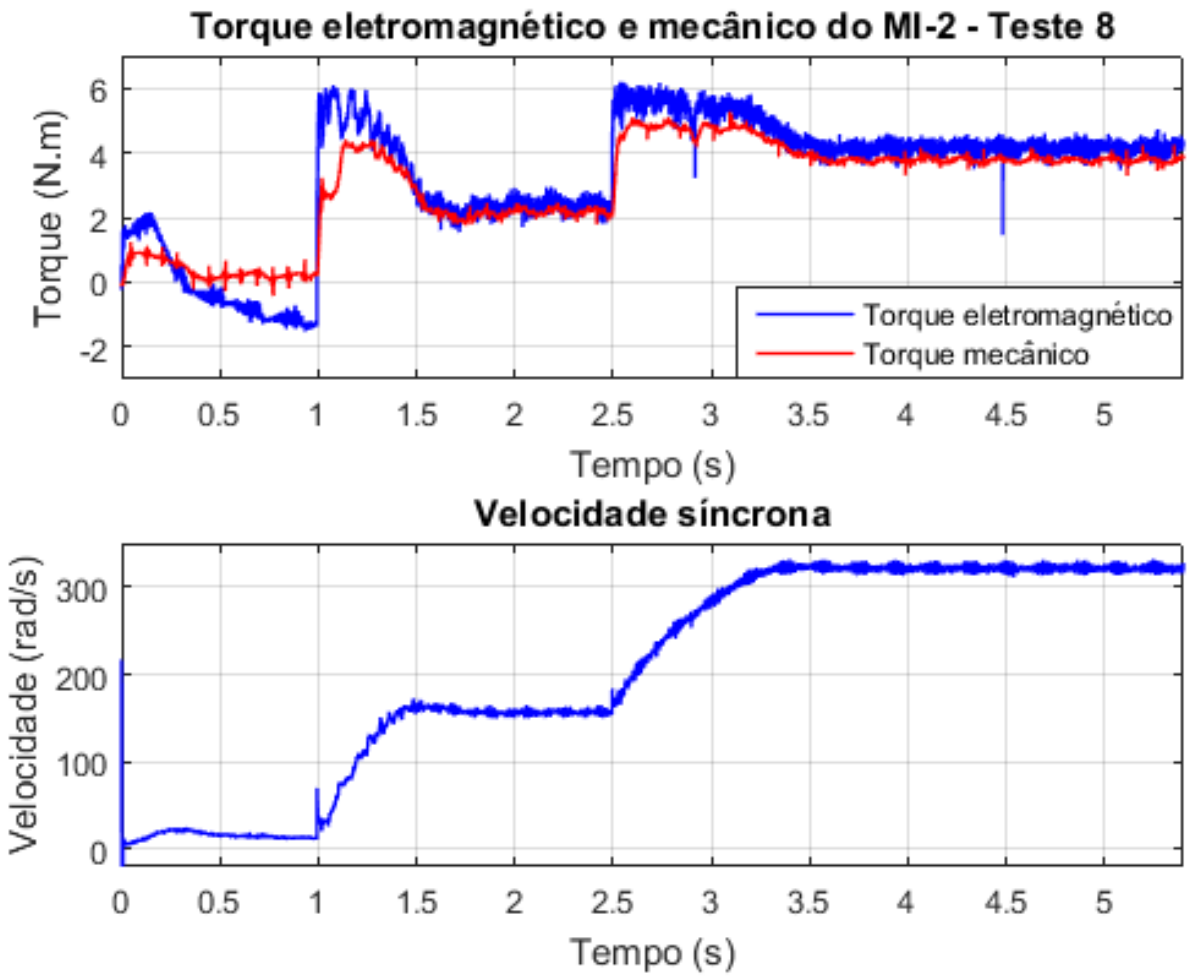

Figura 52 - Dinâmica do torque eletromagnético, mecânico e da velocidade síncrona do MI no teste experimental 8 . 
velocidade do MI-3 somente é necessário alterar os ganhos de normalização das variáveis de entrada da RNA A8. Para a normalização de $\omega_{e}$ utiliza-se $\left(2 \pi f_{m}\right) / z_{p}$, onde $f_{m}$ é a frequência máxima da tensão de alimentação do MI. A normalização das corrente $i_{d}$ e $i_{q}$ utiliza-se os limitadores dos saturadores dos controladores PI de corrente.

A Figura 53 mostra o sinal de saída da RNA A8 frente a velocidade medida no Teste 11, onde o MI-3 é acionado pelo CDC a $8 \mathrm{rad} / \mathrm{s}$. Nesse teste é possível observar menor ondulação da velocidade estimada em relação ao observado no Teste 1 e no Teste 6 . A velocidade estimada nesse teste também apresenta maiores picos durante o estágio de estabelecimento do fluxo magnético nominal no instante $0 \mathrm{~s}$ a $56 \mathrm{~ms}$, em relação aos experimentos realizados com o MI-2. Tal fenômeno é associado aos picos que estão presentes na velocidade síncrona, como mostra a Figura 54 e pode ser desconsiderado, uma vez que a malha de controle de velocidade não está acionada até o estabelecimento do fluxo magnético nominal. Ainda, o erro de velocidade entre o estimador neural e a medida no eixo do MI-3 no Teste 11 de 0,21 rad/s é menor ao obtido com a mesma estratégia de controle no Teste 1. O torque de carga do MI-3 no Teste 11 é de 1,3 N.m., e o seu desenvolvimento dinâmico, bem como o do torque eletromagnético são mostrados na Figura 54.

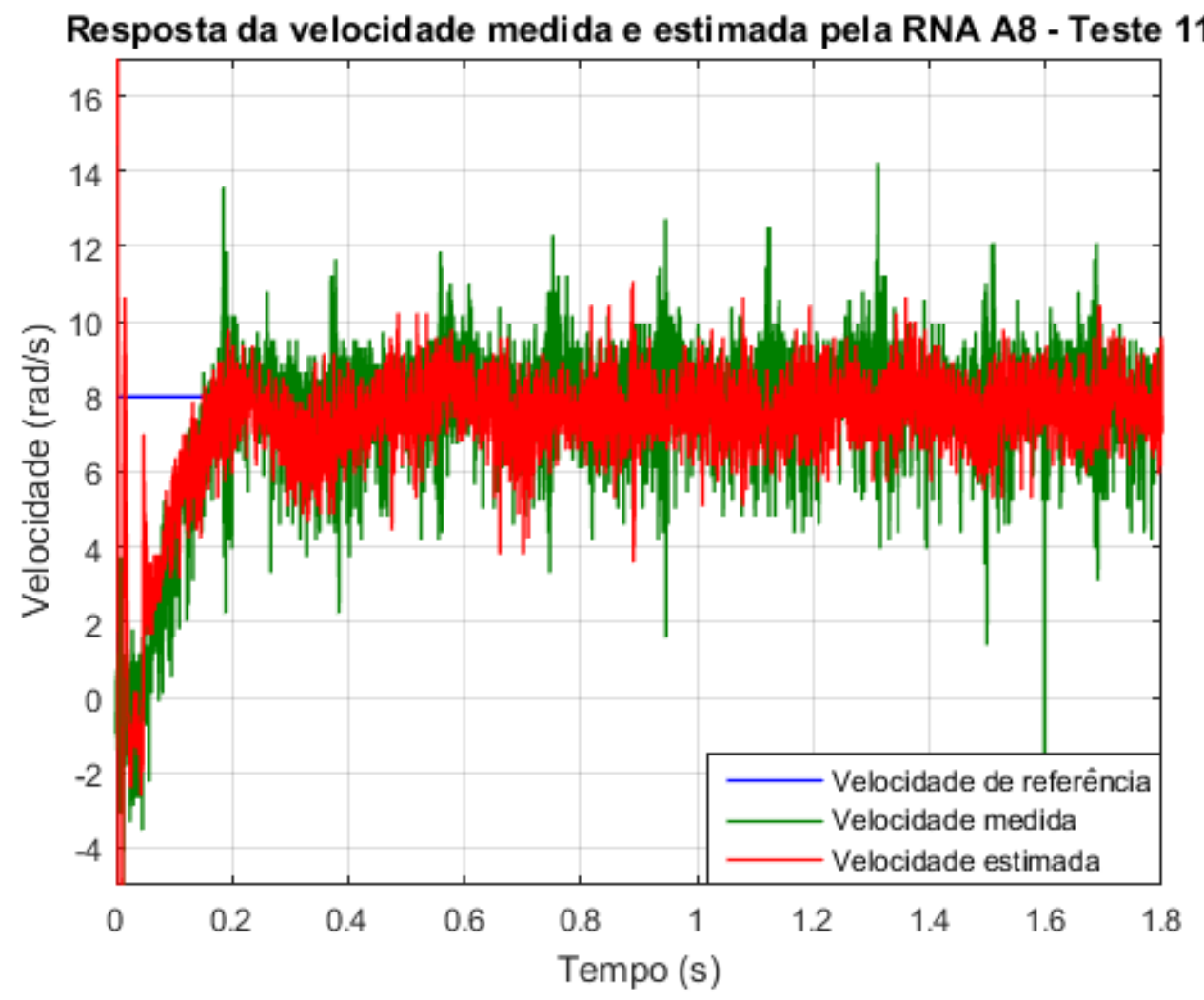

Figura 53 - Resultado da RNA A8 para o teste experimental 11. 

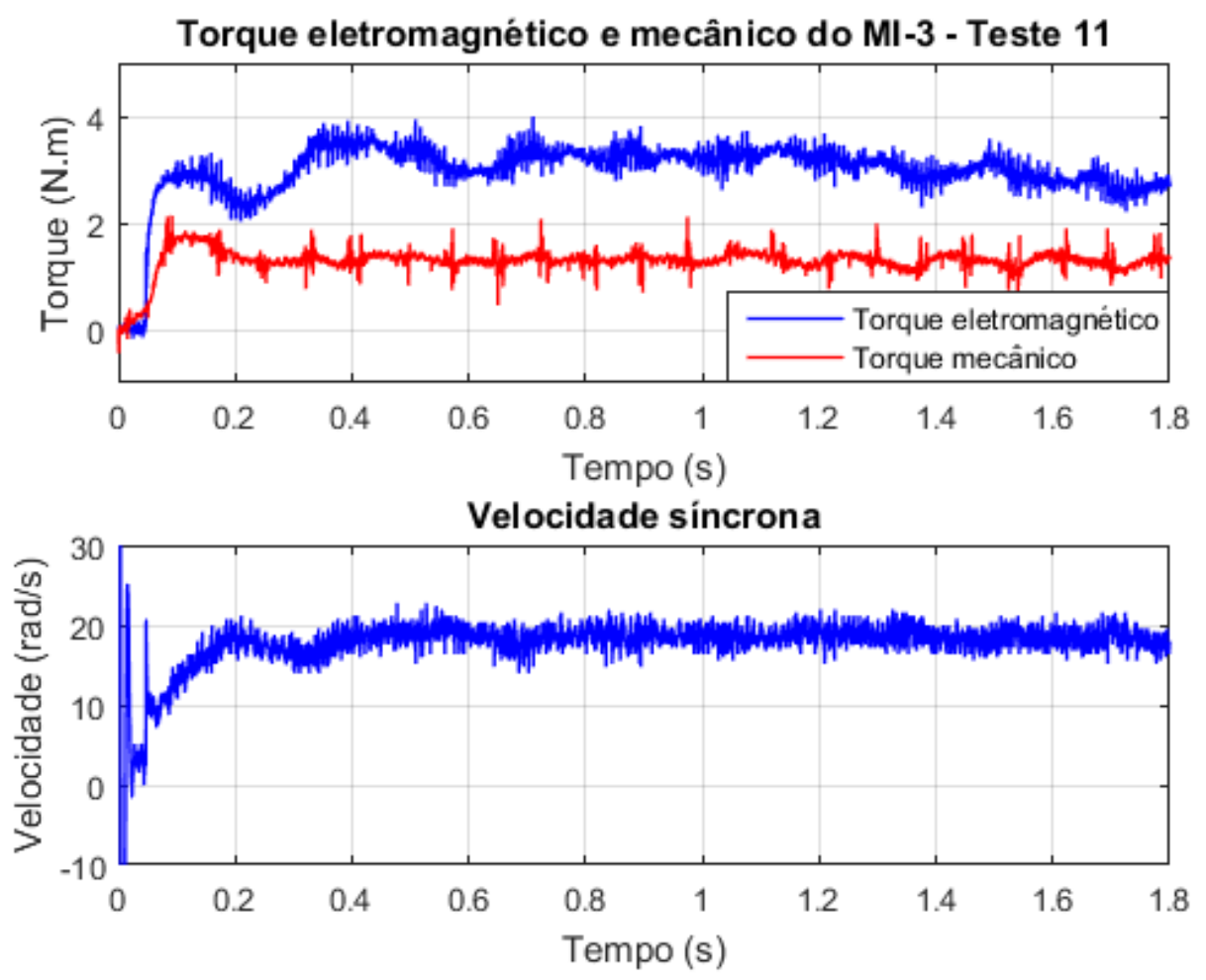

Figura 54 - Dinâmica do torque eletromagnético, mecânico e da velocidade síncrona do MI no teste experimental 11.

O Teste 13, onde o MI-3 é submetido a três degraus sequenciais de velocidade é ilustrado na Figura 55. Esse teste apresentou ruídos na placa de condicionamento de sinais tanto na velocidade medida como na velocidade estimada. Entretanto, esses ruídos externos ao DSP não interferem na estabilidade ou desempenho da malha de controle como mostra a Figura 55. Os erros na estimativa de velocidade nesse teste é de 1,49 $\mathrm{rad} / \mathrm{s}, 0,75 \mathrm{rad} / \mathrm{s}$ e $0,38 \mathrm{rad} / \mathrm{s}$ de acordo com a sequência de velocidade no teste. A Figura 56 mostra o comportamento dinâmico dos torques eletromagnético, mecânico e da velocidade síncrona, onde nesse teste o conjugado de carga sequencialmente foi de 0,6 N.m., 4,9 N.m. e 8,7 N.m.

No Teste 16 a estratégia de acionamento CDC é substituída pelo CDT, com a velocidade de referência em $8 \mathrm{rad} / \mathrm{s}$, obtendo erro de estimativa em regime permanente de 0,35 $\mathrm{rad} / \mathrm{s}$. O menor nível de ondulação da velocidade estimada pela RNA A8 no MI-3 em relação ao MI-2 é mantido, como mostra a Figura 57. Os picos presentes na velocidade síncrona durante o estabelecimento do fluxo magnético é novamente evidenciado nesse teste, como mostra a Figura 58. A referida figura também apresenta o comportamento dinâmico do torque eletromagnético e mecânico no Teste 16, que se mostra similar ao observado no resultado obtido no Teste 11. 


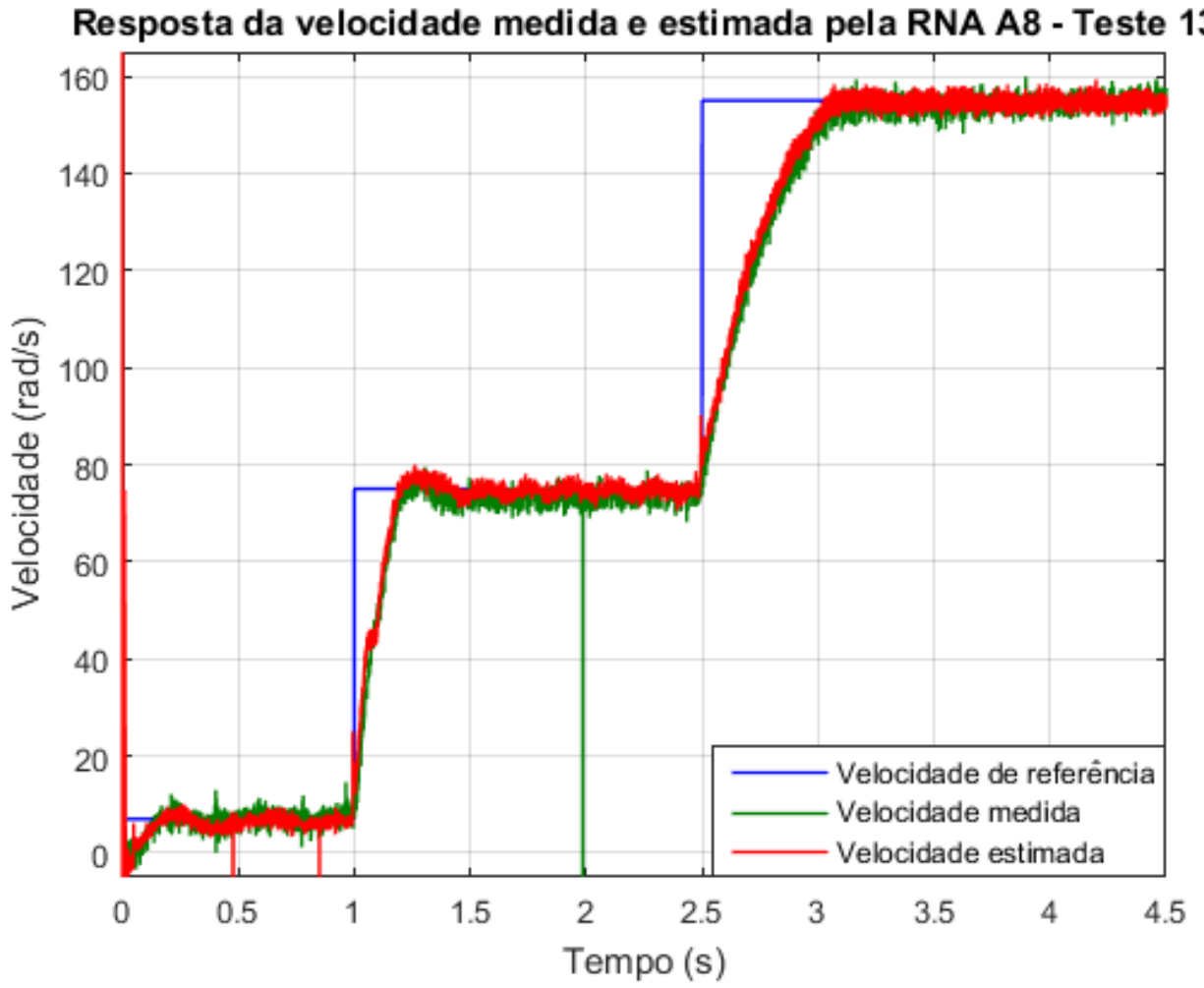

Figura 55 - Resultado da RNA A8 para o teste experimental 13.
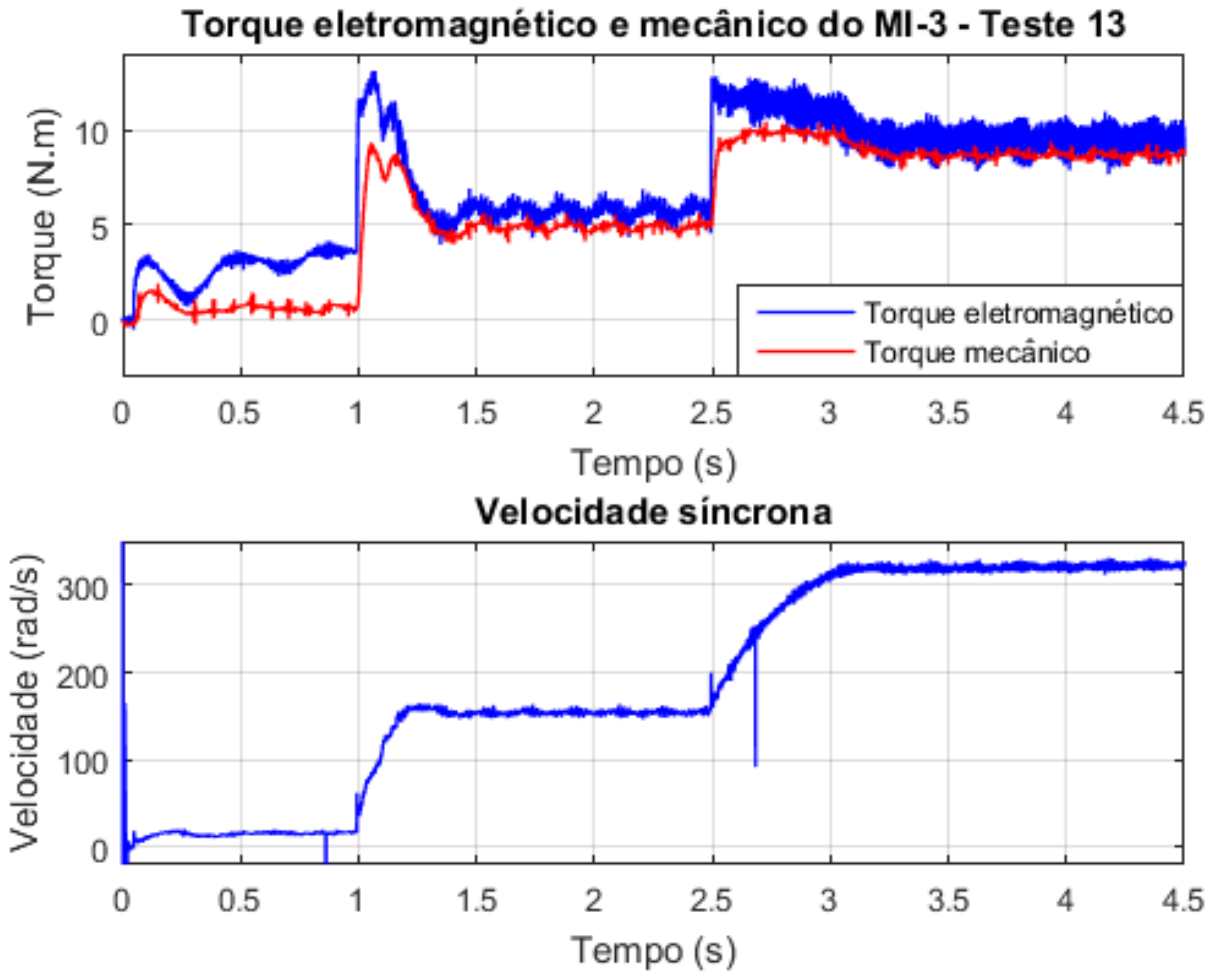

Figura 56 - Dinâmica do torque eletromagnético, mecânico e da velocidade síncrona do MI no teste experimental 13. 
Quando a sequência de degraus de velocidade do Teste 18 é aplicada no MI-3, tem-se o erro de estimativa de velocidade $0,82 \mathrm{rad} / \mathrm{s}, 0,27 \mathrm{rad} / \mathrm{s}$ e $0,56 \mathrm{rad} / \mathrm{s}$. Na Figura 59 são apresentados overshoots, que podem ser atenuados com a alteração dos parâmetros de projeto do controlador PI de velocidade. A Figura 60 mostra o comportamento dinâmico do torque eletromagnético e mecânico e a velocidade síncrona do MI-3 no Teste 18.

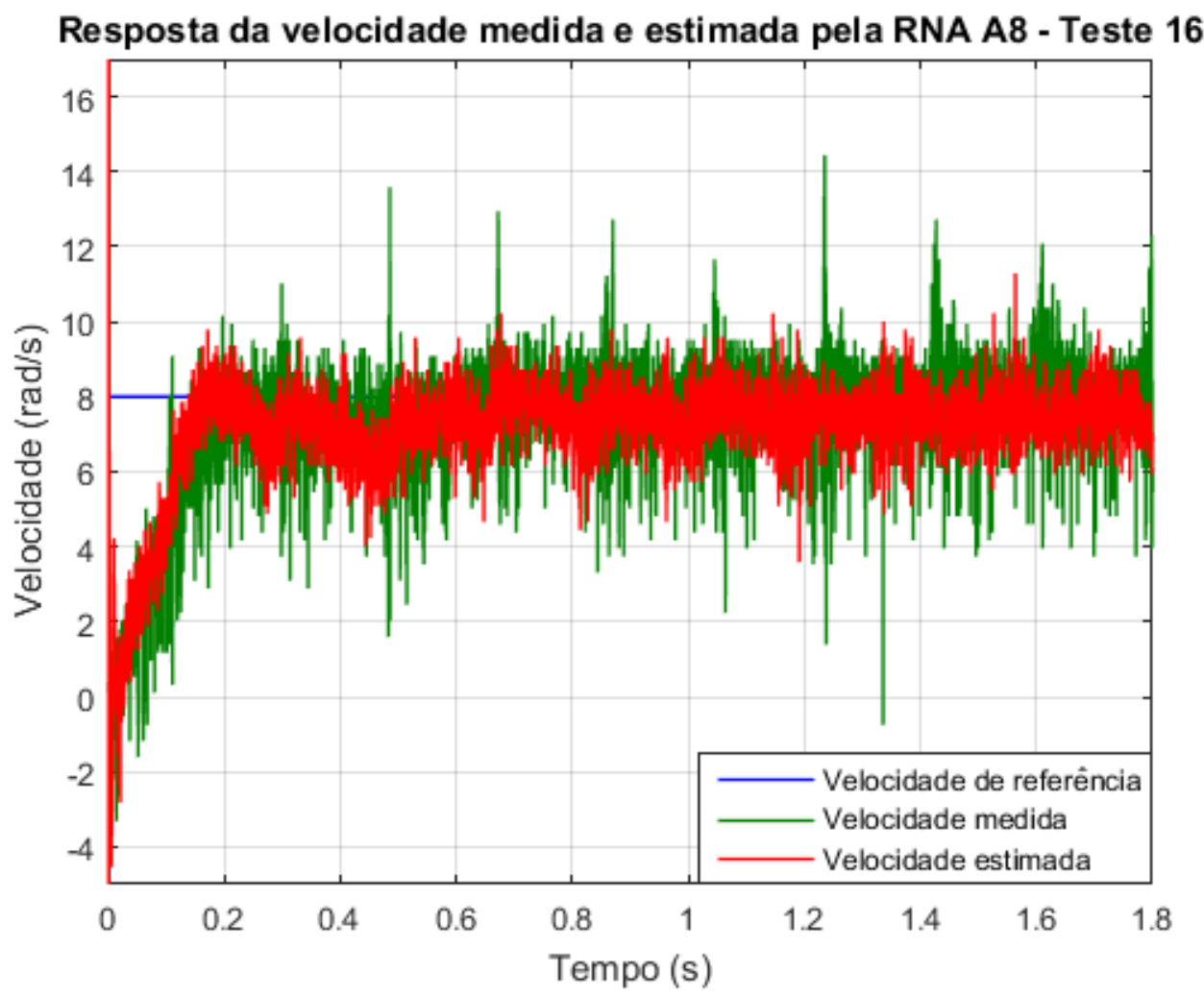

Figura 57 - Resultado da RNA A8 para o teste experimental 16.

A Tabela 4.4 apresenta o desempenho da RNA A8 na realimentação do controle de velocidade nos acionamento CDC e CDT, no MI-2 e no MI-3. Essa tabela mostra o ERM e o erro absoluto de velocidade para os Teste 1 a 20.

As figuras com os gráficos dos resultados de velocidade estimada e medida dos testes não apresentados nesta seção são mostrados no Apêndice A. Tais resultados mostram o desempenho da RNA A8 em diferentes níveis de velocidade, como no Teste 2 e no Teste 7, onde o MI-2 é acionado a $55 \mathrm{rad} / \mathrm{s}$ com torque de carga nominal tanto no CDC bem como no CDT, respectivamente. O erro de estimação em regime permanente do Teste 2 é de $0,32 \mathrm{rad} / \mathrm{s}$, enquanto no Teste 7 o erro é de $0,83 \mathrm{rad} / \mathrm{s}$. O desempenho da RNA A8 é também avaliada nesse mesmo nível de velocidade no acionamento do MI-3, conforme os testes 12 e 17, nas quais é aplicado 7,35 N.m. de torque de carga em regime permanente. Ainda, o erro de estimação da RNA A8 é de $0,05 \mathrm{rad} / \mathrm{s}$ no Teste 12 e de $0,65 \mathrm{rad} / \mathrm{s}$ no Teste 17 utilizando o MI-3. Assim, nota-se que a precisão de estimação de velocidade pela RNA A8 nos testes a $55 \mathrm{rad} / \mathrm{s}$ é superior no MI-3 do que no MI-2. 


\section{Torque eletromagnético e mecânico do MI-3 - Teste 16}

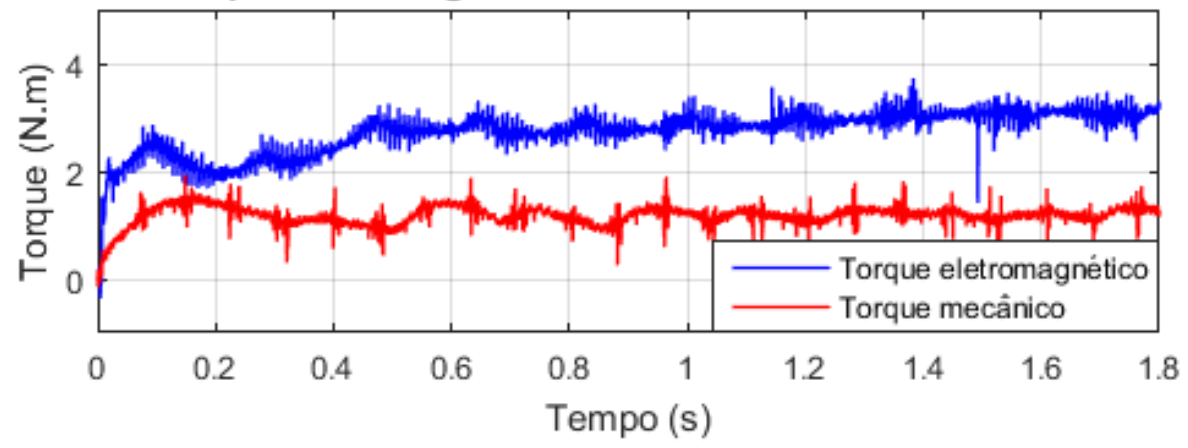

Velocidade síncrona

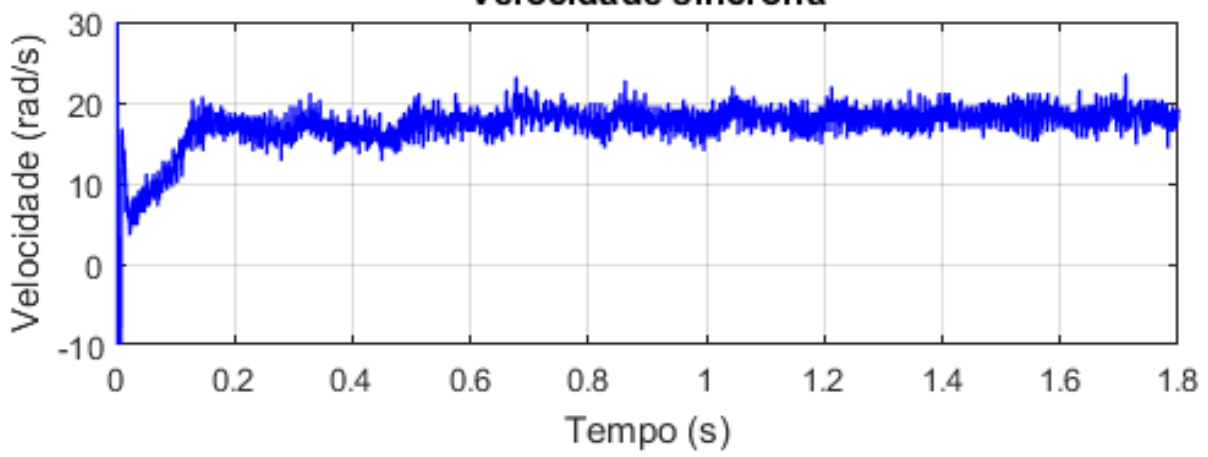

Figura 58 - Dinâmica do torque eletromagnético, mecânico e da velocidade síncrona do MI no teste experimental 16.

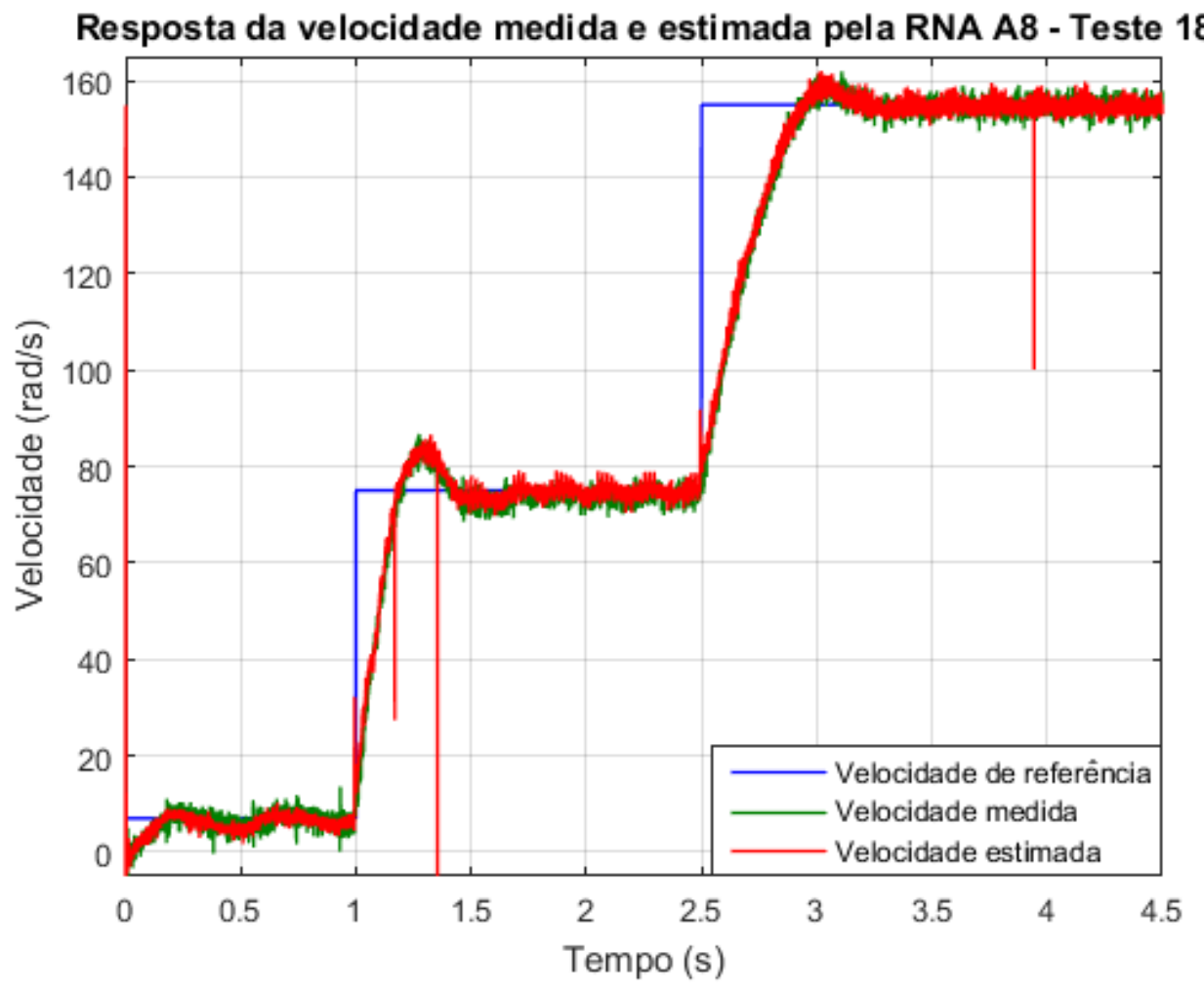

Figura 59 - Resultado da RNA A8 para o teste experimental 18. 


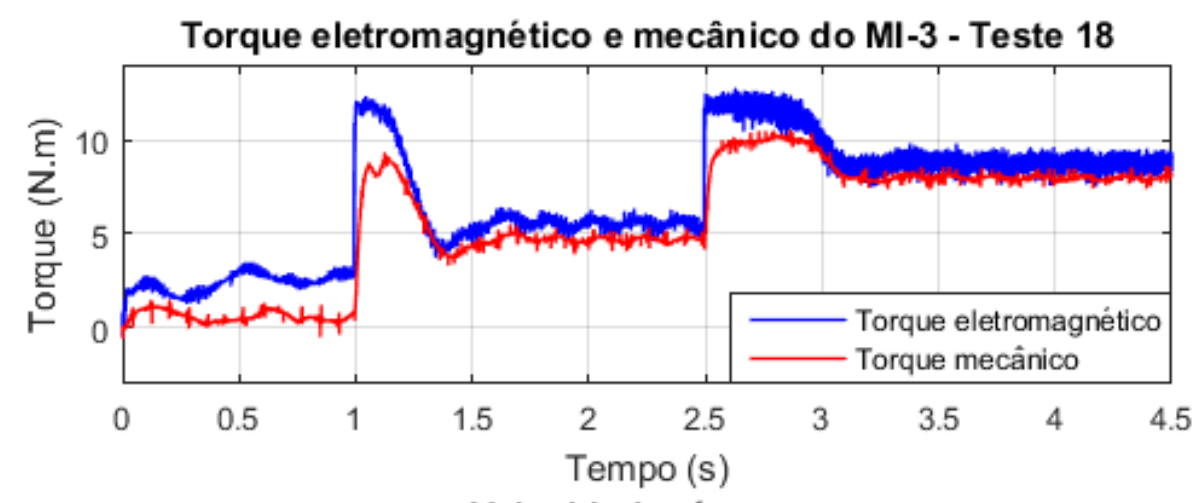

Velocidade síncrona

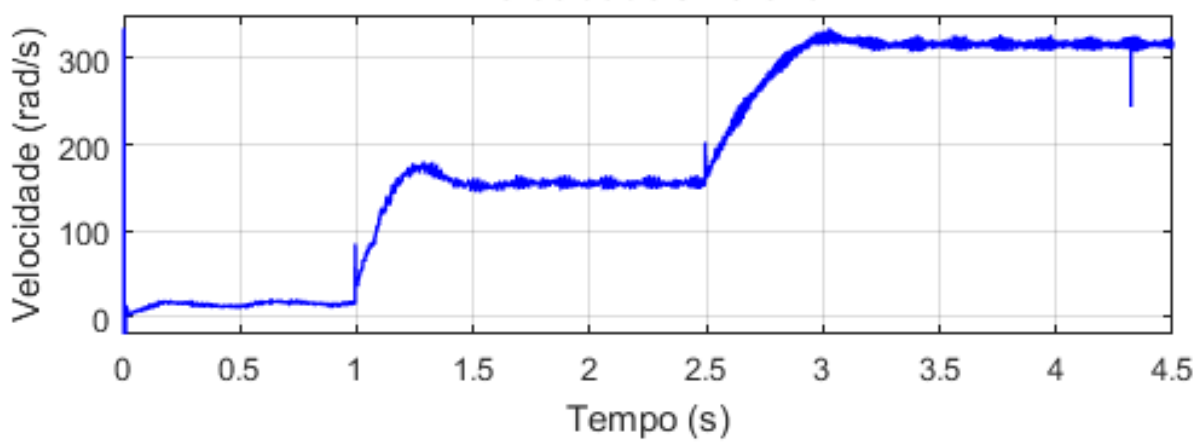

Figura 60 - Dinâmica do torque eletromagnético, mecânico e da velocidade síncrona do MI no teste experimental 18.

Outros testes experimentais são executados como objetivo verificar o desempenho do estimador neural frente à mudança do sentido de rotação do MI. Nos Testes 4 e 9 o MI-2 é acionado pelo CDC e pelo CDT, respectivamente, a $125 \mathrm{rad} / \mathrm{s}$ e após 2,5 $s$ a referência de velocidade é alterada para $-125 \mathrm{rad} / \mathrm{s}$. O erro de estimação de velocidade da RNA A8 é, nos piores casos, de 0,98 rad/s no Teste 4 e de $0,35 \mathrm{rad} / \mathrm{s}$ no Teste 9 . Quando esses níveis de velocidade são aplicados ao MI-3 a precisão do estimador neural de velocidade é de $0,82 \mathrm{rad} / \mathrm{s}$ no Teste 14 e de $0,86 \mathrm{rad} / \mathrm{s}$ no Teste 19 . Outro teste de mudança de sentido de rotação aplicado consiste no acionamento dos MIs a -10 rad/s durante $1 \mathrm{~s}$, e na sequência aplica-se um degrau de velocidade para a referência de $45 \mathrm{rad} / \mathrm{s}$. Essas condições são observadas nos Testes 5 e 10 com o MI-2 e nos Testes 15 e 20 com o MI-3. No P.O.1 do Teste 5 tem-se o erro de estimação da RNA A8 de 1,61 rad/s e de 0,07 rad/s no P.O.2, enquanto no Teste 10 o erro do estimador de velocidade é de 1,65 rad/s no P.O.1 e de 0,11 rad/s no P.O.2. A precisão na estimativa de velocidade de $-10 \mathrm{rad} / \mathrm{s}$ é melhor quando o MI-3 foi usado, pois o erro de estimação é de 0,27 rad/s no P.O.1 e de $0,12 \mathrm{rad} / \mathrm{s}$ no P.O.2 durante o Teste 12. Ainda, no Teste 20, tem-se o erro de 0,21 rad/s no P.O.1 e de $0,42 \mathrm{rad} / \mathrm{s}$ no P.O.2.

Nos testes realizados de 1 a 20, onde a RNA A8 é testada como estimador de velocidade aplicado na realimentação dos controles CDC e CDT no MI-2 e no MI-3, o estimador neural de velocidade mostra-se estável em todos os níveis de velocidade avaliados. Ainda, mesmo com a RNA A8 sendo treinada com dados obtidos via simulações computacional 
do MI-1, esse estimador neural de velocidade teve desempenho equivalente nos testes realizados com o MI-2 e o MI-3.

Tabela 4.4 - Performance da RNA A8 em regime permanente dos testes experimentais de 1 a 20.

\begin{tabular}{|c|c|c|c|c|c|c|}
\hline Testes & \multicolumn{3}{|c|}{$\begin{array}{l}\text { Error do Estimador } \\
(\mathrm{rad} / \mathrm{s})\end{array}$} & \multicolumn{3}{|c|}{$\begin{array}{l}\text { ERM do Estimador } \\
(\%)\end{array}$} \\
\hline CDC MI-2 & P.O.1 & P.O.2 & P.O.3 & P.O.1 & P.O.2 & P.O.3 \\
\hline 1 & 0,79 & - & - & 11,505 & - & - \\
\hline 2 & 0,32 & - & - & 0,570 & - & - \\
\hline 3 & 1,81 & 0,51 & 1,27 & 21,021 & 0,624 & 0,820 \\
\hline 4 & 0,98 & 0,36 & - & 1,350 & 1,529 & - \\
\hline 5 & 1,61 & 0,07 & - & 17,885 & 0,176 & - \\
\hline \multicolumn{7}{|l|}{ CDT MI-2 } \\
\hline 6 & 0,49 & - & - & 6,879 & - & - \\
\hline 7 & 0,83 & - & - & 0,526 & - & - \\
\hline 8 & 1,05 & 0,09 & 0,21 & 13,252 & 0,132 & 0,129 \\
\hline 9 & 0,05 & 0,35 & - & 0,047 & 0,295 & - \\
\hline 10 & 1,65 & 0,11 & - & 16,029 & 0,183 & - \\
\hline \multicolumn{7}{|l|}{ CDC MI-3 } \\
\hline 11 & 0,21 & - & - & 4,110 & - & - \\
\hline 12 & 0,05 & - & - & 0,111 & - & - \\
\hline 13 & 1,49 & 0,75 & 0,38 & 16,025 & 1,146 & 0,121 \\
\hline 14 & 0,82 & 0,65 & - & 0,328 & 0,281 & - \\
\hline 15 & 0,27 & 0,12 & - & 1,807 & 0,204 & - \\
\hline \multicolumn{7}{|l|}{ CDT MI-3 } \\
\hline 16 & 0,35 & - & - & 5,077 & - & - \\
\hline 17 & 0,65 & - & - & 1,143 & - & - \\
\hline 18 & 0,82 & 0,27 & 0,56 & 13,067 & 0,372 & 0,361 \\
\hline 19 & 0,86 & 0,55 & - & 0,761 & 0,365 & - \\
\hline 20 & 0,21 & 0,42 & - & 2,102 & 0,629 & $\begin{array}{l}- \\
-\end{array}$ \\
\hline
\end{tabular}

\subsubsection{Testes experimentais com as RNA B3 realimentando o controle de velocidade no CDC e CDT}

Esta seção apresenta os resultados obtidos pelo estimador neural de velocidade usando a RNA B3, em que este tem como sinais de entrada a velocidade síncrona e o torque eletromagnético. Conforme descrito na Seção 4.2.1, a RNA B3 é o elemento de realimentação das estratégias do CDC e do CDT nos testes com o MI-2 e MI-3, de acordo com os Pontos de Operação mostrados na Tabela 4.5.

Tabela 4.5 - Pontos de operação da validação experimental da RNA B3.

\begin{tabular}{c|c|c|c|c|c|c|c}
\hline \multicolumn{2}{c|}{ Testes } & \multicolumn{3}{c|}{$\begin{array}{c}\text { Pontos de Operação } \\
\text { (rad/s) }\end{array}$} & \multicolumn{3}{c}{$\begin{array}{c}\text { Torque de Carga } \\
\text { (N.m) }\end{array}$} \\
\hline CDC MI-2 & CDT MI-2 & P.O.1 & P.O.2 & P.O.3 & P.O.1 & P.O.2 & P.O.3 \\
\hline 21 & 26 & 8 & - & - & 1,0 & - & - \\
\hline 22 & 27 & 55 & - & - & 4,1 & - & - \\
\hline 23 & 28 & 7 & 75 & 155 & 0,3 & 2,4 & 4,0 \\
\hline 24 & 29 & 125 & -125 & - & 3,6 & $-3,6$ & - \\
\hline 25 & 30 & -10 & 45 & - & $-0,6$ & 2,7 & - \\
\hline CDC MI-3 & CDT MI-3 & P.O.1 & P.O.2 & P.O.3 & P.O.1 & P.O.2 & P.O.3 \\
\hline 31 & 36 & 8 & - & - & 1,3 & - & - \\
\hline 32 & 37 & 55 & - & - & 7,1 & - & - \\
\hline 33 & 38 & 7 & 75 & 155 & 0,7 & 4,7 & 8,1 \\
\hline 34 & 39 & 125 & -125 & - & 7,1 & $-7,8$ & - \\
\hline 35 & 40 & -10 & 45 & - & $-1,6$ & 6,0 & - \\
\hline
\end{tabular}


O Teste 21 é conduzido com o MI-2 acionado com o CDC a $8 \mathrm{rad} / \mathrm{s}$ com 1 N.m. de conjugado de carga em regime permanente. O comando de referência da velocidade, a velocidade medida no eixo da máquina e a estimada pela RNA B3 são mostradas na Figura 61. Devido a menor quantidade de variáveis de entrada da RNA em relação à estratégia de implementação $A$, observa-se que a estimação de velocidade é mais sensível às oscilações dos sinais de entrada. Entretanto, o estimador permanece estável e adequado ao funcionamento do controlador de velocidade. O erro obtido entre a velocidade estimada e a medida foi de $1,21 \mathrm{rad} / \mathrm{s}$.

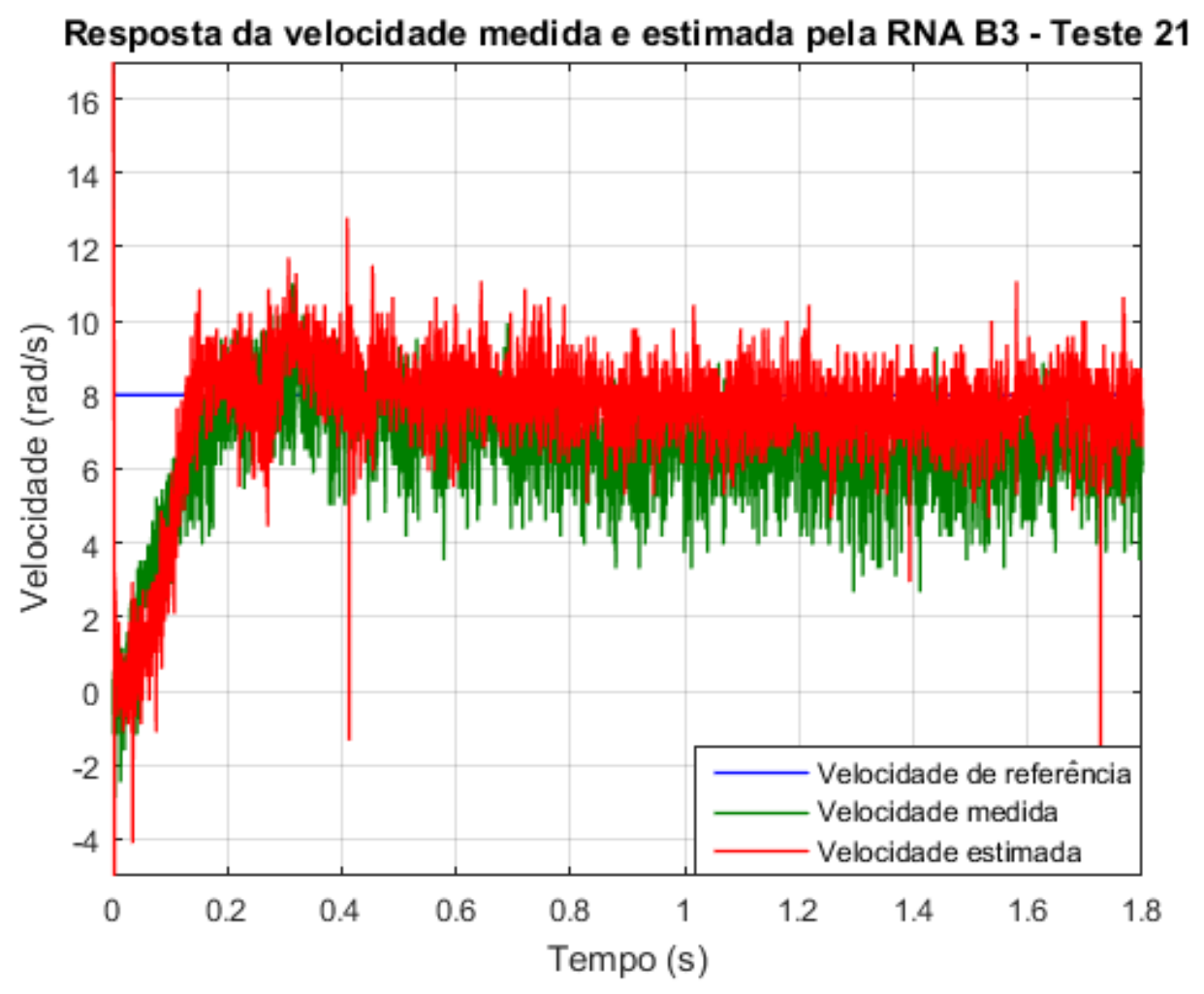

Figura 61 - Resultado da RNA A8 para o teste experimental 21.

No Teste 23, como mostra a Figura 62, é aplicada uma sequência de três degraus de velocidade de $7 \mathrm{rad} / \mathrm{s}, 75 \mathrm{rad} / \mathrm{s}$ e $155 \mathrm{rad} / \mathrm{s}$, fazendo com que o torque de carga em regime permanente seja de 0,3 N.m., 2,4 N.m. e 4,0 N.m. de acordo com o nível de velocidade aplicado. Os erros de estimativa de velocidade no Teste 23, em cada nível de velocidade, foram de 2,52 rad/s, 1,02 rad/s e 1,36 rad/s os quais foram calculados em regime permanente. Nota-se que o erro é elevado quando a MI-2 está a $7 \mathrm{rad} / \mathrm{s}$, sendo superior ao obtido pela RNA A8 no Teste 3 que foi de 1,81 rad/s. Embora o teste apresente elevado ruído na aquisição, é possível notar que quando a velocidade é elevada para $75 \mathrm{rad} / \mathrm{s}$, e após 2,5 s é alterada a velocidade para $155 \mathrm{rad} / \mathrm{s}$, o desempenho do estimador melhora significativamente. A velocidade síncrona e os torques eletromagnéticos e mecânicos do MI-2 são mostrados na Figura 63, e estão em conformidade ao apresentado no Teste 3 e no Teste 8 . 


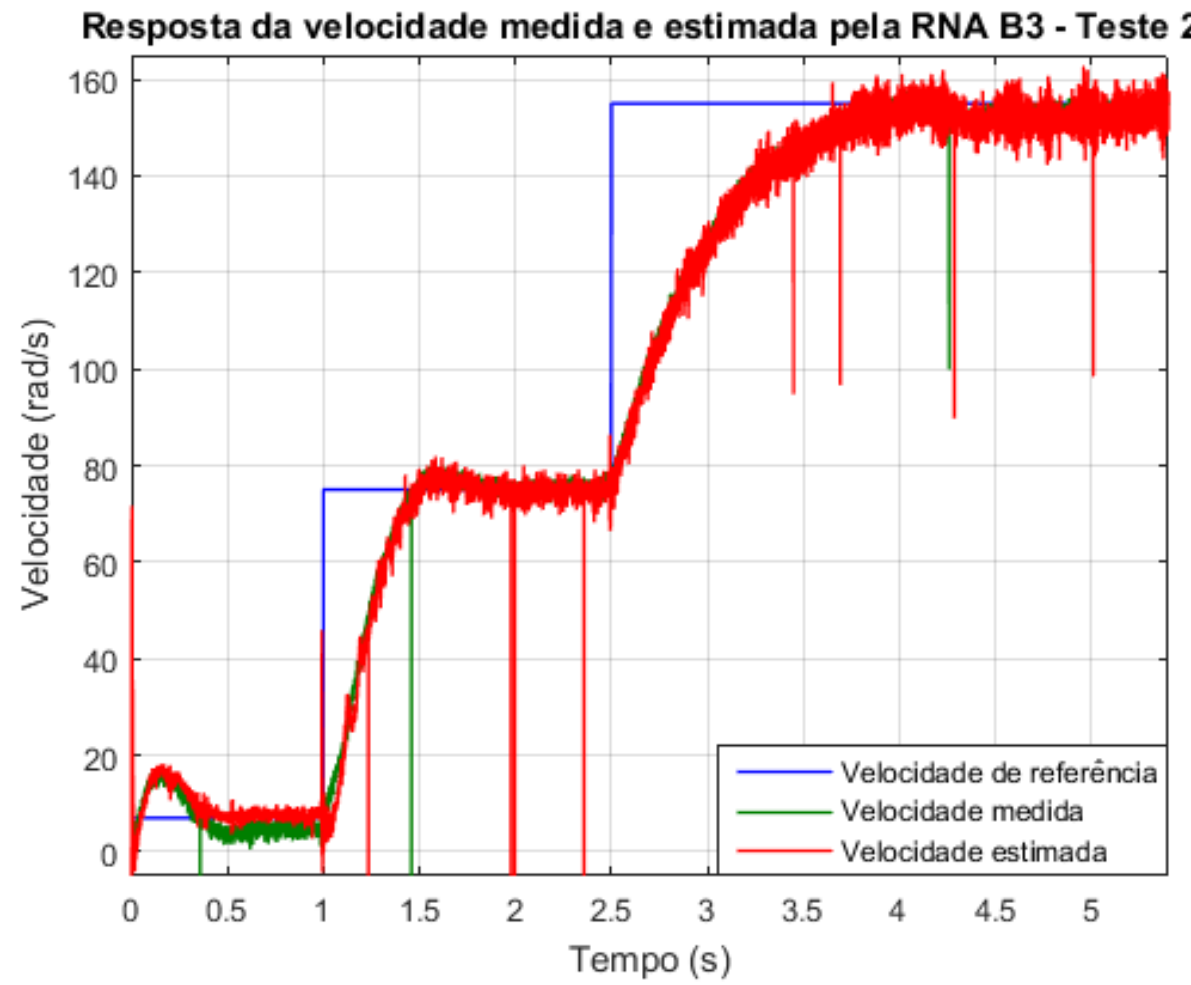

Figura 62 - Resultado da RNA A8 para o teste experimental 23.

Torque eletromagnético e mecânico do MI-2 - Teste 23

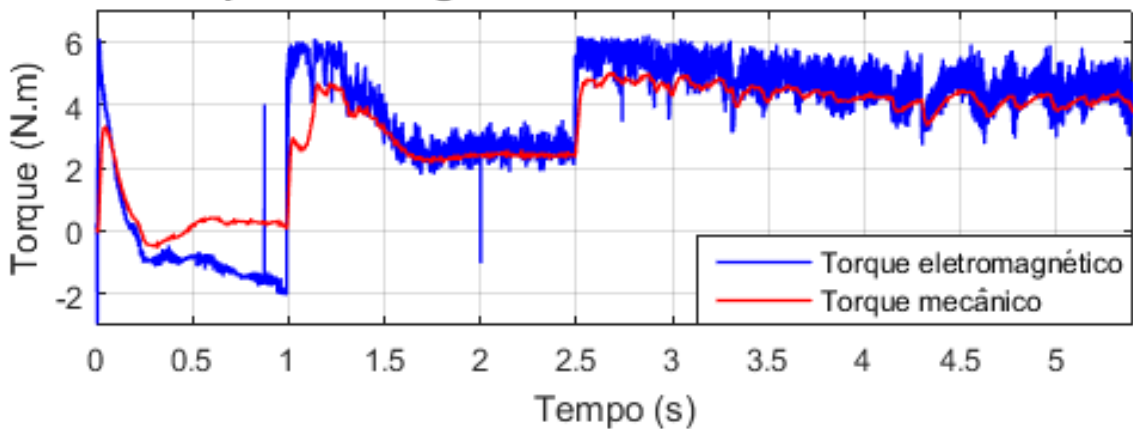

Velocidade sincrona

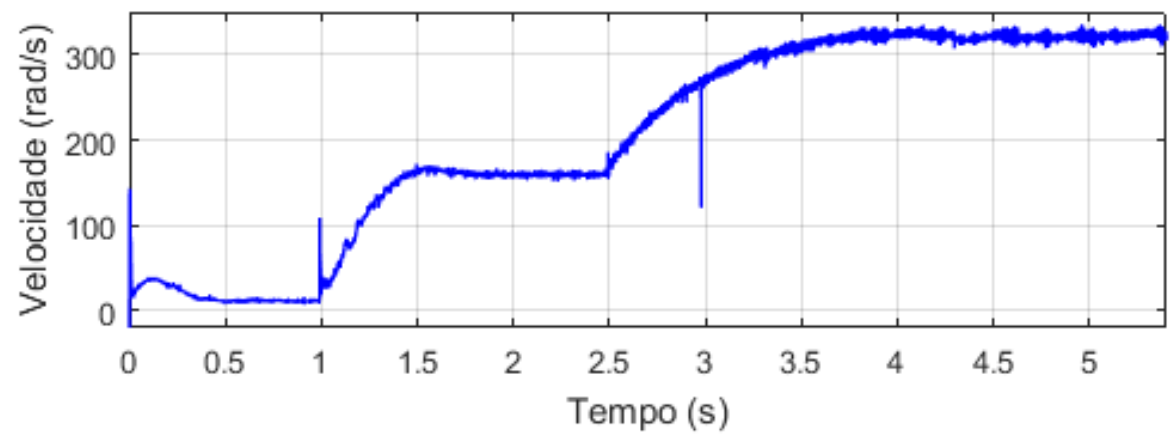

Figura 63 - Dinâmica do torque eletromagnético, mecânico e da velocidade síncrona do MI no teste experimental 23.

Os testes 21 a 25 mostraram que a saída da RNA B3 permanece estável quando esta realimenta a malha de controle de velocidade no CDC com o MI-2. Entretanto, o erro 
de estimação é maior ao apresentado pela RNA A8 nas mesmas condições de teste. Na sequência, a estratégia de controle é substituída pelo CDT, e são conduzidos os testes de 26 a 30. Para efeito de comparação, os gráficos do Teste 26 e do Teste 28 são mostrados nesta seção.

No Teste 26, com o MI-2 operando com o controle CDT, é novamente acionado a $8 \mathrm{rad} / \mathrm{s}$. Neste teste o erro obtido entre a velocidade estimada e a velocidade medida foi de $0,96 \mathrm{rad} / \mathrm{s}$. A performance da RNA B3 nesse teste é melhor do que o obtido no Teste 21, embora tenha desempenho inferior aos obtidos nos testes 1, 6, 11 e 16, onde são consideradas as mesmas condições de ensaios. A Figura 64 mostra os gráficos de velocidades associados ao Teste 26.

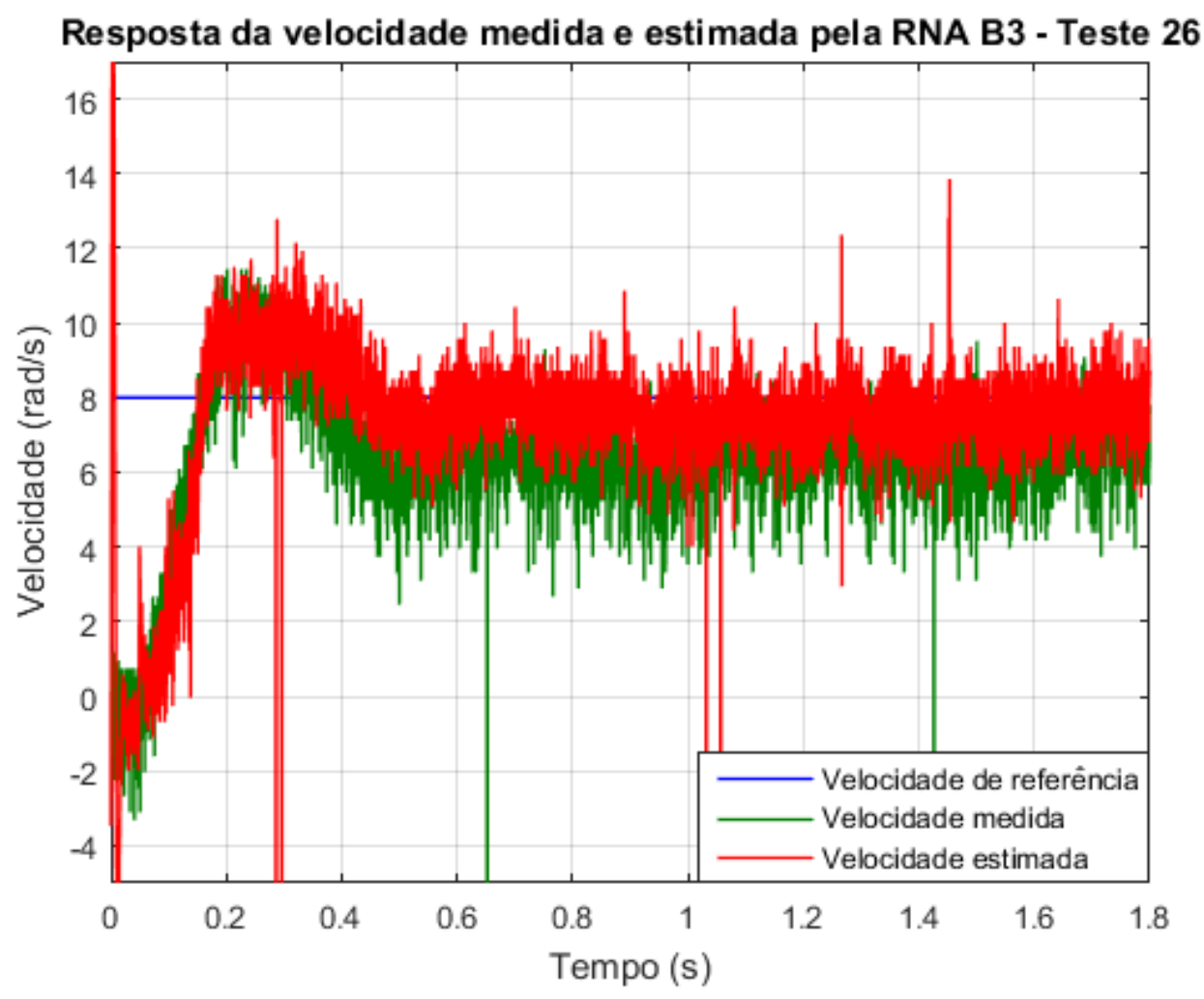

Figura 64 - Resultado da RNA A8 para o teste experimental 26.

A Figura 65 mostra a resposta da RNA B3 no Teste 28 onde, na velocidade de $7 \mathrm{rad} / \mathrm{s}$, o erro de estimação de velocidade foi de $2,51 \mathrm{rad} / \mathrm{s}$. Nas velocidades de $75 \mathrm{rad} / \mathrm{s}$ e 155 $\mathrm{rad} / \mathrm{s}$ o desempenho dinâmico é similar ao observado no Teste 23 , com erros de $1,15 \mathrm{rad} / \mathrm{s}$ e 1,60 rad/s, respectivamente. O comportamento dinâmico dos torques eletromagnético e mecânico, bem como o da velocidade síncrona são apresentados na Figura 66, onde é possível observar o torque de carga em regime permanente de 0,3 N.m., 2,4 N.m. e 4,0 N.m., de acordo com a progressão das velocidades do Teste 28. 


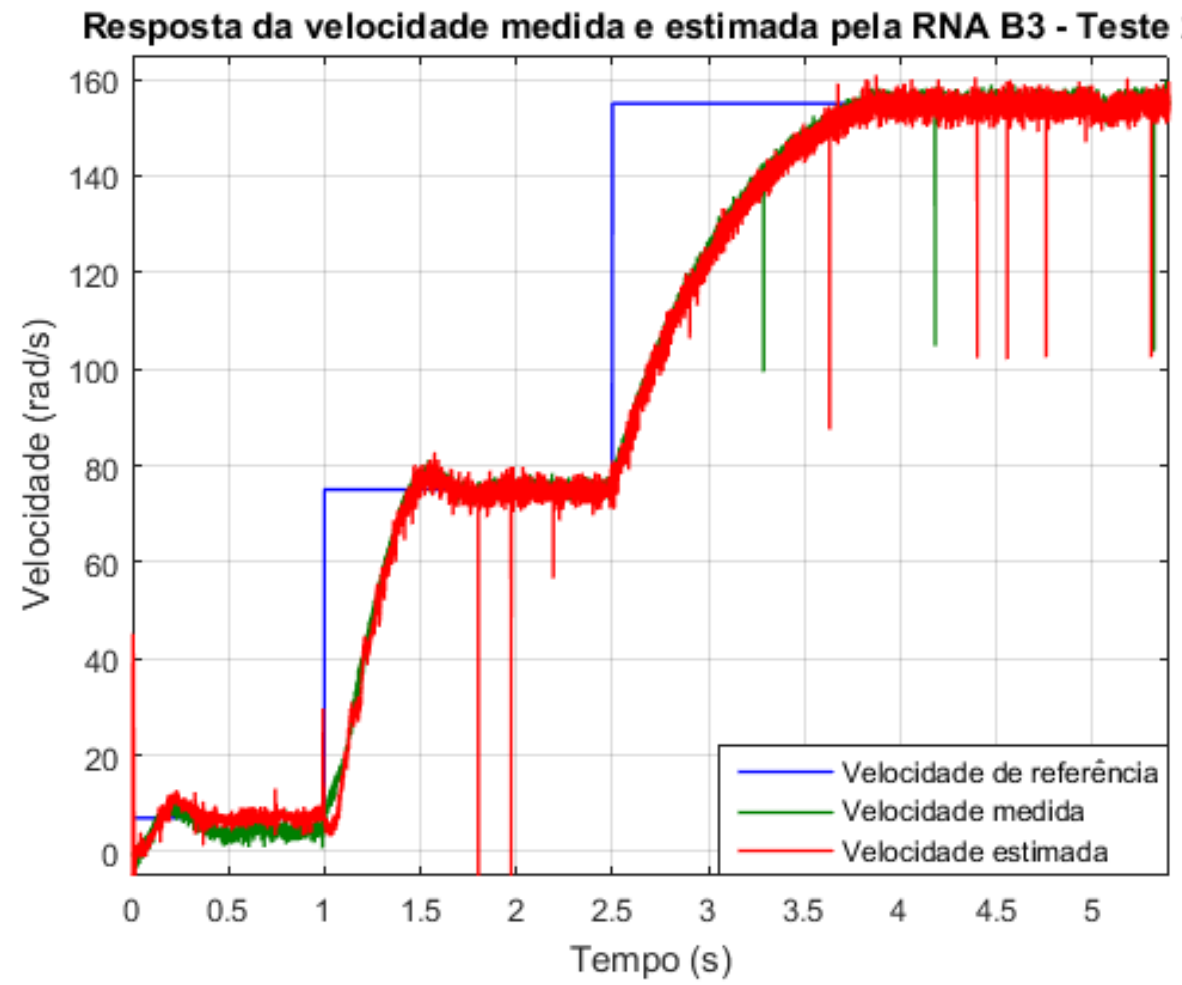

Figura 65 - Resultado da RNA A8 para o teste experimental 28.
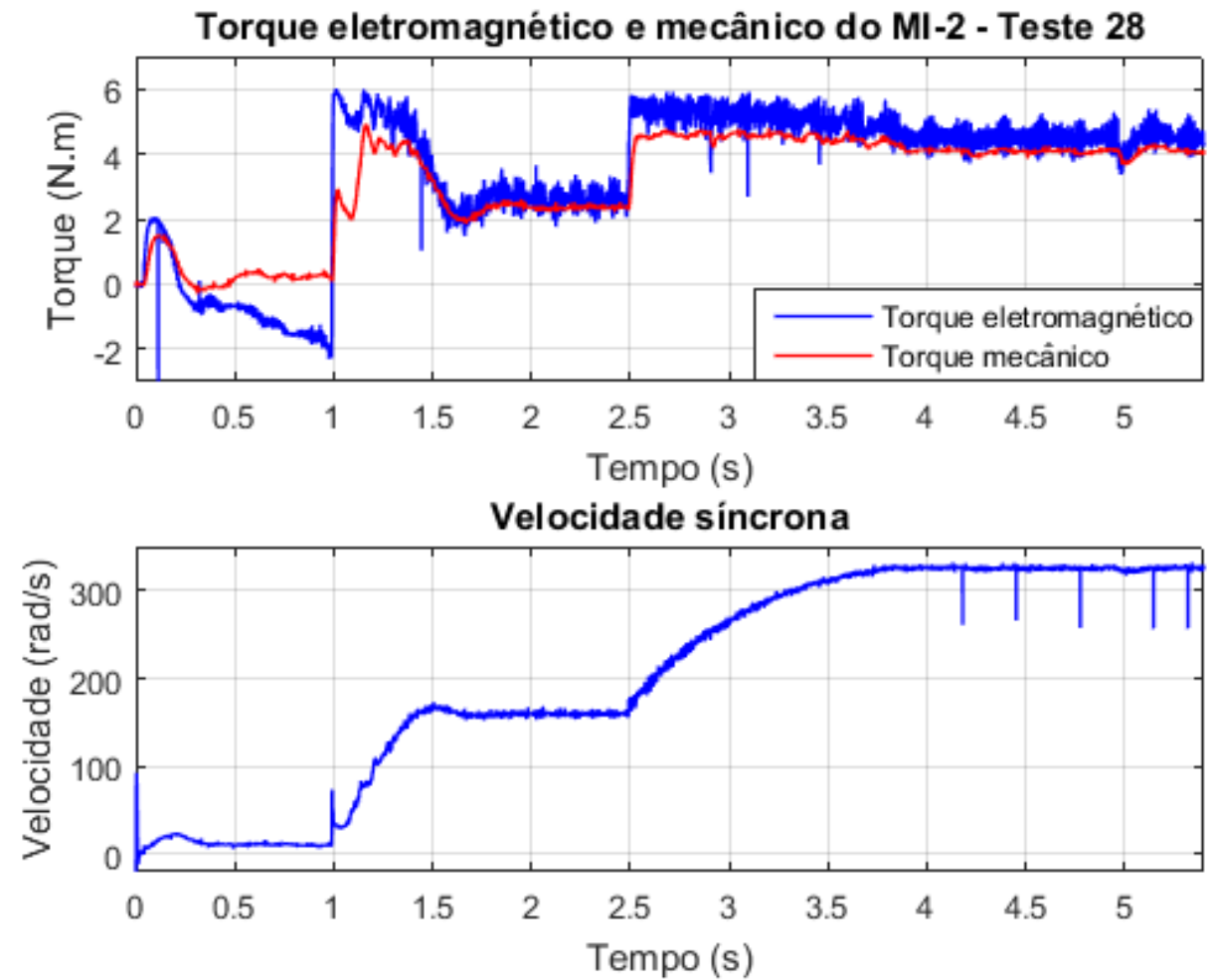

Figura 66 - Dinâmica do torque eletromagnético, mecânico e da velocidade síncrona do MI no teste experimental 28. 
A seguir a RNA B3 é testada no acionamento da MI-3, seguindo a metodologia da Seção 4.2.1. Novamente, os parâmetros do MI usados no estimador de fluxo magnético do estator são atualizados para as características do MI-3, conforme a Tabela 3.1, bem como os ganhos dos controladores PIs de ambas as estratégias de controle de acordo com os parâmetros apresentados na Tabela 3.3. Ainda, o ganho de normalização desse sinal de entrada da RNA é também atualizado devido ao maior torque do MI-3.

No Teste 31 o MI-3 é acionado pelo CDC a $8 \mathrm{rad} / \mathrm{s}$, onde a velocidade medida e estimada em relação à velocidade de referência pode ser vista na Figura 67. Nesse teste é possível observar menor ondulação da velocidade estimada em relação ao observado no Teste 21 e no Teste 26. Tal efeito é também observado na estratégia de implementação $A$ na Seção 4.2.1. A diferença entre a velocidade estimada e a medida no eixo do MI-3 no Teste 31 é de 0,58 rad/s. Este valor é menor ao obtido com a mesma estratégia de controle no Teste 21, porém superior ao visto nos testes com a RNA A8 sob as mesmas condições. O comportamento dinâmico do torque de carga, bem como o do torque eletromagnético e da velocidade síncrona são mostrados na Figura 68.

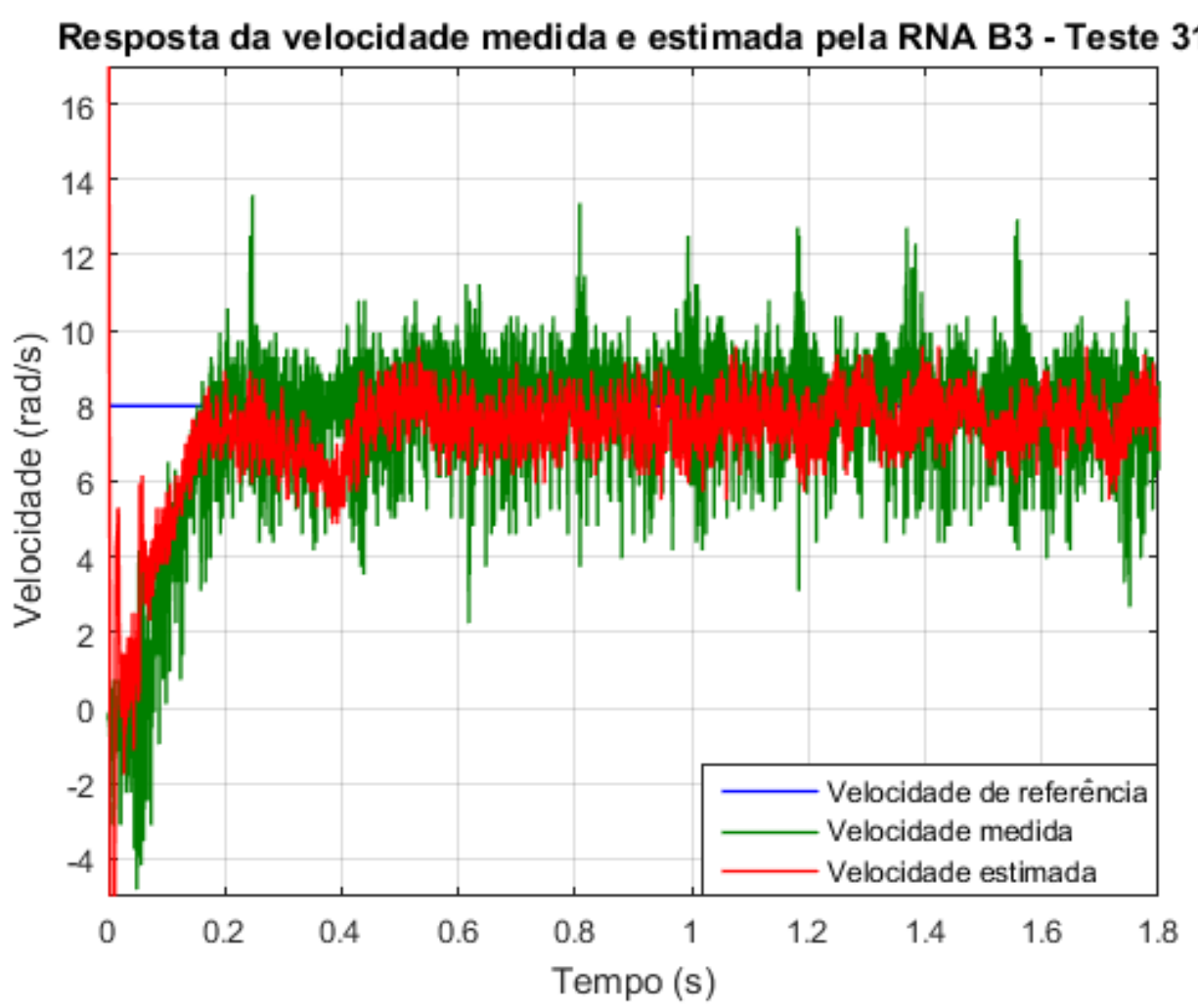

Figura 67 - Resultado da RNA A8 para o teste experimental 31. 


\section{Torque eletromagnético e mecânico do MI-3 - Teste 31}

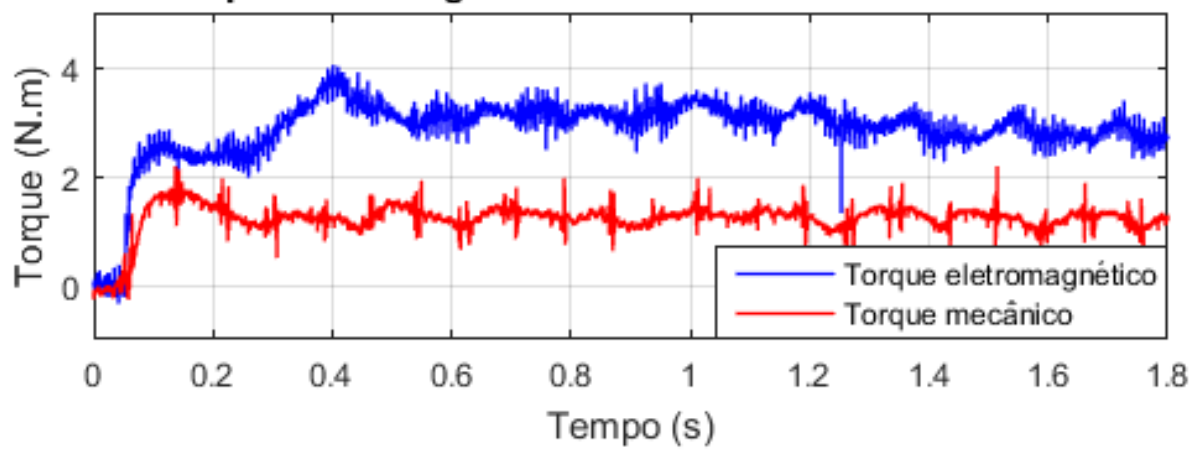

Velocidade síncrona

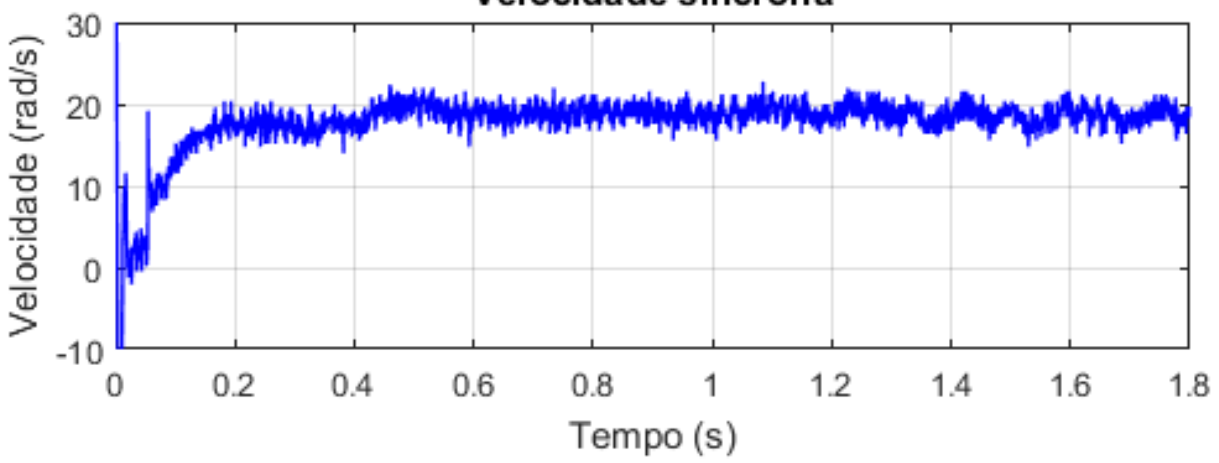

Figura 68 - Dinâmica do torque eletromagnético, mecânico e da velocidade síncrona do MI no teste experimental 31.

No Teste 33 o MI-3 é submetido a uma sequência de três degraus de velocidade, como mostra a Figura 69. Esse teste apresentou um pico elevado na velocidade estimada no instante inicial do teste e esse pico está diretamente relacionado ao também elevado pico da velocidade síncrona no mesmo instante, como pode ser observado na Figura 70. Esse fenômeno mostra a grande sensibilidade da RNA B3 frente às pertubações nos sinais de entrada. Os erros na estimativa de velocidade nesse teste são de 1,53 rad/s, 0,03 rad/s e 0,48 rad/s de acordo com a sequência de velocidade aplicada no teste. Além da velocidade síncrona, a Figura 70 mostra o comportamento dinâmico dos torques eletromagnético e mecânico, onde em regime permanente o conjugado de carga foi de 0,7 N.m., 4,7 N.m. e 8,1 N.m, de acordo com a velocidade aplicada.

Na sequência dos testes a estratégia de acionamento CDC é substituída pelo CDT. Assim, o Teste 36 é conduzido com a velocidade de referência de $8 \mathrm{rad} / \mathrm{s}$, onde o erro de estimativa em regime permanente foi de $0,86 \mathrm{rad} / \mathrm{s}$. No Teste 26 houve oscilação do sinal de saída da RNA B3 e da velocidade medida durante o intervalo de 0,2 s a 0,6 s, embora o sistema permaneça estável. A Figura 70 mostra as dinâmicas dos torques eletromagnético e mecânico, e da velocidade síncrona. O comportamento similar da velocidade estimada e mecânica no referido intervalo demostra que a RNA B3 consegue mapear tal transitório, que não teve representabilidade nos dados de treinamento da RNA. As oscilações nesse intervalo de tempo podem ser observados nos gráficos mostrados na Figura 72. 


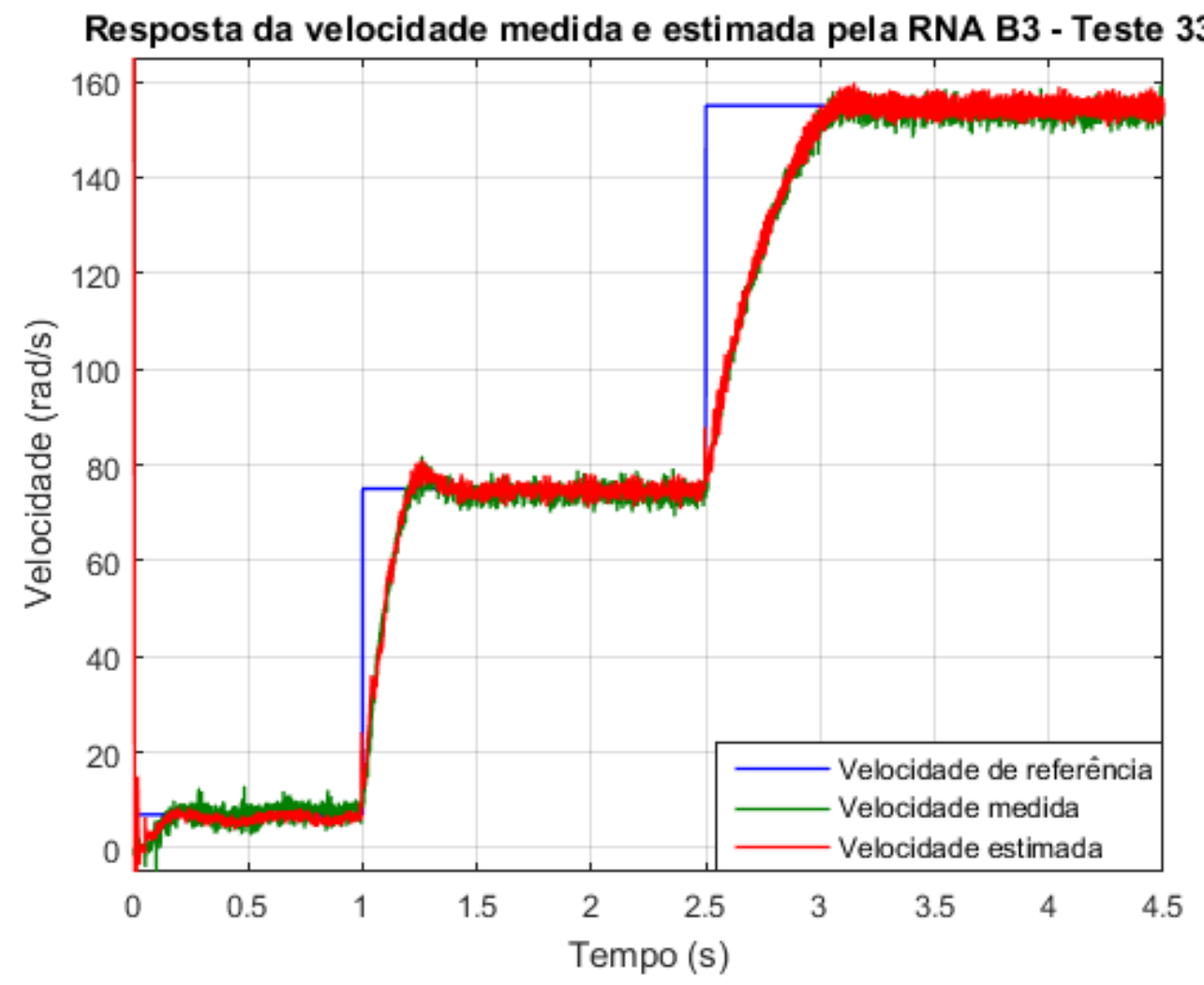

Figura 69 - Resultado da RNA A8 para o teste experimental 33.

Torque eletromagnético e mecânico do MI-3 - Teste 33
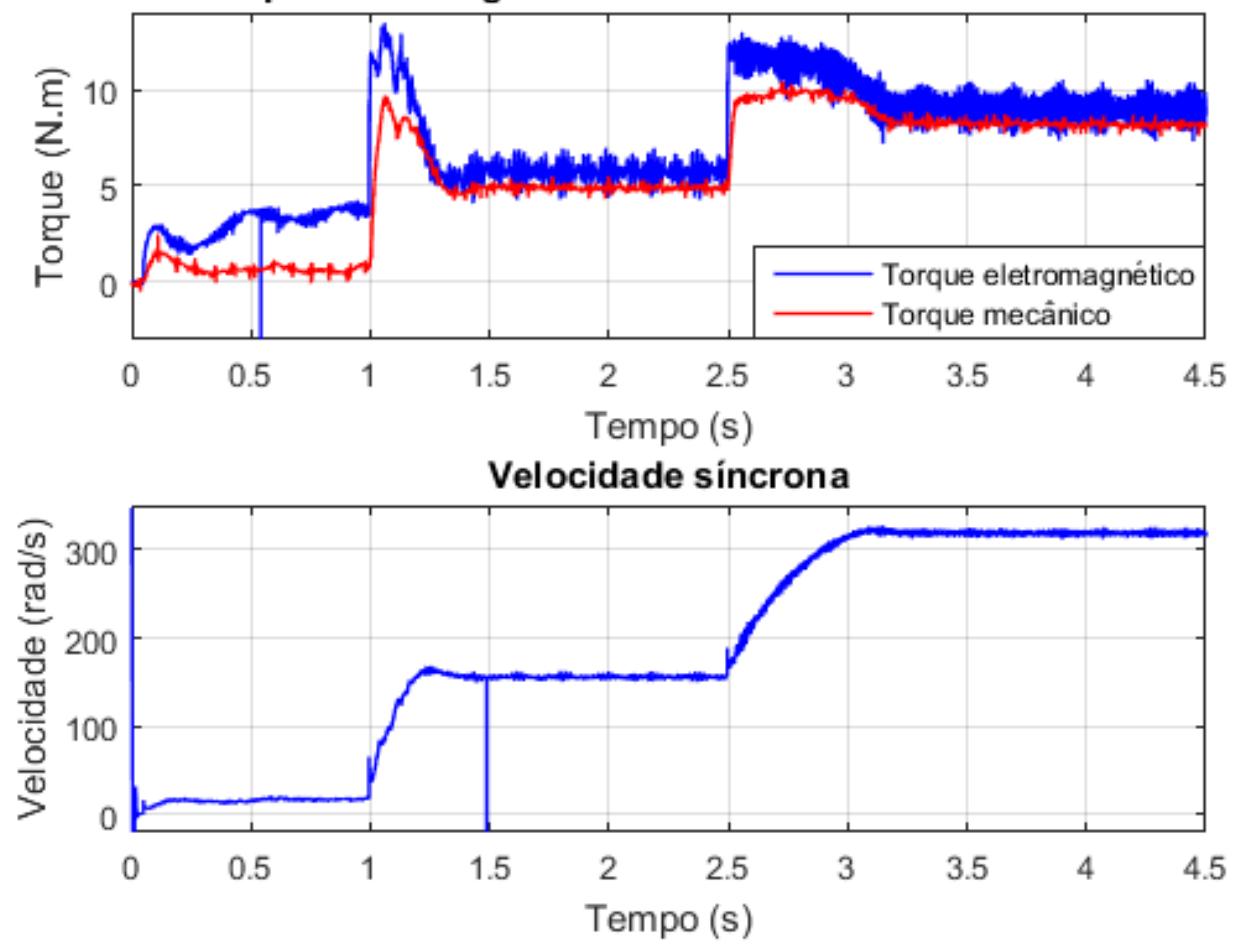

Figura 70 - Dinâmica do torque eletromagnético, mecânico e da velocidade síncrona do MI no teste experimental 33. 


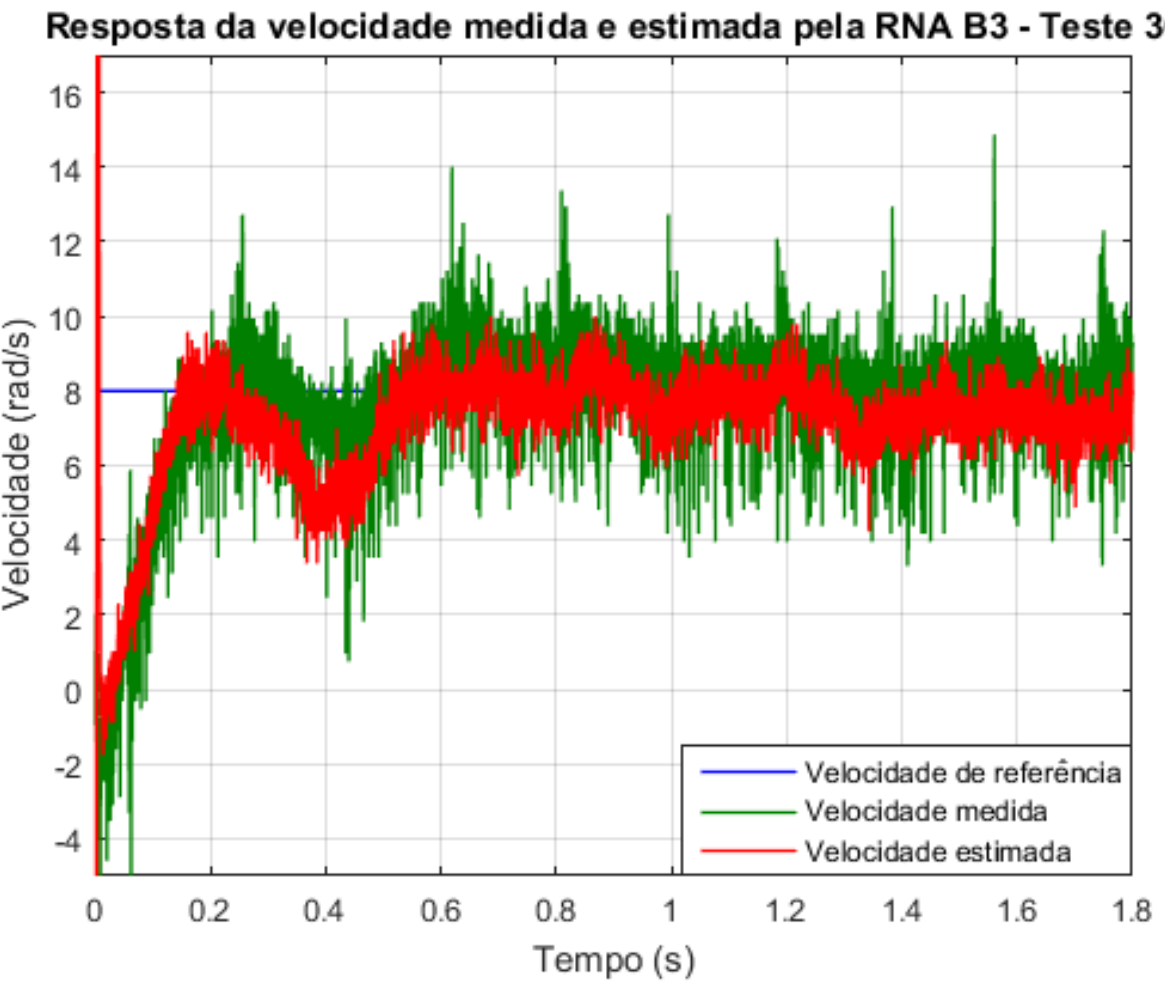

Figura 71 - Resultado da RNA A8 para o teste experimental 36.

Torque eletromagnético e mecânico do MI-3 - Teste 36
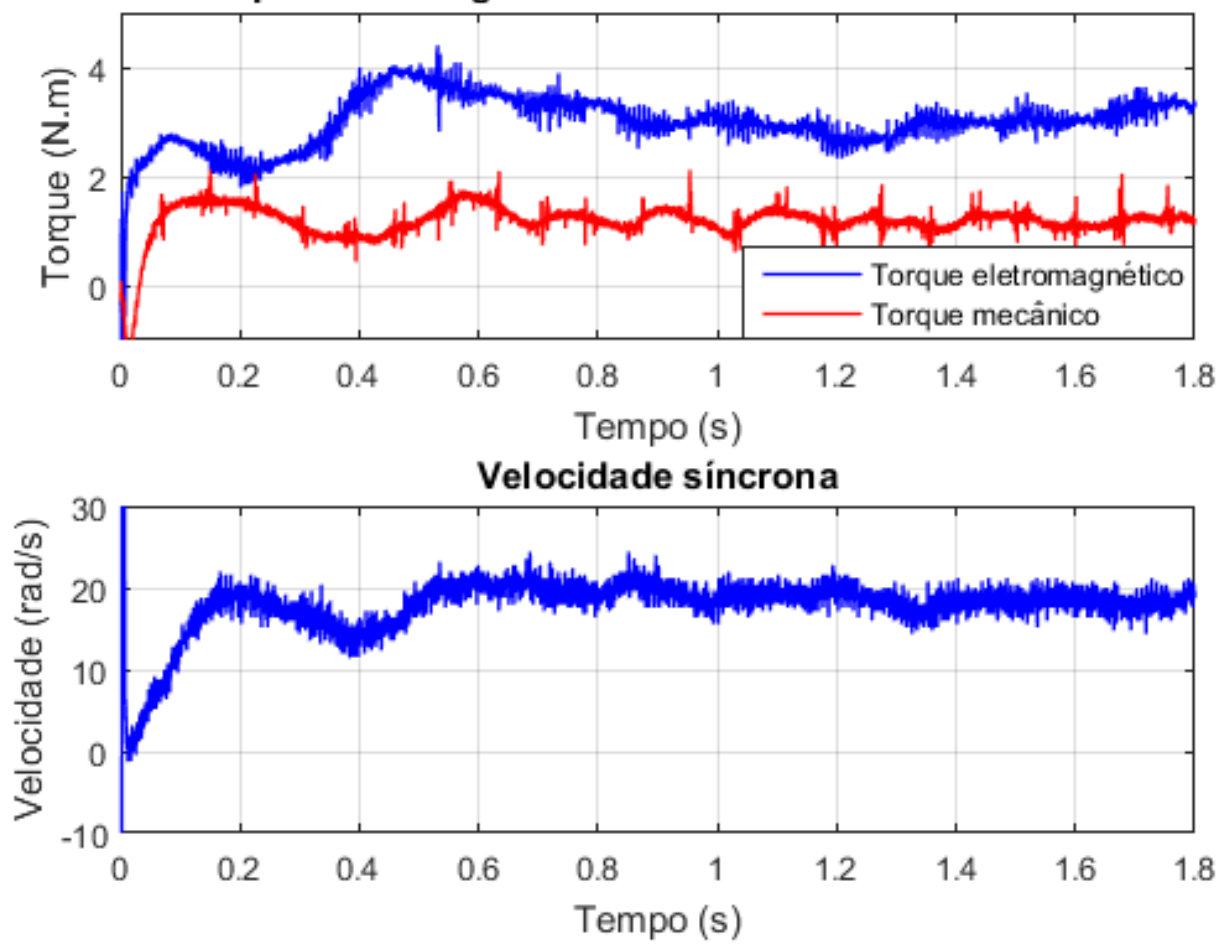

Figura 72 - Dinâmica do torque eletromagnético, mecânico e da velocidade síncrona do MI no teste experimental 36. 
Quando a sequência de degraus de velocidade do Teste 38 é aplicada ao MI-3, o erro de estimativa de velocidade é de $0,86 \mathrm{rad} / \mathrm{s}, 0,06 \mathrm{rad} / \mathrm{s}$ e $0,55 \mathrm{rad} / \mathrm{s}$, respectivamente. Assim como no Teste 18, na Figura 73 são apresentados overshoots, mais acentuado no degrau de $7 \mathrm{rad} / \mathrm{s}$ para $75 \mathrm{rad} / \mathrm{s}$, que também podem ser atenuados com a alteração dos parâmetros de projeto do controlador PI de velocidade. Na sequência, a Figura 74 mostra o comportamento dinâmico do torque eletromagnético e mecânico do MI-3 no Teste 38.

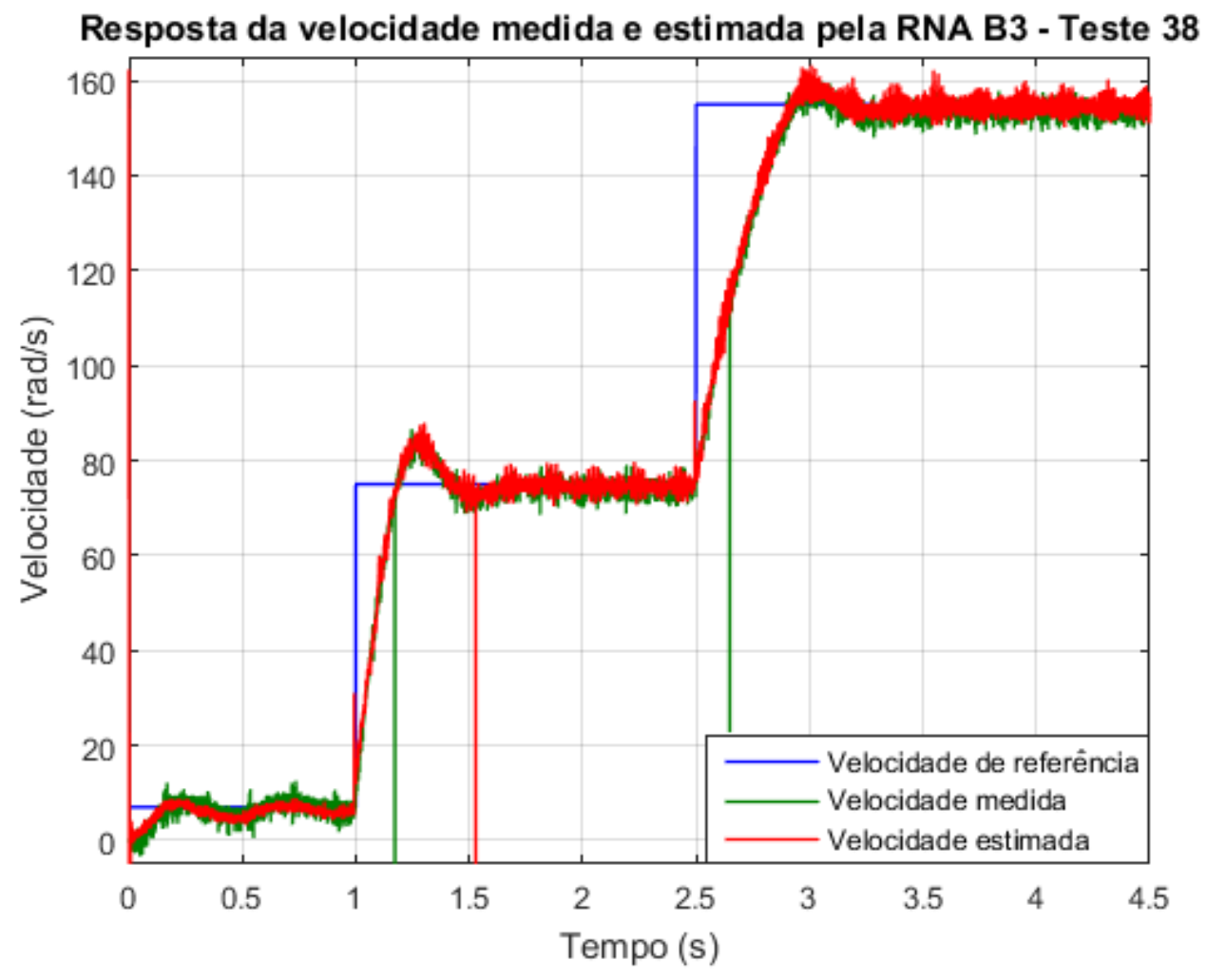

Figura 73 - Resultado da RNA A8 para o teste experimental 38.

A Tabela 4.6 apresenta o desempenho da RNA B3 na realimentação do controle de velocidade dos acionamento CDC e CDT, no MI-2 e no MI-3. Essa tabela mostra o ERM e o erro absoluto de velocidade para os Teste 21 a 40.

Assim como na estratégia de implementação $A$, as figuras com os resultados gráficos de velocidade estimada e medida dos testes não apresentados nesta seção são mostrados no Apêndice A. Esses resultados são relativos ao desempenho da RNA B3 em diferentes condições de ensaio. Nos Testes 22 e 27 o MI-2 é acionado a $55 \mathrm{rad} / \mathrm{s}$ com torque de carga nominal tanto no CDC bem como no CDT, respectivamente. O erro de estimação em regime permanente no Teste 22 é de 1,93 rad/s, enquanto no Teste 27 o erro é de 1,89 rad/s. Quando o MI-3 é usado, conforme os Teste 32 e Teste 37, onde é aplicado 7,1 N.m. de torque de carga em regime permanente, o erro de estimação de velocidade foi de 0,03 $\mathrm{rad} / \mathrm{s}$ no Teste 22 e de $0,05 \mathrm{rad} / \mathrm{s}$ no Teste 37 . Nota-se que a precisão de estimação de velocidade da RNA B3 nos testes a 55 rad/s é melhor no MI-3 do que no MI-2. 

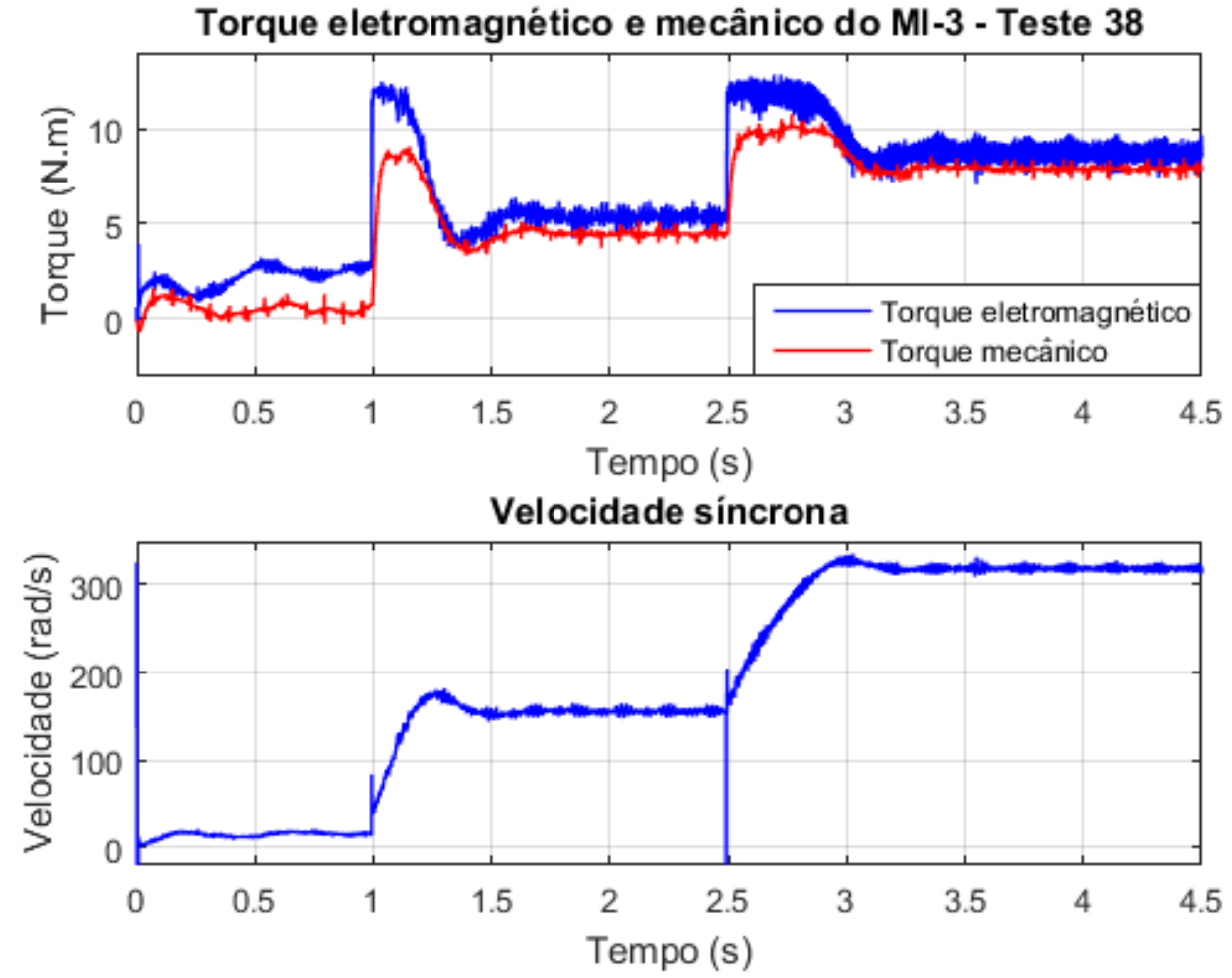

Figura 74 - Dinâmica do torque eletromagnético, mecânico e da velocidade síncrona do MI no teste experimental 38.

Tabela 4.6 - Performance da RNA B3 em regime permanente dos testes experimentais de 21 a 40.

\begin{tabular}{|c|c|c|c|c|c|c|}
\hline Testes & \multicolumn{3}{|c|}{$\begin{array}{l}\text { Error do Estimador } \\
(\mathrm{rad} / \mathrm{s})\end{array}$} & \multicolumn{3}{|c|}{$\begin{array}{l}\text { ERM do Estimador } \\
(\%)\end{array}$} \\
\hline CDC MI-2 & P.O.1 & P.O.2 & P.O.3 & P.O.1 & P.O.2 & P.O.3 \\
\hline 21 & 1,21 & - & - & 19,283 & - & - \\
\hline 22 & 1,93 & - & - & 3,679 & - & - \\
\hline 23 & 2,52 & 1,02 & 1,36 & 47,041 & 1,565 & 1,136 \\
\hline 24 & 1,41 & 1,37 & - & 1,289 & 1,136 & - \\
\hline 25 & 1,71 & 1,44 & - & 17,024 & 3,032 & - \\
\hline \multicolumn{7}{|l|}{ CDT MI-2 } \\
\hline 26 & 0,96 & - & - & 15,384 & - & - \\
\hline 27 & 1,89 & - & - & 3,382 & - & - \\
\hline 28 & 2,51 & 1,15 & 1,60 & 32,141 & 1,486 & 1,022 \\
\hline 29 & 1,43 & 1,34 & - & 1,199 & 1,027 & - \\
\hline 30 & 1,63 & 1,41 & - & 20,254 & 3,062 & - \\
\hline \multicolumn{7}{|l|}{ CDC MI-3 } \\
\hline 31 & 0,58 & - & - & 6,871 & - & - \\
\hline 32 & 0,03 & - & - & 0,059 & - & - \\
\hline 33 & 1,53 & 0,03 & 0,48 & 17,673 & 0,036 & 0,316 \\
\hline 34 & 0,33 & 0,67 & - & 0,262 & 0,535 & - \\
\hline 35 & 0,15 & 0,31 & - & 1,786 & 0,632 & - \\
\hline \multicolumn{7}{|l|}{ CDT MI-3 } \\
\hline 36 & 0,86 & - & - & 10,582 & - & - \\
\hline 37 & 0,05 & - & - & 0,089 & - & - \\
\hline 38 & 0,86 & 0,06 & 0,55 & 13,055 & 0,078 & 0,355 \\
\hline 39 & 0,38 & 0,44 & - & 0,316 & 0,337 & - \\
\hline 40 & 0,27 & 0,11 & - & 2,139 & 0,344 & - \\
\hline
\end{tabular}

No Teste 24 e no Teste 29 o MI-2 é acionado pelo CDC e pelo CDT, respectivamente, a $125 \mathrm{rad} / \mathrm{s}$ e após $2,5 \mathrm{~s}$ a referência de velocidade é alterada para $-125 \mathrm{rad} / \mathrm{s}$. O erro de estimação de velocidade da RNA B3 foi de 1,41 rad/s no P.O.1 e de 1,37 rad/s no P.O.2 
durante o Teste 24 e de 1,43 rad/s no P.O.1 e de 1,34 rad/s durante o Teste 29. Quando esses níveis de velocidade são aplicados ao MI-3, o erro do estimador neural de velocidade foi de $0,33 \mathrm{rad} / \mathrm{s}$ no P.O.1 e de $0,67 \mathrm{rad} / \mathrm{s}$ no P.O. 2 durante o Teste 24 e de $0,38 \mathrm{rad} / \mathrm{s}$ no P.O.1 e de 0,44 rad/s no P.O.2 durante o Teste 39.

$\mathrm{Na}$ sequência são executados outros testes de mudança de sentido de rotação, em que é aplicado nos MIs a referência de velocidade de -10 rad/s durante $1 \mathrm{~s}$, e após esse tempo aplica-se um degrau de velocidade levando a rotação do MI para $45 \mathrm{rad} / \mathrm{s}$. No P.O.1 do Teste 25 o erro de estimação da RNA B3 é de $1,71 \mathrm{rad} / \mathrm{s}$ e de 1,44 rad/s no P.O.2, enquanto no Teste 40 o erro do estimador de velocidade foi de 0,45 rad/s no P.O.1 e de $0,11 \mathrm{rad} / \mathrm{s}$ no P.O.2. Assim como nos resultados obtidos no método de implementação $A$, no método $B$ a precisão na estimativa de velocidade em -10 rad/s é melhor quando o MI-3 é usado do que no MI-2.

Mais uma vez os testes realizados com o MI-2 e com o MI-3 mostram que a RNA B3 é estável quando usada na realimentação da malha de controle de velocidade. Entretanto, a estratégia de implementação $B$ apresenta baixa precisão nos testes de baixa velocidade quando comparada a estratégia de implementação $A$ com erro de até 47,041\% no MI-2 e de $17,673 \%$ no MI-3, como mostram os resultados obtidos com os MIs a $7 \mathrm{rad} / \mathrm{s}, 8 \mathrm{rad} / \mathrm{s}$ e $10 \mathrm{rad} / \mathrm{s}$.

\subsection{Conclusões Sobre a Validação Experimental do Estimador Neural de Velocidade}

Nesse capítulo foi primeiramente aplicado um procedimento para a seleção da melhor RNA nas estratégias de implementação $A$ e $B$. Nesse procedimento a performance das RNAs foram avaliadas como observador de velocidade em três níveis de velocidade do MI-2; a saber: $7 \mathrm{rad} / \mathrm{s}, 90 \mathrm{rad} / \mathrm{s}$ e $180 \mathrm{rad} / \mathrm{s}$.

Uma vez observado que o erro do estimador de velocidade é acentuado nos testes de baixa velocidade de acionamento, foram realizados testes computacionais com o MI2 a $5 \mathrm{rad} / \mathrm{s}$ onde foi observado que o estimador neural de velocidade tem sua precisão influenciada pela precisão do estimador de fluxo magnético, como mostrado na Seção 4.1.3.

A RNA selecionada em cada estratégia de implementação é testada em bancada experimental, onde a velocidade estimada pela RNA é usada na realimentação da malha de controle de velocidade no CDC e no DTC. Os teste são conduzidos em ampla faixa de velocidade e de torque de carga. Além disso, as mesmas RNAs são testadas em duas máquinas de potências diferentes, o MI-2 e o MI-3. Esses testes experimentais mostram que ambas as estratégias de implementação dos estimadores neurais de velocidade são estáveis. Entretanto, a precisão da RNA A8 é melhor do que a da RNA B3, principalmente em baixas velocidades. As principais desvantagens da RNA B3 frente a RNA A8 
são o uso do torque eletromagnético, o qual é diretamente dependente da precisão do estimador de fluxo e também o menor número de sinais diferentes de entradas na RNA para o mapeamento da velocidade do MI.

Na metodologia $A$ a RNA A8 tem como sinais de entrada as correntes $i_{d}, i_{q}$ e a velocidade síncrona $\left(\omega_{e}\right)$. Nos experimentos realizados com o MI-2 a $7 \mathrm{rad} / \mathrm{s}$ o erro máximo na estimativa da velocidade chegou a 1,81 rad/s, enquanto com o MI-3 foi de 1,49 rad/s. Com o MI-2 a $75 \mathrm{rad} / \mathrm{s}$ o erro máximo de estimação de velocidade foi de 0,51 $\mathrm{rad} / \mathrm{s}$ e de 0,75 rad/s com o MI-3. Nos ensaios experimentais com o MI-2 a $155 \mathrm{rad} / \mathrm{s}$ erro de estimação da RNA A8 foi de até $1,27 \mathrm{rad} / \mathrm{s}$ e de $0,56 \mathrm{rad} / \mathrm{s}$.

As entradas da RNA B3, na metodologia $B$, tem como sinais de entrada o torque eletromagnético $\left(T_{e}\right)$ e a velocidade síncrona $\left(\omega_{e}\right)$. Com o MI-2 a $7 \mathrm{rad} / \mathrm{s}$ o erro na estimativa da velocidade foi de até 2,52 rad/s, enquanto com o MI-3 foi de até 1,53 rad/s. Nos ensaios experimentais como o MI-2 à $75 \mathrm{rad} / \mathrm{s}$ o erro de estimação de velocidade foi de até $1,15 \mathrm{rad} / \mathrm{s}$ e de $0,06 \mathrm{rad} / \mathrm{s}$ com o MI-3. Com o MI-2 a $155 \mathrm{rad} / \mathrm{s}$ erro de estimação da RNA B3 foi de até 1,60 rad/s e de 0,55 rad/s com o MI-3.

Os resultados experimentais mostram que na estratégia de implementação $A$, do estimador neural de velocidade, a performance no MI-2 é similar aos testes realizados com o MI-3. Entretanto, na estratégia de implementação $B$, o desempenho de todos os testes conduzidos com o MI-3 é superior em relação aos realizados com o MI-2.

Analisando os resultados pode-se concluir o estimador neural de velocidade do MI quando implementado com a estratégia $A$ tem melhor desempenho do que na estratégia $B$, tanto no CDC quanto no CDT. 


\section{Conclusões Gerais e Proposta de Continuidade}

\subsection{Conclusão}

Este trabalho propõe duas metodologias alternativas para estimar a velocidade do motor de indução baseado em redes neurais artificiais TDNN com treinamento supervisionado off-line. O MI é acionado por um inversor fonte de tensão com controle vetorial orientado pelo fluxo do estator com o CDC e pelo CDT. Essas metodologias estimam a velocidade desde o transitório ao regime permanente, compreendendo ampla faixa de operação de frequência e de conjugado de carga.

Foram formados dois grupos de variáveis para compor os conjuntos de dados para o treinamento e validação via simulações do MI-1. Um conjunto é composto com dados do acionamento do CDC e o outro conjunto é formado pelos dados do acionamento pelo CDT. Duas metodologias de implementação do estimador neural foram propostos, onde na metodologia $A$ usa-se como sinais de entrada da RNA as correntes $i_{d s}, i_{q s}$ e a velocidade síncrona, enquanto a metodologia $B$ são usados os sinais de torque eletromagnético e a velocidade síncrona.

Foram treinadas TDNN de $4^{\mathrm{a}}$ e $5^{\mathrm{a}}$ ordem, em cada uma das estratégia de controle. Essas RNAs são testadas em função ao desempenho do método de implementação da tangente hiperbólica como função de ativação dos neurônios das camadas intermediárias. Devido às limitações de memória e de tempo de processamento do DSP, a técnica usada foi a lookup table, onde os valores de saída da tangente hiperbólica foram armazenadas em um vetor com cinco mil posições. Definido o método de implementação, foram realizados testes computacionais a fim de se obter as RNAs com melhor desempenho em cada ordem de atraso da TDNN.

Visando selecionar as RNAs mais generalistas cada RNA selecionada via simulação foi testada experimentalmente como observador de velocidade do MI-2. Nesse procedimento todas as RNAs selecionadas foram usadas em ambos os métodos de acionamento, CDC 
e CDT. Os estimadores neurais de velocidade de melhor desempenho como observador nessa etapa foram a RNA A8 e a RNA B3.

As RNAs de melhor performance em cada uma das estratégia de implementação foram validadas experimentalmente na realimentação de velocidade em ambos os métodos de controle. Ainda, os testes foram conduzidos em ampla faixa de velocidade e de torque de carga. Visando avaliar a robustez e a capacidade de generalização das RNAs, os testes foram realizados com o MI-2 e com o MI-3. Os resultados dos testes demonstram que os dois métodos de implementação são estáveis. Nos testes conduzidos a $7 \mathrm{rad} / \mathrm{s}$ o erro de velocidade no MI-2 foi de 1,81 rad/s e de 1,05 rad/s no CDC e CDT, respectivamente, e no MI-3 foi de 1,49 rad/s no CDC e 0,82 rad/s no CDT. Nos testes conduzidos na estratégia de implementação $B$ a $7 \mathrm{rad} / \mathrm{s}$ o erro de velocidade no MI-2 foi de 2,52 rad/s e $2,51 \mathrm{rad} / \mathrm{s}$ no $C D C$ e $C D T$, respectivamente, e no MI-3 foi de 1,53 rad/s no CDC e 0,86 $\mathrm{rad} / \mathrm{s}$ no $\mathrm{CDT}$.

Por fim, dentre os métodos propostos nesse trabalho, a estratégia de implementação $A$ demonstra ter melhor desempenho na estimação da velocidade do MI acionamento pelo controle vetorial orientados pelo fluxo do estator no CDC e no CDT.

\subsection{Proposta de Continuidade}

As propostas de continuidade deste trabalho estão descritas como segue:

$\square$ Implementar a estratégia $A$ usando uma menor taxas de amostragem e usar filtros nos sinais de entrada da RNA a fim de atenuar as oscilações da velocidade estimada;

$\square$ Implementar a estratégia $A$ usando outras estratégias de estimação de fluxo magnético do estator;

$\square$ Implementar a estratégia $A$ no controle vetorial orientado no fluxo do rotor;

$\square$ Implementar a estratégia $A$ como estimador da velocidade de escorregamento do MI para a obtenção indireta da velocidade mecânica;

Testar outros tipos de estratégias de controle com o estimador neural de velocidade.

\subsection{Artigos Publicados}

Ao longo da realização deste trabalho, os seguintes artigos foram publicados:

T. H. dos Santos, I. N. da Silva, A. Goedtel e M. F. Castoldi. Estimador Neural da Velocidade do MIT Acionado por um Driver com Controle Vetorial Orientado pelo Fluxo do Estator. XII Símpósio Brasileiro de Automação Inteligente (SBAI), 2015. 
- T. H. dos Santos, I. N. da Silva, A. Goedtel, M. F. Castoldi e R. R. Sumar. Estimador Neural de Velocidade para o Controle DTC-SVM Embarcado em DSP. XIII Símpósio Brasileiro de Automação Inteligente (SBAI), 2017.

$\square$ T. H. dos Santos, I. N. da Silva, A. Goedtel e M. F. Castoldi. Speed Estimation Applied to Stator Flux Oriented Control Drives. Electric Power Components and Systems, 2018. (Submetido)

$\square$ T. H. dos Santos, I. N. da Silva, A. Goedtel e M. F. Castoldi. A Single Neural Speed Estimator Approach Applied to DCC and DTC Vector Drivers. IEEE Transactions on Power Electronics, 2018. (Submetido) 


\section{Referências}

ABU-RUB, H.; STANDO, D.; KAZMIERKOWSKI, M. P. Simple speed sensorless dtc-svm scheme for induction motor drives. Bulletin of the Polish Academy of Sciences Technical Sciences, 2013. v. 61, p. $301-307,2013$.

ALONGE, F.; CIRRINCIONE, M.; PUCCI, M.; SFERLAZZA, A. Input-output feedback linearization control with on-line mras-based inductor resistance estimation of linear induction motors including the dynamic end effects. IEEE Transactions on Industry Applications, 2016. v. 52, n. 1, p. 254-266, Jan 2016.

ALONGE, F.; D'IPPOLITO, F.; SFERLAZZA, A. Sensorless control of induction-motor drive based on robust kalman filter and adaptive speed estimation. IEEE Transactions on Industrial Electronics, 2014. v. 61, n. 3, p. 1444-1453, March 2014.

AMEZQUITA-BROOKS, L.; LICEAGA-CASTRO, J.; LICEAGA-CASTRO, E. Speed and position controllers using indirect field-oriented control: A classical control approach. IEEE Transactions on Industrial Electronics, 2014. v. 61, n. 4, p. 1928-1943, April 2014.

Speed and position controllers using indirect field-oriented control: A classical control approach. IEEE Transactions on Industrial Electronics, 2014. v. 61, n. 4, p. 1928-1943, April 2014.

ANDRIAMALALA, R. N.; RAZIK, H.; RAZAFINJAKA, J. N.; BAGHLI, L.; SARGOS, F. M. Independent and direct rotor-flux oriented control of series-connected induction machines using decoupled kalman-filters. In: IECON 2011 - 37th Annual Conference of the IEEE Industrial Electronics Society. [S.l.: s.n.], 2011. p. 3488-3494.

ANGéLiCO, B. A.; CAMPANHOL, L. B. G.; SILVA, S. A. O. da. Proportionalintegral/proportional-integral-derivative tuning procedure of a single-phase shunt active power filter using bode diagram. IET Power Electronics, 2014. v. 7, n. 10, p. 2647-2659, 2014. ISSN 1755-4535.

AYDOGMUS, Z.; AYDOGMUS, O. A comparison of artificial neural network and extended kalman filter based sensorless speed estimation. Measurement, 2015. v. 63, p. 152 - 158, 2015. 
AZCUE-PUMA, J. L.; FILHO, A. J. S.; RUPPERT, E. The fuzzy logic-based stator-flux-oriented direct torque control for three-phase asynchronous motor. Journal of Control, Automation and Electrical Systems, 2014. v. 25, n. 1, p. 46-54, 2014.

BIERHOFF, M. H. A general pll-type algorithm for speed sensorless control of electrical drives. IEEE Transactions on Industrial Electronics, 2017. v. 64, n. 12, p. 9253-9260, Dec 2017.

BOSE, B. K.; WASYNCZUK, O.; SUDHOF, S. D. Modern Power Eletronics and AC Drives. [S.1.]: Pretice Hall - New Jersey, 2002.

BOUSSADA, Z.; HAMED, M. B.; SBITA, L. Adaptive neuro-fuzzy inference system into induction motor: Estimation. In: 2014 International Conference on Electrical Sciences and Technologies in Maghreb (CISTEM). [S.l.: s.n.], 2014. p. 1-5.

CAMPANHOL, L. B. G. Filtro ativo de potência paralelo utilizando inversores monofásicos FULL-BRIDGE aplicado em sistemas trifásicos a quatro-fios. Dissertação (Mestrado) — Universidade Tecnológica Federal do Paraná, Cornélio Procópio, 2012.

CARUANA, C.; ASHER, G. M.; SUMNER, M. Performance of hf signal injection techniques for zero-low-frequency vector control of induction machines under sensorless conditions. IEEE Transactions on Industrial Electronics, 2005. v. 53, n. 1, p. 225-238, Feb 2005.

CASADEI, D.; PROFUMO, F.; SERRA, G.; TANI, A. Foc and dtc: two viable schemes for induction motors torque control. IEEE Transactions on Power Electronics, 2002. v. 17, n. 5, p. 779-787, Sep 2002.

COMANESCU, M. An induction-motor speed estimator based on integral sliding-mode current control. IEEE Transactions on Industrial Electronics, 2009. v. 56, n. 9, p. 3414-3423, Sept 2009.

EPE. Balanço energético nacional 2014, ano base 2013. [S.l.]: Empresa de Pesquisa Energética, Ministério de Minas e Energia, 2014.

FILADELFO, F. R. Modelagem de controle vetorial orientado pelo fluxo do estator de motor de indução trifásico aplicado em um sistema de propulsão veicular. Tese (Doutorado) — Universidade Estadual Paulista - Faculdade de Engenharia de Guaratinguetá - UNESP, Guaratinguetá, SP, 2016. Disponível em: $<$ https://repositorio.unesp.br/handle/11449/148748>. Acesso em: 23.04.2018.

FU, X.; LI, S. A novel neural network vector control technique for induction motor drive. IEEE Transactions on Energy Conversion, 2015. v. 30, n. 4, p. 1428-1437, Dec 2015.

GADOUE, S. M.; GIAOURIS, D.; FINCH, J. W. Stator current model reference adaptive systems speed estimator for regenerating-mode low-speed operation of sensorless induction motor drives. IET Electric Power Applications, 2013. v. 7, n. 7, p. 597-606, Aug 2013.

GDAIM, S.; MTIBAA, A.; MIMOUNI, M. F. Design and experimental implementation of dtc of an induction machine based on fuzzy logic control on fpga. IEEE Transactions on Fuzzy Systems, 2015. v. 23, n. 3, p. 644-655, June 2015. 
GONZALEZ, H.; RIVAS, R.; RODRIGUEZ, T. Using an artificial neural network as a rotor resistance estimator in the indirect vector control of an induction motor. IEEE Latin America Transactions, 2008. v. 6, n. 2, p. 176-183, June 2008.

HAGAN, M.; MENHAJ, M. Training feedforward networks with the marquardt algorithm. IEEE Transactions on Neural Networks, 1994. v. 5, n. 6, p. 989 -993, nov 1994. ISSN 1045-9227.

HAYKIN, S. Redes Neurais: Princípios e Prática. Porto Alegre, RS: Bookman, 2001.

HERNANDEZ, J. R. Implementação digital utilizando DSP do controle por orientação do fluxo do rotor : metodos direto e indireto. Dissertação (Mestrado) — Universidade Estadual de Campinas, Campinas, Maio 1999.

HINKKANEN, M.; LUOMI, J. Parameter sensitivity of full-order flux observers for induction motors. IEEE Transactions on Industry Applications, 2003. v. 39, n. 4, p. 1127-1135, July 2003.

HOLTZ, J. The representation of ac machine dynamics by complex signal flow graphs. IEEE Transactions on Industrial Electronics, 1995. v. 42, n. 3, p. 263-271, Jun 1995.

IDRIS, N. R. N.; YATIM, A. H. M. An improved stator flux estimation in steady-state operation for direct torque control of induction machines. IEEE Transactions on Industry Applications, 2002. v. 38, n. 1, p. 110-116, Jan 2002.

JANSEN, P. L.; LORENZ, R. D.; NOVOTNY, D. W. Observer-based direct field orientation: analysis and comparison of alternative methods. IEEE Transactions on Industry Applications, 1994. v. 30, n. 4, p. 945-953, Jul 1994.

JEVREMOVIC, V. R.; VASIC, V.; MARCETIC, D. P.; JEFTENIC, B. Speed-sensorless control of induction motor based on reactive power with rotor time constant identification. IET Electric Power Applications, 2010. v. 4, n. 6, p. 462-473, July 2010.

KAISER, M. Time-delay neural networks for control. IFAC Proceedings Volumes, 1994. v. 27, n. 14, p. 967 - 972, 1994. ISSN 1474-6670. Fourth IFAC Symposium on Robot Control, Capri, Italy, September 19-21, 1994.

KAN, J.; ZHANG, K.; WANG, Z. Indirect vector control with simplified rotor resistance adaptation for induction machines. IET Power Electronics, 2015. v. 8, n. 7, p. 1284-1294, 2015.

KARANAYIL, B.; RAHMAN, M. F.; GRANTHAM, C. Online stator and rotor resistance estimation scheme using artificial neural networks for vector controlled speed sensorless induction motor drive. IEEE Transactions on Industrial Electronics, 2007. v. 54, n. 1, p. 167-176, Feb 2007.

KAZMIERKOWSKI, M. P.; FRANQUELO, L. G.; RODRIGUEZ, J.; PEREZ, M. A.; LEON, J. I. High-performance motor drives. IEEE Industrial Electronics Magazine, 2011. v. 5, n. 3, p. 6-26, Sept 2011.

KRAUSE, P. C.; WASYNCZUK, O.; SUDHOF, S. D. Analysis of Electric Machinery and Drive Systems. [S.l.]: Academic Press - New Jersey, 2002. 
KRISHNAN, R. Electric motor drives: modeling, analysis, and control. [S.1.]: Prentice Hall - New Jersey, 2001.

LANG, K. J.; HINTON, G. E. The development of the time-delay neural network architecture for speech recognition. Technical Report CMU-CS-88-152, 1988. Carnegie-Mellon University, Pittsburg, Pennsylvania, 1988.

LASCU, C.; ANDREESCU, G. D. Sliding-mode observer and improved integrator with dc-offset compensation for flux estimation in sensorless-controlled induction motors.

IEEE Transactions on Industrial Electronics, 2006. v. 53, n. 3, p. 785-794, June 2006.

LASCU, C.; BOLDEA, I.; BLAABJERG, F. A modified direct torque control for induction motor sensorless drive. IEEE Transactions on Industry Applications, 2000. v. 36, n. 1, p. 122-130, Jan 2000.

A class of speed-sensorless sliding-mode observers for high-performance induction motor drives. IEEE Transactions on Industrial Electronics, 2009. v. 56, n. 9, p. 3394-3403, Sept 2009.

LIMA, F.; KAISER, W.; SILVA, I. N. da; JR., A. A. de O. Open-loop neuro-fuzzy speed estimator applied to vector and scalar induction motor drives. Applied Soft Computing, 2014. v. 21, p. $469-480,2014$.

LONGJI, Z.; RULIN, W. A novel direct torque control system based on space vector pwm. In: Power Electronics and Motion Control Conference, 2004. IPEMC 2004. The 4th International. [S.l.: s.n.], 2004. v. 2, p. 755-760 Vol.2.

MAITI, S.; VERMA, V.; CHAKRABORTY, C.; HORI, Y. An adaptive speed sensorless induction motor drive with artificial neural network for stability enhancement. IEEE Transactions on Industrial Informatics, 2012. v. 8, n. 4, p. 757-766, Nov 2012.

MAREI, M. I.; SHAABAN, M. F.; EL-SATTAR, A. A. A speed estimation unit for induction motors based on adaptive linear combiner. Energy Conversion and Management, 2009. v. 50, n. 7, p. 1664-1670, 2009.

MARQUES, F. D.; SOUZA, L. d. F. R. d.; REBOlhO, D. C.; CAPORALI, A. S.; BELO, E. M.; ORTOLAN, R. L. Application of time-delay neural and recurrent neural networks for the identification of a hingeless helicopter blade flapping and torsion motions. Journal of the Brazilian Society of Mechanical Sciences and Engineering, 2005. scielo, v. 27, p. 97 - 103, 06 2005. ISSN 1678-5878.

MERABET, A.; TANVIR, A. A.; BEDDEK, K. Torque and state estimation for real-time implementation of multivariable control in sensorless induction motor drives. IET Electric Power Applications, 2017. v. 11, n. 4, p. 653-663, 2017. ISSN 1751-8660.

NUNES, I.; SPATTI, D. H.; FLAUZINO, R. A. Redes Neurais Artificiais para Engenharia e Ciências Aplicadas. São Paulo, SP: Artliber, 2010.

OGUZ, Y.; DEDE, M. Speed estimation of vector controlled squirrel cage asynchronous motor with artificial neural networks. Energy Conversion and Management, 2011. v. 52, n. 1, p. 675-686, 2011. 
ONG, C.-M. Dynamic Simulation of Electric Machinery: Using Matlab/Simulink. Upper Sanddle River, NJ: Prentice-Hall, 1998.

ORLOWSKA-KOWALSKA, T.; DYBKOWSKI, M. Stator-current-based mras estimator for a wide range speed-sensorless induction-motor drive. IEEE Transactions on Industrial Electronics, 2010. v. 57, n. 4, p. 1296-1308, April 2010.

ROSENBLATT, F. The perceptron: A probabilistic model for information storage and organization in the brain. Psychological Review, 1958. v. 65, n. 6, p. 386-408, nov 1958.

SANTOS, T. H. dos; GOEDTEL, A.; SILVA, S. A. O. da; SUETAKE, M. Scalar control of an induction motor using a neural sensorless technique. Electric Power Systems Research, 2014. v. 108, p. 322 - 330, 2014.

SILVA, S. A. O. d.; CAMPANHOL, L. B. G.; GOEDTEL, A.; NASCIMENTO, C. F.; PAIAO, D. A comparative analysis of p-pll algorithms for single-phase utility connected systems. In: Power Electronics and Applications, 2009. EPE '09. 13th European Conference on. [S.l.: s.n.], 2009. p. 1-10.

SMITH, A. N.; GADOUE, S. M.; FINCH, J. W. Improved rotor flux estimation at low speeds for torque mras-based sensorless induction motor drives. IEEE Transactions on Energy Conversion, 2016. v. 31, n. 1, p. 270-282, March 2016.

SOUZA, A. B. de; NETO, T. R. F.; HONóRIO, D. d. A.; DINIZ, E. de C.; BARRETO, L. H. S. C.; REIS, L. L. N. dos. Hybrid position controller for an indirect field-oriented induction motor drive. Eletrônica de Potência, 2014. v. 19, n. 4, p. 343 - 353, 2014.

STOJIĆ, D.; MILINKOVIĆ, M.; VEINOVIĆ, S.; KLASNIĆ, I. Improved stator flux estimator for speed sensorless induction motor drives. IEEE Transactions on Power Electronics, 2015. v. 30, n. 4, p. 2363-2371, April 2015.

SUETAKE, M.; SILVA, I. N. da; GOEDTEL, A. Embedded dsp-based compact fuzzy system and its application for induction-motor v/f speed control. IEEE Transactions on Industrial Electronics, 2011. v. 58, n. 3, p. 750-760, March 2011.

SUN, W.; GAO, J.; YU, Y.; WANG, G.; XU, D. Robustness improvement of speed estimation in speed-sensorless induction motor drives. IEEE Transactions on Industry Applications, 2016. v. 52, n. 3, p. 2525-2536, May 2016.

SUN, X.; CHEN, L.; YANG, Z.; ZHU, H. Speed-sensorless vector control of a bearingless induction motor with artificial neural network inverse speed observer. IEEE/ASME Transactions on Mechatronics, 2013. v. 18, n. 4, p. 1357-1366, Aug 2013.

TAKAHASHI, I.; NOGUCHI, T. A new quick-response and high-efficiency control strategy of an induction motor. IEEE Transactions on Industry Applications, 1986. IA-22, n. 5, p. 820-827, Sept 1986.

TIR, Z.; MALIK, O. P.; ELTAMALY, A. M. Fuzzy logic based speed control of indirect field oriented controlled double star induction motors connected in parallel to a single six-phase inverter supply. Electric Power Systems Research, 2016. v. 134, p. 126 $133,2016$. 
TOLIYAT, H. A.; LEVI, E.; RAINA, M. A review of rfo induction motor parameter estimation techniques. IEEE Transactions on Energy Conversion, 2003. v. 18, n. 2, p. 271-283, June 2003.

UDDIN, M. N.; HUANG, Z. R.; HOSSAIN, A. B. M. S. Development and implementation of a simplified self-tuned neuro-fuzzy-based im drive. IEEE Transactions on Industry Applications, 2014. v. 50, n. 1, p. 51-59, Jan 2014.

VAS, P. Sensorless Vector and Direct Torque Control. [S.l.]: Oxford University Press - Upper Sanddle River, 1998.

VASIC, V.; VUKOSAVIC, S. N.; LEVI, E. A stator resistance estimation scheme for speed sensorless rotor flux oriented induction motor drives. IEEE Transactions on Energy Conversion, 2003. v. 18, n. 4, p. 476-483, Dec 2003.

WAIBEL, A.; HANAZAWA, T.; HINTON, G.; SHIKANO, K.; LANG, K. Phoneme recognition using time-delay neural networks. IEEE Transactions on Acoustics, Speech and Signal Processing, 1989. v. 37, n. 3, p. 328-339, mar 1989. ISSN 0096-3518.

WANG, K.; CHEN, B.; SHEN, G.; YAO, W.; LEE, K.; LU, Z. Online updating of rotor time constant based on combined voltage and current mode flux observer for speed-sensorless ac drives. IEEE Transactions on Industrial Electronics, 2014. v. 61, n. 9 , p. $4583-4593$, Sept 2014.

WANG, S.-Y.; LIU, F.-Y.; CHOU, J.-H. Adaptive $\{$ TSK $\}$ fuzzy sliding mode control design for switched reluctance motor $\{$ DTC $\}$ drive systems with torque sensorless strategy. Applied Soft Computing, 2018. p. -, 2018.

YANG, H.; ZHANG, Y.; WALKER, P. D.; ZHANG, N.; XIA, B. A method to start rotating induction motor based on speed sensorless model-predictive control. IEEE Transactions on Energy Conversion, 2017. v. 32, n. 1, p. 359-368, March 2017. ISSN 0885-8969.

YANG, H.; ZHANG, Y.; WALKER, P. D.; LIANG, J.; ZHANG, N.; XIA, B. Speed sensorless model predictive current control with ability to start a free running induction motor. IET Electric Power Applications, 2017. v. 11, n. 5, p. 893-901, 2017. ISSN 1751-8660.

YANG, S.; LI, X.; DING, D.; ZHANG, X.; XIE, Z. Speed sensorless control of induction motor based on sliding-mode observer and mras. In: 2016 IEEE 8th International Power Electronics and Motion Control Conference (IPEMC-ECCE Asia). [S.l.: s.n.], 2016. p. 1889-1893.

YIN, Z.; ZHAO, C.; LIU, J.; ZHONG, Y. Research on anti-error performance of speed and flux estimator for induction motor using robust reduced-order ekf. IEEE Transactions on Industrial Informatics, 2013. v. 9, n. 2, p. 1037-1046, May 2013.

ZADEH, L. A. Fuzzy logic, neural networks, and soft computing. Communications of the ACM, 1994. ACM, New York, NY, USA, v. 37, p. 77-84, March 1994. ISSN 0001-0782. Disponível em: <http://dl.acm.org/citation.cfm?id=175255>. 
ZBEDE, Y. B.; GADOUE, S. M.; ATKINSON, D. J. Model predictive mras estimator for sensorless induction motor drives. IEEE Transactions on Industrial Electronics, 2016. v. 63, n. 6, p. 3511-3521, June 2016.

ZELECHOWSKI, M. Space Vector Modulated - Direct Torque Controlled (DTC-SVM) Inverter - Fed Induction Motor Drive. Tese (Doutorado) - Faculty of Electrical Engineering - Warsaw University of Technology, Warsaw, Poland, 2005. Disponível em: <http://ufnalski.edu.pl/zne/pimedeo/rozprawy/M_Zelechowski.pdf $>$. Acesso em: 01.4.2018.

ZHANG, X. Sensorless induction motor drive using indirect vector controller and sliding-mode observer for electric vehicles. IEEE Transactions on Vehicular Technology, 2013. v. 62, n. 7, p. 3010-3018, Sept 2013.

ZHANG, Y.; ZHU, J.; ZHAO, Z.; XU, W.; DORRELL, D. G. An improved direct torque control for three-level inverter-fed induction motor sensorless drive. IEEE Transactions on Power Electronics, 2012. v. 27, n. 3, p. 1502-1513, March 2012.

ZHAO, L.; HUANG, J.; CHEN, J.; YE, M. A parallel speed and rotor time constant identification scheme for indirect field oriented induction motor drives. IEEE Transactions on Power Electronics, 2016. v. 31, n. 9, p. 6494-6503, Sept 2016. 
Apêndices 


\section{Resultados Complementares dos Testes Experimentais do Capítulo 4}

Neste anexo são mostrados os gráficos das respostas dinâmicas da velocidade estimada e medida dos resultados experimentais complementares da Seção 4.2.

A.0.1 Resultados Complementares dos Testes experimentais com as RNA A8 realimentando o controle de velocidade

A seguir são apresentados as figuras dos testes experimentais realizados, cujos parâmetros são apresentados na Tabela 4.3 e com o desempenho da RNA em cada ponto de operação mostrados na Tabela 4.4. 


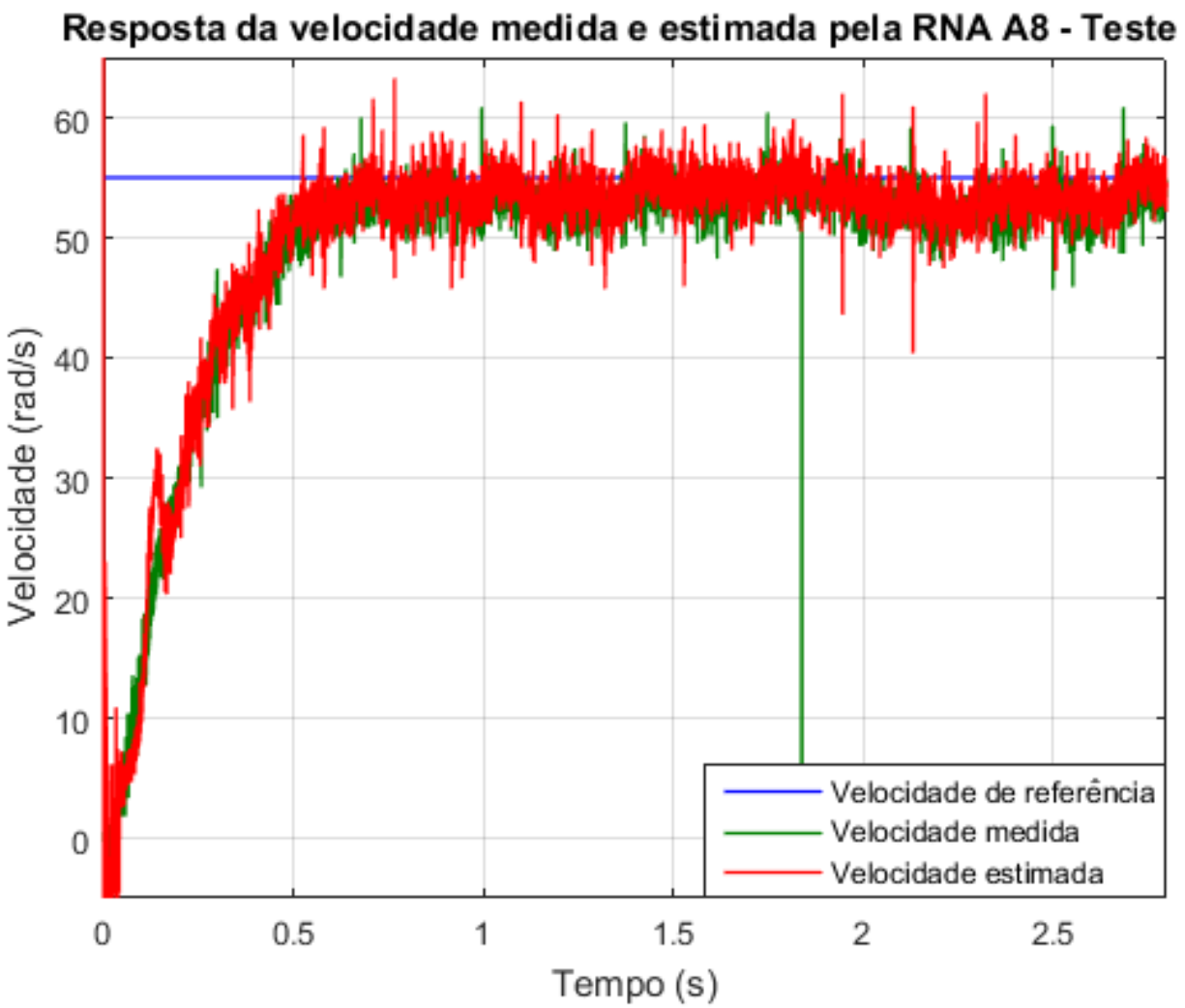

Figura 75 - Resultado da RNA A8 para o teste experimental 2.

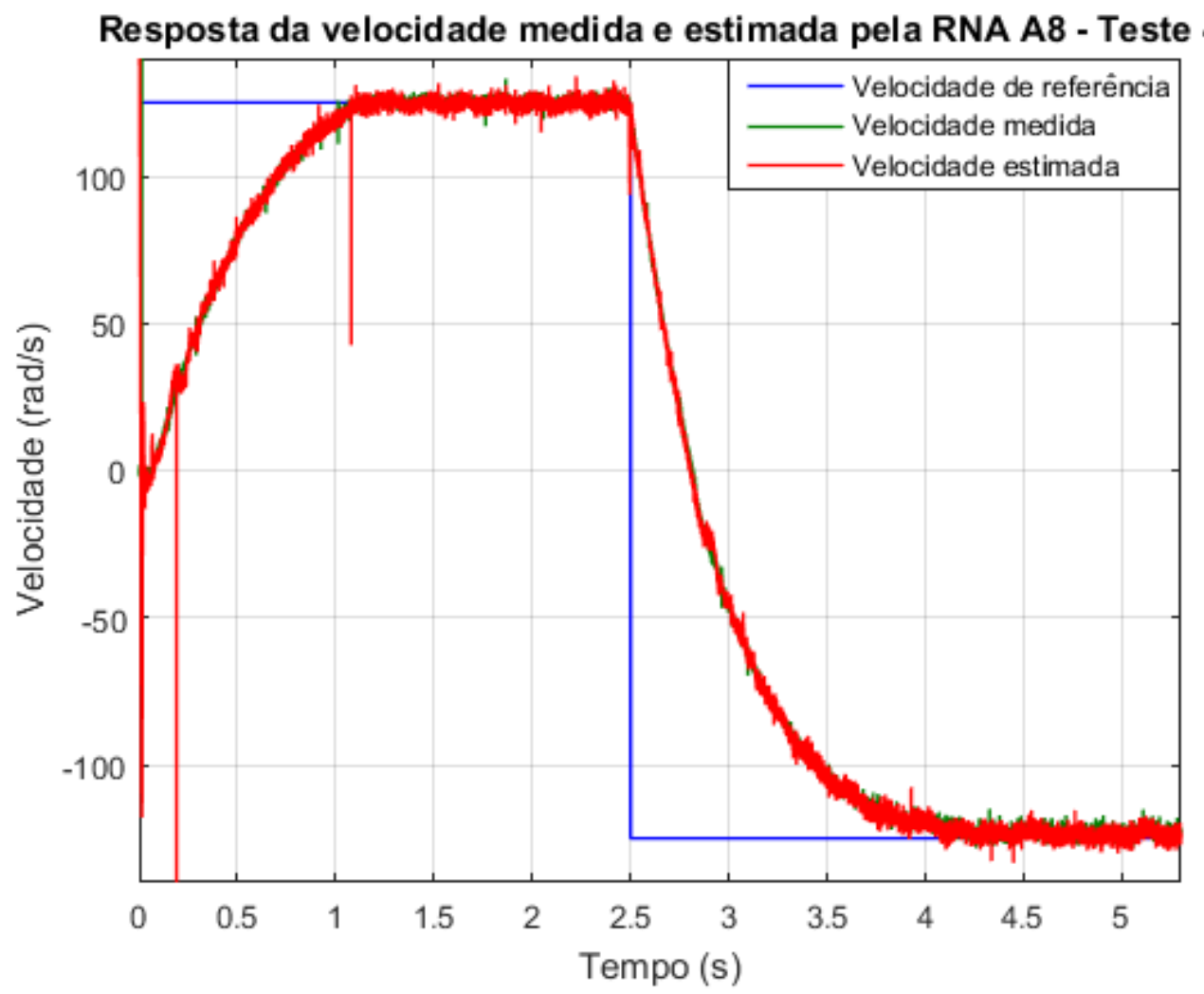

Figura 76 - Resultado da RNA A8 para o teste experimental 4. 


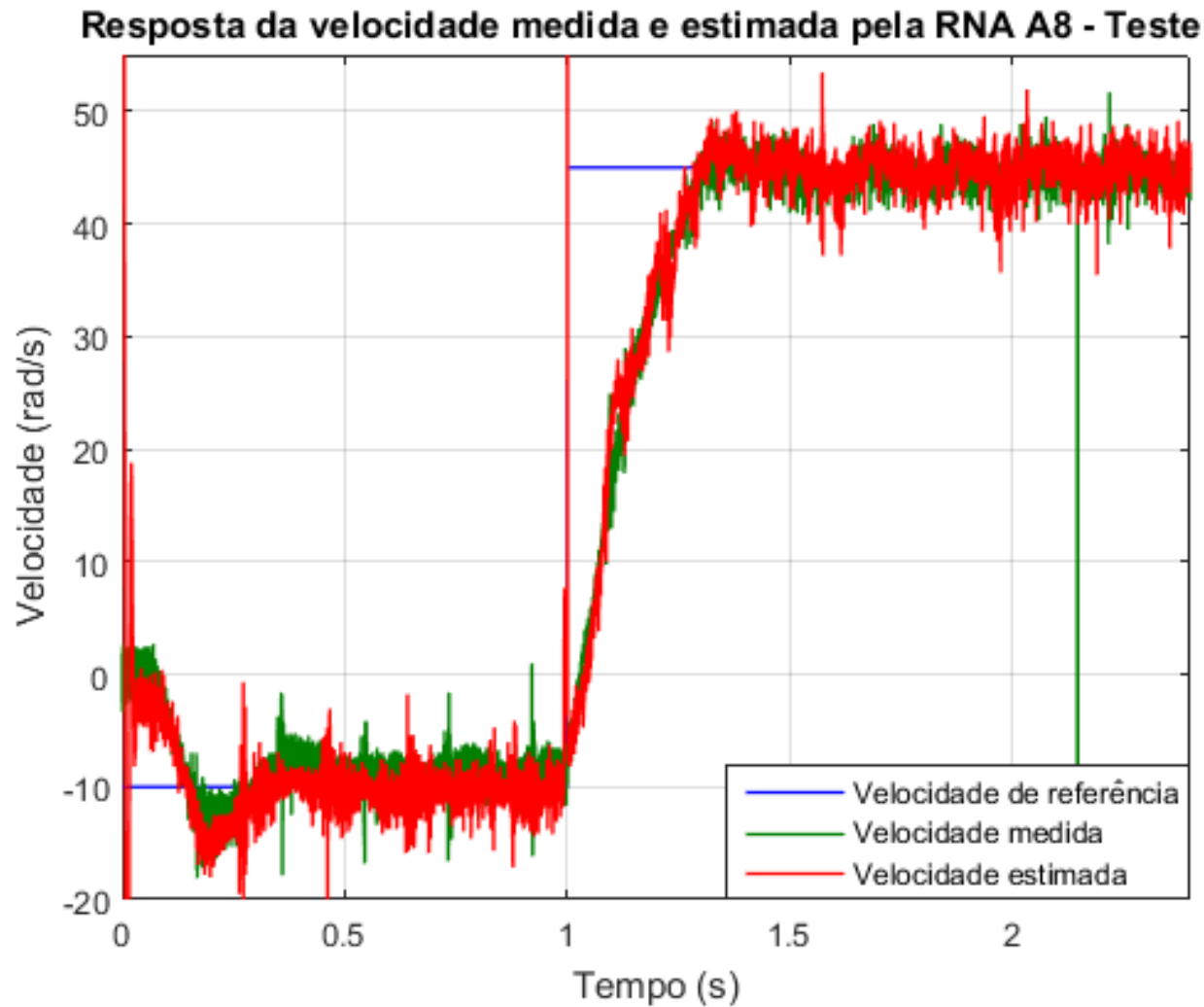

Figura 77 - Resultado da RNA A8 para o teste experimental 5.

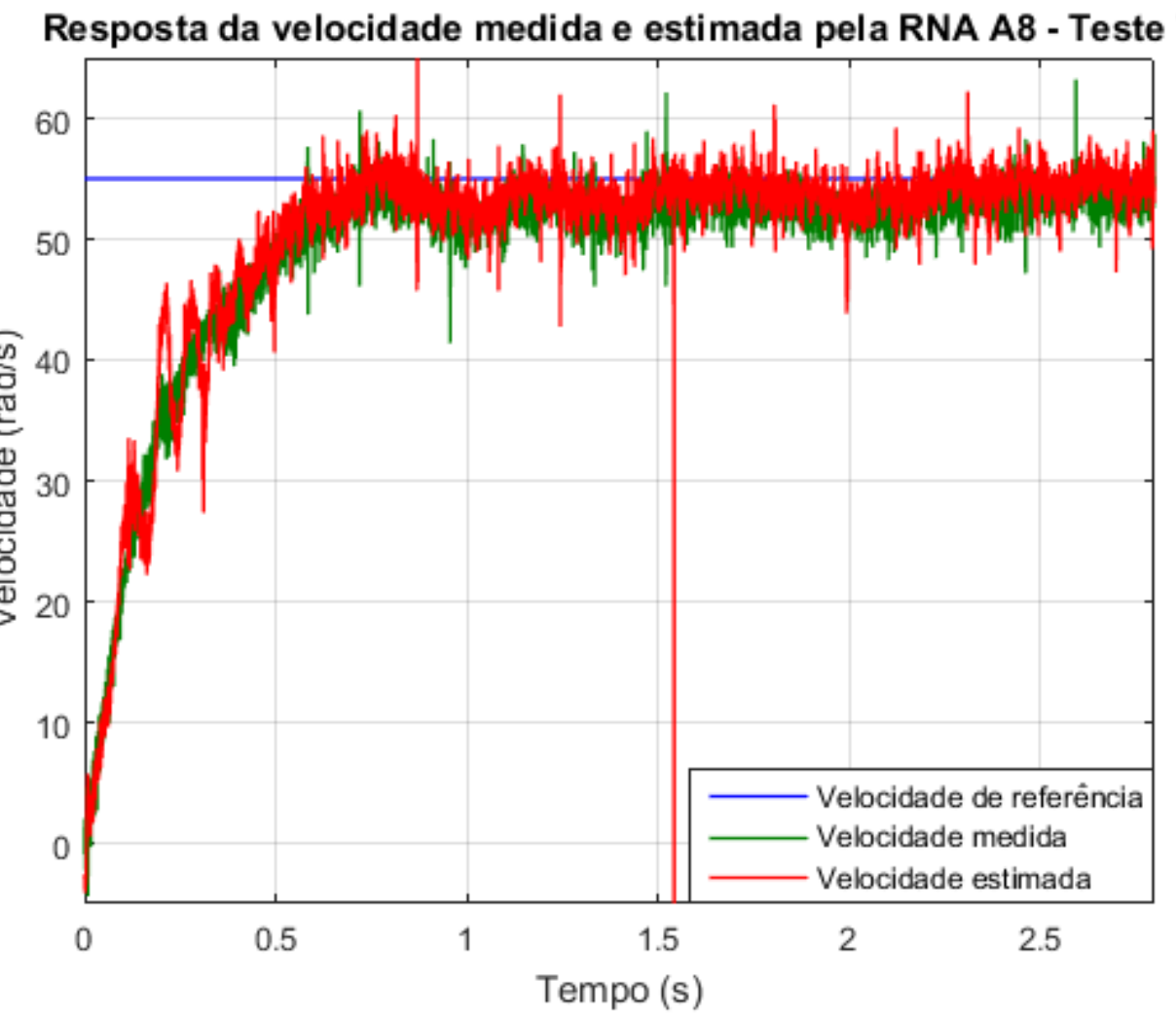

Figura 78 - Resultado da RNA A8 para o teste experimental 7. 


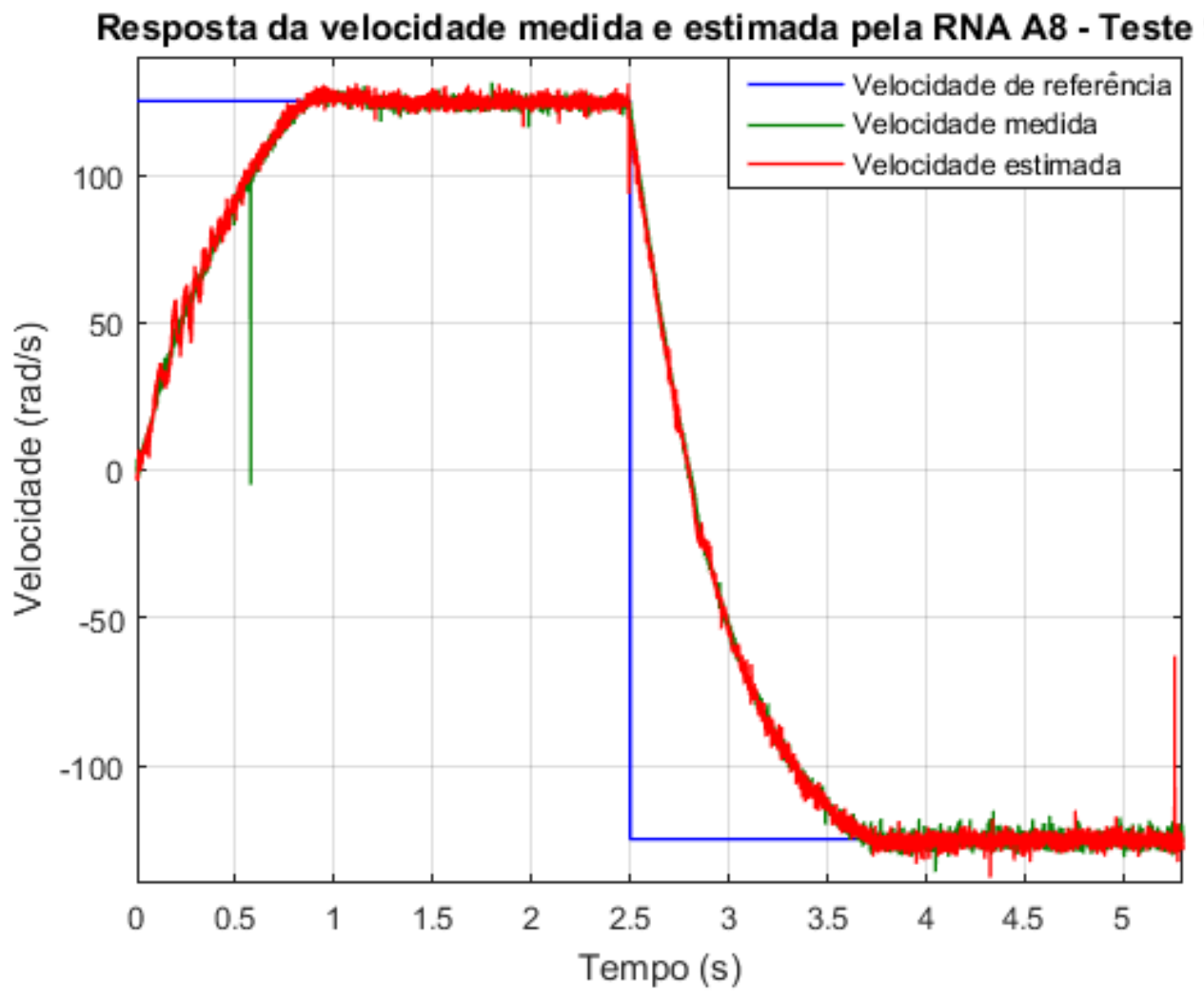

Figura 79 - Resultado da RNA A8 para o teste experimental 9.

Resposta da velocidade medida e estimada pela RNA A8 - Teste 10

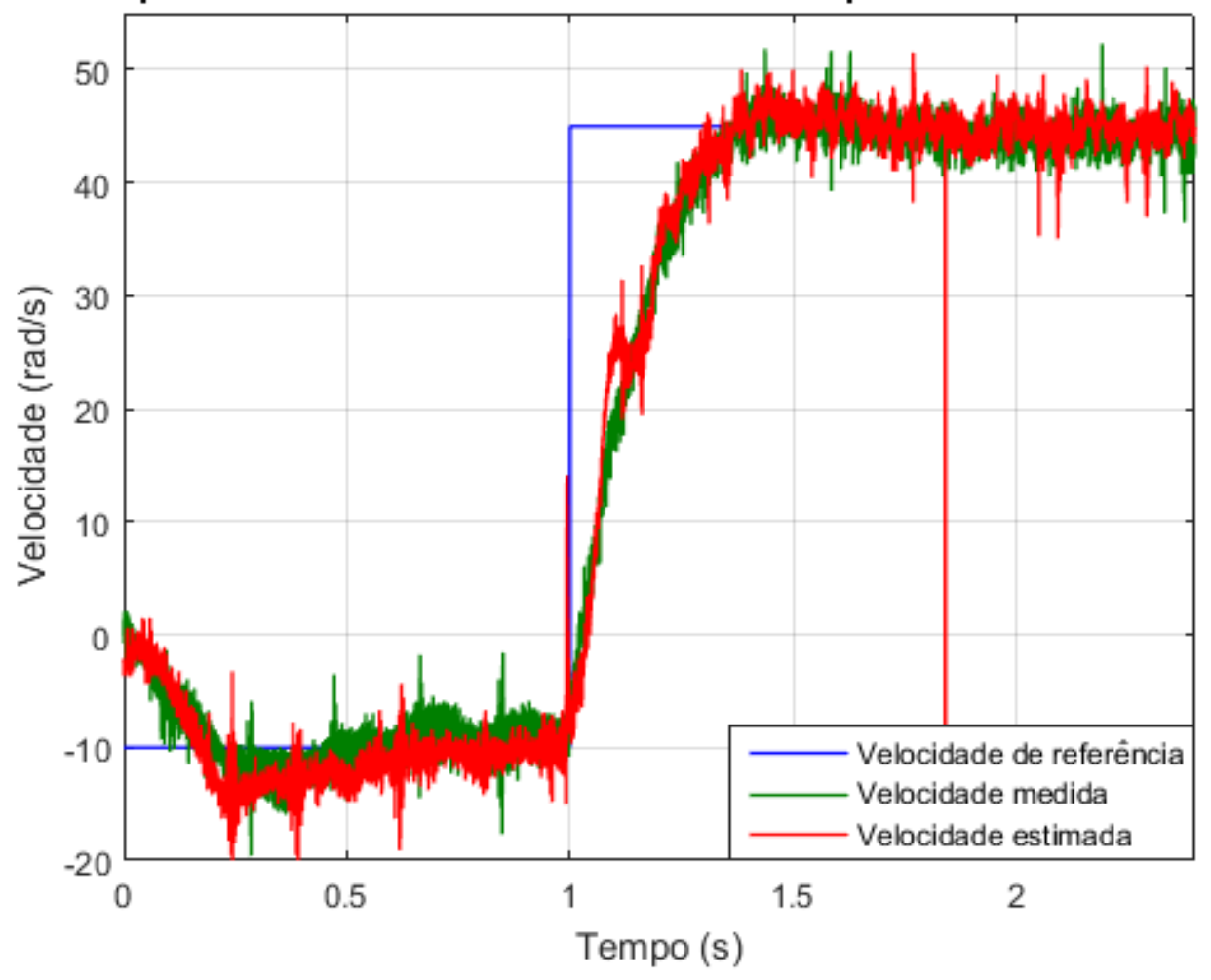

Figura 80 - Resultado da RNA A8 para o teste experimental 10. 


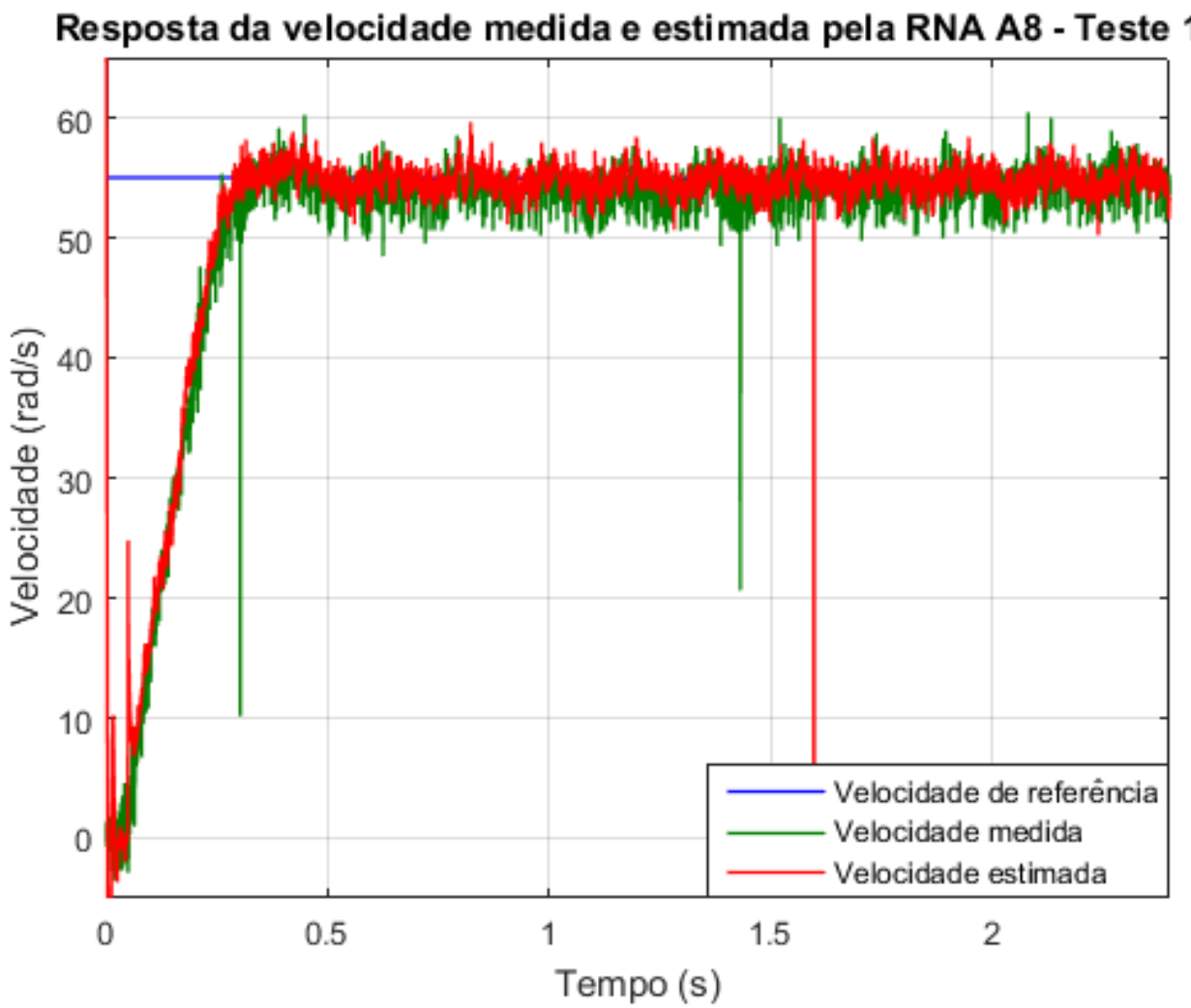

Figura 81 - Resultado da RNA A8 para o teste experimental 12.

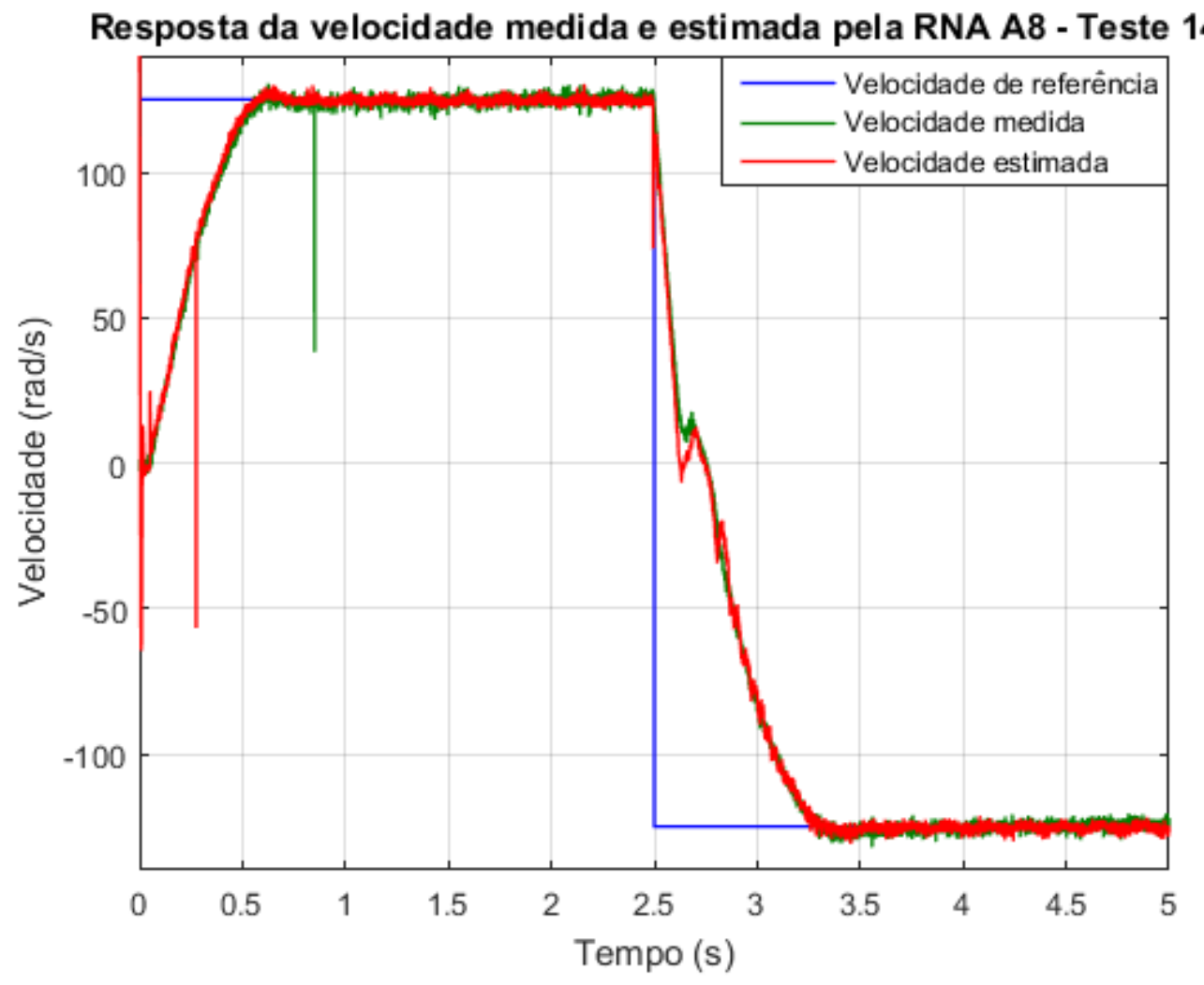

Figura 82 - Resultado da RNA A8 para o teste experimental 14. 


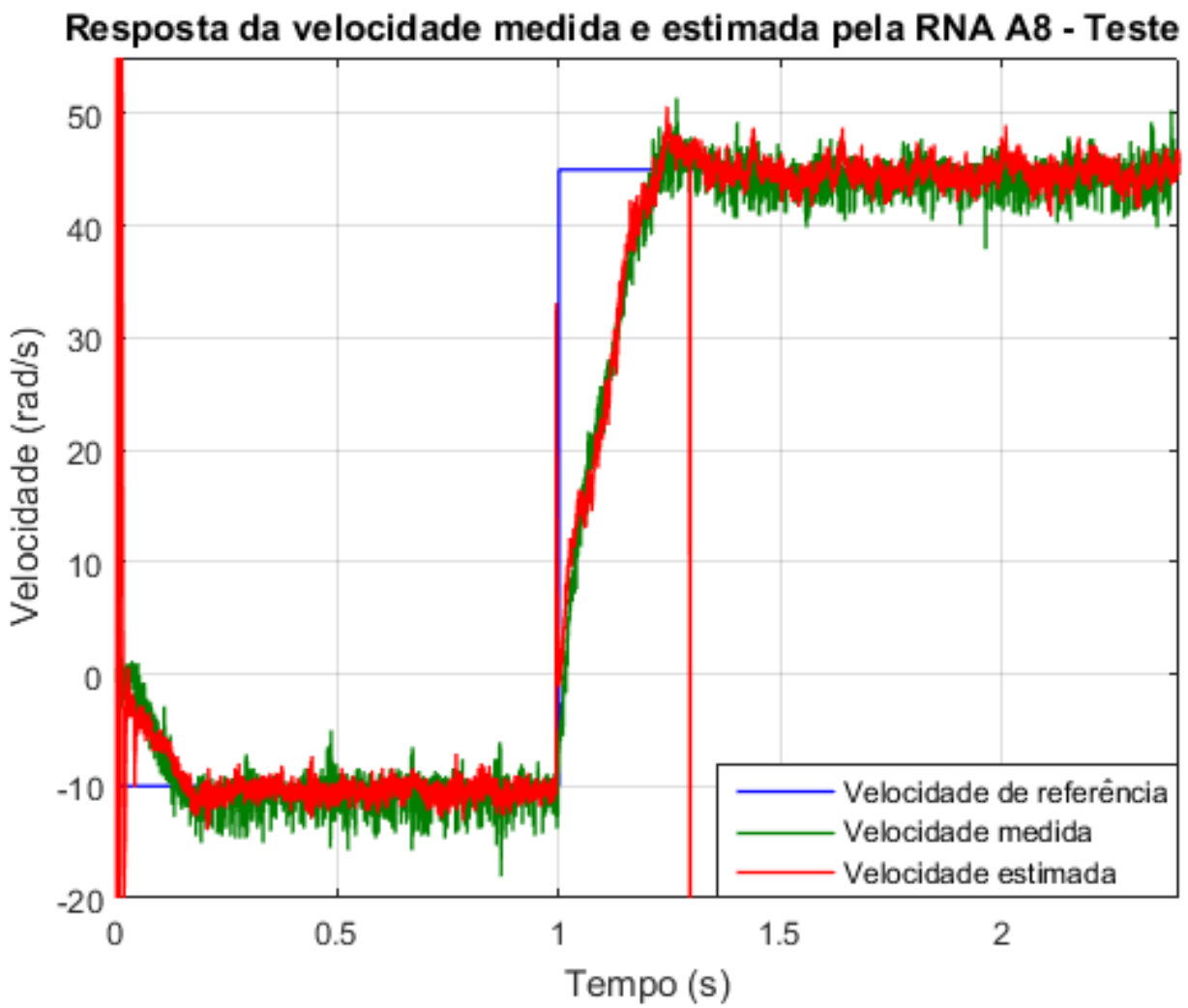

Figura 83 - Resultado da RNA A8 para o teste experimental 15.

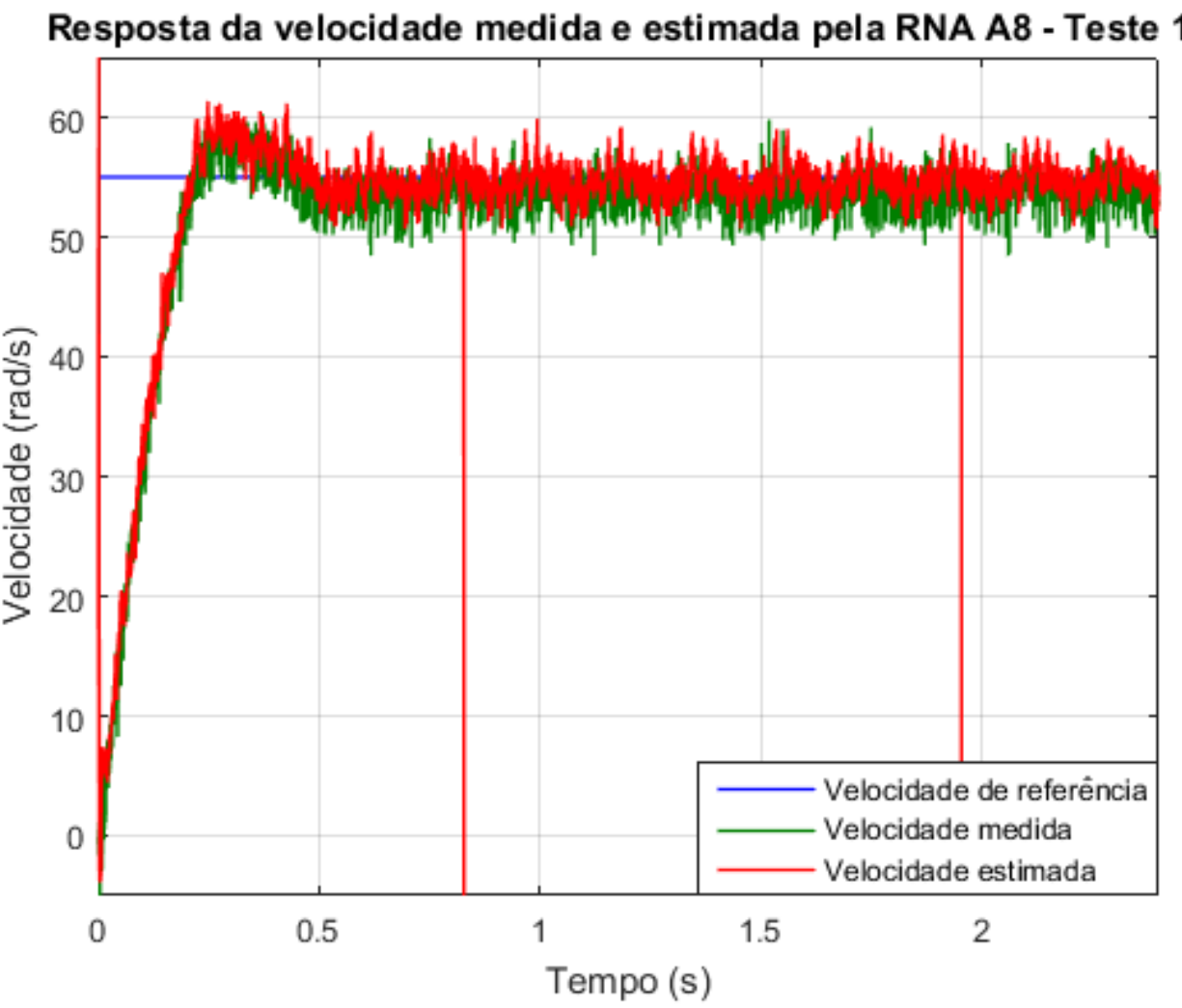

Figura 84 - Resultado da RNA A8 para o teste experimental 17. 


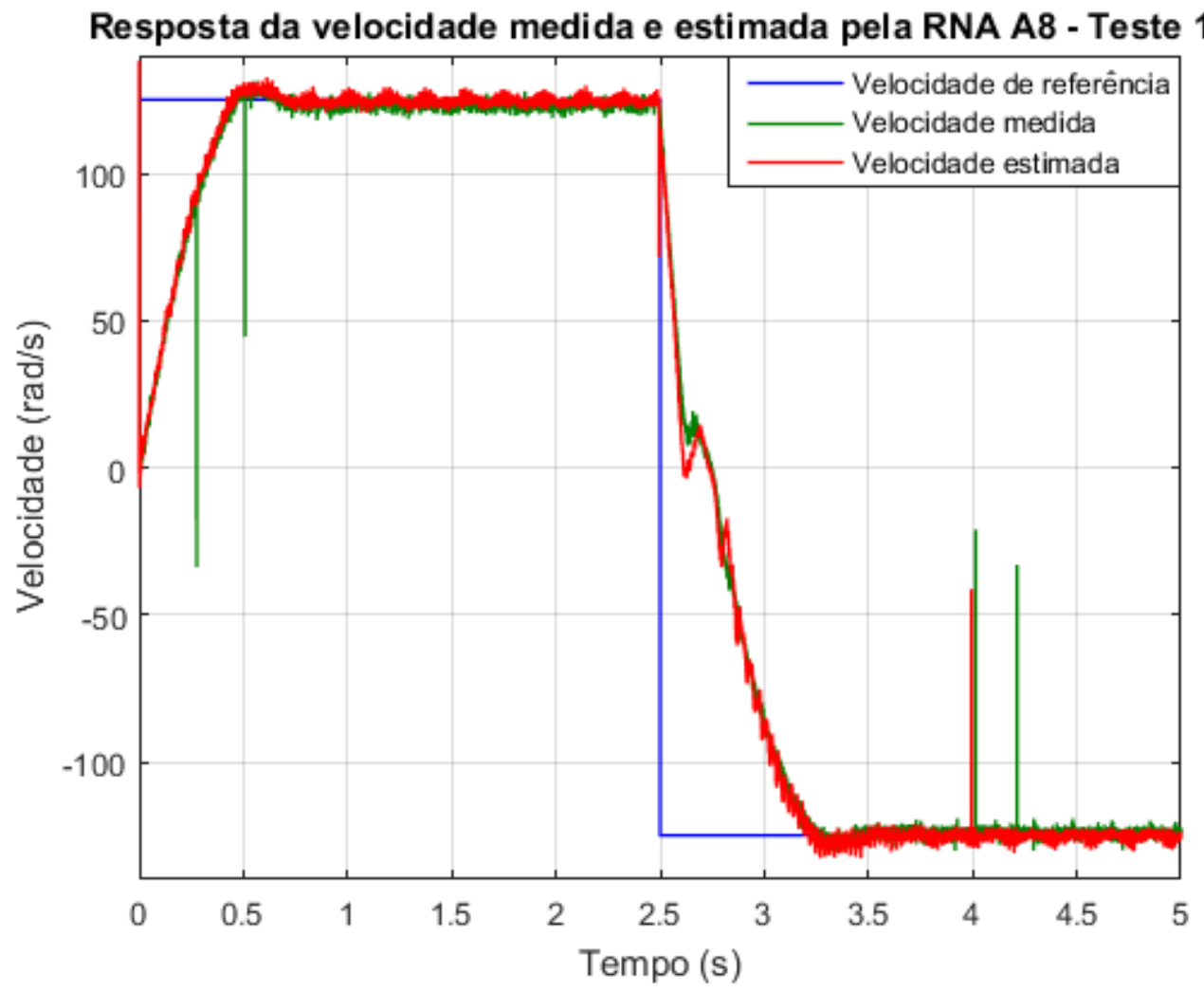

Figura 85 - Resultado da RNA A8 para o teste experimental 19.

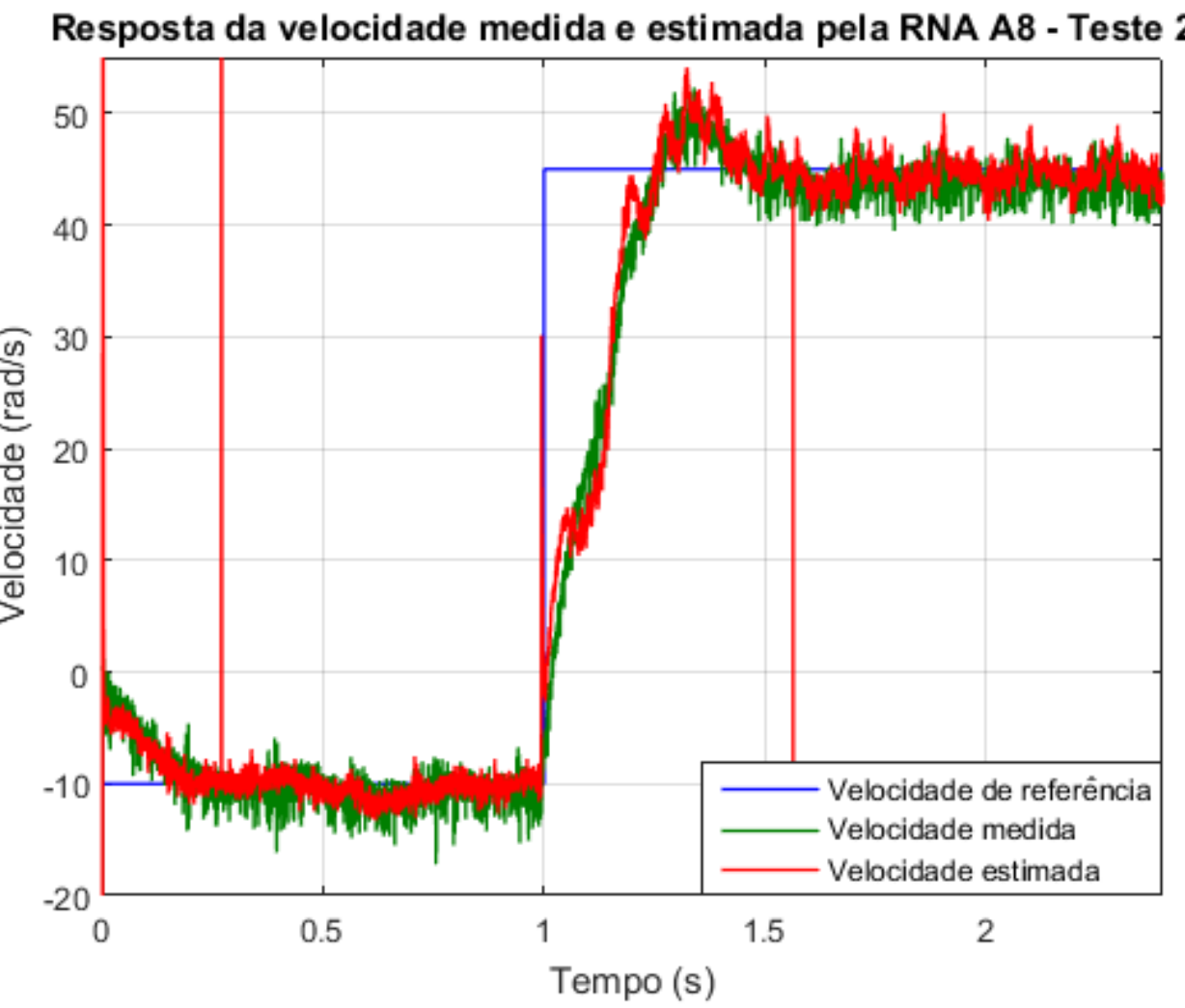

Figura 86 - Resultado da RNA A8 para o teste experimental 20. 


\section{A.0.2 Resultados Complementares dos Testes experimentais com as RNA B3 realimentando o controle de velocidade}

A seguir são apresentados as figuras dos testes experimentais realizados, cujos parâmetros são apresentados na Tabela 4.5 e com o desempenho da RNA em cada ponto de operação mostrados na Tabela 4.6.

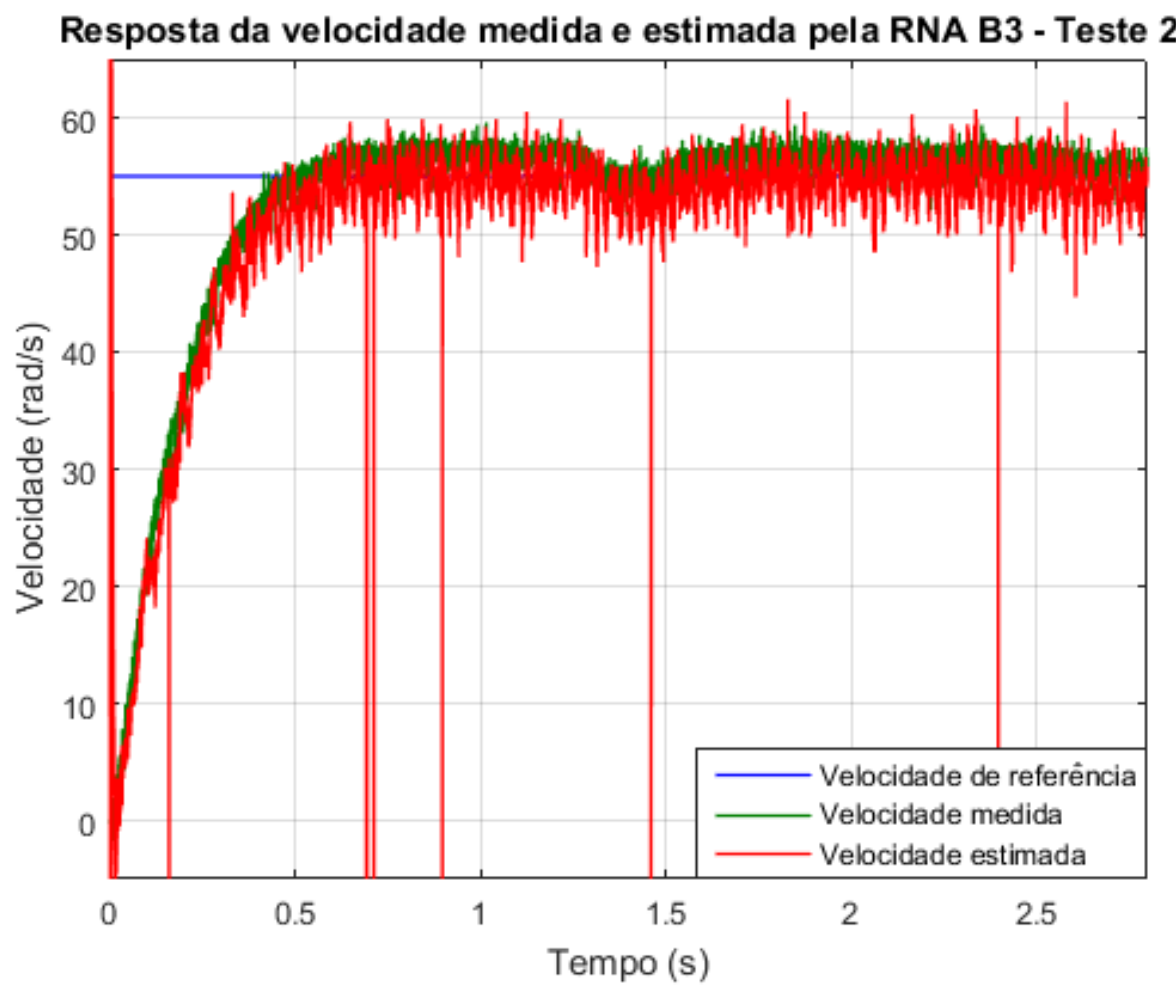

Figura 87 - Resultado da RNA A8 para o teste experimental 22. 


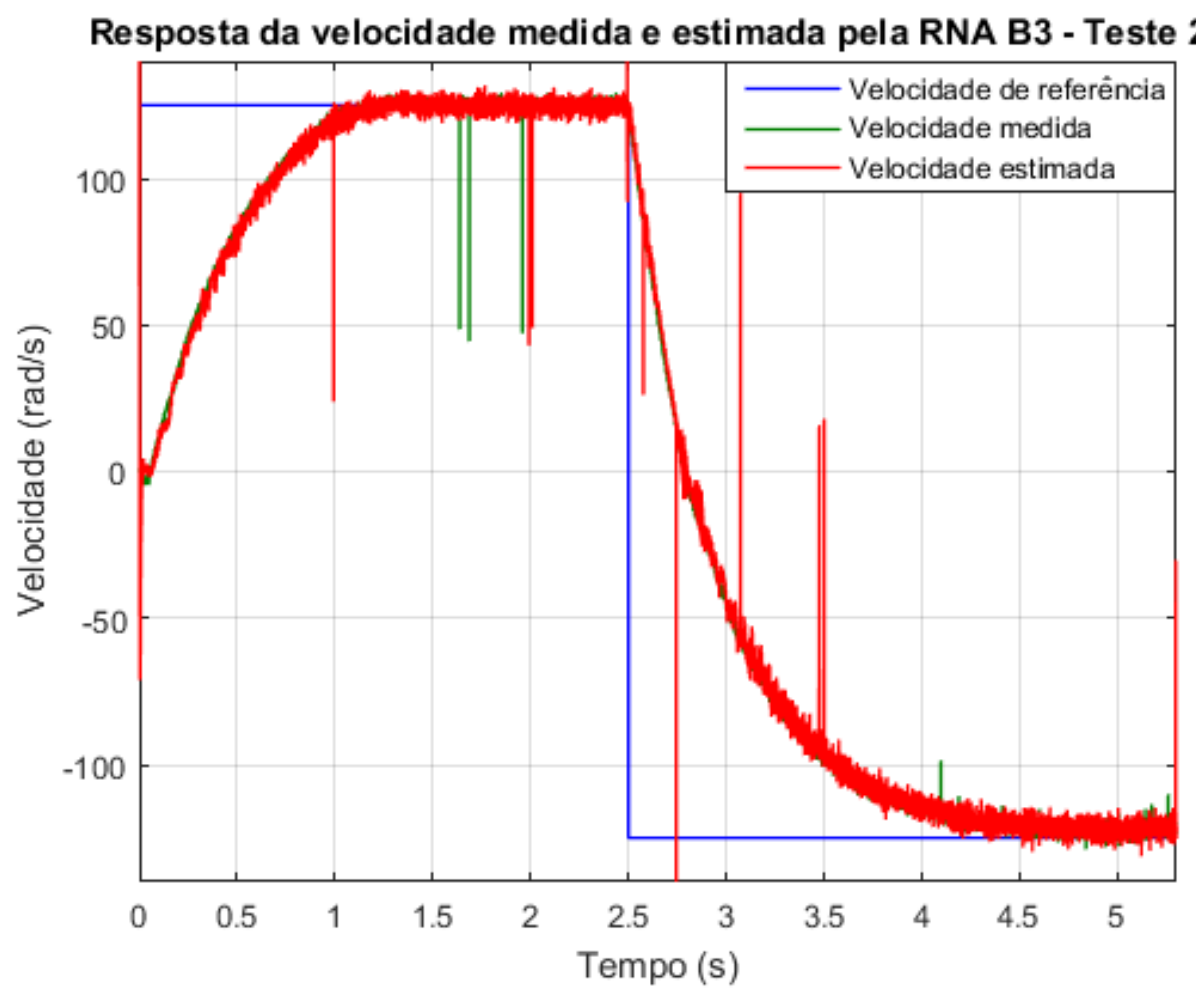

Figura 88 - Resultado da RNA A8 para o teste experimental 24.

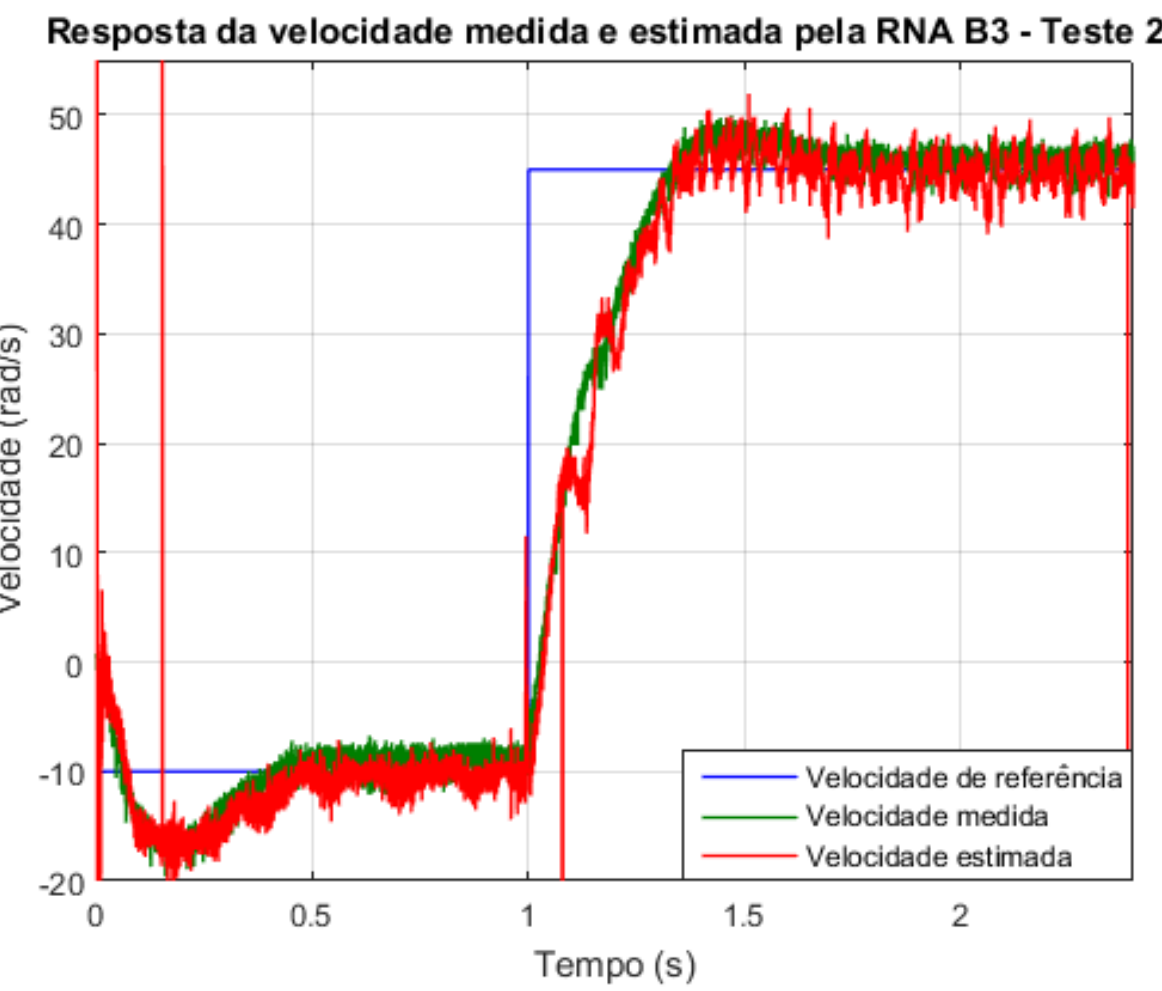

Figura 89 - Resultado da RNA A8 para o teste experimental 25. 


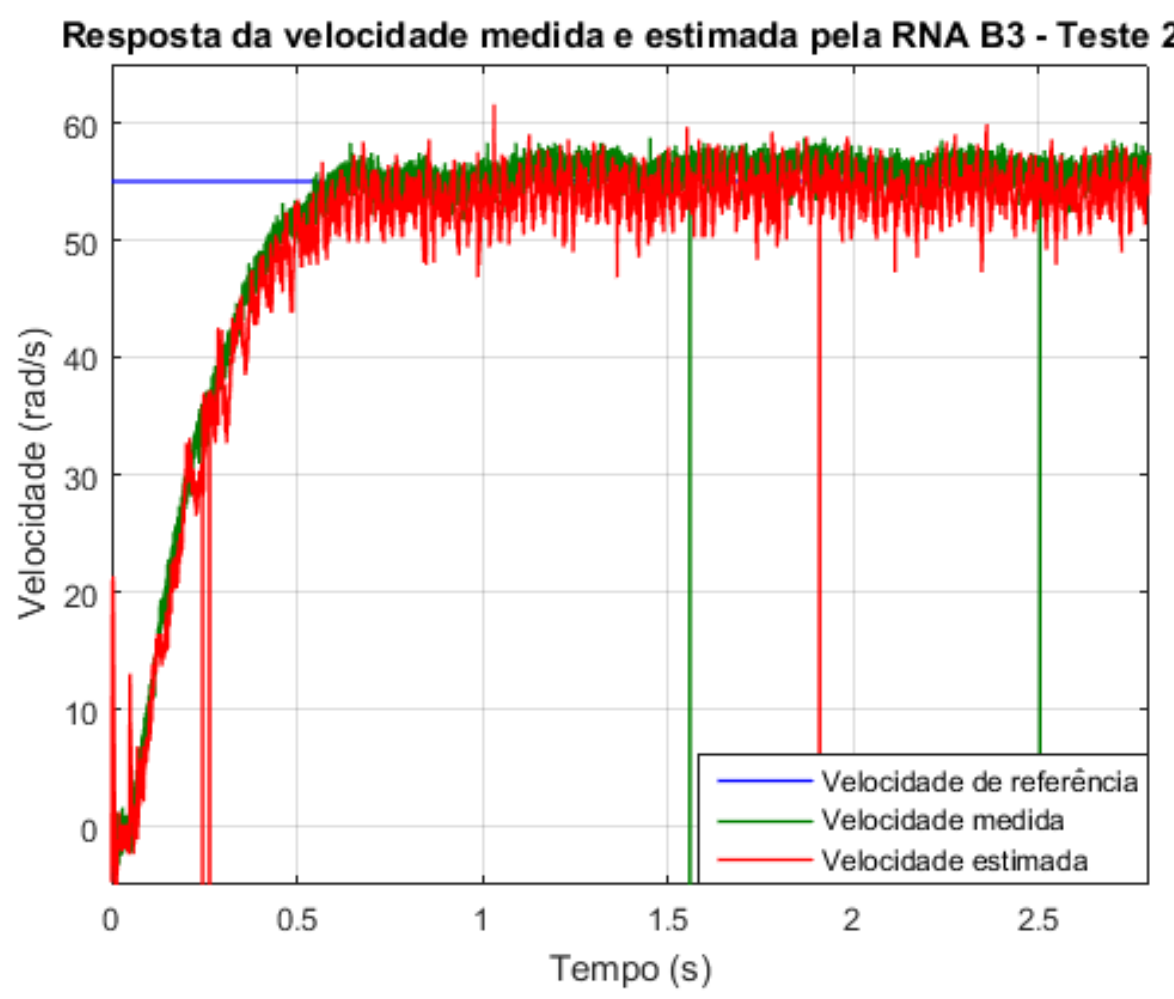

Figura 90 - Resultado da RNA A8 para o teste experimental 27.

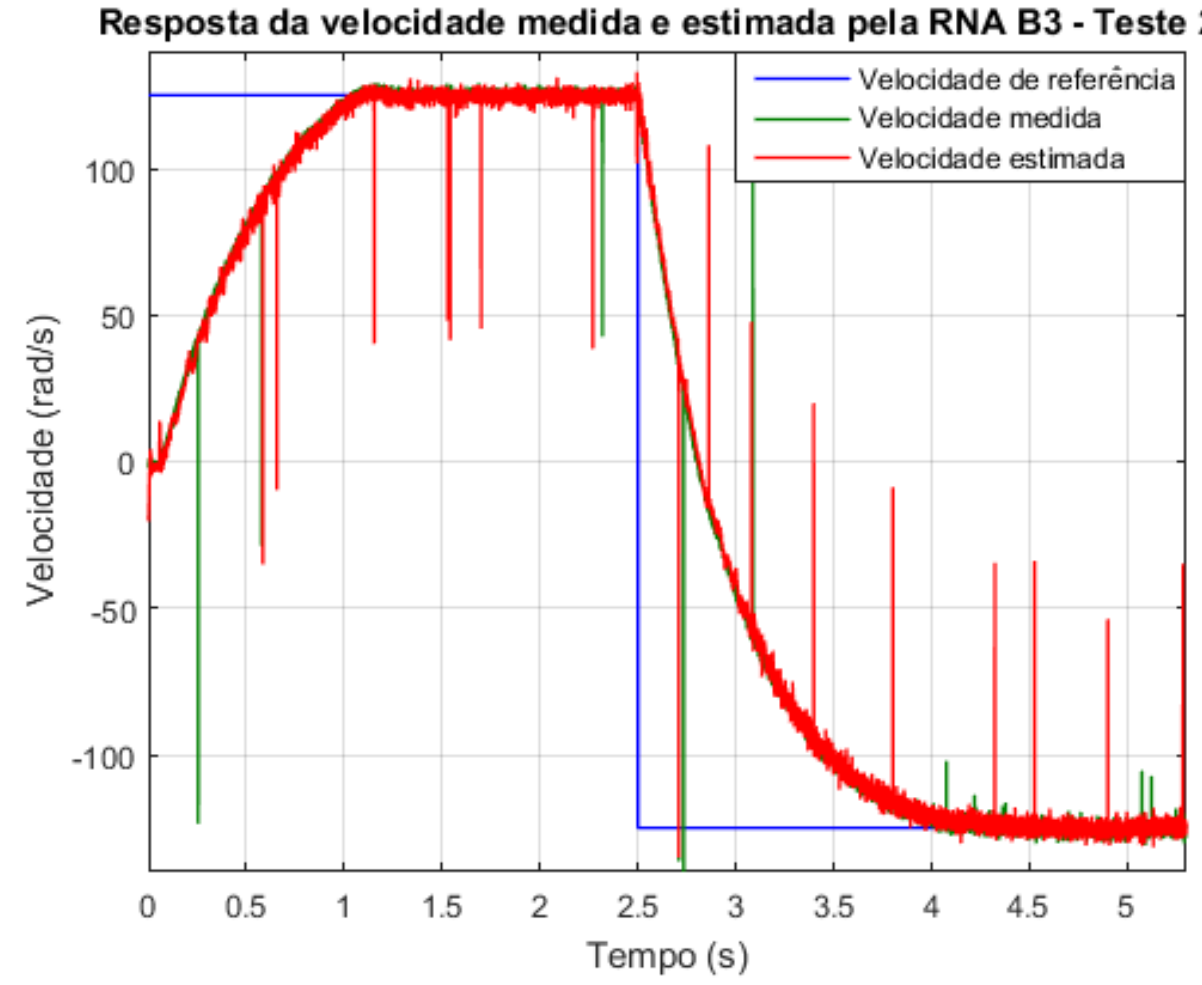

Figura 91 - Resultado da RNA A8 para o teste experimental 29. 


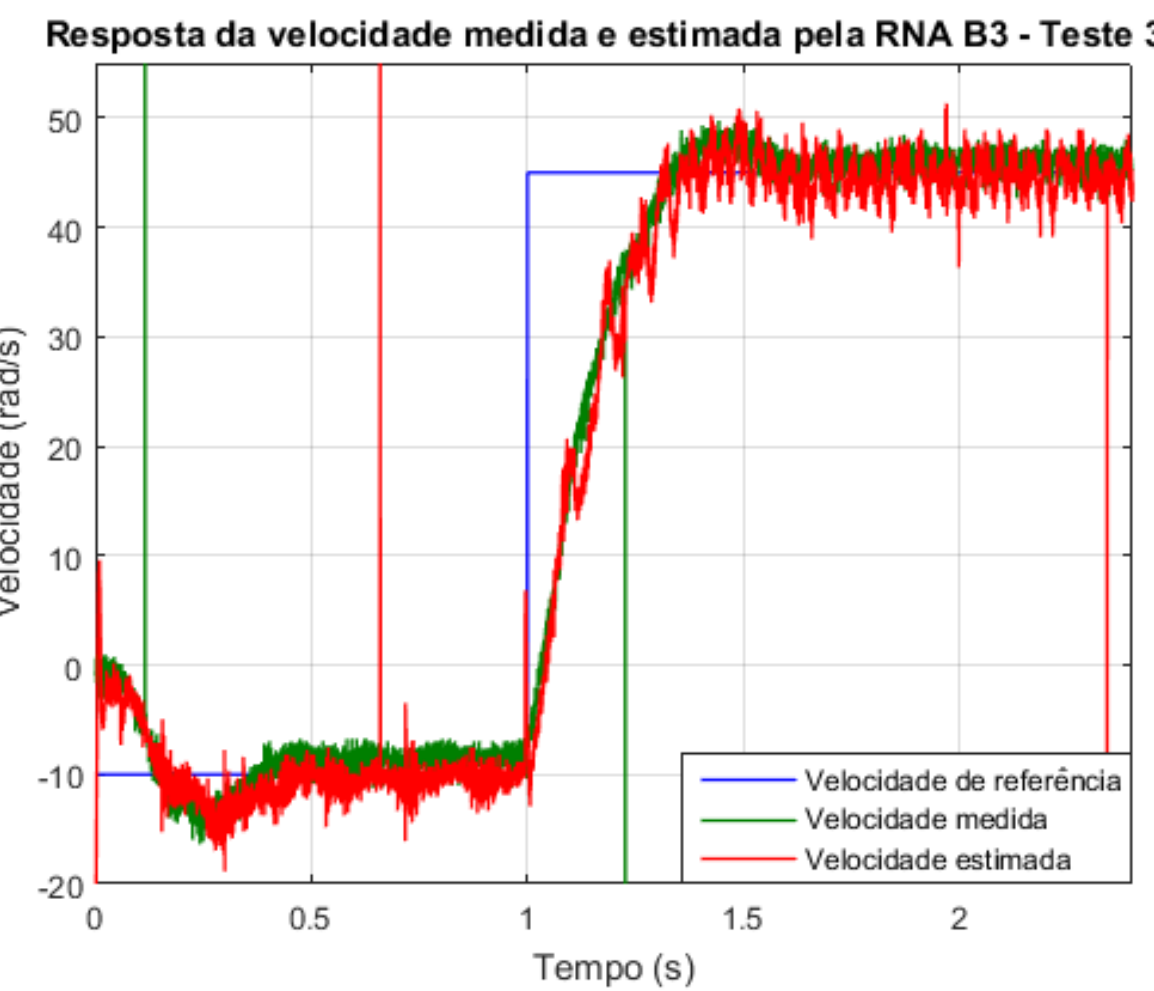

Figura 92 - Resultado da RNA A8 para o teste experimental 30.

Resposta da velocidade medida e estimada pela RNA B3 - Teste 32

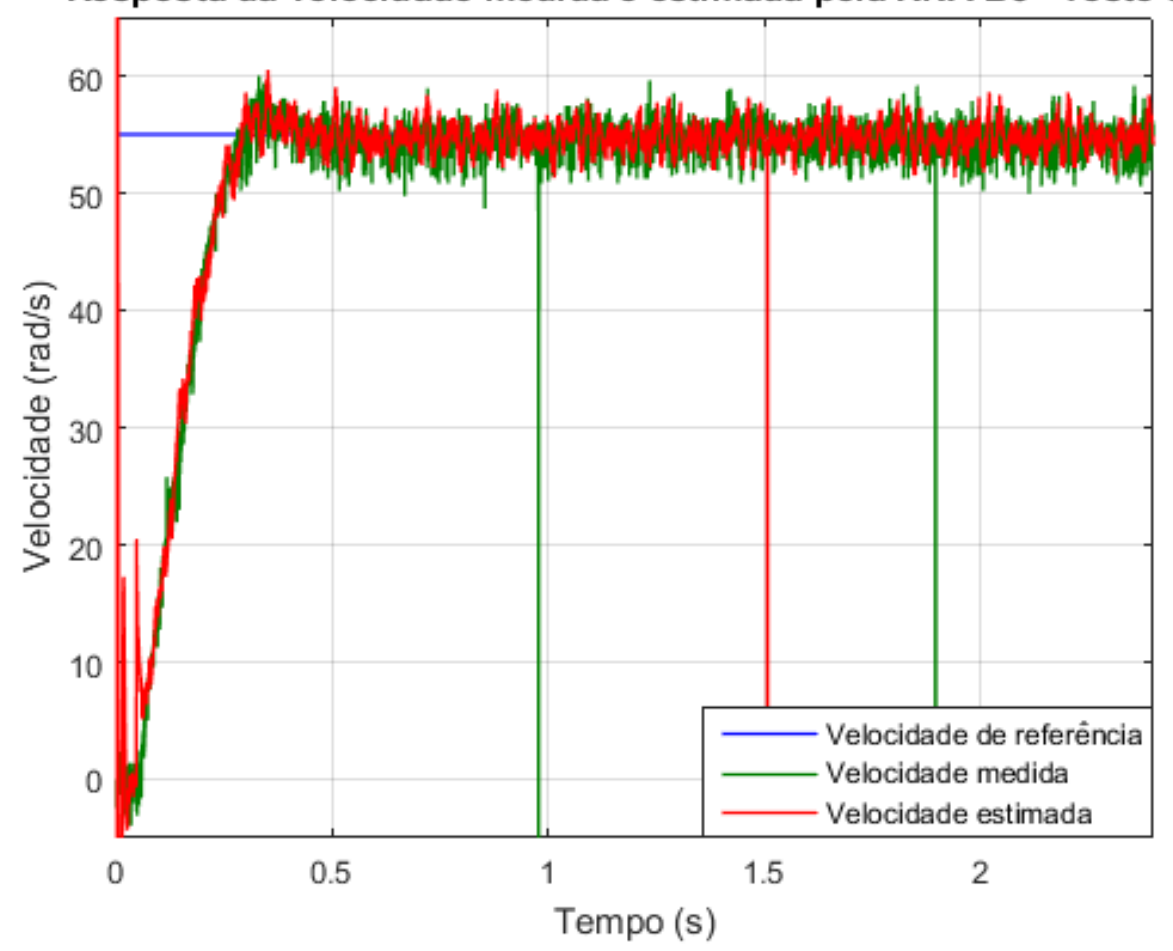

Figura 93 - Resultado da RNA A8 para o teste experimental 32. 


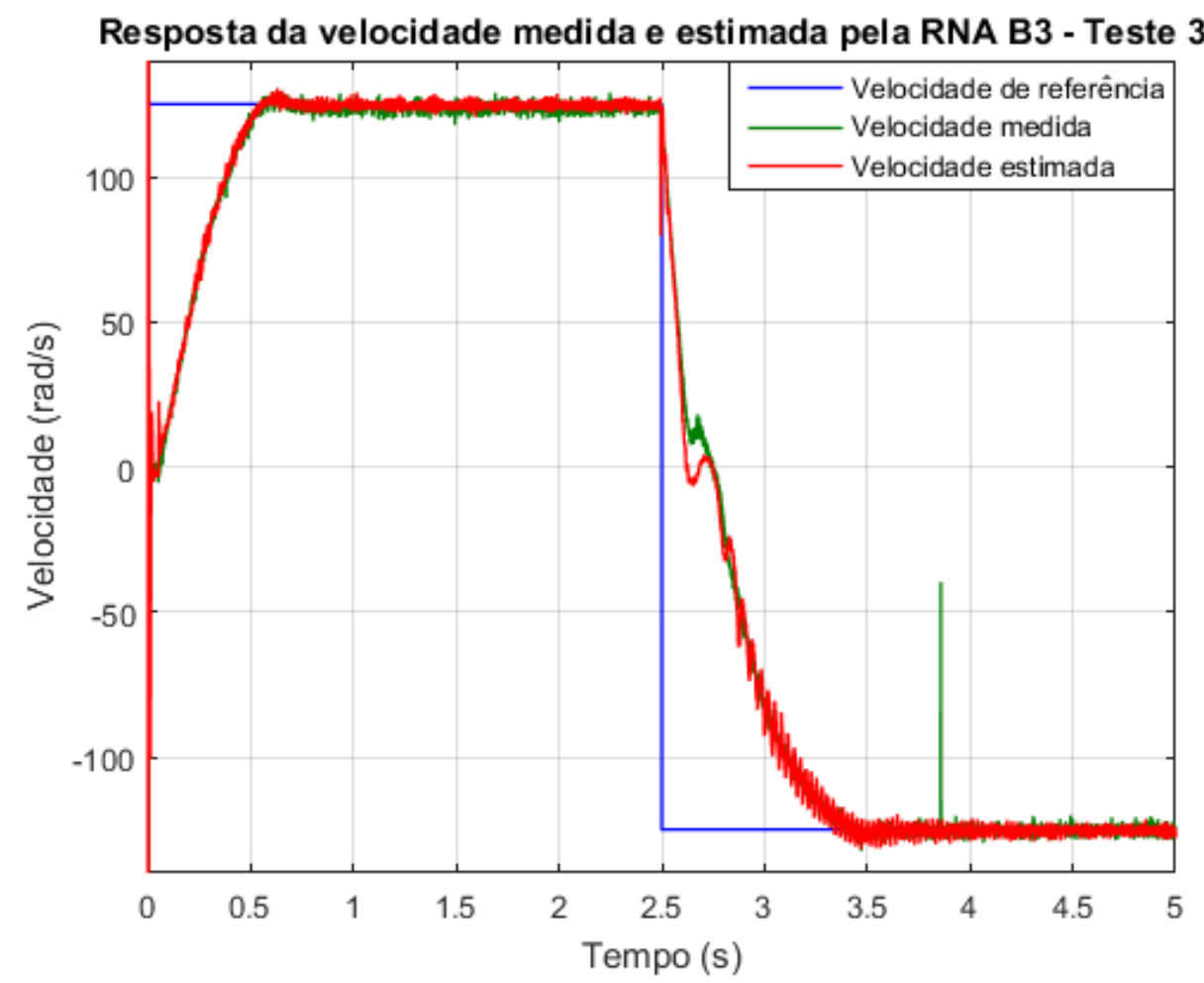

Figura 94 - Resultado da RNA A8 para o teste experimental 34.

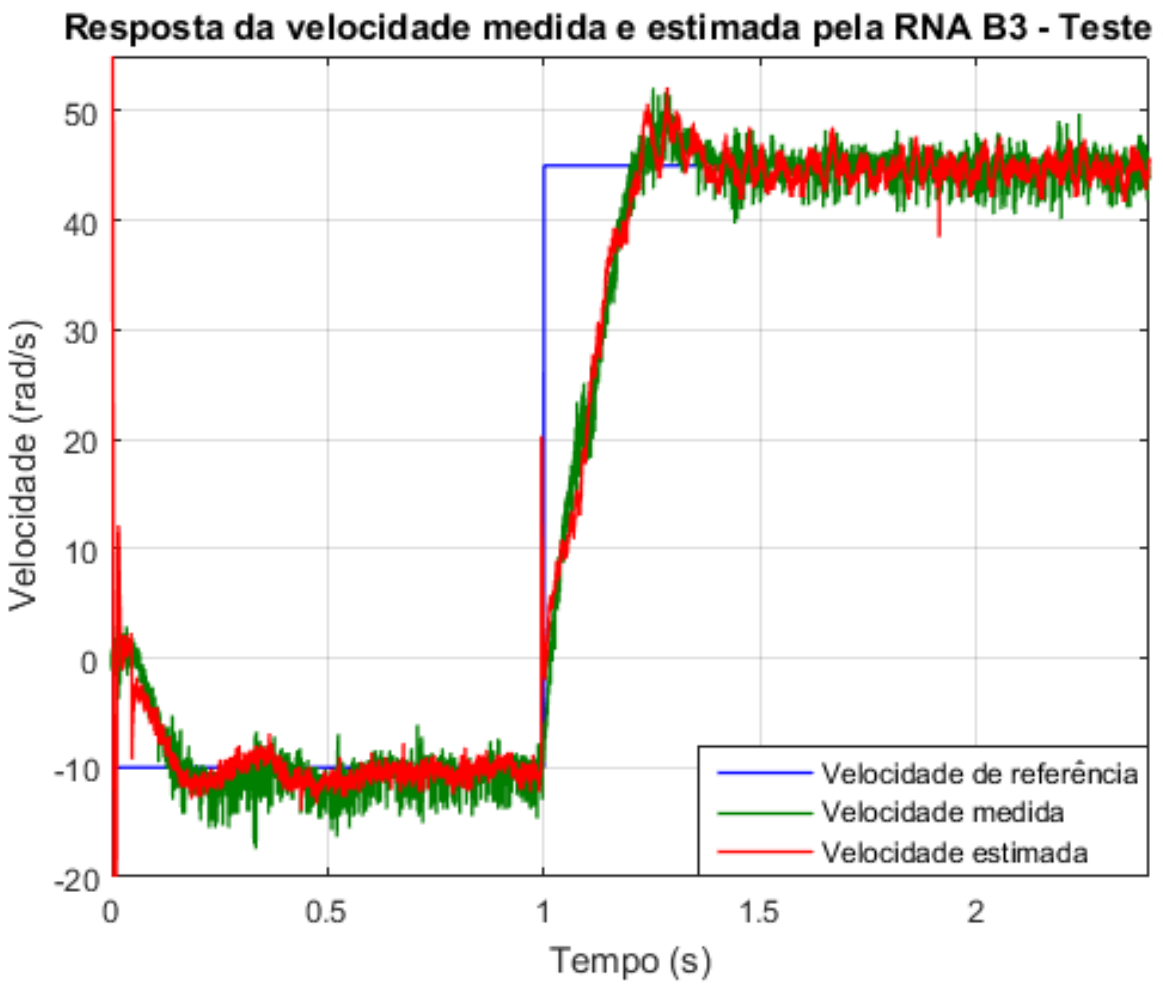

Figura 95 - Resultado da RNA A8 para o teste experimental 35. 


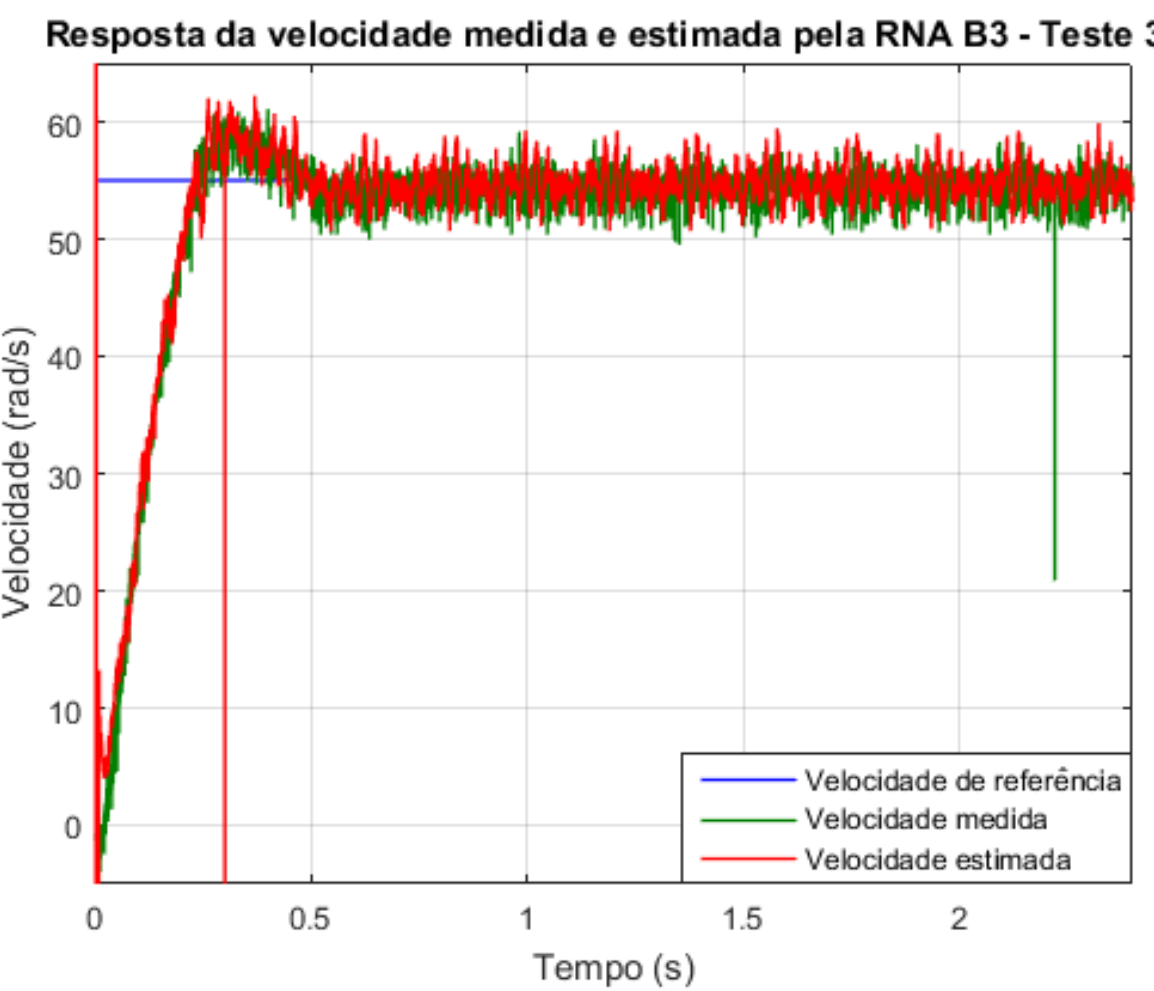

Figura 96 - Resultado da RNA A8 para o teste experimental 37.

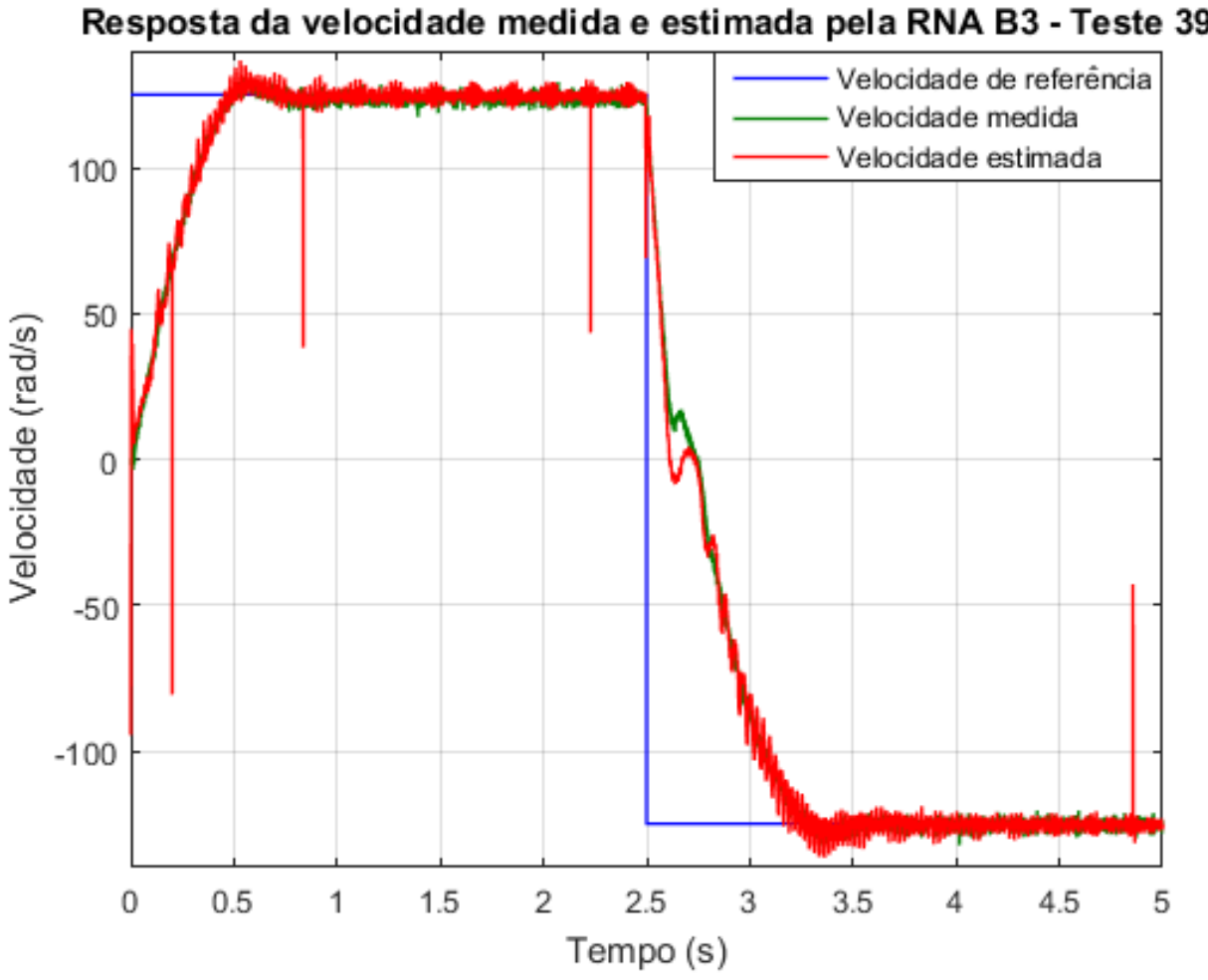

Figura 97 - Resultado da RNA A8 para o teste experimental 39. 


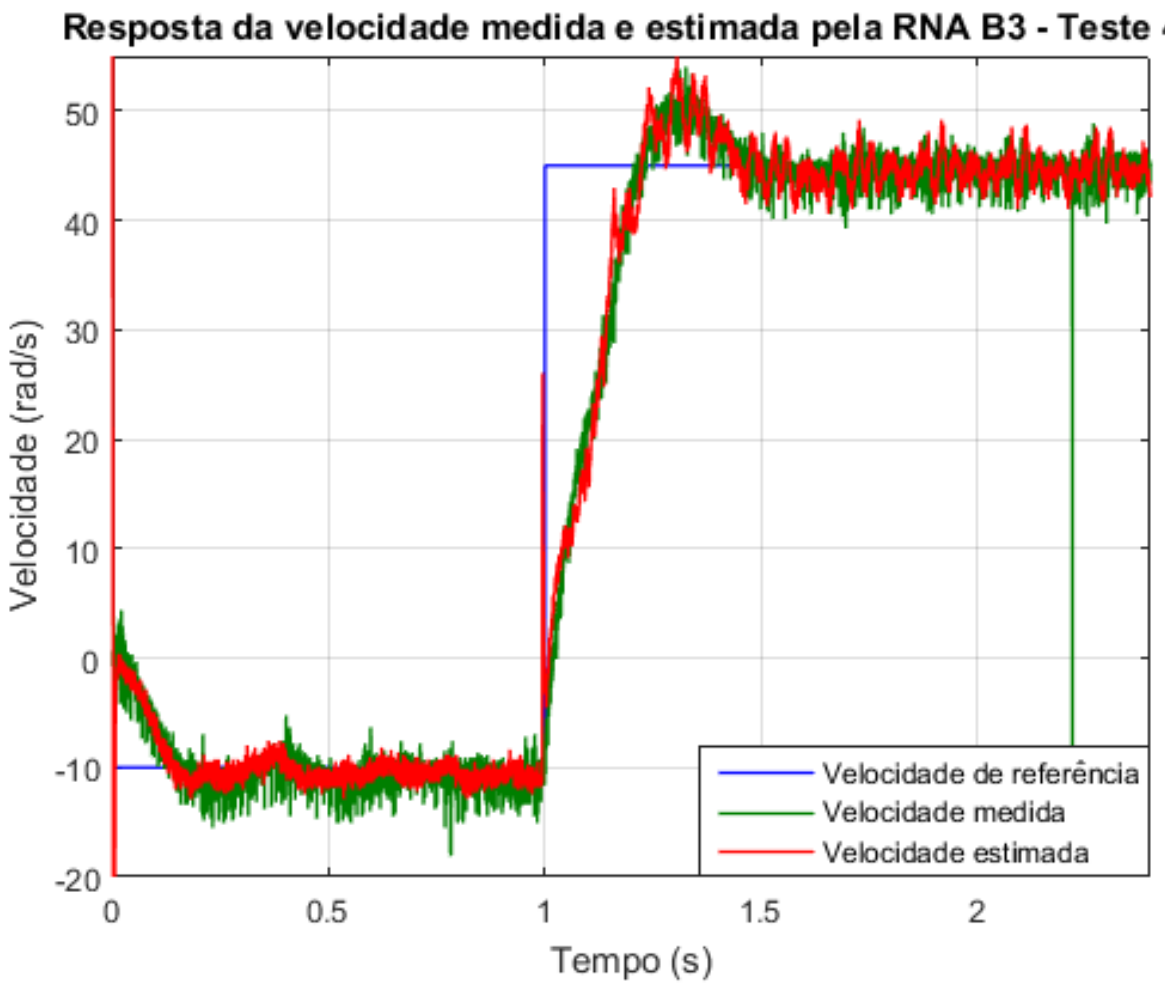

Figura 98 - Resultado da RNA A8 para o teste experimental 40. 
Anexos 


\section{Procedimento de Projeto dos Controladores PI}

Neste trabalho é adotada a metodologia de projeto de controladores PI apresentada em Angélico, Campanhol e Silva (2014), Campanhol (2012), a qual utiliza como parâmetros de projeto a margem de fase e frequência de cruzamento do sistema compensado.

Estabelecido tais parâmetros, o procedimento de sintonia divide-se em três etapas (CAMPANHOL, 2012), a saber:

$\square$ Etapa 1 - Obter o ângulo de fase desejado para a frequência de cruzamento específica, utilizando a função de transferência da planta;

$\square$ Etapa 2 - Inserir o compensador em série com a planta, com o objetivo de ajustar o ângulo de fase do sistema compensado, em malha aberta, a partir da margem de fase desejada;

$\square$ Etapa 3 - Inserir um ganho em série com o sistema compensado que faça com que o módulo do sistema compensado em malha aberta cruze com $0 \mathrm{~dB}$ na frequência de cruzamento desejada.

Inicialmente, considera-se a Função de Transferência (FT) de uma determinada planta genérica $\left(G_{p}\right)$ dada por:

$$
G_{p}(s)=\frac{K}{L_{s}+R}
$$

onde $K$ é o ganho do inversor fonte de tensão, $L_{s}$ é a indutância da carga em Henry $(H)$ e $R$ é a resistência de carga em Ohms $(\Omega)$. O ângulo de fase desta planta $\left(\varphi_{p}\right)$, em uma dada frequência de cruzamento $\omega_{c}$, pode ser obtido por:

$$
\varphi_{p}=\left.\angle G_{p}(j \omega)\right|_{\omega=\omega_{c}}
$$


Substituindo $s$ por $j \omega_{c}$, a equação (128) pode ser reescrita como:

$$
G_{p}\left(j \omega_{c}\right)=\frac{K}{L_{j \omega_{c}}+R}
$$

Multiplicando ambos os termos de (130) por $R-L j \omega_{c}$ e através de algumas manipulações matemáticas, obtém-se:

$$
G_{p}\left(j \omega_{c}\right)=\left(\frac{K R}{R^{2}+\left(L_{\omega_{c}}\right)^{2}}\right)-j\left(\frac{K L_{\omega_{c}}}{R^{2}+\left(L_{\omega_{c}}\right)^{2}}\right)
$$

A Figura 99 mostra o plano complexo referente à equação (131).

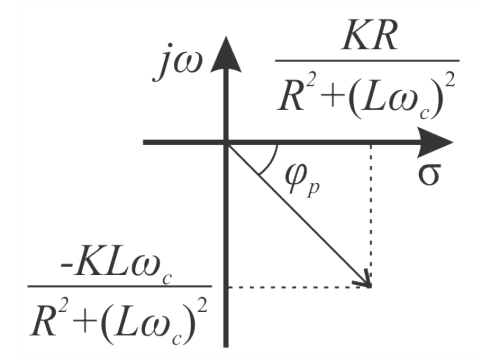

Figura 99 - Plano complexo com as coordenadas de $G_{p}$.

A partir deste plano de coordenadas, é possível escrever a seguinte expressão:

$$
t j\left(\varphi_{p}\right)=\left(\frac{-K L_{\omega_{c}}}{R^{2}+\left(L_{\omega_{c}}\right)^{2}}\right)\left(\frac{R^{2}+\left(L_{\omega_{c}}\right)^{2}}{K R}\right)
$$

Manipulando (132) obtém-se (133), sendo esta a equação para o cálculo do ângulo de fase da planta $\left(\varphi_{p}\right)$ na frequência de cruzamento especificada $\left(\omega_{c}\right)$.

$$
\varphi_{p}=t g^{-1}\left(\frac{-L_{\omega_{c}}}{R}\right)
$$

Obtido $\left(\varphi_{p}\right)$, é inserido um compensador de fase em série com a planta para que o sistema compensado apresente, em malha aberta, ângulo de fase em $\omega_{c}$ de acordo com a margem de fase desejada $\left(M F_{d}\right)$. Portanto, considera-se a FT escrita na equação (134):

$$
C(s)=\left(\frac{T_{s}+1}{s}\right)
$$

Substituindo $s$ por $j \omega_{c}$ e fazendo-se algumas manipulações matemáticas, obtém-se:

$$
C\left(j \omega_{c}\right)=T-\frac{j}{\omega_{c}}
$$

A Figura 100 mostra o plano complexo referente à equação (135). A partir da referida figura é possível determinar a constante $T$, conforme equação (136);

$$
T=\frac{-1}{\operatorname{tg}\left(\varphi_{c}\right) \omega_{c}}
$$




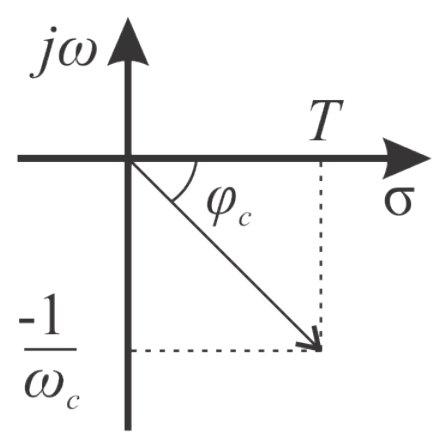

Figura 100 - Plano complexo com as coordenadas de $C$.

onde $\varphi_{c}=M F_{d}-\left(\varphi_{p}+180^{\circ}\right)$ representa a compensação angular a ser imposta pelo controlador.

Aplicando a constante $T$ na equação (134) e inserido esta em série com $G_{p}$, tem-se a FT em malha aberta do sistema compensado $\left(G_{M A_{c}}\right)$, conforme mostra a equação (137).

$$
G_{M A_{c}}(s)=\left(\frac{T_{s}+1}{s}\right)\left(\frac{K}{L_{s}+R}\right)
$$

Para garantir a margem de fase desejada $M F_{d}$, deve-se encontrar o valor do ganho a ser aplicado no sistema compensado de modo que a curva de magnitude cruze a linha $0 \mathrm{~dB}$ na frequência $\omega_{c}$. Para isso, substitui-se $s$ por $j \omega_{c}$ em (137) e, através de algumas manipulações matemáticas, obtém-se (138):

$$
G_{M A_{c}}\left(j \omega_{c}\right)=\left(\frac{K T R \omega_{c}^{2}-K L \omega_{c}^{2}}{L^{2} \omega_{c}^{4}+R^{2} \omega_{c}^{2}}\right)+\left(\frac{-K T L j \omega_{c}^{3}-K R j \omega_{c}}{L^{2} \omega_{c}^{4}+R^{2} \omega_{c}^{2}}\right)
$$

onde o módulo desta função é obtido por (139):

$$
\left|G_{M A_{c}}\left(j \omega_{c}\right)\right|=\sqrt{\left(\frac{K T R \omega_{c}^{2}-K L \omega_{c}^{2}}{L^{2} \omega_{c}^{4}+R^{2} \omega_{c}^{2}}\right)^{2}+\left(\frac{-K T L \omega_{c}^{3}-K R \omega_{c}}{L^{2} \omega_{c}^{4}+R^{2} \omega_{c}^{2}}\right)^{2}}
$$

O valor do módulo de $G_{M A_{C}}$, em $d B$, pode ser calculado por (140):

$$
\left|G_{M A_{c}}\right|_{d B}=20 \log _{10}\left(\left|G_{M A_{c}}\right|\right)
$$

A partir disso, obtêm-se o valor do ganho $K_{C}$ a ser aplicado no sistema, conforme (141):

$$
K_{c}=10^{\left(\frac{K_{C d B}}{20}\right)}=\frac{1}{\left|G_{M A_{c}}\right|}
$$

Portanto, a FT em malha aberta do controlador em série com a planta é descrita por (142):

$$
G_{M A_{P I}}(s)=K_{c}\left(\frac{T_{s}+1}{s}\right)\left(\frac{K}{L_{s}+R}\right)
$$


Assim, a FT do controlador $\operatorname{PI}\left(G_{P I}\right)$ é dada por (143):

$$
G_{M A_{P I}}(s)=\left(\frac{K_{c} T_{s}+K_{c}}{s}\right)=\left(\frac{s K_{P}+K_{I}}{s}\right)
$$

